\title{
A STUDY OF EFFICIENCY MANAGEMENT IN NEW ZEALAND PUBLIC HOSPITAL SERVICES
}

By

\section{AJIT M. ARULAMBALAM}

\author{
A thesis \\ Submitted to the Victoria University of Wellington \\ In fulfilment of the requirements for the degree of \\ Doctor of Philosophy
}

Victoria University of Wellington 2018 


\begin{abstract}
There is increasing policy interest in ensuring that resources are used efficiently within New Zealand public hospitals which are under increasing constraint. This thesis presents a narrative based on a qualitative analysis of the impact of the regular provision of efficiency management information on manager behaviour and achievements based on a single exploratory case study research of 11 senior service managers in New Zealand's largest public hospital. How performance information is currently used by service managers is unknown. The research questions seek to understand to what extent managers' use the information, what behaviours and actions result, if these managers know what they need to learn to improve performance, and what barriers impede their actions.
\end{abstract}

A qualitative research design was used to collect data from hospital service managers over a six month period. A model for a three stage information response was re-developed from existing processes and applied to the service managers who all received the hospital's routine monthly performance information; while some participants also received specific efficiency related information. In each of the months, the participant's perceptions of the performance information and the management of service improvement was obtained. The methodological approach is inductive using both observational and ethnographic approaches to collect qualitative data from regular surveys and interviews with participants. The findings appear to show enhanced collaboration in performance improvement discussions by managers who are provided with the specific performance information than is seen in those managers provided with the routine hospital management information. The enhanced collaboration appears to lead to greater improvements in service efficiency. The qualitative data provides a rich supplementary database of the participant managers' experience of using performance management information, and from applying a formal Thematic Analysis (TA), management themes are identified to define the experience of the hospital service managers in using 
performance information. The TA provides a deeper understanding of the use of performance information by hospital service managers. The four themes were identified as: (1) direct leadership, (2) operational feedback; (3) performance signal; and (4) management development. These provide contextual meaning to purposeful management response and performance improvement. 


\section{Preface and Acknowledgements}

I began this study with a background in management and policy practice, business behaviour, and performance measurement, with experience working in the public and private sectors in New Zealand, as well as periods overseas. Through reading performance related literature, I become aware of a new performance benchmarking technique called Data Envelopment Analysis (DEA). I then learnt and used DEA in two operational settings. Then, having joined a district health board I was appointed to the joint Treasury/Ministry of Health/District Health Boards National Benchmarking Programme and its technical pricing committee, where DEA was used (in the absence of a 'market') to set efficient prices for hospital treatments.

The more I became involved in the work on efficiency-centred performance measurement, the more I realised that while there was considerable policy effort and resources spent to produce performance and efficiency information, there was at the same time very little interest in learning how hospital managers actually use the information and if this use led to improved performance. This research was a journey, for me, to understand better, the use of efficiency information; to improve performance of services.

I am very grateful to the service managers who took part in this study; for their cooperation and the months of interview and questionnaire completion. The research would not have been possible without the support of Dr Denis Jury the Chief Planning and Funding Officer and Mr Garry Smith the Chief Executive of Auckland DHB, who both gave their very generous encouragement to this thesis. I also want to thank Mr Andrew Boyd Chief Executive of HealthShare Limited for continuing with the both the financial and moral support for the completion of this PhD. I am deeply grateful to my two supervisors, Dr Jaiki Desai and Professor Jackie Cumming, for their guidance, continued support and advice. 
On a personal level, I want to thank my family for their humour and support by keeping all of the times good.

Thank you, Nerupi, Miles and Sachin! 


\section{A STUDY OF EFFICIENCY MANAGEMENT IN \\ NEW ZEALAND PUBLIC HOSPITAL SERVICES}

Table of Contents

Abstract

Preface and Acknowledgement

List of Tables

List of Figures

$\begin{array}{ll}\text { Chapter 1: Introduction } & 8\end{array}$

$\begin{array}{lll}1.1 & \text { Overview } & 8\end{array}$

$\begin{array}{lll}1.2 & \text { The issue } & 8\end{array}$

$\begin{array}{lll}1.3 & \text { Research questions } & 12\end{array}$

$\begin{array}{lll}1.4 & \text { The analytical approach } & 13\end{array}$

$\begin{array}{lll}1.5 & \text { Summary overview of the thesis } & 15\end{array}$

1.6 Organisation of the thesis 16

Chapter 2: Review of literature on improving hospital performance and the use of efficiency information

18

$\begin{array}{lll}2.1 & \text { Introduction } & 18 \\ 2.2 & \text { Organisational setting and management } & 20\end{array}$

2.3 Perspectives of the use of information $\quad 24$

2.4 Measuring technical efficiency 30

2.5 Conclusion 38

Chapter 3: Research methodology and methods 40

3.1 Introduction 40

3.2 Research design 41

3.3 The interpretive research approach 44

3.4 The case study strategy 45

3.5 Methods 47

3.6 Avoiding bias and risks 49

3.7 Study setting 56

3.8 Methods of data collection $\quad 77$

3.9 Methods of data analysis $\quad 83$

3.10 Thematic analysis (TA) 84

3.11 Limitations $\quad 89$

3.12 Strength of the study approach 90

3.13 Conclusion 91

Chapter 4: Thematic Analysis of Managers' use of Efficiency information 93

4.1 Introduction 93

4.2 Thematic analysis $\quad 94$

4.3 Coding results 96

4.4 Development of initial themes 103 
4.5 Thematic insights 108

4.6 Final themes 111

$\begin{array}{lll}4.7 & \text { Conclusion } & 118\end{array}$

Chapter 5: Narratives of Experience $\quad 120$

$\begin{array}{lll}5.1 & \text { Introduction } & 120\end{array}$

5.2 Participant narratives 122

$\begin{array}{lll}5.3 & \text { Using the efficiency information } & 123\end{array}$

5.4 Actions in response to efficiency information 129

$\begin{array}{lll}5.5 & \text { Learning need } & 135\end{array}$

5.6 Barriers to performance improvement 140

5.7 Conclusion 146

Chapter 6: Connecting Perceptions and Behaviour 148

$\begin{array}{lll}6.1 & \text { Introduction } & 148\end{array}$

6.2 Perception scorings 150

6.3 Change in focus 156

6.4 Impact of information use 158

6.5 Management and behaviour - some exploratory findings 162

$\begin{array}{lll}6.6 & \text { Conclusion } & 179\end{array}$

$\begin{array}{ll}\text { Chapter 7: Conclusions } & 181\end{array}$

7.1 Summary of thesis 181

$\begin{array}{lll}7.2 & \text { Research questions and themes } & 184\end{array}$

$\begin{array}{lll}7.3 & \text { Implications and lessons } & 187\end{array}$

7.4 Future research 190

$\begin{array}{lll}7.5 & \text { A final reflection } & 192\end{array}$

$\begin{array}{ll}\text { References } & 193\end{array}$

Appendix 1: Narrative text and coding labels 205 


\section{List of Tables}

Table

$1.1 \quad$ Hospital performance information (Survey by Researcher, 20012)

Page

1.2 Purpose of performance reports (Survey by Researcher, 2012)

9

3.1 Participant profile

3.2 Service monthly data used in DEA measurement (inputs and outputs)

3.3 Monthly questionnaire survey

3.4 Participant interview questions

4.1 Summary TA Phases

4.2 Initial coding result

4.3 Revised coding of narrative data

98

4.4 Results of initial and revised coding of narrative data

4.54 Outcome of TA

4.6 Final themes and research questions

6.1 Participants scoring

6.2 Actual management actions \& service technical efficiency (\%)

\section{List of Figures}

Figure

Page

$2.1 \quad$ Input output process model

3.1 Framework for research (from Creswell, 2009)

3.2 Overview of methods

3.3 MRE

4.1 Overview of TA 


\section{Chapter 1}

\section{Introduction}

\subsection{Overview}

This thesis explores the impact of performance information use by managers on their behaviour and on service efficiency, and presents a thematic analysis of hospital management on the ways that hospital service managers use information to improve the efficiency of their services. Themes are identifiers of experience (Saldana, 2009) and presented to reflect the experience of hospital service managers in relation to using efficiency information. There is increasing policy interest in ensuring that resources are used efficiently within New Zealand public hospitals which are under increasing constraint. How performance information is used by hospital service managers to improve efficiency is relatively unknown and is the interest of this research.

Section 1.2 outlines the issue that motivated this study and the New Zealand hospital setting surrounding hospital service efficiency and performance improvement. Section 1.3 presents the research questions and definitions of scope. The research questions are presented early before the literature review, because of the exploratory nature of the research in this study. Section 1.4 briefly introduces the analytical approach for the study and the intended contribution of this research. In Section 1.5, an outline of the Thesis is summarised and Section 1.6 outlines the organisation of the Thesis.

\subsection{The Issue}

In New Zealand, public hospital service managers are generally tasked with managing the use of resources as efficiently as possible according to an agreed annual budget for the delivery of a target level of patient treatments, usually measured as numbers of people discharged from hospital. But, there is no 'market environment' for public hospital services to provide a clear 
performance objective; and accordingly a range of extensive management performance benchmarks have been provided by health policy makers and funding agencies.

As part of the preparatory analysis for this research topic, the type and purpose of management performance reports that are typically made available to hospital service managers was surveyed. There are 417 internal indicators which are issued monthly, quarterly, or six-monthly, across process, quality, volume, and cost categories. The intent of these indicators are to serve as performance feedback and signals to hospital managers on the level of achievement towards organisational and national goals, shown in Table 1.1.

Table 1.1: Hospital performance information (Survey by Researcher, 2012)

\begin{tabular}{|l|l|l|l|l|l|}
\hline Source & Cost KPIs & $\begin{array}{l}\text { Process/ } \\
\text { Efficiency } \\
\text { KPIs }\end{array}$ & $\begin{array}{l}\text { Quality } \\
\text { KPIs }\end{array}$ & $\begin{array}{l}\text { Volume } \\
\text { KPIs }\end{array}$ & Total \\
\hline National Performance Measures & 3 & 12 & 12 & 13 & 40 \\
\hline $\begin{array}{l}\text { Ministry of Health (MOH) } \\
\text { Indicators of Performance }\end{array}$ & 10 & 21 & 20 & 21 & 72 \\
\hline $\begin{array}{l}\text { Hospital Performance Indicators } \\
\text { (for service managers) }\end{array}$ & 18 & 157 & 169 & 73 & 417 \\
\hline
\end{tabular}

The implication of the large volume of indicators is the effort required by the manager to monitor and keep abreast of the array of performance data; and likely to mean a high level of distraction from what may be the crucial measure at one time. Much has been written in theory about performance measures for public sector managers; with most of this work focussed on specific measures, and their need to be quantifiable, objective and measurable (Kravchuk and Schack, 1996; Mannion and Goddard, 2000). Much less, however, is known in practice about their operation and how these are used by managers, particularly in the public sector (Propper and Wilson, 2003). Within New Zealand public hospitals, there is on-going and increasing investment in information technologies, measurement and data analytical systems, that are all designed to help the manager better understand their environment, their current performance, and particular benchmark results. Intense government pressure to 
improve performance is a major force that is driving public hospitals to increase efficiency. Yet, there is a dearth of empirical research into how efficiency information is used by hospital service managers in order to improve performance. With growing pressures on funding, it is timely to investigate how service managers use efficiency information and can improve performance.

\section{New Zealand hospital setting}

Public hospitals are not-for-profit and funded through general taxation. Across New Zealand, public hospitals vary in size and in the services offered to patients, who may be transferred to larger hospitals for specialised care. Only in the larger cities are the more complex public hospitals of a tertiary nature, offering the range of medical and surgical specialities, including specialised children and women's health care to a national or sub-national population; and as well general secondary care services to its local district populations.

The hospital service manager is the onsite senior operational manager and is accountable for the use of resources and operational improvement as well as routine management of staffing, quality and risk. The service manager has a clinical director as a management peer who is the head of clinical staff and practice for the service, and a number of clinical team leaders as well as ward nurse managers who are direct reports. Within the hospital setting, budgets are set in discussion with senior executives and finance staff, but are the service manager's responsibility; and that, notwithstanding nationally agreed employment contracts and policy directives or guidelines for clinical care, the manager is expected to exert a dominating control over the service budget. Table 1.2 sets out the purposes of the management reports that a hospital service manager receives. There are constraints as well as options and incentives on service managers in public hospitals. Their management choices are covertly constrained by quasi-legislative policy (the National Service Coverage Framework, and the 
Operational Policy Framework), that requires managers to provide appropriate service with acceptable access for patients with efficient delivery.

Table 1.2: Purpose of Performance Reports (Survey by Researcher, 2012)

\begin{tabular}{|l|l|l|}
\hline Frequency & Content & Objective \\
\hline Daily & $\begin{array}{l}\text { ・ Bed occupancy } \\
\text { - Admissions }\end{array}$ & $\begin{array}{l}\text { To determine level of risk \& } \\
\text { availability of 'freed-up' } \\
\text { beds }\end{array}$ \\
\hline Weekly reports & $\begin{array}{l}\text { • Volumes } \\
\text { - Case mix discharged }\end{array}$ & $\begin{array}{l}\text { To review progression } \\
\text { against contract }\end{array}$ \\
\hline Monthly & $\begin{array}{l}\text { - Budget Variance } \\
\text { - Revenue allocations } \\
\text { - Volume production to } \\
\text { contract }\end{array}$ & $\begin{array}{l}\text { To assess performance } \\
\text { against contract and budget }\end{array}$ \\
\hline Six-monthly & $\begin{array}{l}\text { - Patient costing profiles } \\
\text { information }\end{array}$ \\
\hline
\end{tabular}

Since 2002, New Zealand public hospitals have participated in a national service pricing and benchmarking programme, aimed at improving the efficiency of services, by: (i) setting an annual efficient price for hospital treatment on a case weighted discharge basis; and (ii) allowing hospital managers to benchmark their efficiency on a national basis (Swales and Rouse, 2006). The results are primarily used as default prices in a service trading mechanism where patients who are transferred from one hospital to another have a 'price' calculated using the case weighted efficient price in order to pay the hospital delivering the service. To date, however, how the information is used by managers to improve the efficiency of their service is yet unknown empirically. Research as to how information on efficiency is used by hospital managers to make informed decisions to produce an efficient service does not appear to be readily available in the literature. A search of Englishlanguage studies and articles on the topic, in hospital service settings indicated no empirical management research. On the other hand, the broader academic management literature provides an abundance of descriptive frameworks for achieving high performance, such as Peters and Waterman's In Search of Excellence (1982) or Collins' Good to Great (2001). As 
Waal (2010) points out there are many different characteristics of high performance, which variously include manager skills, the availability of performance information and the development of performance measures and organisational culture. In a review of 290 'studies of high performance' Waal (2010) notes there is a diversity of research perspectives taken; and that this means it is difficult to develop a single set of evidence-based high performance characteristics or even to formulate a generally accepted definition of determining factors of high performance. If this view is accepted, then the implication is that deductive analysis may well be fruitless to search for how performance can be improved. The search for the 'how' of performance improvement may require inductive research at an empirical level to develop some understanding of the manager's use of information to improve performance. A further implication of Waal's study (2010) is it questions the current policy assumption about the relationship between performance information, management behaviour and performance improvement.

\subsection{Research Questions}

There are few available earlier studies that can be used to refer to about the use of efficiency information by hospital service managers. This raises the question of how service managers use efficiency management information. Four related research questions are covered in this thesis:

- To what extent do managers use specific pieces of information that are made available to them within the context of their routine reporting and performance environment?

- From the information that is provided, what behaviours and actions do managers take that they perceive as necessary to improve efficiency?

- What do managers perceive that they need to learn in order to improve the management of their service units? 
- What factors do managers perceive as impeding their actions as they seek to improve service performance?

The questions aim to address our understanding of managerial behaviours, responses and result in relation to the use of efficiency information. The main primary aim is to explore and to interpret the performance related behaviour of hospital service managers as a result of performance information. There is a secondary aim which is to use a method of Thematic Analysis (TA) to extract from the interpretation of managers' behaviour a set of core themes on the use of information. A tertiary aim is to develop an efficiency performance metric, additional to the routine performance information that is made available to hospital service managers, using Data Envelopment Analysis (DEA) to influence the use of information in order to obtain an improvement in service efficiency.

\section{Scope}

The exploratory nature of the research questions necessitates a framework of qualitative inquiry that should provide an understanding of, rather than an explanation or answers for, the phenomenon under study (Patton, 2002). The scope of the research is a single exploratory case study of a cohort of hospital service managers. Here, by using the term cohort, I refer to a collected group of managers who share similar experiences within a selected period. Hence this study will view hospital service managers in the context of gaining knowledge, their responses and change in perceptions.

\subsection{The analytical approach}

The research is primarily exploratory, and qualitative, with an inductive, subjective process of inquiry in a natural setting in order to develop an understanding of a complex work environment. 
The epistemological position for this research is interpretative (Prasad and Prasad, 2002). This bounds the research to developing a view of the world in which developing understandings of the similarities are more important than the particular differences, in order to develop coherence (Holloway \& Todres, 2003). The study uses a qualitative research methodology with a design for qualitative analysis. There is 'methodological fit' with the research questions, given the lack of similar prior research.

\section{Contribution of the research}

The research will contribute new information to the literature on how hospital service managers use performance information to improve service efficiency. At the policy level, the relationship between information and management behaviour has been largely assumed and yet its role to performance has not been studied in-depth. Policy and practice decisions can be informed by findings from qualitative research. Qualitative research is useful to policymakers because it often describes the settings of the social world and the behaviours of people within, which is not easily quantifiable. The thesis provides an insight to both policy makers and to hospital executives of the impact of the provision of management information and the behaviours of senior managers.

As there is no empirical information readily available that shows how senior operational service managers within public hospitals actually use information in their day-to-day management of services, this research will gather empirical data from a New Zealand public hospital setting. This will help in identifying the key organisational factors relating to service manager use of information. The thesis also makes a useful contribution to qualitative methodology by setting out in a detailed process the steps to complete a formal thematic analysis from the case study data. 


\subsection{Summary overview of the thesis}

The research collected empirical data over a six month period with participants at Auckland City Hospital. On a monthly basis, data was collected from participants on their use of performance management information and impact on service performance. Some of the participants were provided with DEA generated efficiency information as well as the routine hospital management reports; whilst other participants continued to receive the routine hospital reports. For this research, the current management process was re-developed as an iterative, three part 'information response process'; where the service manager: i) first, at the start of each month - receives performance signals and considers intended action; ii) secondly, at mid-month - reviews the intended action and adjusts response as appropriate; and iii) finally, at the end of the month - confirms the action that was taken and considers the performance result.

The subjective experience of managers' use of efficiency information is a complex phenomenon for measurement. Thus, drawing on the strengths of the qualitative approach, the research methods included both survey and interviews. In order to understand how managers perceive the management of efficiency and performance a monthly questionnaire was utilised to elicit their perceptions about aspects relating to efficiency and performance. Structured questionnaires are used to empirically capture the managers' perceptions of their monthly experience in the use of efficiency related performance information. In addition to completing the monthly questionnaire, each participant was interviewed at each stage of the information response process. A descriptive analysis of the data collected finds that the efficiency information appears to enable more collaborative management actions that are strategic, and appear to lead to improved service efficiency performance. The responses from the participants show that as hospital service managers, they gain a sense of having better control over their services. 
The qualitative data provides a rich database of the participant managers' experience of using performance management information, and provides the source for a qualitative analysis. The primary form of the qualitative analysis undertaken is by applying a formal Thematic Analysis (TA), whereby core themes are identified to define the experience of the hospital service managers in using performance information. The TA provides a deeper understanding of the use of performance information by hospital service managers. Four core themes were identified: (1) direct leadership, (2) operational feedback; (3) performance signal; and (4) management development. These provide contextual meaning to purposeful management response and performance improvement.

\subsection{Organisation of the thesis}

The organisation of the thesis follows Anderson (2010) as an appropriate structure of presenting qualitative research and its findings. Given that the validity of research refers to the extent to which the findings are an accurate representation of the phenomena they are intended to represent (Pope and Mays, 2006), the data and the qualitative analysis including the researcher's interpretation are clearly set out in this thesis. Chapter Two provides a review of the literature that frames this study. The complexity of the topic and the gap in the literature means takes an overview of related literature is discussed with a description of the New Zealand hospital system. Chapter Three explains and discusses the philosophical assumptions for the research methodology, the study setting and the qualitative research approach to the gathering of data, as well as the techniques used for analysis. In this chapter I also discuss how bias and risk can impact on the study and outline the way these are managed. Then, Chapters Four, Five and Six present aspects of the case study. First, Chapter Four presents the results of the thematic analysis as the interpretative aspect of the study. This chapter outlines both the process adopted for the thematic analysis and its results in 
identifying key management themes. Secondly, Chapter Five discusses the qualitative analysis using participant interviews and their narratives of their behaviour and actions in response to information. The narratives are a way of 'letting the participants speak for themselves' (Bloomberg \& Volpe, 2012). These narratives are also used to illustrate the discussion to portray the multiple perspectives of the participants. Third, Chapter Six discusses the perceptions of managers on their experience of using the performance information to improve the efficiency of their service. The final Chapter Seven completes the thesis and provides conclusions on the research and recommendations for hospital information policy. 


\section{Chapter 2}

\section{Review of literature on improving hospital performance and the use of efficiency information}

\section{1}

\section{Introduction}

This chapter reviews the literature on the use of management or performance information by hospital service managers to improve service performance. The focus on service performance in this study is the technical efficiency of hospital services. Hollingsworth and Peacock (2008, p.1) refer to technical efficiency as "the maximisation of outputs for a given level and mix of inputs, or conversely the minimisation of input use for a given output level." This meaning of technical efficiency is theoretically rooted in early definitions of productivity as the ratio of output over the consumption of input. Technical efficiency as defined provides a relative measure of the level of optimal conversion of input to output (Eakin, 1991).

For the purpose of the review, performance information refers to the production of reports which contain data on performance and is designed to assist managers monitor and review their services. Hospital services are also described as secondary care and tertiary care services or hospitals. I have chosen to refer to public hospital to include all secondary care and tertiary care hospitals. The emphasis in this chapter is on public hospital service managers and their management link between performance improvement and public hospital services managers through the use of efficiency information. The review is focused on the following topics: the organizational setting and management for performance information; the use of information by managers; and the measurement of technical efficiency, in terms of its influence on hospital service performance. 
The use of information is addressed in different disciplines but for this study the literature described is restricted to managerial behaviour. Managerial behaviour relates to performance improvement (Mintzberg, 2009) and one key aspect is efficiency performance that is defined in terms of the relationship between service costs, resource use and maximum outputs on the optimal utilisation of service-level resources (Slack, Chambers \& Johnston, 2004). Efficiency performance is a widely used term in policy management and in economics broadly refers to the best use of resources in production (Hollingsworth and Peacock, 2008).

The definition of technical efficiency provides a framework for a hospital's services to be viewed as a series of production processes; where each service uses resources to undertake activities that lead to treatment outputs (Hollingsworth and Parkin, 2003). Two different perspectives of technical efficiency can apply: input orientation and output orientation, and refer to their respective measurement stance. Each of these two perspectives hold a fundamentally different management philosophy with unique implications for performance improvement: (i) input orientation refers to a compliance based approach where the management effort is on minimizing the use of resources to produce the required level of outputs; and (ii) output orientation refers to an improvement based approach where the management effort is on maximizing the production of outputs to the highest level possible (Hollingsworth and Peacock, 2008). Management can achieve technical efficiency when it adopts a compliance philosophy and so minimises its use of resources for a given treatment output level, or conversely when it adopts an improvement philosophy to maximise outputs for a given level and mix of inputs (Hollingsworth and Peacock, 2008). Technical efficiency is based on the use of inputs and outputs which are largely under the manager's control (Rouse \& Ryan, 1994). 
For the literature review, the use of a systematic search allowed the identification of the best available information from primary and secondary sources. Articles were located in the MEDLINE, CINAHL, Psych INFO, and the Cochrane Library databases. Key terms were used to conduct an extensive search of the literature through The University of Auckland (Auckland District Health Board). In addition, search for literature on the use of efficiency information to improve hospital service performance was conducted by Waikato DHB Library Service. The other Internet search engine that was used was Google scholar (http://scholar.google.co.nz). The rest of this Chapter is organised as follows. Section 2.2 discusses the organizational setting and management within public hospitals. Section 2.3 outlines some key perspectives on information use by hospital service managers. The use of information is referenced based on principal-agent relationships where multiple interests exist and are not necessarily aligned with the focus and interests of the entire hospital (Ludwig, van Merode and Groot, 2010). Section 2.4 describes the general approach to measuring technical efficiency and includes comment on empirical applications in public hospitals. Finally, Section 2.5 concludes by outlining what is currently known in the literature about hospital service managers using technical efficiency performance information to improve service performance.

\subsection{Organisational setting and management}

Hospitals are complex systems having multiple services and multiple decision makers with varying patient flows and treatment capabilities. The organisational setting in public hospitals is described as being within a high velocity environment, where there are multilayered and different groupings of clinicians and linked service departments, with different objectives being pursued (Shortell and Kaluzny, 1994; Buttell, Hendley and Daley, 2008). Given the interlinked nature of care (diagnosis and treatment), the consumption of resources and the delivery of treatment tends to require a heavily layered matrix of interactions and 
relationships for both patients and staff; such that the performance of services which are heterogeneous can be viewed to have varying intangible outcomes (Shortell and Kaluzny, 1994). Each service within a hospital has a different perspective on performance. Merode et al (2004) argue that hospital services (as separate clinical specialties or departments) tend to seek to optimize their own function and performance independently of other services. The central element around all hospital activity is the human and managerial relationship between managers and clinicians (Crema and Verbana, 2013).

Managerial activities tend to be comprised of: data-centred activities, addressing staffing issues, the promotion of culture and strategy as well as goal setting and providing feedback to staff and senior executives (Parand, et al., 2014). Hospital service managers are viewed as decision-makers who are directly responsible for efficiency, making tactical or strategic decisions on resource consumption and hence on productivity and efficiency, and on operative practices on staffing management, case scheduling and resourcing and performance measurement (Peltokorpi, 2011). Within the formal structure of a hospital organization, there is, however, a pragmatic separation of purpose in the managerial and clinical roles. Clinicians have a high degree of autonomy in their clinical practices and customarily have direct unfettered interaction with patients. Clinicians typically focus on the individual diagnosis and treatment of patients on a case-by-case basis. Shortell and Kaluzny (1994) note a key feature of hospitals is being a highly variable and complex organization where services involve a high degree of clinical specialization, where clinicians have minimal tolerance for management and where clinical care is often acute with limited margin for error. Yet, Sherman (1984) and Ramanathan (2005) suggest that in hospitals, managers must effectively manage resources and also staffing in order to accomplish the organisation's desired goals. 
The managerial effort at the service level is to ensure that input resources are being used within budget and not reach deficit, and as well, to support the clinical effort on the individual patient diagnostic, treatment and discharge process. The technical efficiency perspective that is being adopted here is an input orientation (Hollingsworth and Peacock, 2008). In New Zealand, demands can be made on managers to have an almost single-minded orientation to achieve favourable budget outcomes; and to meet service treatment targets that required by funders, who also expect to see an increase in efficiency in the delivery of services (Van Thiel and Leeuw, 2002).

\section{The unique challenge of public hospitals}

Mintzberg (1997) identified quadrants of influence within the hospital, each quadrant being self-interested agents having separate objectives and methods of working with others. Mintzberg's quadrants included managers and clinicians in separate quadrants as well as nursing staff and external trustees (Board members). At hospitals, the managers of clinical care and treatment services face a unique set of challenges. To provide successful diagnosis and treatment, there is a high interdependence of activities within a service department that require precision and coordination between clinicians, groups, and service departments always at an individual patient level.

The reality facing the hospital manager in their work environment has interesting parallels in a study by Bhaskar (1998) who suggested humans working together need to be able to move across three distinct social realities in order to function appropriately. The social reality facing individuals working together within society (or, as managers within an organisation) has been studied by Bhaskar $(1998,2011)$ who describes three interlinked and overlapping levels of reality: 
- At Level one, the inner or primary level called the Empirical world, where individuals have direct experiences and observation of life situations;

- At level two, called the Actual world, where the individual connects several Empirical worlds (of others that the individual has interactions with) to create a sense of their environment; and

- At Level three, called the Real world, where the individual makes broader and more connected judgments about what actions to take and where wider societal engagement occurs.

Bhaskar (1998) explains that the Real world is intangible but has underlying tendencies and causal rules of how social life operates. A manager's physical and mental capacity may be concentrated in the domain of the Real, while his work, as an activity that generates the effect of power, is mostly concentrated in the domain of the Actual (Clandinin and Connelly, 2004). In order for a service manager to improve performance would require interactions with clinicians, and so, it would be necessary for the manager to understand as much as is possible about the Real world rules and mechanisms. The three interlinked and interdependent 'realities' that an individual operates their consciousness within, by moving across the three realities they can operate at a higher level of strategic intent (Clandinin and Connelly, 2004). Although Bhaskar's theory is a transcendental philosophical view of social relations, it resonates in this management research because of its simplicity in mapping the possible progression of a manager's behaviour in terms of understanding their realities. The traditional view of managers being bound by rationality gives way to behavioural factors in the way they function to influence the operating systems within organizations. As Latham (2003) suggests, managers do desire to have meaning and clarity for their work and involve seeking appropriate signals from the organization or from outside. 


\subsection{Perspectives on the use of information}

The use of information is defined as the acceptance of a signal provided by the information into account when taking action or making a decision (Moorman et al, 1992); that is, use is a process. The process has several dimensions: (i) the direct application of the signal to solve a specific problem; (ii) action on a particular issue; or (iii) to broaden the knowledge base. The use of information can be dynamic, immediate or a planned action (Hayes, 2002). The information is communicated or exchanged which leads to increased understanding by the recipient, knowledge development and finally decisions (Hayes, 2002). This exchange is a process that is the presentation of performance information to a recipient who may be the user or an intermediary. Having information can mean it will be used and there will be a response and management action taken (Wilson, 1999). A contradictory view to Wilson (1999) is provided by Moynihan (2005) who notes that having information will not necessarily mean its use or that there will be actions that are taken to improve performance.

Behaviour is important in this regard. Early seminal work by Feldman and March (1981) indicates that within organisations, management actions would often be made without reference to the use of information and available information would be ignored. Feldman and March (1981) regards the use of information as being largely inductive and an exploratory process of discovery. Both Hayes (2002) and Feldman and March (1981) suggest that information provides a learning context for knowledge. This view is supported by a study of research organisations and their internal decision-making by Amara et al (2004) that identifies information would not be used by managers: if the characteristics of the information make it difficult to comprehend; if it requires effort and time; if the information is perceived as not meeting the manager's need; or where there is an inferior social linkage between the preparer of the information and the recipient; or, when a cultural gap exists with the information provider. Amara et al (2004) believes that the technical nature of 
information may inhibit its use. The potential to not use or to misuse the information in order to meet a personal particular need is also always present (Bolton \& Stolcis, 2003).

Another perspective is that organisational pressure may drive the managers' use of information. Van de Walle and Bovaird (2007) note information from presenters who have high social standing will have more influence on the recipient, who will increase their perception on the need for, and use of the presented information. The work described so far above refer broadly refers to the user's motivation for seeking information. The work of Davenport and Beck (2002) add another perspective, in that these authors note managers can be overwhelmed to effectively manage competing information. A discussion of the volume of incoming information (Karr-Wisniewski and Lu, 2010) suggests that managers who face information overload can have poorer performance. The problem of the overload of information is discussed in Cognitive Load Theory (CLT) developed by Sweller (2011, 1994) in relation to learning and problem solving. It is a major theory that provides a framework from a management perspective to understand both the cognitive processes and the instructional design aspects of information (Paas, Renkl and Sweller, 2003). CLT developed largely to understand how people process information and to allow learners gain data more quickly. CLT proposes that learning can be enhanced by the presentation of information if it is structured in a way to utilise both the person's short term (with limited span of recall) and their long term memory that is virtually unlimited.

According to CLT, learners tend to first categorise information by the manner in which it will be used ('Schemas'). Secondly, through repeated and related exposure to related problems, the learner then automates their learning to be stored in long-term memory for recall when needed ('Rules'). Schemas in the shorter working memory were shown to only process a limited seven items at a time. The theory suggests that users of information have a limited 
working memory even through repeated exposure, can become distracted by too much information, unless Schemas are built and Rules are automated for recall when needed. Performance information may serve the user better if it is instructional in focus and intent and its design is linked to Paas, Renkl and Sweller's (2003) CLT understanding of learning. An indirect view of how information is used is the theoretical model of the processing of information (a theory of reasoned action) which suggests the gaining of knowledge can lead to intention and to a response or action (Fishbein and Ajzen, 1975; Ajzen and Fishbein, 1980; Ajzen, 1991). The model assumes that behaviour can be influenced by information which is a pre-determining function of the intention to perform the action. The assumption is that the intention is jointly determined by the person's attitude, salient beliefs and subjective norms concerning the behaviour in question. The theory of reasoned action is a widely accepted model in social psychology to explain human behaviour (Fishbein \& Ajzen, 1980). It can help to provide insight to the theoretical basis to explain information use and the affected knowledge sharing behaviours of managers. This theory may provide understanding on 'why' managers use information, but not on the 'how' the information is used. What is particularly helpful in understanding the use of information is that the theory of reasoned action assumes all other factors influence behaviour only indirectly by influencing the above mentioned attributes of attitude or subjective norms (Davis, Bagozzi and Warshaw, 1989).

\section{Using information}

Using information for greater awareness and for the development of performance action is generally viewed as being superior decision making to that without the use of information (Davenport, 2000). Information defines knowledge and needs to be accurate, timely; current; relevant; complete; easily interpretable; consistent; traceable and finally easily accessible. Based on these requirements, information will be used if its precision, relevance, and reliability outweigh the cost of its accessibility and readability. In using information, the 
process should focus attention on the issues raised by the performance measures and the necessary actions to meet organisational objectives.

Bearing this in mind, the use of information in order to improve performance will require two conditions to be met: (1) the making of meaning and (2) the signalling of actions to being taken. The making of meaning is to provide context for a purposive action according to Choo (2002). Context allows the response to the information to be therefore behavioural (Solomon, 2002; Saracevic \& Kantor, 1997). The early work of Wilson (1999) similarly describes information response behaviour that is based on three separate sequential steps, first the need for information is realised; second there is information seeking and finally behaviour response is the outcome of the interaction of the use of information and result of the earlier identified need for information (Wilson, 1999). Choo (2002) supports the view of the use of information as a behavioural response process. This process begins first with the identification of the content of the information; secondly, the development of action options and selection of action option/s by the user; and thirdly followed by an active behavioural response in relation to the situation. In almost all cases, this behavioural response can be observed. Choo (2002, p.45) describes this as "the form of representation that provide meaning and context for purposive action". Information use is therefore viewed as the mechanism by which action occurs - based on the tradition that the user of information has a need for information and will actively seek out what is then required. This traditional view is beginning to change, with Jarvalin and Ingwersen (2004) who suggest that information use should be considered in the light of the eventual result of its actual use. 


\section{Challenges for hospital managers}

Managers operate within the context of employing organisations and are influenced by corporate strategy as well as environmental local pressures. The work of Greenberger and Strasser (1996) identifies managers as seeking to increase their personal control to effect desired change. For hospital managers, their focus is on improving the patient service flow, and managing the inputs within the production process to result in targeted outputs that are quantified. Information use can be viewed as a process of managing the work environment, that managers use information to become aware of an otherwise unknown situation and to respond appropriately. Taylor (1991) identifies models of management for using information. These include to understand a problem in order to purposefully improve the comprehension of a specific situation, or to gain general enlightenment on a subject in order to obtain more contextual information. Other models include developing the need for factual understanding to obtain precise data in relation to a situation; and in seeking clear direction on an action; confirmation to provide validation of a particular situation; projection in order to get a sense of a likely future; and, lastly, motivational to ensure personal commitment or to enhance relationships. These models refer to the range of the motivations for seeking of information. Ho (2005) and Askim (2006) also consider that information may be used for different reasons, while Behn (2003, p.588) identifies the many reasons for using information as "to evaluate, control, budget, motivate, promote, celebrate, learn, and improve". In decision theory, the traditional view of information is that it can improve the quality of decision-making amongst competing sets of actions or priorities. This is a largely deductive approach where the user's objective is to plan and expedite actions. However, information can also be for non-active purposes where managers make no direct specific decision to act, but simply use the information to acquire knowledge (Behn, 2003). A manager is essentially exploring the situation for reassurance or for alerts, on an inductive basis, where the information has no immediate value. Hospital-based information is 
fundamentally limited and there is uncertainty because patient illness and their treatment care can vary across patients. This uncertainty of hospital information and management challenge is echoed in sense- making theory (Dervin, Foreman-Wernet and Lauterbach, 2003), which was an early contribution to the study of information use behaviour. Sensemaking theory establishes information as the bridge between a situational need and the outcome. While, the theory helps in the understanding of the need for information so that the user makes sense of a situation correctly, it does not consider how the information is then used by the user. In hospitals, managing for efficiency requires consideration of the relationship between the consumption of resources and their associated output, and to simultaneously satisfy as best as possible the objectives of the clinicians.

\section{Empirical Indicators}

According to Willis and Ricketts (2004) performance improvement requires two necessary conditions, these being: an iterative learning cycle being available, and second that the learning cycle be set at local levels within the organisation (operational levels). For such internal performance improvement, the indicators that provide local managers with information will need to measure the particular process of study and signal a valid assessment of possible improvement (Davenport and Harris, 2007). There must be precise and valid data with agreement amongst the participants on sample, appropriate risk adjustments and collection period. To be reliable, data underlying the indicators are required to be complete, accurate, consistent and reproducible (Anema, Kievit, Fisher et al, 2013). Indicators provide precise viewpoints of aspects of service performance, and therefore to obtain an overall view will require a range of individual indicators required to provide adequate coverage. The approach of having such a spread of indicators is generally counterproductive because managers' attention is diluted across all the measurements. 
Another approach to providing a more complete picture of performance includes the development of a 'balance' of indicators with Kaplan and Norton's balanced scorecard, with four quadrants each with four or five measures (Kaplan and Norton, 1993). This approach, however, produces sixteen to twenty-four measures (four quadrants, each with four or six measures) for the manager to assess the various different signals on performance (Anema et al, 2013; Davenport and Beck, 2002).

\subsection{Measuring technical efficiency}

\section{Performance measurement}

In performance measurement, the key consideration is to do with what is to be measured and from whose perspective. Measurement is important if the service (or Government's healthcare policy makers, and the funder of the hospital service) wishes to compare how well the service is doing and want to know how it can improve further. Rouse and Putterill (2003) define performance measurement as: "the comparison of results against expectations with the implied objective of learning to do better." (Rouse and Putterill, 2003, page 795). But, Rouse and Ryan (1994) note that the more difficult part of performance measurement is in the identification and acceptance of appropriate measures to provide an overall understanding of performance, and that which are of use to the hospital manager. In these circumstances there are difficulties in measuring the performance of services. It follows then; the management of performance becomes complex and problematic. There is a growing central government tendency to increase the range and complexity of measurement, with sophisticated hierarchies of multiple financial and non-financial measures that are connected by explicit structures which identify critical success factors and underlying activities (Rouse \& Ryan, 1994). 
Performance measurement is a basic precursor for performance improvement. Jacobs and Dawson (2003) studied the impact of the measurement of hospital efficiency targets in the United Kingdom's National Health Services, and concluded that the efficiency targets did not result in performance improvement, or a reduction in unit costs. The authors note from interview data that the lack of any impact on costs could be attributed to the targets that had been negotiated locally that bear little relationship to the published targets. This suggests that managers who are to be responsible for delivering on performance need to have a degree of ownership and understanding of the targets. A second observation by Jacobs and Dawson (2003) is that the cost was influenced by clinical practice variations such as increased intake or early discharge of patients.

\section{Technical efficiency}

In economics, technical efficiency is represented by a function that can be viewed as a ratio to approach to the optimum levels in the functionally represented activities (Tutulmaz, 2014). The concept of technical efficiency is related to productivity, which is the measure of the ratio of outputs produced for inputs. Koopmans (1951, p.61) also formally defined technical efficiency as an optimum state for any service production by stating that: "If a producer needs to decrease one of the outputs or increase one of the inputs in order to increase its output, the situation [for the provider] is technical efficient". A similar but converse position, whereby if the input needs to increase or one of the outputs is decreased in order to decrease its input is also a technical efficient state, (Kumbhakar and Lovell, 2000; Fried, Lovell and Schmidt, 1993).

These two definitions of technical efficiency refer to the philosophical perspective on the best use of resources (Hollingsworth \& Peacock, 2008). This means that management of technical efficiency of an organisation can be by using either or both of the input and output oriented 
approaches. From an economic perspective, technical efficiency is defined around a production function. From a management viewpoint, the underlying philosophy for technical efficiency can mean the manager aims to reach the maximum output for a given or minimum input; to they aim to minimise the use of the inputs for a given level of output. For managers technical efficiency can be viewed as the optimal combination of, or 'effectiveness' with which, a given set of resources (known as inputs, such as staffing and materials) is used to produce a required output, or a set of outputs. Adopting Hollingsworth and Peacock's (2008) definition, technically efficient service production in terms of its use of resources is where the combination of inputs uses the least resources to produce a given level of output for a given state of technology. Technical efficiency represents the possible best use of resources in the production process; as the maximisation of outputs for a given level and minimal mix of inputs (or its converse). The basic premise underlying this concept of efficiency is that the outputs cannot be produced without any resources (or inputs). These resources are limited in supply. From this, it also follows that there is a limit to the volume of product (outputs) that can be produced.

Efficiency generally refers to using the minimum number of combined resources (inputs) to produce a set number of outputs that are of an acceptable standard. This presents an interpretative approach to enable managers to gain insight into causes of inefficiency and to better manage resource utilisation at a service production level (Hollingsworth and Street, 2006). Accordingly the operational efficiency performance of a service is indicated by the relationship between its consumption of inputs and production of outputs (Fried \& Jarden, 2008). In such a relationship between the outputs and the inputs that are involved in production, the performance of technical efficiency is viewed as a function of management in a simple economic production process concept to link management to behaviour considerations. 
A simple input - output representation is illustrated in Figure 2.1 modelled on Hollingsworth (2008) and reflecting the production technology and management state. In this input output relationship, technical efficiency is viewed as a result of a production process (for a given state of technology and quality), which conceptually links management to behaviour considerations.

Figure 2.1: Input output process model

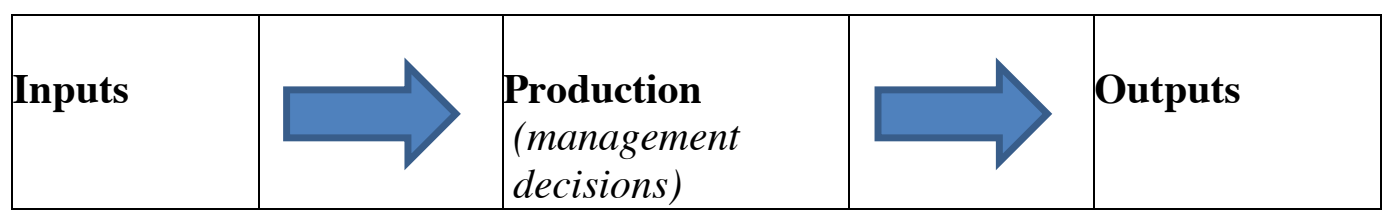

Depending on the information available to, and attitudes of, a manager, they may decide on different combinations of inputs and outputs in order to achieve a technical efficient position (Hollingsworth \& Peacock, 2008).

\section{Data Envelopment Analysis (DEA)}

Introduced in 1978, Data Envelopment Analysis (DEA) has become widely accepted for use in public sector settings across the world, and since 1997 that has included the New Zealand health sector. The concept of technical efficiency was first` introduced by Farrell (1957) and further extended by Charnes, Cooper, and Rhodes (1978) who developed a mathematical programming approach to measure relative efficiency of decision making units. Over 4000 articles have been published using DEA since its inception in 1978 (Emrouznejad, Parker, \& Tavares, 2008). DEA is a linear programming technique, developed by Charnes, Cooper, and Rhodes (1978) to measure technical efficiency.

There are a number of theoretical principles underpinning the use of DEA. Drawn from the economic theory of production, DEA is based on a theoretical notion of technically efficient production that defines the optimum relationship between a given level of inputs and outputs. 
The mathematical formulation of DEA has been well documented in the literature. Further developed by Banker, Charnes and Cooper (1984), DEA constructs a production frontier of production possibilities that are based on empirical data and produces a measure of the technical efficiency which is typically constrained to lie between $0 \%$ a measure of having no production of output or a state at zero efficiency and $100 \%$ that is a technically efficient state (Charnes, Cooper, \& Rhodes, 1978; Banker, Charnes \& Cooper, 1984). In DEA, the central assumption is that the rate of production is represented by the empirical set of inputs or resources used and outputs delivered. As a result, the efficiency measure is deemed to be feasible (Hollingsworth \& Peacock, 2008). The analysis through DEA provides an estimate of an empirical level of productivity, presenting efficiency scores, target values and exemplar peers for comparison. The input of interest is optimal use of staffing or labour cost and related resources as the factor for production.

Public hospitals have a production function based on transforming inputs into outputs (Rutledge et al, 1977). It is understood that hospitals are organizations that usually operate multiple production processes, each process supported by its own set of resource inputs (Barnum and Gleason, 2008). In a hospital, these multiple production processes can be separate or networked in various ways such as joint-interrelated and sequential, and the resources or inputs of each production process can be allocable or non-allocable to multiple outputs (Färe and Grosskopf, 2000). The particular advantage in using DEA is that the efficiency score is optimised by the selection of the most favourable weights (Worthington, 2004). Each of the outputs and inputs to be used in the DEA model is weighted to provide the best possible score of efficiency; or, to as far as possible reach a $100 \%$ efficiency. This means that the relationship between resource inputs and output levels are being optimised as far as is feasible (within weights) for each of the units being benchmarked. To date, most of the above DEA studies have focused the measurement of efficiency on inputs and their controllability; 
using an input orientation of the DEA model. This input orientation assumes that the managers have control over inputs; whereas an output orientated model would assume managers have more control over their outputs (Ozcan, 2008). In hospital services, the manager's controllability is going to be stronger over the inputs than the outputs because the latter (as currently measured in terms of treatments) are heavily dependent on clinician effort.

\section{Decision Making Units (DMUs)}

In the DEA literature, the term 'decision making units' (DMU) is used to represent any service provider as a producer of outputs by consuming inputs. DMUs are viewed as management entities capable of making resource use decisions in their own right. In DEA, each DMU is assumed to perform the same nature of tasks, have similar objectives, and operate in the same set of environmental conditions and pressures (Golany \& Roll, 1989). The DMUs that are being measured are all assumed to be responsible and in control of their use of the inputs and outputs under measurement (Ozcan, 2008).

\section{Disadvantages of DEA}

In the literature, there are potential disadvantages of using DEA to measure efficiency as an entity's performance (Vinkova, 2005). DEA calculates an estimate of the relative efficiency of a selected DMU within the group of DMUs. The relative efficiency is not an absolute efficiency estimate but a positional rank amongst the group of DMUs. The DEA estimation is based solely on the chosen criteria for analysis (the inputs and outputs) and is deterministic in its calculation. A second shortcoming of DEA is that the technique of calculation is based on extreme points and ignores any random fluctuations. This means that the DEA analysis is more sensitive to data noise and any input or output data measurement errors. For hospital services, DEA may be skewed by crude measurement problems in the input-output data set for instance, severity of illness and treatment costs can vary immensely between patient types. 
The real overall concern of DEA is that the result can be misused by the uninformed reader and provide potentially misleading avenues for performance improvement (Hollingsworth and Peacock, 2008; Rouse and Swales, 2006).

\section{DEA measurement of hospital services}

DEA has been widely used to measure and benchmark efficiency in hospital services (Hollingsworth, 2008; Hollingsworth et al, 1999; Hussey, de Vries, Romely et al, 2008) and increasingly is being viewed as an effective tool for efficiency management (O’Neill, Rauner, Heidenberger et al, 2008; Cruise and Nyhan, 2000). Researchers have used DEA to measure the efficiency of hospital services and specific sub-systems of hospital-based health care (Rutledge, Parsons and Knaebel, 1995). Dexter and O’Neill (2004) used DEA to examine efficiency of elective inpatient surgical workloads, while Dexter, O’Neill, Lei et al (2008) investigated surgical workloads. Chilingerian (1995) extended the measurement of efficiency to individual clinicians. Magnussen and Nyland (2008) measured the efficiency of clinical departments. In Rutledge et al's (1997) study, the efficiency of separate clinical departments within a hospital organisation was measured over time. Rouse, Putterill and Ryan (2002) conducted a study which used a time series (of data) for separate departments within an international airline. In these latter studies, time periods were used as DMUs within the single entity, and benchmarked relative to each time interval ${ }^{1}$. DEA studies on public hospitals are numerous, but these are often academic studies on the measurement of hospitals as a single DMU and on its performance as an entire organisation (Sherman, 1984, Burgess and Wilson, 1993). Hollingsworth (2008) reviewed 317 published papers on efficiency measurement of health service delivery; but fewer than 10 of these are studies at a hospital's service or departmental level. Some other studies have focused on aspects of hospital organisation,

\footnotetext{
${ }^{1}$ Professor Rouse has advised that as unpublished work in his doctorate research and included in his $\mathrm{PhD}$, nurses in a medium sized hospital assessed their staffing and ward efficiency. In this study, the wards were benchmarked against themselves at periodic time intervals (Paul Rouse, pers. comm.).
} 
including: (Nunamaker, 1983 - nursing staff, Farsi and Filipini, 2004- nursing homes, Gonzalez and Gascon, 2004 - pharmacy, Ozgen, 2006, Kontodimopoulos and Niakas, 2005 renal haemodialysis, Nathanson et al, 2003 - neurotrauma patients in intensive care; Franklin, O’Neill and Xin, 2008- surgical workload by specialty, and Safdar et al , 2016 - outpatients services.).

\section{DEA efficiency as a hospital managerial tool}

DEA enables answers to questions about how well each DMU is doing, and what each DMU needs to do to improve (Rouse, Putterill, \& Ryan, 2002). Parkin and Hollingsworth (1997) developed efficiency indicators from using DEA techniques for a selected set of Scottish hospitals within the National Health Service in the United Kingdom. The approach included the presentation of the information using a series of graphs, pie charts and tables to present efficiency results to senior hospital staff. This work however looked at efficiency from a 'whole of hospital' viewpoint. Hollingsworth and Peacock (2008) have suggested, somewhat aspirational, that acceptance of the DEA information by potential users is equally important as its measurement; and by inference its use by those who have been subjected to DEA measurement.

The work that has been done to date has focused on hospital services, the Scottish hospitals (Parkin and Hollingsworth, 1997), or in New Zealand, from the policy centre, Ministry of Health (Swales and Rouse (1997). Since 1997, DEA has been used in New Zealand to assess the efficiency of public hospitals for benchmarking purposes and to model an optimised efficient cost of hospital production (Rouse and Swales, 2006) ${ }^{2}$.

\footnotetext{
${ }^{2}$ Professor Paul Rouse and I were commissioned by a joint MOH/The New Zealand Treasury/District Health Boards Committee to jointly develop a DEA efficiency toolkit for hospital managers using hospital specific data on operating costs and production volumes.
} 


\subsection{Conclusion}

The published studies in the literature are sparse in relation to addressing the use of efficiency information by hospital service managers to improve service efficiency. The general context for research within the New Zealand public hospital environment will reference the available and related theoretical literature with empirical applications on the use of efficiency information to improve hospital service performance. The literature suggests that there is a diffusive and cumulative effect of information and that it may be either: a deductive effect, where the information serves to validate a performance action that has been already developed; or, an inductive effect, where the information provides for greater awareness of a performance issue and the subsequent development of performance action. Conceptually service managers in public hospitals can aim to deliver services efficiently according to a production function that includes both the use of resources to produce treatment of patients. However, in the literature there is a dearth of empirical studies, further weakened by a lack of examination of the actual use of information by managers and their actions that are undertaken. It is a research area of under-development currently.

For the purpose of this thesis, the literature that has been cited above are drawn together to provide a platform for the research and analysis. The problem that managers often face is not the scarcity of information but the contrary situation where there is often an overload of information. CLT (Sweller, 2011) provides some clues as to the preparation and format for information to better enable its use. Structuring information so a learner can quickly develop schemas and automated rules possibly enhances the development of information use and subsequent knowledge and performance. The management perspective on the use of efficiency information is of the interaction and behaviour of hospital managers with other 
hospital staff on improving performance of services. Performance improvement refers to the managerial effort in collaborating with clinical staff towards optimising the input-output process model to increase the technical efficiency of the service. The adoption of Hollingsworth's and Peacock's (2008) definition of technical efficiency provide a pragmatic approach at hospital service level that lends itself well to uncovering inefficient behaviour, in the managers' use of resources and control or influence over clinicians. DEA makes it possible to measure the efficiency of the production of services to understand managerial actions in relation to improving service performance. DEA will model individual services' relationship between their multiple inputs and outputs. Each service can be viewed as a single decision making unit (DMU) capable of managerial control for its efficiency.

The research questions are drawn from the gaps in the literature, in seeking to address key issues relating to the extent hospital service managers use specific information within the context of their performance environment, and to understand their management actions to improve service performance. By addressing the research questions, I hope to begin to be able to better understand how managers use efficiency performance information in order to improve service performance. In the following Chapter Three, the approach and process that was used to address these questions are discussed and outlined. 


\section{Chapter 3}

\section{Research methodology and methods}

\subsection{Introduction}

This study was not intended to identify an absolute truth or to provide answers, but to instead develop and present an understanding of the phenomenon under study and to be able to describe commonalties or themes of the studied experience. The philosophical assumptions underlying this research come from the interpretive tradition. This implies a subjective epistemology and the ontological belief that reality is socially constructed. The research strategy adopted was to conduct an exploratory case study in one organisation with 11 key informant participants. The fieldwork was conducted onsite with the different informants during the period from July 2012 to January 2013. The data collection techniques used in this research study included semi-structured interviews, participant observation, and questionnaires.

The exploratory nature of the research questions that were posed in Chapter One requires a consideration of the appropriate framework and approach for the research that addressed the research questions (Patton, 2002). The approach taken to achieve this research aim was to describe a phenomenon as it is being experienced from the point of view of the persons involved. The purpose of this chapter is to present the philosophical assumptions underpinning this research, as well as to introduce the research strategy and the empirical data collection and analysis methods applied. The chapter defines the scope and limitations of the research design. The research is situated among existing research traditions in social science and management research.

Section 3.2 describes the overall research design for the study. In Section 3.3 the interpretive stance taken in this research is discussed. Section 3.4 outlines the use of case study as the 
research strategy. Section 3.5 discusses the concurrent use of various methods to cover the data collection and analysis. Section 3.6 discusses the quality concerns for the study and potential risk of bias and their management. These issues are discussed ahead of the study methods so as to inform the appropriate level of rigour required. The subsequent Sections 3.7 to 3.11 details the study setting, methods of data collection, analysis and interpretation while Section 3.12 presents the strength of the research methodology. Finally Section 3.13 concludes the Chapter.

\subsection{Research design}

Creswell's (2009) framework for research design is shown in Figure 3.1. It connects worldviews, strategies of inquiry and research methods for the researcher and so provides a theoretical framework to map out the underlying assumptions, the design of the research and the use of particular methods to collect and to analyse the data.

Figure 3.1: Framework for research (from Creswell, 2009)

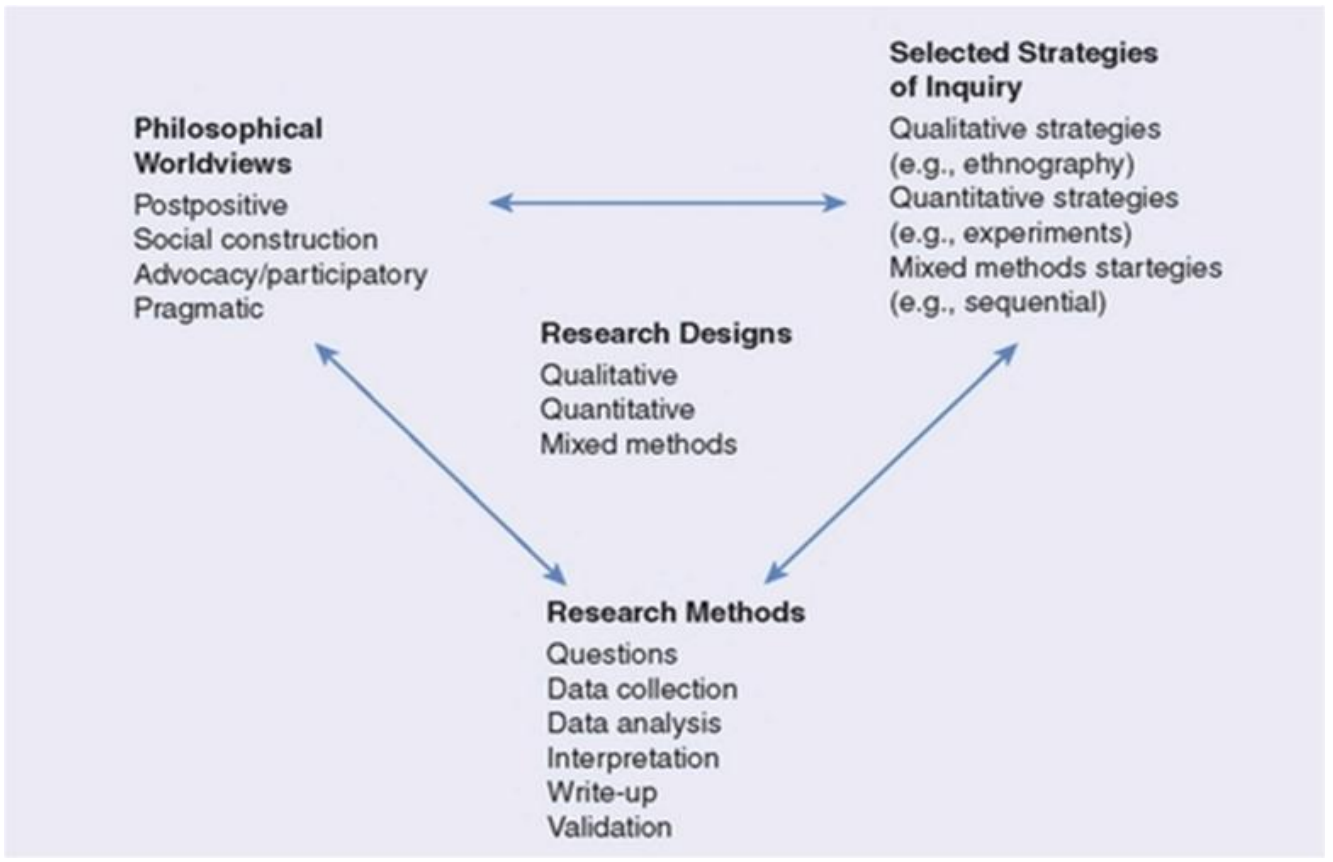

In Figure 3.1 there are three levels in orientating research. Each level is now briefly discussed in the context of this research. 


\section{Level 1 - Philosophical Worldviews}

The philosophical worldview held by the researcher is their beliefs and values that serve to orientate the research to a particular methodological approach and design (Guba, 1990). According to Creswell (2007) these beliefs represent the Worldviews which are shaped by the discipline area of the student, the beliefs of advisers and faculty in a student's area, and past research experiences. All research can be viewed as of phenomena within a world setting, but the underlying philosophical assumptions held by the researcher will mean a different study approach is taken. Four different worldviews are briefly noted: post-positivism, constructivism, advocacy, and pragmatism (Creswell, 2009).

Post-positivism refers to the extension from the traditional positivist scientific and deterministic view in which causes are viewed as probably determining the effects or outcomes and where being objective is a core aspect of competent inquiry (Creswell, 2007). The extension of post-positivism is to shift the consideration onto the dependence of social context and the person's perception of reality as important factors in outcomes to reveal a true nature of how society operates (Ellingson, 2011). Research can be considered positivist if there is evidence of formal propositions, quantifiable measures of variables, hypothesis testing and deductive inferences concerning the phenomena from the representative sample to a stated population (Orlikowski and Baroudi, 1991). This approach assumes that the relationship between social reality and humans is independent, and objective of cause and effect. However the positivist approach has been criticised for its assumption that reality can be deduced through statistical analysis when often it is regarded as complex (Galliers, 1991; Creswell, 2009). The positivist approach is noted by Galliers (1991) as deeply rooted in functionalism with its focus on causal analysis at the expense of understanding closely the phenomenon being studied. Thus, the post positivist approach's approach is to shift the early 
positivist's deterministic view to a more referenced approach taking into account social reality and context.

The Advocacy (and Participatory) Worldview has the philosophical assumption that the positivist assumptions imposed structural laws and theories do not satisfy issues of social justice which need to be addressed (Creswell, 2007, Neuman, 2000). The researcher often begins with one of these social justice issues as the point of the study and focuses on the needs of groups and individuals in society that may be marginalized (Creswell, 2007). Its primary purpose is to critique the status quo conditions as restrictive and alienating to particular individuals or populations in the community (Klein and Myers, 1999). This approach assumes that populations and the individuals within can behave differently to consciously change their social and economic reality (Ngwenyama and Lee (1997).

The Pragmatic Worldview emphasises the focus on the research problem and will use all approaches that are available to understand the problem (Morgan, 2006; Patton, 2002). Pragmatism is not committed to any one system of philosophy and its researchers draw from both quantitative and qualitative assumptions in their research. Pragmatic research tends to use mixed methods to collect and analyse data.

The Constructivist Worldview (or Interpretivism, as in Mertens, 1998) is an approach to qualitative research. The assumption is that the understanding of the world in which people live and work is important to be able to develop subjective meanings of their experiences of certain objects or things. The goal of the researcher is to rely on the participants' views of the situation being studied, so that the participants can construct the meaning of a situation. The researcher's intent is to make sense of (or interpret) the meanings others have about the world. 
Rather than starting with a theory (as in post-positivism), inquirers generate or inductively develop a theory or pattern of meaning (Crotty, 1998).

\section{Level 2 - Selected strategies of Inquiry}

The strategy of inquiry is also called approaches to inquiry by Creswell (2008) or research methodologies by Mertens (1998) and refers to the type of study and whether a qualitative, quantitative, or mixed methods design has been selected, by the researcher. The choices made by the researcher on type and methods will provide direction on the procedure of the study for the collection and data analysis.

\section{Level 3 - Research Methods}

Research methods are the conduct and process of collecting, analysing, and interpreting data in order to understand a phenomenon (Leedy \& Ormrod, 2001). Creswell and Plano (2011) note that either, or together both, quantitative or qualitative methods can be used to collect, analyse, and integrate research data in a single study or a longitudinal program of inquiry. Qualitative research can provide a better contextual understanding of a research problem than what can be expected from a quantitative method process (Creswell, 2008). The remaining sections now outline the methodology and methods used in the research.

\subsection{The interpretive research approach}

The epistemological stance on interpretive approaches is that knowledge is gained only through social constructions of reality (real world) such as language, shared meanings, and documents (Walsham, 1993). Access to reality is only possible through social constructions such as language and shared meanings. In interpretive research there is no requirement for any predefined dependent and independent variables. The focus of the research is on the complexity of human sense-making as the situation emerges (Kaplan and Maxwell, 1994). 
The assumption of the interpretive approach is that phenomena must be understood in the social context within which they are constructed to give meaning to their actions or reality. Adopting an interpretive stance means the researcher has accepted that social reality is constructed as a result of intentional actions (Burrell and Morgan, 1979).

There will be no a priori theory to guide the research or its analysis. Using the philosophical basis of interpretive research will increase understanding of the social and organisational issues related to the use of management information by hospital service managers. With this approach, there is greater scope to address issues of influence and impact, and to ask questions such as 'why' and 'how', rather than to focus on 'what is'. It is clearly understood that in the interpretative description of the experience of hospital service managers in their use of management information to improve efficiency, it is appropriate to explore 'what is perceived to be' (Oiler, 1982).

\subsection{The case study strategy}

Yin (2014) defines a case study as an empirical inquiry that investigates a contemporary phenomenon within its real-life context, especially when the boundaries between phenomenon and context are not clearly defined. Yin (2014) argues that the case study is useful in investigating and interpreting the meaningful characteristics of real-life events such as managerial processes. It is recognised that not all case studies are necessarily interpretive and can be used to produce qualitative or quantitative data if used as a method of inquiry with a positivist epistemology and ontology.

Yin (2014) warns against confusing case studies with ethnographic studies using qualitative methods. The ethnographic method is derived from cultural anthropology, is of a long duration, requires detailed observational material (Yin, 1994), and is useful in studying 
organisations to help researchers extract cultural knowledge and identify everyday life actions of participants (Prasad and Prasad, 2002). Case study as defined by Yin $(2015,2014)$ is typically conducted within a defined time frame and does not necessarily use detailed observational or ethnographic techniques and instead may collect their data through secondary sources (or interviewing respondents using telephone or now, by e-mail). Therefore, the case study approach is especially useful where the contextual conditions of the events being studied are out of the researcher's direct control. The context and social action within the setting becomes the object of analysis and potential factors of the phenomena under study; based on the observation of facts and interpretations (Glaser and Strauss, 1967; Charmaz, 2006). However, any theoretical development is limited to the generation of thematic sense making from the collected data through activities of analysis, coding and interpretation (Czarniawska, 2014). The type of case study is intrinsic, where the case is unique and is therefore not representative of others. The purpose of conducting this type of case study is not to build a theory, but because of its intrinsic interest, to provide insights (Stake, 2005).

Yin (1993) distinguishes three purposes of case studies: exploratory, causal and descriptive case studies. The causal case study will look for cause-and-effect relationships, and search for explanatory theories of the phenomena. The descriptive case study has a focus on a theory to guide the collection of data. Yin (2005) notes that the theory should be openly stated in advance and be the subject of review and later serve as the design for the descriptive case study. In an exploratory case study, the collection of data can occur before specific research questions are formulated (Yin, 2014). The exploratory case study is often followed up by more systemic case studies, as the process begins to define the issues to be researched. Case studies can also be single or multiple and can be embedded where the study includes more than one sub-unit (or informant). 
Given the interpretive stance adopted in this research and the nature of the research question of understanding how hospital service managers are using management information, I selected the exploratory case study approach as the appropriate research strategy for this specific and unique topic. The same research questions could have been approached using other strategies to survey or examine hospital service managers' use of the management information, but this might not have revealed in detail the unique experiences of individuals and the layers of factors influencing their use of information. The exploratory case study method was chosen because of its advantage in creating new insights.

\subsection{Methods}

Within the qualitative research paradigm an exploratory case study methodology is used (Creswell and Plano, 2011). Here in this study, the use of methods consisted of three distinct streams of work (Figure 3.2). Over the case study period, work stream one and two began together; with work stream one on the collection and analysis of data from a structured questionnaire and from DEA. Work stream two collected qualitative data from narrative text. Then with the completion of the case study, work stream three provided a qualitative analysis of the data built on the information from both the other two paths as outlined in Figure 3.2.

\section{Figure 3.2: Overview of methods}

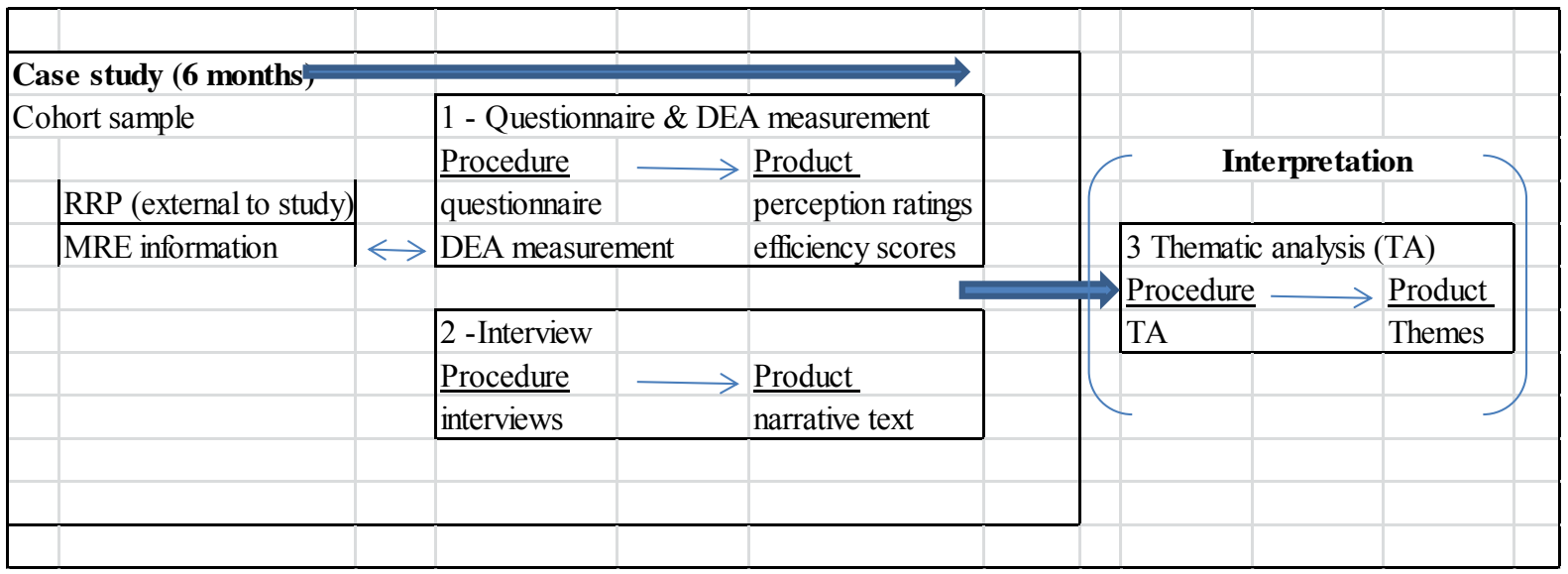


The cohort sample of participants receive the usual routine and monthly reports on performance (RRP); while some of the participants also receive additional DEA calculated and specific efficiency related performance information (MRE). The unit of analysis is tied directly to the research questions and is the hospital service managers. Interviews provided the source of the narrative data, while questionnaires and DEA measurement provided data on aspects related to the participant's experience. The two forms of information provided to participants allowed for behaviour or response differences to be highlighted. Thematic Analysis (TA) was preferred for this study because it provides a relatively precise way of inferring a subjective dimension to the understanding of the use of efficiency information (Tuckett, 2005; Davidson, 2009). The implication of using the qualitative design is that this research is viewed as grounded in a constructivist (or, interpretative) philosophy which is concerned with the complexities of the sociocultural experience and assumes that it is best interpreted and understood at a particular point in time and in a particular context (Merriam, 2009, Schram, 2003).

There are significant issues of what constitutes quality in research method design as opposed to simply being the opinions of the author (Morse et al, 2001). Guidance has been offered (Kuper, 2008; Lockwood, Munn and Porritt, 2015) on how to ensure that the sample used in the study was appropriate to its research questions, and the data was collected and analysed appropriately. In addition another key aspect of appraisal is for the reader to ask if the study adequately addresses potential ethical issues, including reflexivity. Kuper (2008) states that finally the reader must be satisfied that what the researcher did is clear. At the same there are other researchers who do not acknowledge the value of critical appraisal of qualitative research, because it stifles creativity (Dixon-Woods, 2004). To a large extent, the assessment of quality is itself an interpretive act and requires informed reflective thought. However in this research, the ontological need together with the issue of the epistemological position 
supported the design of the methods in this research, as a data driven inductive study (Cresswell, 2015).

The core philosophical assumption was to develop a generic view of the experience of the use of efficiency information based on an interpretative understanding in order to find coherence (Holloway, 2005). A further important consideration is the potential for bias and impact on research validity (truthfulness of the research findings) from both the role of the researcher (the effect of the interviewer on subjects) and the uncontrolled effect of the research on participants (Hawthorne Effect). The concept of validity needs to be applied to qualitative research (Norris, 1997), to avoid the potential for error and bias in the research (Maxwell, 1992).

\subsection{Avoiding Bias and Risks}

This discussion precedes the discussion on the methodology because it helps inform the appropriate rigour of the methods and procedures utilised for the research. According to Pannucci and Wilkins (2010) the ideal research is to have an unprejudiced consideration with a lack of bias of a research question or study. Bias can be present across the entire progression of a study, from its design, its strategy of inquiry and in its data collection and analysis. Bias is defined here as either when systematic error is introduced into the sampling or testing by selection, or when a particular answer or outcome is encouraged (Gerhard, 2008).

\section{Risk of Hawthorne Effect}

In contemporary management research, the Hawthorne Effect concerns research participants' awareness of being studied and the possible influence on behaviour during the study to produce performance which may be wrongly attributed to the experimental independent variables (Gale, 2004, Chiesa \& Hobbs, 2008). The original Hawthorne Effect related to 
productivity increases observed among workers who were supervised intensively under a research programme (Gillespie, 1991; Coombs \& Smith, 2003). Participant behaviour during the course of an experiment can change solely by the subject being aware of the study and therefore provides an experimental bias which will need to be controlled. In this study, there is no experimental effect, no dependent variable to be tested on a comparative basis between two groups of subjects. I have taken the viewpoint that there may well be the possibility of an observer effect on participants. The following strategies were adopted in the study:

(a) Fully inform the participants of the purpose of the study as De Walt et al. (1998) consider this to be a technique to minimise the Hawthorne effect. It was explained to the participants that the study was for my doctorate and not for any management purpose. My researcher role was a balance of insider and outsider roles thus allowing a combination of involvement and necessary detachment to remain objective (De Walt et al., 1998). My insider role with the participants occurred three times a month during their core business hours and primarily involved interacting with the participant on their use of efficiency information, asking a set of open ended questions and recording their responses. This was done entirely overtly to keep the participants fully knowledgeable about the study. There was never any attempt to be covert about the collection of data for my study.

(b) Additionally, there was also a process of engagement that began prior to the start of the study and occurred at the beginning of each meeting, which was to allow adequate time for the participants to feel relaxed and be confident about being honest about their responses.

(c) Inclusion of an entire cohort to elicit data. Narratives of experience were obtained from all participants using the same protocol and procedure. The purpose of the research was to 
generate common themes of the experience of the participants in their use of information as a single group of service managers.

There is a secondary concern of the sharing of information between the participants and its potential impact on this study. In this study, the risk is limited because as a case study, manager behaviour is interpreted in their natural 'real world' setting where the participants are working managers and already have well-established professional and social communication routines which need not be disrupted.

\section{DEA calculation bias}

The DEA calculation is on an inter-temporal basis and its efficiency score for each service each month is at a point in time. Thus, in a new month, the efficiency score that had been calculated for an earlier month may change with the availability of new monthly data. However the intent of this research is to observe managerial use and action as a result of the use of performance reports that are produced on a monthly basis at a point in time. For the observation study of manager use of efficiency information, the DEA calculation at a fixed point in time each month is appropriate.

\section{Researcher Bias (selection and recording of data and analysis)}

This research is an interpretative study and will contain reflective thought that is informed by the researcher, and therefore there is a need for critical appraisal (Kuper et al, 2008). There is considerable literature on this matter (Grbich, 2007; Marshall and Rossman, 2011, Bloomberg and Volpe, 2012, Mays and Pope, 2000; Mauthier et al, 2002). Within the qualitative paradigm, reflexivity is particularly significant (Lingard and Kennedy, 2007), because it refers to a recognition by the researcher of their influence on the entire research process including the relationship with research participants and the study assumptions that are made 
which can be being affected by the researcher's gender, social position and ethnicity (Seale (1999). According to Webb (1992), reflexivity may be demonstrated by the use of the 'first person' in the report writing, where the researcher describes the aspects of the research in which they have had personal involvement. The use of the first person and the acceptance of the researcher as integral to the research enterprise does not suggest that the research, or conclusions drawn, lack rigour; rather, that the research should be evidenced by clear explication and outline of the process and its result (Webb, 1992, 1996).

The descriptive and interpretative nature of the analysis, within the framework of social phenomenology (Guba and Lincoln (1998), can be assessed on factors of trustworthiness and goodness, such as credibility and dependability, confirmability and transferability Gerhard (2008). This research was through design, restricted by context-bound extrapolations (Patton, 2001), and the factors of confirmability, where the findings can be replicated elsewhere, and transferability, where, the findings can be generalised to other setting or populations, are not specifically necessary requirements.

The manner in which I addressed the concern of researcher bias was by employing strategies and protocols that have been used and recommended by qualitative researchers, as follows:

- Credibility: Where the accuracy of the findings is entirely dependent on the research design. I adopted Creswell's (2008) research framework and on-going self-reflection to continually test the process of collecting and converting data to interpretative findings. The transcripts were subject to the method of discrepancy to challenge my interpretative findings and emergent expectations. This was constructive in also providing me as the researcher a reality check and a useful reminder to be careful of imposing my assumptions, interests and perceptions onto the data collected and analysed. 
In this research, strategies to ensure the trustworthiness of data collection (Merriam, 2002, Bryman, 2003) included:

- Triangulation - by using multiple sources of data, and more than one approach to confirm the emerging findings.

- Participant checks - by referring back to the participants to verify both the data and interpretations; and to ensure that both myself as the researcher and the participants are viewing the data consistently to enable plausible findings.

- Dependability: Where the findings are consistent and influenced by the collected data.

As the researcher, I did not eliminate inconsistencies but rather sought to understand when these occurred and to ensure that the coding schemes and categories that I have used were used consistently (Miles \& Huberman, 1994). I adopted a formal and detailed TA, so that the process that identified themes of the participants' experience was made transparent. Protocols to ensure credibility of analysis and findings (Merriam, 2002, Fetterman, 2010):

- Engagement of participants with the researcher - by allowing adequate time to relax the participants and to collect data; and providing opportunity to exclude themselves or any data, at any time.

- Audit trail - by providing in this thesis a detailed account of the procedures and decision points in carrying out the research, and presenting a detailed process of the theme development.

- Reflexivity - by engaging in personal self-reflection on my assumptions, and relationship with the participants to identify factors that may affect the exploration. 
- Rich description - by providing in the thesis sufficient description so that the study can be contextualised and allow readers to determine for themselves the credibility of any conclusions, for building on the basis of a knowledge foundation (Fetterman, 2010).

By the very nature of this study being doctorate research, I was the sole researcher in the collection of data, the interpretation of the data and in the extraction of meaning to build onto the foundation of knowledge (Morrow, 2005). To some extent, the reader must be able to consider the degree to which bias was prevented by the strategies adopted in the study. These

strategies are all built into the ensuing methods that were used for the study (Cameron, 2011). The reporting of the findings from a thematic analysis can be considered a disadvantage in research because it is an interpretation (Marshall and Rossman, 2011); but however in this research here, the interpretation was tested by referral to the participants to ensure its general validity.

\section{Accessing data sources}

I undertook this research in a role as a current manager within the governing district health board structure of the hospital. My position of Planning \& Funding Manager for hospital and specialist services for Auckland District Health Board (ADHB) provided a high level of access to senior hospital managers, clinicians and the hospital's performance reporting systems. For this reason, overt observation of participants by me in a research role was not problematic as it would have been for an external researcher 'outsider'. My dual 'insider' roles allowed me regular access to the participants and establish a good rapport and gain their interest in the study. The strength of the research approach undertaken here was my insider role and view of the service manager in their normal work setting that provided for a greater level of engagement with participants (Dwyer and Buckle, 2009). To prompt candid and 
honest responses, the participants were guaranteed confidentiality and complete access (at all times) to any research notes made during or after the meetings. The participants were also advised that no information arising out of the interviews would be used in any management discussion with senior executives of the hospital or governing district health board officers; and that the research information would be sequestered and secured under 'lock and key', until its destruction, following the completion of this doctorate. Informed consent was obtained from all participants and that all data used in this thesis would be under preservation of confidentiality.

\section{Ethics and participant confidentiality}

Approval for this study was obtained from (i) the Victoria University of Wellington Pipitea Human Ethics Committee (reference approval email received from the Chair of Pipitea Human Ethics Committee, 23 July 2010.) and (ii) from the Auckland District Health Board's Research Office (reference letter from the Acting Manager ADHB Research office dated 19 July 2010). At the onset of this study, informed consent was obtained from each participant and full disclosure of the purpose of the study and the nature of the inquiry. All participants were informed of my $\mathrm{PhD}$ candidature; the purpose of the research and advised at the beginning of each month, that their continued participation was voluntary and that they could withdraw at any time. Participants were informed of the data collection methods, and the process and frequency by which feedback on the study would be given to participants. They were assured of confidentiality of any discussions and that no information (or quotes) would be attributable to specific named individuals. The participants were also advised that if at any time during the study they had any complaint, they could address the concern directly with either the CE ADHB or directly with my Supervisors at VUW. Continually throughout the case study, prior to each interview with each participant, I reminded each of the participants of the option of choosing to not participate further in the study. 
The literature on research design and the ethical codes of professional associations offer virtually no specific or practical guidance on disguising respondents' identities and preventing deductive disclosure in qualitative research (Giordano et al., 2007; Wiles et al., 2008). However, Kaiser (2009) warns researchers using human subjects to ensure that there are adequate provisions to protect respondent privacy and maintain confidentiality. Tolich (2004) has also provided caution about the need to ensure that the reporting of research fulfils confidentiality for participants. The reporting of the research must avoid any possible 'deductive disclosure' as from the descriptive data of individuals make them identifiable in research reports (Sieber, 1992). As the researcher, I recognise the strong ethical responsibilities for protecting the participants from being able to be identified for any views expressed in the thesis (Dresser, 1998). The ultimate goal is complete confidentiality for every research participant (Baez, 2002). For this research, participants were made aware that as a single cohort of ACH's service managers they were already identifiable as a group. I advised that I would protect individual participants from being able to identified in the thesis and will accordingly remove personal identifiers or otherwise mask individual identities (such as the removal of individual budgets and service particulars). The details of the methods and their sequencing over the case study period are now discussed below. The discussion follows the chorological order of the use of the methods.

\subsection{Study setting}

\section{Population setting}

The study involved comparing the use of efficiency information by two groups of hospital service managers; with one group given additional and more specific data on efficiency for their use. The case study is situated at ACH Auckland, with all 11 of the senior hospital operational managers, who are titled 'service managers' participating. $\mathrm{ACH}$ is the largest 
hospital in New Zealand with an annual operating budget approximating New Zealand two billion dollars. ACH is a major tertiary and quaternary service centre, and has complex management linkages, often crossing regional and national boundaries, with about 94 clinical sub-specialties and service departments, that are grouped for management purposes into eleven major services. Each of the service managers manage a portfolio of services, ranging in number from 3 to 15 services. The services vary in budget and staffing size, ranging from New Zealand \$35 million to \$200 million in annual operating expenditure.

\section{Participant sample}

This is a case study at a single hospital location, with individual participants forming the entire cohort of senior operational service managers within the hospital. All participants are female and have a similar age and work profile. The participants have all worked in hospital service management for a similar length of time.

To protect the confidentiality of the participants I have opted to not identify any of the services being managed (Table 3.1).

Table 3.1: Participant profile

\begin{tabular}{|l|c|}
\hline & $\begin{array}{l}\text { Participant } \\
\text { group }\end{array}$ \\
\hline Sample size & 11 \\
\hline Gender - Female/Male & $11 / 0$ \\
\hline Range in Age (in 2013) in years & $43-65$ \\
\hline $\begin{array}{l}\text { Range in length of total health service } \\
\text { in NZ and overseas in years }\end{array}$ & $24-25$ \\
\hline $\begin{array}{l}\text { Range in Hospital service } \\
\text { management experience in years }\end{array}$ & $5-7$ \\
\hline Range in current service manager role & $3-4$ \\
\hline
\end{tabular}


These managers have responsibility for managing services, and functional accountability for service delivery, budget control, stakeholder relationships, and quality outcomes. They report to one of three General Managers, who reports to the Chief Executive. The service manager has responsibility for a mix of clinical (medical, nursing) and administrative staff. The hospital's senior clinicians have a national collective employment agreement, which puts them with line responsibility, above the service manager, directly to the Chief Executive and Chief Medical Officer.

In terms of this study, the individual manager characteristics, their background and academic qualifications are not detailed here because the interest was on management behaviour and actions across the group of participants. The basic biodata presented in Table 3.1 show a consistency across the participants of their work experience.

\section{Change in focus}

The initial plan was to approach a number of public hospitals from across New Zealand. My initial approach received favourable responses from hospitals at six locations with a total of 26 managers. However, over the period leading to the start of this research, several of the managers showed signs of reluctance. They had different reasons; one hospital had a change in top management who was not interested in supporting the research; two other hospitals were embarking on re-structuring plans and felt the research would be an added distraction, and the other two hospitals advised that their service managers had been asked to focus on delivering particular targets and so would not have the time available to participate in the research. After discussion with my Supervisors, and in looking at the potential cost of the research, it was agreed that the focus for the research be on the one available hospital facility $\mathrm{ACH}$. 


\section{Enrolment process}

At the invitation of the Chief Executive, I presented and discussed the proposed study at a DHB senior leadership team meeting (comprised of the Chief Executive and direct reports, which included the general managers of the hospital). At the meeting, I received their endorsement to undertake this research as a case study using the service managers (if they should agree voluntarily). At a subsequent hospital service managers meeting, the study was presented and received their support. To enrol participants formally into the study I made a presentation on the research to all eleven service managers. The eleven service managers were effectively the entire relevant sample pool from the ACH research site (Merriam, 2009). These eleven managers were the target participants in the case study because they all managed clinical services. At the conclusion of the presentation, I asked for volunteers by a show of hands. All managers put their hands up.

\section{Participant group allocation}

The participants were simply counted into two groups, with the first six seated at the front at the meeting, and then the next five, to be allocated as:

(i) MRE participant group (Seven participants) - the group of managers who received the new DEA generated Management Report on Efficiency (MRE) which contained specific efficiency data also in addition to the hospital's routine reports on performance (RRP); and

(ii) RRP participant group (Four participants) - the group of managers who received only the routine report on performance, as a comparison group.

From a performance information standpoint, each service manager receives the monthly RRP with a range of performance information. All service managers were subject to the same hospital environment and thus, faced the same strategic, policy and operational pressures. The 
grouping of participants into the two groups was purposeful judgement sampling considered appropriate to provide information-rich cases (Gay, Mills and Airasian, 2006).

The selection of seven for the MRE participant group came about because one member of the 'second five' asked to be part of that group. At this stage, I did initially consider conducting a random ballot of the managers into two groups of six and five, but decided in the interest of time and to retain the good will of all participants, to permit the participant to shift into their preferred group. This was also considered appropriate for the following two reasons. First, the purpose and intent of this research was to describe the contextual experience of all the managers only within the case study and not to otherwise generalise any particular information use or transfer the findings to other populations in other contextual settings. Thus the non-random selection of a particular group by a participant would not influence the 'representativeness' of the group's data (Bloomberg and Volpe, 2012, p.104). The second reason is that it was more important for the participants to provide contextual information to yield insight to the phenomenon under investigation. The exploratory approach of the study meant that the data collection would be accepted on a non-probabilistic sampling of participants. As the data that would be generated from the two groups would be of a primary nature (Denzin and Lincoln, 2005) and be context bound there would be no influence on the findings by the higher number of participants in one participant group compared to the other group. The primary narrative data will be used in a secondary process to develop themes.

The process of thematic analysis (explained later in this thesis) will take the primary data through a categorisation and sorting technique to identify different meanings from the data. This technique is not reliant on volume of data. The fact that one member of a participant group was a forceful volunteer was unlikely to influence the findings of the thematic analysis because a general set of core themes were developed to reflect the use of efficiency 
information by all service managers.

Each of the managers had been in their senior management position for at least two years. This ensured that all participants had a complete understanding of the management role and adequate experience in service management. The research involved the following sequence of seven steps, as follows.

(1) Each month, the Technical efficiency was determined for each service, using DEA costing and volume activity data which is routinely collected and reported to the organisation's managers.

(2) Each month, the DEA result was developed into a specific management report (called 'management report on efficiency', or MRE), with indicative targets for improvement (in order to achieve $100 \%$ efficiency). This information was then provided to the MRE participant group. The other RRP participant group continued to receive their routine performance information.

(3) A monthly questionnaire was completed by all participants, on various aspects relating to the use of efficiency information

(4) Managers were interviewed monthly over the course of the six month case study.

(5) Interview transcripts were prepared; these were made available to participants to examine and correct.

(6) The transcripts were then read and re-read to categorise and sort their contents by inductive identification of coding labels for each piece of narrative text.

(7) At the end of the case study, a thematic analysis was carried out to identify key insights relating to the use of efficiency information.

The initial preparation of the new efficiency information (MRE) was set to generate new efficiency information every month, to be presented to one set of managers in the case study - 
incorporated existing data from separate sources and several existing routine reports. Hence, this activity was an intensive period of negotiation: (i) to convince analysts and report writers that there was no agenda to replace either them or their reports, (ii) to seek the release of the required data and to have access to this each month of the study (service costs and staffing and treatment outputs), and (iii) to install and run the DEA software and set up the calculation of an efficiency rating by each service. In addition, development work also occurred on designing a report on the new efficiency information for service managers. This design observed the principles of CLT by minimising the content of the DEA results and explicitly identifying an efficiency target and areas where management action could be taken; and contained all relevant information on a single page to minimise reading time for the manager. The report did not identify the management action for the manager. This report is detailed and discussed further later in the chapter.

\section{Pilot study of phase $1 \& 2$}

A pilot study was first completed to test out the above approach. The pilot study aimed at developing procedural processes for the above two phases; and to demonstrate the use of DEA as an appropriate measurement technique to produce a valid and acceptable service level metric of efficiency. The pilot was undertaken for two months with one senior manager at Auckland DHB's Auckland City Hospital - with equal organisational rank as a service manager with responsibility for non-clinical allied health services. Over the two months, the service's technical efficiency was measured on a monthly basis for the service using the hospital costing and volume reporting systems. I developed a short three page report to signal the service's performance to the manager. The manager accepted both the result and the report as a useful representation of the service's performance. In the pilot, I undertook only one interview with the manager each month. I was not comfortable with this because of the dynamic issues that can occur over a month. 
Feedback discussion with the manager also revealed that the frequency of the observation could be increased and the duration perhaps shortened, in order to be able to gain insight into the working week of the manager. It is worth noting that the report for the Pilot study was presented in colour and had large graphical illustrations (over two and half pages). I received negative feedback from the manager who suggested that the colour printed report would be viewed as 'extravagant'. Accordingly for the case study, I prepared this report in 'black and white' and on a single A4 piece of paper.

The length of the monthly questionnaire was also reduced to encourage completion. The above two phases were applied concurrently for each of the six months. The two interviews during the pilot were taped - however, at the end of the pilot, the manager fed back to me extreme discomfort with being recorded. They did not like having every utterance recorded; and felt the interviews were not a one on one conversation. It was suggested that other service managers would be similarly uncomfortable. At the first briefing meeting, all participants were asked if the interviews could be taped to allow for a full transcription or that I would take notes and then prepare a transcript. All participants opted for the latter.

\section{Efficiency information reports}

At the beginning of this study, I met with service managers to discuss their use of the routine performance information. In the course of this discussion, I identified and re-developed their on-going activity as a three stages schematically to represent the service managers' use of performance information over a month. For the purpose of this research the data collection was set to align with the process of routine hospital activities, where the use of hospital performance information is viewed as three key stages within the monthly cycle, described below: 
Information response process (Monthly model adopted for the case study)

1. The service performance and financial reports for the previous month (RRP - routine reports on performance) that are available at month-end, and provided to hospital service managers. At this time, there may be briefing meetings between the service manager and their General Managers and with senior clinicians. The service manager was also expected to report on any negative variance, and to prepare an action plan that provided mitigation steps to recover the variance.

2. Initial review by mid-month by the service manager in conjunction with their General Manager of major variances against targets in budgeted cost and service activity and identification of what areas of concern will be covered in further explanatory reports; and discussion with senior managers and staff on matters of concern. There is usually a meeting with the General Manager and other corporate managers, including a review on output delivery with the DHB funder of their service (Planning and Funding). Clinicians may be involved in these meetings, at the discretion of the service manager.

3. Closing review in the last week of the month to compete all agreed required actions identified in Stage 1. Most services will host team meetings to discuss and review overall performance and consider team issues.

The extent of the review process covering the month has the result of keeping the managers 'busy with review' and 'preparing reports'. In terms of the three stages, individual managers may have varying schedules and different practices. There are continuous disruptions such as staffing problems, organisational change management initiatives, and patient and purchaser inquiries to contend with each month; in addition service managers as befitting their senior role, can be absent on regional and national liaison and service development activities. The RRP which is available to hospital service managers is prepared by hospital administration; include data on any national and local targets and KPIs, key measures of treatment processes, 
overall costs and budget variances. In this report, there is no measure of technical efficiency as defined in Chapter 2. A treatment process measure, 'average length of stay' measures the number of days from admission to discharge home or transfer elsewhere, is regarded to indicate the efficiency of the treatment process. Two management reports were used in the case study: (1) the hospital's routine performance information which all of ACH service managers receive on a monthly basis; and (2) information with efficiency measurement which I developed to present specific information on efficiency targets for the services. Each of the two information reports is discussed below.

\section{Routine performance information (RRP)}

This report is produced by the hospital administration and financial teams on a monthly basis, and forms the service manager's routine review and monitoring of service performance. Relevant data to the service manager covered monthly and year to date performance on a number of areas, as follows. All of the participants, as hospital service managers, receive hospital performance reports routinely on a monthly basis (Routine reports on performance, RRP). During the study period, the RRP participant group continued to receive the RRP which were designed to convey the full spectrum of performance to the service managers; covering KPI and variance reports relating to aspects of service delivery, quality and performance. The RRP included:

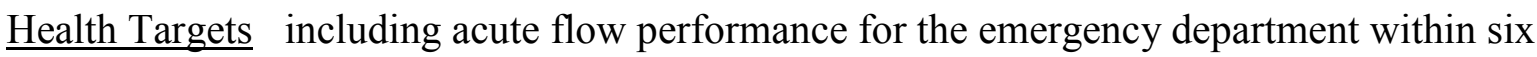
hours, elective volumes, advice to hospitalized smokers to quit, waiting times for surgery and rates.

ESP 1-5 Targets refers to five Government priority elective surgical procedures (each a separate healthcare and surgical area of focus) focused on ensuring no patient waited longer than six months for first specialist assessment or elective surgery. 
Financial position that reported a profit and loss, on operating expenditure, revenue for work completed employee costs and direct treatment costs.

Volume Related Variance (cf. Plan) reports on the achievement of the target treatment volume, on which the service's revenue and profit $\&$ loss is based.

Month inpatient production details the production of case weighted discharges at procedure level and provides variance to plan.

The use of routine hospital performance information is an on-going business activity in line with normal business practice and reporting requirements. The performance information is generated within the hospital organisation to capture the month-end or year-to-date activity and cost results of services against their activity targets and budget. The process of review and the use of the performance information is a month-long process.

\section{Management report on service efficiency (MRE)}

Each service's point of comparison was its previous 24 months. The service is benchmarked against itself using its two year history as a reference point (Rutledge et al, 1995). This approach allowed the single service to be treated as a homogenous unit and the efficiency in any one month could be easily understood by the manager in terms of the decisions that she had made for that month as well as in the previous months. This was important in gaining the acceptance of the service managers, because it meant that each service was not being benchmarked against other services. This allowed each participant manager to compare their current month's efficiency performance against the service's previous months. This was deemed appropriate because the purpose of the study was to explore the use of efficiency information by service managers; and this is supported by the DEA literature. In using DEA, for each service, each month of the 24 months was treated as a DMU and was used to quantify and develop service efficiency scores at each month-end. As each month's data is added to the 
24 month reference means that the previous month's efficiency score would have changed as it is relative to the addition of the new month's data. For my research, this was not a concern because the participants had already received the efficiency information for the previous month; and the study observations were on how the participant uses the current efficiency information. The input and output data selected for the DEA represented the service's resource inputs and production outputs is shown in Table 3.2.

Table 3.2: Service monthly data used in DEA measurement (inputs and outputs)

\begin{tabular}{|l|l|}
\hline Inputs & Outputs \\
\hline Total operating expenditure \$. & $\begin{array}{l}\text { Treatment discharges for acute and } \\
\text { elective output volume production (Case } \\
\text { weighted discharge - of case weighted } \\
\text { discharges as a measure of the sum of } \\
\text { patient discharges from the service based } \\
\text { on treatment complexity, CWD). } \\
\text { Other volume related production indexed } \\
\text { to CWD value. }\end{array}$ \\
\hline
\end{tabular}

The Output variables were as follows:

- Volume of weighted discharges by severity of patient case-mix. This is a calculated figure that is reported for the service and hospital using nationally agreed definitions. The case weighted discharge (CWD) creates an equivalent measure in terms of resources consumption and is regarded as an output of the service. CWD represents patients based on the complexity of their illness, diagnosis and treatment that was provided by the service.

- Other patient related activity that are undertaken by services and are case weighted, such as the initial assessments of patients who are referred to medical specialists. These activities consume resources, require manpower and their total expenditure is divided by the average CWD cost to generate an output volume figure. 
The Input variables used were the following:

- The number of staff employed within the service on a full time basis.

- The total operational costs associated with the service for the month in question (This is obtainable from the ACH's financial reports for each service, which are produced at month end.

I have previously used the DEA technique in my professional capacity to measure the relative efficiencies of administrative offices, and to benchmark DHB hospitals on a national cost and volume basis. For this study, the DEA software used was the Meridian DEA developed by Professor Paul Rouse and made available on a gratis basis.

There are DEA model variations possible depending on the specification for: input or output orientation, and constant or variable returns to scale. Given a set of inputs and outputs, the two key stances are an input or an output orientation. Input orientation refers to the DEA calculating the efficient use of resources (inputs) to achieve a given target output. This is the case in New Zealand's public hospitals that are funded to achieve a desired level of volume. Thus, the input orientation of the DEA provides the manager with a model for compliance. The assumption is that the manager has more control over the inputs consumed and their intent is to focus on managing the use of inputs in a minimal way whilst delivering the desired level of service and thereby becoming more efficient. The output orientation is a calculation of the efficient production of outputs from a given set of inputs. This assumes the manager has control over the outputs (in health care with national collective employments in place, staffing can be 'sticky') and the focus is on managing for higher levels of output. This can be viewed as an improvement model.

Another DEA model variation is to consider the service as being one where there is 'constant return to scale (CRS) or variable return to scale (VRS)'. The CRS refers to a service whose 
production and technology consumes inputs at the same rate as it produces outputs. In this model, the assumption is output changes in the same proportion inputs are consumed. From a management perspective, CRS mean that there is minimal marginal gain and that inputs increments are equal in impact on outputs. VRS refers to a service whose production and technology consumes an increment of inputs but does not generate equal increments of output. The VRS suggests that input increments are scalable to achieve output improvement. For the manager of a clinical service there are implications for performance improvement because the scalability issue will mean that effort (or additional input) will not necessarily result in a corresponding gain or output. In the use of DEA for participants, I choose to retain both orientation and both scale models so as to be able to interpret the performance issue for the participants, calling the two orientations: (i) input TE (technical efficiency) score and (ii) the output TE score. With the financial constraints on hospital managers, focusing only on the input orientation may create a cost reduction attitude at a crude budget cut level. And, focusing only on the output orientation may create pressure to push more work by lowering the quality and standards of service (such as discharging too early to allow patient throughflow). The scale models were referred to as: (i) CRS and (ii) VRS to present a performance range, rather than a single efficiency rating, as a target. The intent was to encourage the manager to focus on solutions and not fixate on a target outcome. At the end of each month, the DEA model was re-run based on the previous month's input and output data. Each month, the MRE participant group was provided with a brief report that contained additional information on their service efficiency that had been generated from DEA. I developed the design of the report in discussion with the subject of the pilot study and with other senior staff. Overall feedback was positive and there was acceptance of the content and format for the efficiency information. The feedback from hospital managers was that they preferred the report to be contained to one page and accepted that this would necessitate a somewhat cramped graphical presentation with no narrative. The report indicated specific 
performance signal using graphs to identify, for the participant, the notion of an efficient frontier, that is, relative to the past month's performance a previous month when performance was much better. The graphs provided the location of individual months in terms of input use and output mix. In the first month, the first interview with the participants started with a referral to, and explanation of, the report. In following months, the most recent efficiency rating would be clarified and its relativity with the previous months outlined. The performance improvement targets would be pointed out to the participants. At the beginning of each month, this report would be reproduced with the more recent DEA efficiency result (based on the previous month's input and output data).

Each month, the MRE presented the past months' efficiency and identified efficiency improvement opportunities if the service was to achieve $100 \%$ efficiency. The report contained the following items:

i. The Average Month Operating Cost Figure This graph shows the operating cost per FTE (full-time-equivalent staff). This is calculated by dividing the month's total operating costs by the month's total FTE numbers. Values for the first month (June) were calculated using the budgeted values for that month. This information is part of the routine hospital KPIs and it serves to provide a reference link to the normal report on KPIs.

ii. The Case Weighted Discharge (CWD) table. This table shows the breakdown of CWDs for the month. District health board funded hospitals are funded on a "price volume purchase agreement in which all diagnostic and treatments performed within the hospital are coded to relatively unique identifiable codes called purchase unit codes (PUC) - and it is these that are to identify the output volumes. The output 
treatment volumes are separately identified for urgent un-planned work (acute) and non-urgent planned admissions (electives).

- CWD Portion - these values are taken straight from the tables supplied by the hospital administration, each month. During the month these reports are updated but the participants are told that the efficiency result is a static value for the most recent month end.

- Non-Diagnostic Resource Group (DRG) Contract Portion - these values were also taken from supplied tables. An indexed CWD volume for this work was calculated by taking the actual value of the contract for each PUC each month, and multiplying this by a ratio of the PUC's price to the CWD \$ value (which was $\$ 4,410$ at the time of the study).

The presentation of the data that was used in the DEA provided the participant with the opportunity to correct any error in data and gain confidence in the DEA generation of efficiency.

iii. DEA Model Table. This demonstrates the inputs and outputs used in the DEA generation of efficiency. The recorded inputs and outputs are noted so that the participant may verify the data that was used. Two inputs are used: the number of FTEs and the Operating Costs, and one output, the Total CWDs for the month. The input and output orientation efficiency scores are recorded in this table; as well, CRS and VRS efficiency is also calculated and presented.

- Inputs TE (Technical efficiency) Score Figure. This graph displays the efficiency scores of the service for the month when using an input orientation. This means that we assumed that there was very little we could do to change the outputs, but were able to make changes to the inputs. Because the inputs 
changed only slightly each month, this caused a reporting of very high efficiency, since each month is very similar to the others. The inputs TE score figure is a compliance model where the manager is seeking to control inputs (costs) whilst delivering the required output target.

- Outputs TE Score Figure. This graph displays the efficiency scores of the service for the month when using an output orientation. This means that we assume that there was very little we could do to change the inputs, but were able to make changes to the outputs. The CWD values are used as the output value and therefore based on patient profile in the month, it can vary between months. However, the patient variability can be identified and understood and so provides an explanation for the cause and effect' on output variability. The outputs TE score figure is in effect an improvement model, where the manager is seeking to improve on their service efficiency by increasing their output.

- Total Efficiency Scores Figure. This graph displays the efficiency scores of the service for the month when using a combination of both input and output orientation. This means that we assume that we were able to make changes to both the inputs and outputs. The CWD values in several services often varied greatly between months, which caused variability in efficiency scores. The CWD values are the measure of the output volume value and therefore can result in seemingly fluctuating efficiency scores. This can create the impression of instability of the DEA model although the DEA has correctly captured the change in value and calculate the efficiency based on the values of the inputs and output (refer earlier to discussion on DEA as an extreme point method in Chapter 2). The root cause of the variability in CWD values is because of changes to the patient profiles being treated in the month. 
iv. Targets for month Table. This table shows the values that have been identified, through the DEA models, as the targets required for $100 \%$ efficiency. By applying the previous month's targets to the following month's levels of inputs and outputs, efficiency will move either to $100 \%$ efficiency or to an area between $90 \%-100 \%$. The CRS and VRS targets are also presented. The 'Total efficiency score' -provided a 'combined' rating on the relative efficiency of the month's performance in delivering the outputs with the inputs used. The targets are technically achievable because in a previous month the $100 \%$ efficient state had been achieved. The targets were calculated for technology aspects of service production. The targets were separated for staffing (FTE), operating expenditures (OPEX) and output (CWD).

Figure 3.3 sets out the format of the management report on efficiency ('MRE'). Based on feedback during the pilot stage of this research, the MRE was purposefully kept to one page, in one colour (black/white). The focus point of the service being managed is the "production of care'. This requires resources (inputs) that are used to produce care (outputs) for patients. As outlined in Chapter 1, the outcome for the patient is assumed to be in accordance with expected standards and is outside the scope of this study, which is interested in the efficiency of service. The interest in efficiency in this study is twofold: (i) the managers use of information to improve efficiency; and (ii) the measurement of actual efficiency. For both of these, the significant contributing factors in the production of care and therefore for data collection is inputs (service staffing, operating expenditure) and outputs (discharges that are case weighted, that is equalised across different treatments). In committing significant resources to data collection, the researcher would first need to know what data is feasible to collect and that the data will be reliable. For this research, the input and output data for individual services are already being recorded by $\mathrm{ACH}$ and reported on a monthly basis. The inputs and outputs are appropriate to the assessment of service efficiency. Staffing, operating 
expenditure and discharges are recorded by the facilities as part of financial and volume monitoring and these meet national Ministry of Health data standards. The discharges are case weighted discharges which allow all service discharges to be summed.

Using different inputs might result in a different conclusion, but I used the same type of inputs that have been empirically validated and common to most published hospital DEA articles (Sikka, Luke and Ozcan, 2009). In developing the measurement activities referred to above, my professional knowledge and experience guided the development of the DEA Measurement. I also hold a Master of Science in Resource Management and have extensive experience within the health care and public service sectors as a senior manager, as a performance evaluator, a planning consultant and as an auditor (best practice and standards of excellence). The data collection centred on an ethnographic and observational study of these service managers on their use of, and management responses to, the efficiency information.

The framework for data collection and of analysis draws on the importance of management as a focus point for the 'production of service'. This requires resources (inputs) that are used by processes to produce care outcomes (outputs). The key point of interest is the production of service, being patients being diagnosed, treated and discharged from the service. The significant contributing factors in the production of service and therefore for data collection is (i) inputs) and (ii) outputs (earlier in Chapter two, Figure 2.1 summarised this concept) 


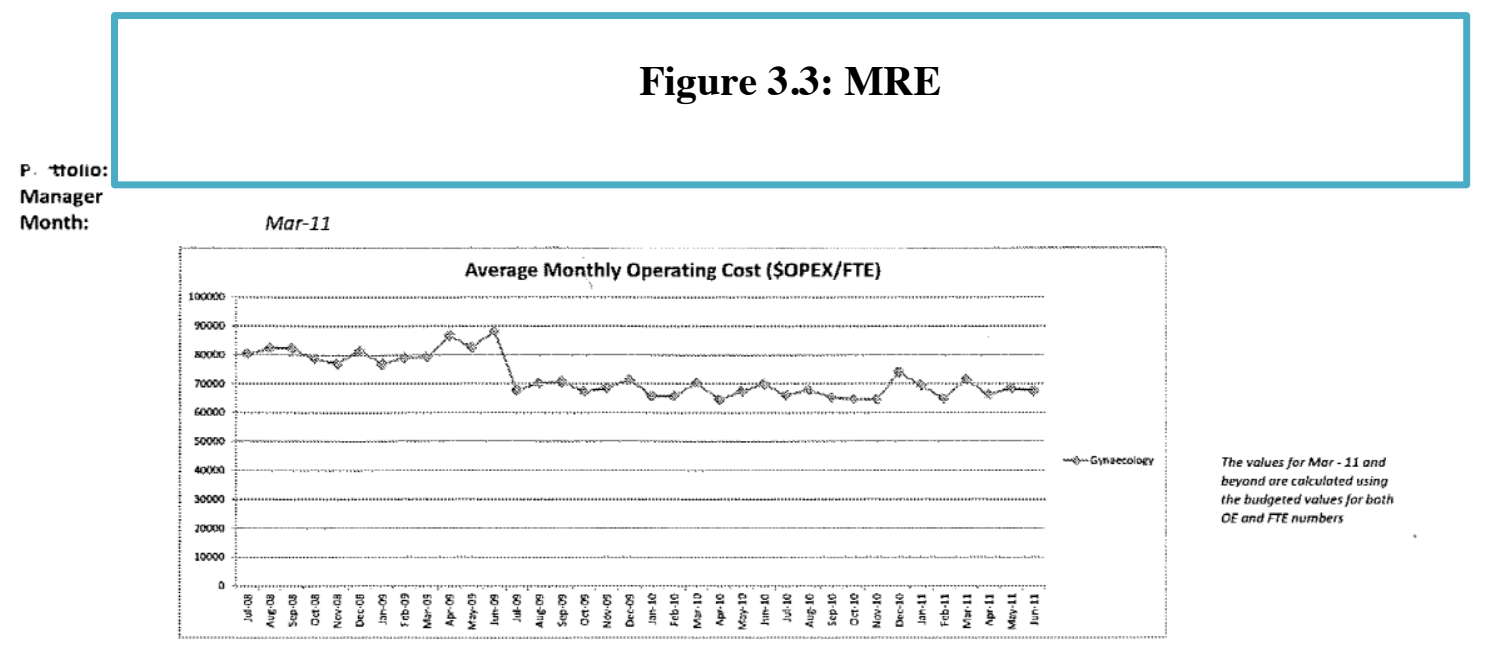

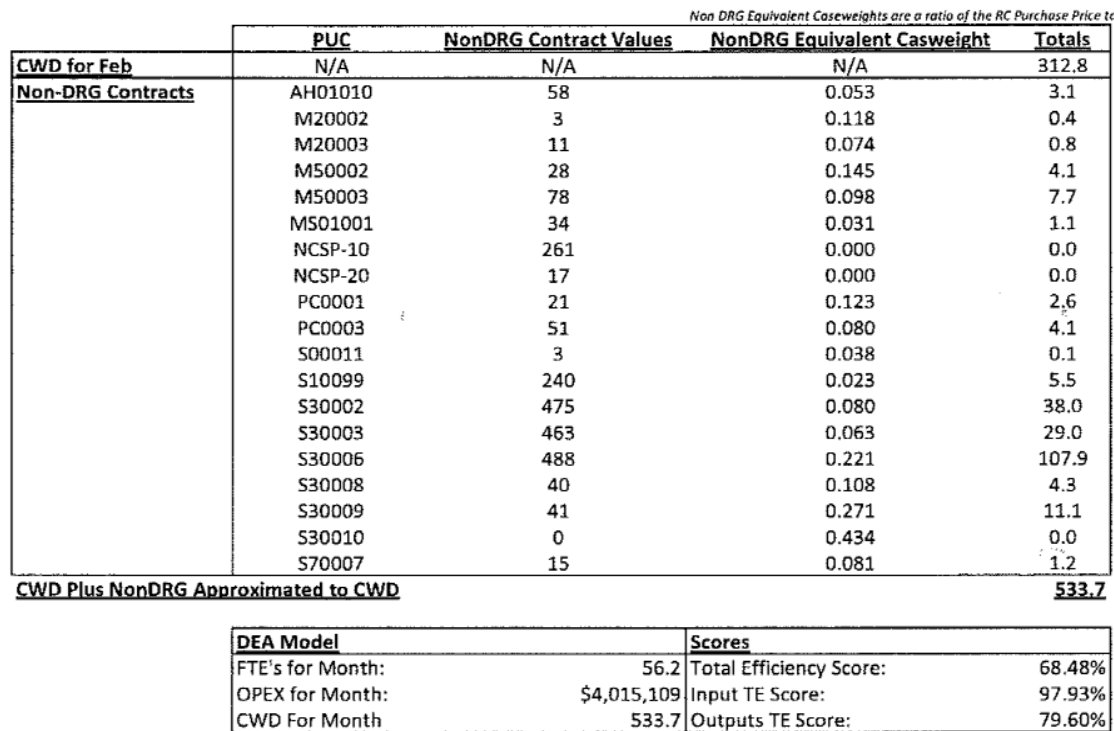

Inputs TE Score

Management of Resource Use

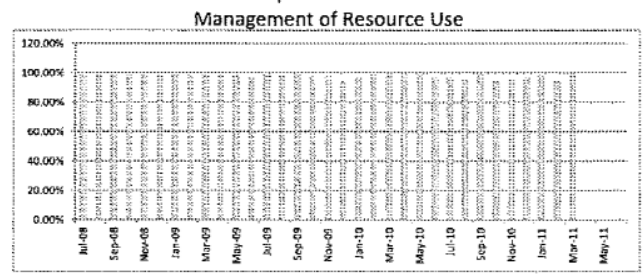

Outputs TE Score

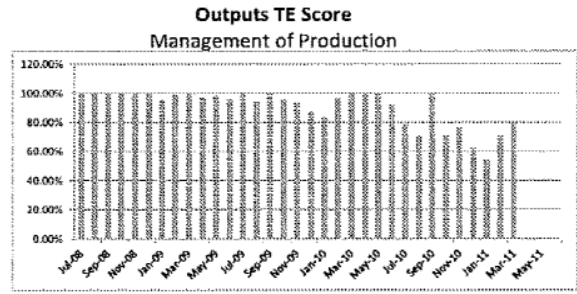

Total Efficiency Score

Overall Service Performance

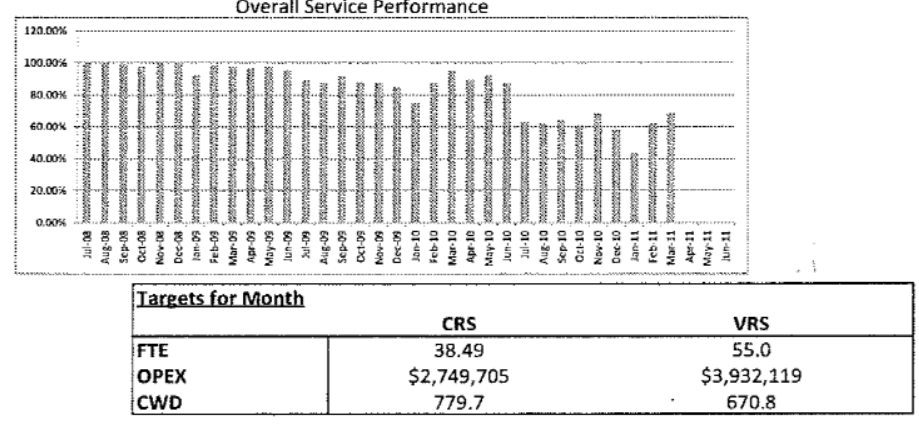

\begin{tabular}{|c|c|c|}
\hline \multicolumn{3}{|c|}{ Recommended Changes to move towards efficiency } \\
\hline & CRS & VRS \\
\hline Reduce FTE's By: & 17.71 & 1.2 \\
\hline Reduce OPEX By: & $\$ 1,265,404$ & $\$ 82,990$ \\
\hline Increase CWD's By: & 246.0 & 137.1 \\
\hline
\end{tabular}




\section{Action Research}

A primary method in terms of my involvement with participants for my research was action research. Action research has been defined at its essential core as a reflective process that allows for inquiry and discussion with participants as components of the research (Ferrance, 2000). The use of action research helped in strengthening the quality of this study because of the cyclic nature of the participants' critical reflection followed by action followed by reflection and so forth. I was also focused on change in the research participants' own local work community or organisation (Argyris, 1985, Gold, 1999).

Reason and Bradbury (2001) point out that in action research, the researcher becomes actively involved in the process. The provision of efficiency information to managers is an intervention utilising a form of action research. Given this, the action research method of the thesis therefore is also the method of presenting the efficiency information. Greenwood and Levin (1998) have described this type of research as challenging the status quo.

In this research action research was used as a general method to manage the interactions and discussions I have with the subjects. I did not challenge or provide direction on courses of action that (guided by the efficiency information for each service) but instead I assisted and led as appropriate, the discussion on interpretation and use of the efficiency information to enable the subject to develop knowledge and insights during the process. This was appropriate for the thesis and allowed a similar interaction with all participant managers. The potential of the action research model is as a means of appropriately collecting qualitative data about hospital management and business practices, more generally thereby providing local context (Festinger \& Thibaut, 1951). 
The participants as managers received information that was not made available to any other staff member. There was no control or restriction placed on the distribution or sharing of this information, as would be natural in their normal work setting. I discussed with participants their critical reflections and explored their behaviour in terms of any actions that were considered and taken. This is a useful approach for exploratory research (Thomas, 2006).

\subsection{Methods of data collection}

\section{Monthly questionnaire for participant self-rating}

To collect experiential data from participants, a dual-method sourcing strategy was adopted through (i) questionnaires and (ii) structured interviews. A third data collection strategy used outside of the participants was to use DEA to measure the service's efficiency at the end of each month incorporating the service's costing and volume data. Although this measurement was undertaken directly by me, it was with the full knowledge of all the participants and that the results were also utilised in the monthly MRE reports. Each participant was asked to complete a questionnaire for each month of the case study. The questionnaire required each participant to provide a self-rating on various aspects relating to the use of efficiency information. Both groups of participants received the same questionnaire at each month end and were asked to have it completed before the following month end.

The questions were based on the research questions for this study and were set to survey the participants' perceptions on a number of aspects relating to learning, knowledge, attitude and behavioural intention (motivation) with regard to service efficiency improvement. The questions are shown in Table 3.3 below. Items to measure attitude, knowledge, attitude and behavioural intention were modified from Fishbein and Ajzen's (1980) previous work to make them relevant to this study's context of information use. 
Table 3.3: Monthly questionnaire survey

\begin{tabular}{|c|c|}
\hline Questionnaire item & Purpose, literature connection \\
\hline $\begin{array}{l}\text { 1. What do you know overall about service } \\
\text { efficiency? } \\
\text { 2. Do you have a particular definition of } \\
\text { efficiency you use? }\end{array}$ & $\begin{array}{l}\text { Awareness of the prevailing service } \\
\text { efficiency (Bellinger, 2004) }\end{array}$ \\
\hline $\begin{array}{l}\text { 3. Do the current KPIs indicate to you that your } \\
\text { service is performing efficiently? } \\
\text { 4. Are you confident that the efficiency } \\
\text { information provided fits with the } \\
\text { organisation's goals? }\end{array}$ & $\begin{array}{l}\text { Localised measurement of } \\
\text { efficiency (Ackoff 1989) }\end{array}$ \\
\hline $\begin{array}{l}\text { 5. How much information are you being } \\
\text { provided with on service efficiency? } \\
\text { 6. Do you find it useful to compare current } \\
\text { efficiency against previous months? } \\
\text { 7. Do the current hospital report KPIs allow you } \\
\text { to monitor efficiency of your service of } \\
\text { responsibility }\end{array}$ & $\begin{array}{l}\text { Use of existing efficiency } \\
\text { information (Rusu, 2016) }\end{array}$ \\
\hline $\begin{array}{l}\text { 8. At month-end, are you able to discuss the } \\
\text { efficiency of your service with your clinical } \\
\text { colleagues? } \\
\text { 9. In terms of efficiency do you know what you } \\
\text { should do to improve? } \\
\text { 10. How would you rate yourself as being able to } \\
\text { manage the eefficiency of your service? }\end{array}$ & $\begin{array}{l}\text { Willingness to engage with } \\
\text { clinicians (Mukherjee, White \& } \\
\text { Wuyts, 1998) }\end{array}$ \\
\hline $\begin{array}{l}\text { 11. How much influence do you have on } \\
\text { performance in your responsibility area? } \\
\text { 12. How frequently do you initiate efficiency- } \\
\text { related discussions? }\end{array}$ & $\begin{array}{l}\text { Level of personal influence on } \\
\text { service performance (Clandinin and } \\
\text { Connelly, 2004) }\end{array}$ \\
\hline $\begin{array}{l}\text { 13. How important is your contribution to } \\
\text { improving your service's efficiency? } \\
\text { 14. Do other priorities leave little room for } \\
\text { improvement because of failure in the } \\
\text { organisation? }\end{array}$ & $\begin{array}{l}\text { Contribution to service efficiency } \\
\text { (Bandura, 1986) }\end{array}$ \\
\hline $\begin{array}{l}\text { 15. Are your senior managers committed to the } \\
\text { idea that you can be more efficient around } \\
\text { here? } \\
\text { 16. How much is the proportion of your } \\
\text { responsibility for efficient performance? }\end{array}$ & $\begin{array}{l}\text { Leadership issue (Clandinin and } \\
\text { Connelly, 2004) }\end{array}$ \\
\hline $\begin{array}{l}\text { 17. Will the information you receive contributes } \\
\text { to you work productivity? } \\
\text { 18. Will the information you receive enable you } \\
\text { to set a higher performance target? }\end{array}$ & $\begin{array}{l}\text { Contribution to work productivity } \\
\text { (Rouse, 2006) }\end{array}$ \\
\hline $\begin{array}{l}\text { 19. Is it clear from the efficiency information } \\
\text { where you have opportunities for } \\
\text { improvement? } \\
\text { 20. How much control do you have over the } \\
\text { performance of your service? }\end{array}$ & $\begin{array}{l}\text { Clear improvement signal } \\
\text { (Bhaskar, 1998). }\end{array}$ \\
\hline
\end{tabular}

The questions were designed to avoid 'leading' participant responses in any particular way.

The same questions were used each month in order to track any change in response and thus 
any shift in perception or attitude in relation to the use of information. The questions required a numerical response on a ten point Likert scale.

\section{Content validity}

Given the descriptive nature of the questionnaire, content validity was established in multiple stages. I as the doctoral candidate developed the instrument in line with guidance from Davis (1989) drawing parallels from his published article on the 'Perceived usefulness, perceived ease of use, and user acceptance of information technology'. The questionnaire was then reviewed by my Supervisors, who provided comment. Based on this feedback the instrument was slightly modified to collect the targeted information.

Content validity has been defined by Messick (1993, p13): "validity is an inductive summary of both the existing evidence for and the potential consequences of score interpretation and use". Therefore validity is not applied to an instrument, but to the inferences about scores and the interpretation and application of actions based on those scores. The data from my study is intentionally descriptive and is not intended to examine cause and effect of participants' managerial behaviour or on its quality.

\section{Interviews and monthly observation}

In each month of the case study, three interviews were held with each participant to fit into the three stage information response process. At each of the interviews, the participants were asked open-ended questions in order to elicit a response on aspects of their experience in relation to the use of the efficiency information. . The participants were asked about their use of and experience with the management information. For each interview, three open-ended questions were posed to the participants. The open-ended questions were derived from the four research questions, as depicted in Table 3.4. The interviews were approximately 30 
minutes in duration. The interviews were termed 'meetings' as a way of normalising the event for the participant as a part of their work week, rather than as a special research event; and were held, as follows:

○ Interview 1 - at the beginning of the month (between 2 and 5 working days). This interview was to present the information to individual participants. The purpose at this interview was to discuss the management information and to ask Questions one, two and four (refer Table 3.4).

○ Interview 2 - at mid-month (between 14 and 17 working days). This interview was to give the opportunity to the participant to ask further questions on the efficiency information, and to ask Questions three, five and seven (refer Table 3.4).

- Interview 3 - at the end of the month. This interview followed up on any issues or concerns held by the participant, and also to ask Questions six, eight and nine (refer Table 3.4). Most of these face to face interviews lasted about 45 minutes. On one occasion when one participant was on annual leave the interview was conducted by telephone call. This sequence of interviews was repeated for each month of the six month period.

The intent was to be able to use the participants' responses as narrative on the level and nature of the use of performance information to manage service efficiency. In addition, the interviews were a way of identifying the participants' managerial change in behaviour that may have been informed by their use of the performance information compared to the routine reporting (traditional normative information, such as budget variance, P\&Ls, Balance sheets, KPI ratios). Each month, the questions were repeated. This allowed me to have a periodic and 'targeted' focus on eliciting as much data on the managers' experience and attitudes about using the efficiency information, and to understand the dynamic nature of their service. In addition to the structured interview questions, there were supplementary questions which 
were asked at appropriate times in the interview to probe the participant's understanding of the drivers for improved performance.

Table 3.4: Participant interview questions

\begin{tabular}{|c|c|c|}
\hline $\begin{array}{l}\text { Research question } \\
\text { focus (Chapter 1) }\end{array}$ & Participant interview questions & $\begin{array}{l}\text { When question } \\
\text { was asked }\end{array}$ \\
\hline $\begin{array}{l}1 \text { Using the efficiency } \\
\text { information. }\end{array}$ & $\begin{array}{l}1 \text { We have discussed the MRE; is there } \\
\text { anything you want to discuss/ask? (Also covers } \\
\text { research questions } 3 \text { and } 4 \text { ). } \\
2 \text { In terms of efficiency, do you know what you } \\
\text { should do to improve? - Based on the } \\
\text { information, what do you think you would do? } \\
\text { (Also covers research question 3). } \\
3 \text { How are you finding the MRE information? }\end{array}$ & $\begin{array}{l}\text { Interview } 1 \\
\text { Interview } 1 \\
\text { Interview } 2\end{array}$ \\
\hline $\begin{array}{l}2 \text { Actions in response to } \\
\text { efficiency information }\end{array}$ & $\begin{array}{l}4 \text { What do you intend to do to improve } \\
\text { efficiency? } \\
5 \text { Do you intend to share this MRE } \\
\text { information? Will you share this information } \\
\text { with your service colleagues? } \\
6 \text { At month end, are you able to discuss the } \\
\text { efficiency of the services with your clinical } \\
\text { colleagues? }\end{array}$ & Interview 1 \\
\hline 3 Learning need & $\begin{array}{l}7 \text { Do you now have an overall measure of } \\
\text { efficiency of the service? Are you aware of any } \\
\text { learning you need to improve your } \\
\text { management? Including questions } 1 \text { and } 2 \text {. }\end{array}$ & Interview 2 \\
\hline $\begin{array}{l}4 \quad \text { Barriers } \\
\text { performance } \\
\text { improvement }\end{array}$ & $\begin{array}{l}8 \text { Over this last month, what did you actually } \\
\text { do? } \\
9 \text { What do you think stops you from having a } \\
\text { more efficient service? Including question } 1 \text {. }\end{array}$ & Interview 3 \\
\hline
\end{tabular}

The 'probing' of the participant was to assess whether the participant had a compliance focus or an improvement focus in relation to performance improvement of the service. In all of the interviews, participants were reminded that all responses and comments made during the interview and all of the material written by myself as the researcher would remain confidential and subject to Victoria University of Wellington's confidentiality requirements. 
The participants were also reminded at the first meeting each month that two Ethical approvals had been obtained. I also advised each participant that at any time in the course of the case study, they could 'opt out' and, or, request that material collected be destroyed. The interview data were prepared into narrative transcripts. From notes made at each interview I transcribed these into to a transcript for the month, by putting the three interview data together and identifiable by question. The transcripts were aimed to reflect the data and were written as complete coherent sentences in keeping with the meaning of the original verbatim comment at each interview. Preamble and socialising comments were excluded from the transcript unless these related to one of the four research questions. At the end of each month, the transcribed narrative was sent back to the respective participant to examine and correct if necessary. Further supplementary comments and observational data collected were recorded in observation notes. These help in understanding of the nature of particular aspects of the experience of the use of efficiency information. To illustrate: a subject's attitude change, detected by a different response to their past responses, would mean further interrogatory questions to elicit if the subject were aware of the change herself, and the reasons for the change. The narrative texts are attached in Appendix 1.

In the preparation of the transcripts, the verbatim responses from participants were written as complete coherent sentences in keeping in with the meaning of the original verbatim comment at interview. The participants were given the opportunity to review the transcripts and provide correction if necessary. The preamble to the meetings to relax the participants (social questions and responses) was excluded from the transcript (for example, "I have had a great holiday since we last met"). I recognised that the preparation of the transcripts was an interpretative act in that meanings were being potentially created from the interview responses of the participants act (Braun and Clarke, 2006). This was then the start of the analytical and qualitative part of the research methodology and approach (Bird, 2005). In terms of any 
convention for transforming spoken texts into written texts, Braun and Clarke (2006, p88) argue that "as there is no one way to conduct thematic analysis, there is no one set of guidelines to follow when producing a transcript”. However, Braun and Clarke (2006) note that it is necessary that the transcript retains the information needed and is true to its original nature. In this study, the review of the transcripts by participants helped maintain the rigour of authenticity and accuracy.

\subsection{Method of data analysis}

The methods employed provided for the collection of participant responses of their experience of the use of efficiency information and on performance improvement in two forms: (1) survey of participants on their perceptions, and measurement of service efficiency; (2) narratives on experience.

\section{Analysis of the narratives of experience}

The subsequent 198 transcripts formed the entire data set for analysis. The use of the full data set of transcripts was intended to ensure that narratives of the experience in the use of the information could be extracted from both the participant groups of managers. This approach fitted the intent of the analysis which aimed for an overall view of the experience across both participant groups. There was no intent to conduct a content analysis of the data. Standard content analysis, where collected qualitative data is 'analysed' typically using software to yield a quantified result of key text, tends to value the frequency of key words or phrases; whereas, here I was more interested in any comment that could be important to the development of generalised themes. I also wanted to adopt the more traditional way of reading (and re-reading) the data collected to begin to experience the participants' use of the efficiency information, and to form some meanings of the experience. Boyatzis (1998) has explained that the process of listening to participants' responses and summarising these and 
the subsequent transfer to transcripts enters information into the researchers' conscious and unconsciousness. The analysis of the narratives for themes is discussed now.

\subsection{Thematic Analysis (TA)}

The TA process is the mapping of meaning (Burback, 1988) through a hierarchical process building meaning from a micro level to a more abstract level, first by looking for symbols, then patterns of events and finally overall meanings. The TA here can be described as basic interpretive in which data are inductively analysed to identify recurring patterns or common themes that cut across the data (Merriam, 2002). As Patton (2002, p433) states: "because each

qualitative study is unique, the analytical approach will be unique". Having no clear canonical path also allows flexibility in the application of methods to appropriately answer research questions (Chamberlain 2000). This flexibility prevents the production of data as internal to a particular methodological theory and inhibits an emphasis on selecting methods (Janesick 2000, Avis, 2003). Miles and Huberman (1994, p3) offer the more pragmatic view that any method that produces "clear, verifiable, credible meanings from a set of qualitative data adds grist to the mill".

The data set was represented by narrative texts as the voice of participants. TA was used as both the method and process for the search of the key themes important to the description of the phenomenon under study (Daly et al., 1997). It is worth noting here again, TA represents broadly the researcher's reflected view of what the subject speaks or thinks, and that, this representation or representations are described using aspects of the narrative data that had been viewed as significant to the particular research questions under study. In this thesis, then, the construction of themes is as a meaning of the observed human action, consistent with the previous work of Braun and Clarke (2006). TA here is described as a process, with an active role for the researcher to play in identifying patterns/themes, selecting which are of interest, 
and in reporting these to the reader. The analysis of subjective experience was inductive. In an inductive analysis (or bottom up, Frith \& Gleeson, 2004), the identification of the themes are strongly linked to the data themselves. In this approach, the data collected specifically for the research (e.g., via interviews) would also not be driven by the researcher's theoretical interest in the area or topic. Inductive analysis is a process of coding the data without trying to fit it into a pre-existing coding frame, or the researcher's analytic preconceptions (Braun \& Clarke, 2006). In this sense this form of thematic analysis is data-driven. However, there have been criticisms of this approach in the past due to the lack of clear guidelines for researchers employing such methods. This has subsequently contributed to some researchers presenting results without detailing how the actual analysis of their data was undertaken (AttrideStirling, 2001).

The process and methodology adopted for TA here is Braun and Clarke's (2006) six-phase process with an adaptation. The strength of using this process was that it provided a welldefined explanation whilst maintaining the flexibility tied to its epistemological position. In this, I incorporated both the individual participant experiences and the meanings they attached to these' and the impact of the wider social context on these meanings. The process involved an inductive approach whereby the content of the data directs the categorisation and coding of the narrative (and theme development). The narratives served as the primary data. A semantic way was adopted to reflect the explicit content of the data; and a realist way to report on an assumed reality evident in the data. The initial coding part of TA was to describe pattern(s) in the data (narrative) with a second theme development phase to interpret aspects of the patterns. At this point I want to acknowledge I do not subscribe to any naïve realist position within qualitative research whereby the proposition is that this research will simply give a voice to the experience of those under study (Braun and Clarke, 2006). Such a qualitative analytical practice may rise to a validity question that the nature of qualitative and 
interpretative analysis might not be real and may 'made up'; or that the resulting themes might be anecdotal rather than patterned from the data. All research, whether qualitative or quantitative will rely on honest and good research practices. Reporting quantitative data only does not circumvent this issue such that counting misses the point of qualitative research, as frequency does not determine value (Pyett, 2003). Researchers have used the case study research method and thematic analysis for many years across a variety of disciplines. Social scientists, in particular, have made wide use of this qualitative research method to examine contemporary real-life situations and provide the basis for the application of ideas and extension of methods. Yin as early in 1984 defined such analysis as "an equally formal and proper method of empirical inquiry that investigates a contemporary phenomenon within its real-life context; when the boundaries between phenomenon and context are not clearly evident; and in which multiple sources of evidence are used" (Yin, 1984, p. 23).

All of the data collection and development of the narrative evidence, as well as the subsequent selection of text and its deployment to support the identification of patterns and themes, are affected by my own values. In this context it is important to note that unlike content analysis, TA is designed to search for patterns by repeated reading of the data (Rice and Ezzy, 1999). Hence, a single comment by one subject was as significant to developing themes and meaning, as those comments that are made multiple times and by a number of subjects. The construction of meaning - to represent the observed human action from the developed themes - comes broadly from my reflected view of the subjects' narrative and was consistent with Rice and Ezzy (1999) and Braun and Clarke (2006),

\section{TA phases of data analysis}

A summary of the six phases as outlined by Braun and Clarke (2006) is outlined here. The first phase dealt with the transcription of the narrative data. The data collected from all the 
participants was first transcribed by me as the researcher; this is considered an essential stage in analysis (Riessman, 1993). The transcribed data was then read and re-read several times and in addition, to mitigate against my potential bias, all of the participants were provided the transcripts to confirm the accuracy of the interview transcription. This process resulted in considerable data immersion and my (as the researcher) closeness with the data.

The second phase follows on from this initial stage and builds on the transcription narratives to identify the initial codes from the text. These code labels identified features of the data that I consider may be relevant to the research questions. Furthermore, and intrinsic to the method of active immersion of 'reading and re-reading', the whole data set of narratives was given equal attention so that primarily full consideration could be given to repeated patterns within the data and secondly the code labels be examined for duplications and similarity of meaning, which were then subsequently removed.

The third phase began the search for themes where, first, the code labels were again reviewed to begin grouping them within similar clusters, by combining different code labels that may have been very similar or may have been considered to have the same meaning within the narrative data. Braun and Clarke (2006) refer to this the code collation from the codes, and because I have already applied code labels to all narrative within the data set, the entire data set can be accessed for later analysis. In the second part of this phase, the codes with similar meanings are clustered into groups categorised to the research questions, meaning that all of the narrative is now similarly connected to a research question. At this point, these group clusters are renamed to present a refined label; first, to ensure that each group, cluster is logical and consistent with the data within, and has coherence across the data set; and second, to ensure that these groups form a natural fit (coherent pattern) with the data set. This ensured the group clusters accurately reflected what was evident in the data set as a whole (Braun \& 
Clarke, 2006). At this stage a further check also took place to ensure no codes had been missed in the earlier stages and that the narratives had been coded appropriately.

The fourth phase involved the development and review of preliminary themes. The group clusters were examined as well as the collated code labels and connected narrative to identify patterns of meaning in the context of the connected research question. These patterns were then articulated as simple statements or phrases and are referred to as 'initial themes'. This phase 4 identified the various themes and their fit to the data and to each other to reflect the participants' experiences.

The next fifth phase involved a review of the initial themes. The intent of the review was to either merge or exclude the initial themes' patterns of meaning into more broader, meaningful and coherent patterns. In this, the key consideration was of the 'story' within individual themes and their relationship to the overall experience that was evident within the data. In addition, Fielden, Sillence and Little (2011) advised of the importance of developing short but punchy 'names' to convey an immediate indication of the essence of each theme (Braun and Clarke, 2006).

In the final sixth phase, the resulting finalised themes as pieces of texts that are reported with selected examples of narrative to illustrate elements of the themes. These extracts aim to clearly identify key and core issues within the theme and presented a lucid example of the point being made. I interpreted the narratives in the context of the final themes and consider how the hospital's organisation, its policies and goals play a part in the managers' use of information. The process of undertaking the TA process is further detailed in Chapter Four to add transparency to the research. 


\subsection{Limitations}

In any study there are choices made by the researcher on the focus of the research and on methodology and methods. These choices result in necessary restrictions on the study and are acknowledged now. This study was designed as an interpretive study, using the case study participants. Accordingly the results cannot be generalised for all populations in all settings except for other managers who may have had similar experiences (Metcalfe, 2005). A longer longitudinal study was not feasible because of costs and the imposition on senior managers as participants and of my time availability (I was employed on a full time basis during the study). The study focus did not permit any investigation into differences in manager experience that are related to background and education or ethnicity. Nor was my research interest ethnographic or anthropological.

There are also other limitations. The use of interviews and self-reporting by participants to provide responses to various aspects of the use of information raises the possibility of the common responses being given over time (participant fatigue) and bias the result. This is somewhat remedied by the use of open ended questions in addition to a structured questionnaire with a ten point scale to self-report (Podsakoff et al, 2003). In future and further investigations it would be appropriate to develop more direct and objective measures for manager behaviour.

The key to this study was the TA which was interpretative and so lends itself to focus on the participants experiential narratives. The data of this study was collected from a single organisation's (ACH) cohort of service managers. The results may not clearly be generalizable to other organisations in wider settings due to the organizational characteristics unique to the public organizations at $\mathrm{ACH}$. In order to generalize the results from this study, further collection of data from various other settings will be needed. The use of information 
can be a very individualistic behaviour, and so the focus of the study was on the salient aspects which affect attitude, learning and behaviour toward the use of the performance information. However, according to Fishbein and Ajzen (2000), the manager's behavioural intention, and action are determined by social factors as well as by their attitude. Thus, the insights and common themes on the managers' experience that will be gained from this research will be of future research will need to consider these social factors in order to increase the explanatory power of the research. By the nature of this being a doctoral study both the data transcripts and the qualitative analysis are the product of me being the sole researcher. However, as a way of seeking external verification of the data and the analysis, all participants were given the opportunity to review and verify or correct the transcripts as to their accuracy and context. The theme development and results were also discussed by a smaller group of participants post case study.

\section{A note on the sample selection}

This study was concerned with the process of exploring on an a priori basis the experience of how managers use information, regardless of the type or source of its source. This thus permitted me to construct a sample that included a manager who wanted to sample a particular information type. This deliberate choice of sample does not prejudice the inductive nature of the inquiry (Palinkas et al, 2015). In this light, earlier Yin (1984) noted that cases in qualitative research can be selected either because either similar results are predicted or to generate different results for predictable reasons.

\subsection{Strength of the study approach}

The choice of an inductive, exploratory data driven research approach was recognition of the lack of an existing theoretical foundation in the current research literature. The selection of a qualitative research design was a reflection of the dynamic and complex nature of gathering 
data from a work setting. The study was designed to allow the researcher to gain, and provide, understandings and insights, of managers' use of efficiency information to improve the efficiency of the service being managed.

As the researcher, I have had considerable practitioner experience in both qualitative analysis (interviews) and quantitative performance measurement in public/private health and other service sectors in different settings and policy jurisdictions, both in New Zealand and overseas. I have also had experience with using DEA to benchmark performance and present management information at both policy and management levels.

I have also been working at ADHB and with ACH's service managers for several years prior to the research. This contributed to a research setting that was relaxed, trustful and positive, and more likely to elicit honest responses.

\subsection{Conclusion}

In concluding this chapter on the research methods, it is worth noting here that the intent of the research was not anthropological in nature or to present a general ethnographic study of hospital managers. The study was to explore the behaviour and actions of managers in response to information. The research design and the organisation of the data collection, analysis and their interpretation have been framed by considering the issue of bias or the potential distortion of research outcomes due to unintended influences from the researcher as well as research participants. This is recognised as a particularly critical issue in qualitative research where interviewers take extraordinary efforts to establish strong relationships with their interviewees in order to delve deeply into the subject matter (Pannucci \& Wilkins, 2010). The methods used here and their organisation are designed to enhance the 
trustworthiness, transparency, and accountability of my research to offset the asymmetrical power relationship between the researcher (interviewer) and the interviewed participants (Kvale, 2002). This study's research approach, data collection and analysis have been outlined as a qualitative design. The measurement of subjective perceptions was by self-rating on Likert scores and so provided a way of describing the experience between the two groups of participants. Qualitatively, the collected narratives provide the basis for the development of general themes on the use of efficiency information within an organisation. The case study participant sample was small, but, it surveyed the entire cohort of senior service operational managers within New Zealand's largest and most complex hospital system. As such, the case study encompassed ACH's entire range of direct patient treatment services. The separation of the managers into two participant groups allowed a natural context that was different for each participant group in their use of different management information. Bearing in mind the scope of this study was a single exploratory case study, no statistical inferences are being considered on the use of information or of any of their behaviours.

During this research, I had a role as an incumbent manager in a funding and planning role overviewing ACH's hospital services and service managers who were the participants in the case study. I conducted my 'insider' researcher role alongside being a senior manager at ADHB to provide modified action research participation. The advantage of the modified action research participation role is that the data collected as a result leads to the development of a framework for understanding the managerial role in service performance. The next three chapters present and discuss the case study results and findings. 


\section{Chapter 4}

\section{-The Thematic analysis of managers' use of information}

\subsection{Introduction}

This chapter describes the use of the thematic analysis (TA) as a process and discusses the results of that TA process. The case study on the use of efficiency information is exploratory, to investigate and begin to learn about the management factors which potentially can affect performance improvement. There has been little previous research on the management factors relating to the use of efficiency information by hospital service managers. Therefore, this analysis should provide a better understanding of the patterns or themes of management behaviour, attitudes and actions.

For the TA, the participants are viewed as a whole in terms of the experience as a cohort of managers in using efficiency information. The holistic view from a thematic analysis is not for the purpose of providing a generalizable viewpoint beyond the case study but instead is to describe the case study, "in order to understand the complexity thereof" (Bloomberg and Volpe, 2012 p31).

Section 4.2 presents the overview of the TA that was conducted. Section 4.3 discusses the initial search and coding of narrative text patterns. Section 4.4 then outlines the initial development of preliminary themes, while in Section 4.5 the initial themes are discussed and linked to broader thematic insights. These preceding sections provide a description of the process of TA, whilst the forthcoming section, Section 4.6 presents the final themes, including key analytic narrative and data extracts to appropriately support and contextualise the identified themes. Section 4.7 then concludes this Chapter. 


\subsection{Thematic analysis}

The TA treatment of the narrative data that was collected in the case study is outlined in terms of the data familiarisation, analytical and interpretative effort in Figure 4.1.

Figure 4.1: Overview of TA

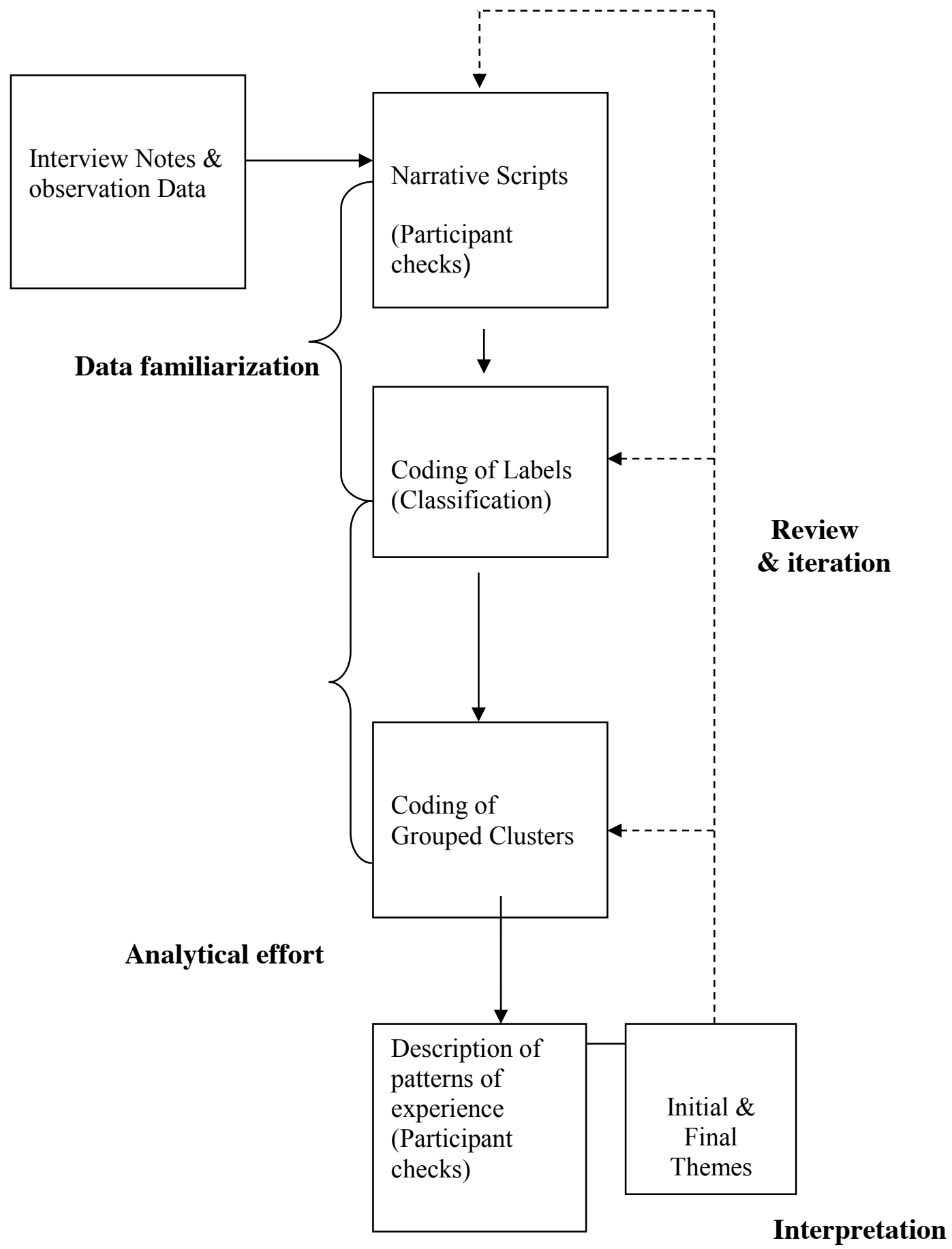


Bearing in mind that a field-based case study may not have clear beginnings or an end point (Merriam, 2009) in this use of the TA the boundaries are bound by the six months of narrative and the subsequent analysis and interpretation.

\section{Summary of TA phases}

A summary of each part of the TA process is outlined in in Table 4.1. Throughout the process, the emphasis is on using the participants' narratives as captured to 'speak' for their own experiences, regardless of the participant group they were in for the case study.

\section{Table 4.1 Summary TA Phases}

\begin{tabular}{|l|l|}
\hline Phase 1 & $\begin{array}{l}\text { This is a very initial phase in which I familiarised myself with the } \\
\text { collected data set of all the participant interview notes. I then } \\
\text { prepared scripts of the participant narratives. These scripts were } \\
\text { checked with the participants for accuracy of content and meaning. } \\
\text { The scripts were then used as Braun \& Clarke (2006) intended to } \\
\text { read and reread noting down initial ideas. }\end{array}$ \\
\hline Phase 2 & $\begin{array}{l}\text { Generating initial codes: This involves the grouping of the } \\
\text { narrative data in a systematic manner to recognise patterns. The } \\
\text { narratives within each of the patterns were tested for 'likenesses' } \\
\text { and similarity of meaning. The pattern was then described (code } \\
\text { label). }\end{array}$ \\
\hline Phase 3 & $\begin{array}{l}\text { Searching for initial themes: The code labels and their derivative } \\
\text { narratives are now collated into possible initial themes. All of the } \\
\text { narratives are gathered to a possible initial theme. }\end{array}$ \\
\hline Phase 4 & $\begin{array}{l}\text { Reviewing themes: Rechecking the initial themes in relation to the } \\
\text { coded extracts (Level 1) and the entire data set (Level 2), } \\
\text { generating an overall thematic map of the analysis. }\end{array}$ \\
\hline Phase 5 & $\begin{array}{l}\text { Defining and naming secondary themes: Ongoing analysis to refine } \\
\text { the specifics of each theme, to generate a clear definition and name } \\
\text { for each secondary theme. } \\
\text { Reporting: final analysis of selected extracts, relating back of the } \\
\text { analysis to the research question and literature. }\end{array}$ \\
\hline Phase 6 &
\end{tabular}

The TA process is presented here as a linear process, although in practice it is a recursive exercise for the coding of participants narrative, recognising patterns and developing these 
into themes (Boyatzis, 1998). A theme has been defined by Saldana (2009, p.139) "as a phrase or sentence that identifies what a unit of data is about and/or what it means".

Therefore, TA is not for the purpose of generalising beyond the case, but instead its purpose is to allow a deeper understanding of the complexity within the case and thereby to enable the exploration of the behavioural experience in relation to the research questions.

\subsection{Coding results}

This section refers to the coding of the narrative data to more meaningful patterns (Bloomberg and Volpe, 2012). Coding refers to the exercise of identifying (or, 'placing') each identified piece of narrative text with a summary statement or term. A piece of narrative text is viewed as the individual data item from the data set. In this research narrative text is distinguished as a sentence or sentences from participants that have been recorded (written down by me as the interviewer) and referred to here as scripts. This treatment of the participants' responses simplifies the task of distinguishing narrative text whilst allowing for complete coverage of all the narrative. The coding process does not separate between the MRE and RRP participants as the aim is to obtain a holistic view of the managers' use of efficiency information. The aim is to achieve an initial conceptual description of the narratives. No prior assumptions are made. The code labels describe the narrative text to enable the sorting of text by common description. As a first step in the TA process, all of the narratives recorded were analysed by hand and allocated a code label (Braun \& Clarke, 2013). The entire data set of narratives was coded, because it was intended to ensure that no pre-selection of any of the narratives could occur. All of the narrative would be used to cover all participants or the entire six month study period. Each separate narrative text was categorised by a code label to identify in that text the important feature that might be relevant to answering the research questions. The descriptions of text were based on the presumed reality of the perspective of the manager's response to the efficiency information. This approach fits the intent of the 
analysis which aims for an overall view of the experience. The development of initial themes was undertaken sequentially. Each of the steps is discussed below and the findings of each step are also presented.

\section{(1) Identified code labels for text}

Each piece of text was read and the key feature or meaning in relation to the manager's behavioural response to information was identified. Each of the meanings were identified and compared to all previous texts and their code labels to ascertain if there was a fit with an already developed code label. If no existing code labels would fit the new text, then a new code label would be identified. Coding labels were identified for each piece of text.

These coding labels are not meant to precisely define the piece of text; rather they serve as markers to separate the text from each other on a point of difference. As explained above, this process was an active immersive as well as iterative process of analysis (Crabtree and Miller, 1999). This meant that I as the researcher continually read and re-read the texts during the coding exercise. Each narrative text only received one code label. A cross all of the narratives a total of 40 code labels were assigned as shown in Table 4.2. 
Table 4.2: Initial coding result

\begin{tabular}{|c|}
\hline Identified code labels for text \\
\hline $\begin{array}{l}\text { 1. Challenge to information } \\
\text { 2. Resistance to signal } \\
\text { 3. Resistance to new performance signal } \\
\text { 4. Resistance to change - isolation } \\
\text { 5. Information challenge } \\
\text { 6. No acceptance } \\
\text { 7. Indifference to performance need }\end{array}$ \\
\hline $\begin{array}{l}\text { 8. Confusion } \\
\text { 9. Lack of knowledge } \\
\text { 10. No specific knowledge } \\
\text { 11. Disbelief in results } \\
\text { 12. Questioning of actions } \\
\text { 13. Lack of confidence } \\
\text { 14. Seeking feedback }\end{array}$ \\
\hline $\begin{array}{l}\text { 15. Refer to senior management need } \\
\text { 16. Refer to variance reporting } \\
\text { 17. Refer to targets and KPIs } \\
\text { 18. Focus on targets delivery } \\
\text { 19. Reactive ad hoc } \\
\text { 20. Status quo/barrier } \\
\text { 21. Barrier } \\
\text { 22. Reactive } \\
\text { 23. Routine/reactive } \\
\text { 24. Status quo/reactive }\end{array}$ \\
\hline $\begin{array}{l}\text { 25. Reflection on information - no action } \\
\text { 26. Reflection } \\
\text { 27. No action } \\
\text { 28. Isolated management } \\
\text { 29. Uncertainty about performance levers }\end{array}$ \\
\hline $\begin{array}{l}\text { 30. Performance review intent } \\
\text { 31. Improved understanding of performance } \\
\text { improvement } \\
\text { 32. Collaboration influence } \\
\text { 33. Accountability practice }\end{array}$ \\
\hline $\begin{array}{l}\text { 34. Awareness } \\
\text { 35. Performance interest } \\
\text { 36. Performance focus } \\
\text { 37. Acceptance } \\
\text { 38. Awareness increase } \\
\text { 39. Growing awareness } \\
\text { 40. Information acceptance }\end{array}$ \\
\hline
\end{tabular}

These 'code labels' represent narratives of a pattern, each of which contains a different meaning. The code labels can be connected back to the narrative contained within the 
participants' scripts, and provides a transparent link between the managers' script and the derive patterns of meaning.

\section{(2) Revisions of code labels}

The code labels were reviewed and duplications in meaning or inconsistency were removed, as follows:

(i) The identified code labels for pieces of narrative text included: resistance to signal, resistance to new performance signal, and resistance to change - isolation. These three code labels can be viewed as having a similar and consistent meaning that refers to a general resistance to the performance information that is being presented. Accordingly, the three code labels are now replaced with one revised code label of 'Resistance'.

(ii) The code labels termed 'lack of knowledge' and 'no specific knowledge' are viewed as having a similar meaning from a behavioural response perspective; that both refer to the lack of comprehension or understanding of the signals being presented in the performance information. Both of these were termed 'lack of knowledge'.

(iii) Four code labels, 'Reactive ad hoc', 'Reactive', 'Routine/reactive' and 'Status quo/reactive'; had similar terms and similar meaning. Focus was on time constraints and the need to manage everyday business pressures. These code labels were all revised as 'reactive ad hoc'.

(iv) Two code labels, 'Barrier' and 'Status quo/Barrier' were viewed as duplicated in their meanings. The narratives indicated an intent (or focus of the managers) to maintain a business as usual environment seemingly on a no risk basis. Using the performance information may necessitate managerial actions that would upset the situation. Both of these code labels were revised to 'Status quo'.

(vi) Two other code labels, 'Reflection on information - no action' and 'Reflection' were of similar meaning and thus duplicated, referring in both codes to the performance information 
being used to reflect on with no management action intended. Both of these code labels were revised to 'Reflection'.

(vii) Both of the following two code labels 'Performance interest 'and' Performance focuses were viewed as having similar meaning. The availability of the information stimulated an interest to focus on performance. To remove the duplication, the two code labels were termed as 'Performance interest'.

(viii) The following two code labels 'Acceptance' and 'Information acceptance' also were of similar meaning, referring to the willingness for accepting the performance information as presented. Both of these code labels were termed 'Acceptance'.

(ix) The two code labels termed 'Refer to targets and KPIs' and 'Focus on targets delivery' had duplicated meaning in that both referred to the managers' intent to focus their attention onto the already required standard reporting. Here, performance was viewed as complying with the reporting requirements. Both of these codes were termed 'Refer to targets and KPIs'.

As a result of the revision of the code labels, a final 26 revised code labels were identified for all of the narrative. These final 26 revised code labels were also presented in Table 4.3. In the following Table 4.4, the 26 revised code labels are further grouped and 'clustered' into an overall group meaning. The meaning for each cluster represents a unique experience to indicate areas of commonality and of like experiences (Namey et al, 2008). 
Table 4.3: Revised coding of narrative data

\begin{tabular}{|c|c|}
\hline $\begin{array}{c}\text { Identified code labels for text } \\
\text { (from Table 6.2) }\end{array}$ & Revised Code labels \\
\hline $\begin{array}{l}\text { 1. Challenge to information } \\
\text { 2. Resistance to signal } \\
\text { 3. Resistance to new performance } \\
\text { signal } \\
\text { 4. Resistance to change - isolation } \\
\text { 5. Information challenge } \\
\text { 6. No acceptance } \\
\text { 7. Indifference to performance need }\end{array}$ & $\begin{array}{l}\text { 1. Challenge } \\
\text { 2. Resistance } \\
\text { 3. Indifference } \\
\text { 4. No acceptance }\end{array}$ \\
\hline $\begin{array}{l}\text { 8. Confusion } \\
\text { 9. Lack of knowledge } \\
\text { 10. No specific knowledge } \\
\text { 11. Disbelief in results } \\
\text { 12. Questioning of actions } \\
\text { 13. Lack of confidence } \\
\text { 14. Seeking feedback }\end{array}$ & $\begin{array}{l}\text { 5. Confusion } \\
\text { 6. Lack of knowledge } \\
\text { 7. Disbelief } \\
\text { 8. Questioning } \\
\text { 9. Lack of confidence } \\
\text { 10. Seeking feedback }\end{array}$ \\
\hline $\begin{array}{l}\text { 15. Refer to senior management need } \\
\text { 16. Refer to variance reporting } \\
\text { 17. Refer to targets and KPIs } \\
\text { 18. Focus on targets delivery } \\
\text { 19. Reactive ad hoc } \\
\text { 20. Status quo/barrier } \\
\text { 21. Barrier } \\
\text { 22. Reactive } \\
\text { 23. Routine/reactive } \\
\text { 24. Status quo/reactive }\end{array}$ & $\begin{array}{l}\text { 11. Refer to senior management } \\
\text { need } \\
\text { 12. Refer to variance reporting } \\
\text { 13. Refer to targets and KPIs } \\
\text { 14. Reactive ad hoc } \\
\text { 15. Status quo }\end{array}$ \\
\hline $\begin{array}{l}\text { 25. Reflection on information - no } \\
\text { action } \\
\text { 26. Reflection } \\
\text { 27. No action } \\
\text { 28. Isolated management } \\
\text { 29. Uncertainty about performance } \\
\text { levers }\end{array}$ & $\begin{array}{l}\text { 16. Reflection } \\
\text { 17. No action } \\
\text { 18. Isolated management } \\
\text { 19. Uncertainty about } \\
\text { performance levers }\end{array}$ \\
\hline $\begin{array}{l}\text { 30. Performance review intent } \\
\text { 31. Improved understanding of } \\
\text { performance improvement } \\
\text { 32. Collaboration influence } \\
\text { 33. Accountability practice }\end{array}$ & $\begin{array}{l}\text { 20. Performance review intent } \\
\text { 21. Improved understanding of } \\
\text { performance improvement } \\
\text { 22. Collaboration influence } \\
\text { 23. Accountability practice }\end{array}$ \\
\hline $\begin{array}{l}\text { 34. Awareness } \\
\text { 35. Performance interest } \\
\text { 36. Performance focus } \\
\text { 37. Acceptance } \\
\text { 38. Awareness increase } \\
\text { 39. Growing awareness } \\
\text { 40. Information acceptance }\end{array}$ & $\begin{array}{l}\text { 24. Awareness } \\
\text { 25. Performance interest } \\
\text { 26. Acceptance }\end{array}$ \\
\hline
\end{tabular}




\section{(3) Cluster grouping of code labels}

The code labels were further refined into higher level patterns of meaning (group clustering).

Table 4.4: Results of initial and revised coding of narrative data

\begin{tabular}{|c|c|c|}
\hline \multicolumn{2}{|l|}{ Initial coding labelling } & \multirow[b]{2}{*}{$\begin{array}{l}\text { Group clustering name and } \\
\text { meaning }\end{array}$} \\
\hline Identified code labels for text & Code labels (revised) & \\
\hline $\begin{array}{l}\text { Challenge to information } \\
\text { Resistance to signal } \\
\text { Resistance to new performance } \\
\text { signal } \\
\text { Resistance to change - isolation } \\
\text { Information challenge } \\
\text { No acceptance } \\
\text { Indifference to performance need }\end{array}$ & $\begin{array}{l}\text { Challenge } \\
\text { Resistance } \\
\text { Indifference } \\
\text { No acceptance }\end{array}$ & $\begin{array}{l}\text { Detachment and challenge to } \\
\text { information, relating to the } \\
\text { receipt of information. }\end{array}$ \\
\hline $\begin{array}{l}\text { Confusion } \\
\text { Lack of knowledge } \\
\text { No specific knowledge } \\
\text { Disbelief in results } \\
\text { Questioning of actions } \\
\text { Lack of confidence } \\
\text { Seeking feedback } \\
\end{array}$ & $\begin{array}{l}\text { Confusion } \\
\text { Lack of knowledge } \\
\text { Disbelief } \\
\text { Questioning } \\
\text { Lack of confidence } \\
\text { Seeking feedback }\end{array}$ & $\begin{array}{l}\text { Unskilled and inexperience } \\
\text { with new knowledge, relating } \\
\text { to the interpretation and } \\
\text { understanding of } \\
\text { performance information }\end{array}$ \\
\hline $\begin{array}{l}\text { Refer to senior management need } \\
\text { Refer to variance reporting } \\
\text { Refer to targets and KPIs } \\
\text { Focus on targets delivery } \\
\text { Reactive ad hoc } \\
\text { Status quo/barrier } \\
\text { Barrier } \\
\text { Reactive } \\
\text { Routine/reactive } \\
\text { Status quo/reactive }\end{array}$ & $\begin{array}{l}\text { Refer to senior } \\
\text { management need } \\
\text { Refer to variance } \\
\text { reporting } \\
\text { Refer to targets and KPIs } \\
\text { Reactive ad hoc } \\
\text { Status quo }\end{array}$ & $\begin{array}{l}\text { Reactive performance focus } \\
\text { and reporting relating to } \\
\text { using information. }\end{array}$ \\
\hline $\begin{array}{l}\text { Reflection on information }- \text { no } \\
\text { action } \\
\text { Reflection } \\
\text { No action } \\
\text { Isolated management } \\
\text { Uncertainty about performance } \\
\text { levers }\end{array}$ & $\begin{array}{l}\text { Reflection } \\
\text { No action } \\
\text { Isolated management } \\
\text { Uncertainty about } \\
\text { performance levers }\end{array}$ & $\begin{array}{l}\text { Low confidence in capacity } \\
\text { to overcome barriers, relating } \\
\text { to uncertainty about what or } \\
\text { how to use the information. }\end{array}$ \\
\hline $\begin{array}{l}\text { Performance review intent } \\
\text { Improved understanding of } \\
\text { performance improvement } \\
\text { Collaboration influence } \\
\text { Accountability practice }\end{array}$ & $\begin{array}{l}\text { Performance review intent } \\
\text { Improved understanding } \\
\text { of performance } \\
\text { improvement } \\
\text { Collaboration influence } \\
\text { Accountability practice }\end{array}$ & $\begin{array}{l}\text { Enhanced collaborative } \\
\text { action and influence, relating } \\
\text { to increased, positive use of } \\
\text { the information. }\end{array}$ \\
\hline $\begin{array}{l}\text { Awareness } \\
\text { Performance interest } \\
\text { Performance focus } \\
\text { Acceptance } \\
\text { Awareness increase } \\
\text { Growing awareness } \\
\text { Information acceptance }\end{array}$ & $\begin{array}{l}\text { Awareness } \\
\text { Performance interest } \\
\text { Acceptance }\end{array}$ & $\begin{array}{l}\text { Focussed Performance } \\
\text { improvement and } \\
\text { accountability, relating to a } \\
\text { positive use of the } \\
\text { information. }\end{array}$ \\
\hline
\end{tabular}




\subsection{Development of initial themes}

Table 4.4 shows the connections of code labels to group clusters. In order to draw connections, on a heuristic basis, the narratives underlying the code labels were examined for patterns and where this occurred the code labels were grouped. A repeat exercise was undertaken (at another time) to confirm the grouping of code labels. As shown in Table 4.4 the revised code labels are grouped around common and overlapping categories of meaning. These can now be developed into preliminary themes, which are discussed next.

By grouping the similarities contained within the categories of the revised code label list, six cluster groups were identified and identified with a cluster name of generalised meaning unique to that cluster group. The initial thematic ideas which are the preliminary and exploratory themes identified from the above narrative. These initial themes that are identified in this discussion on are numbered sequentially from 1 to 12 .

\section{Detachment and challenge to information, relating to the receipt of information.}

This denotes the result of perceived barriers by participants that they view as preventing their use of efficiency information and to undertake any improvement action.

This cluster grouping represents managers' behavioural responses to information, such as: challenge, resistance, indifference and a lack of acceptance to information. The narratives indicate that there were concerns about making necessary decisions; a lack of trust in their superiors; also there was uncertainty about the impact of using the new information. Within the narrative, some managers also expressed a lack of interest in performing better and no motivation in performance improvement. Generally, these narratives expressed distrust in the information provided and as a result formed barriers to performance improvement. The narratives indicate that there is no acceptance of the use of performance information or their signals for service performance improvement. From a detached perspective, there is no 
imperative to consider any further, the management choices in inputs and outputs under the control of the manager. These narratives question the validity of the information on performance and therefore pose both a challenge to the use of information and a detachment from taking further responsibility for performance improvement. In this cluster there are three initial themes numbered 1 to 3, as follows:

- IT1 Performance signals should be respected and accepted by all within senior teams so that there is credibility in using the information;

- IT2 Managers will first place emphasis on ensuring that available information is both, correct and validated by the organisation, before taking any action; and

- IT3 Managers do need performance feedback on their actions taken.

\section{Unskilled and inexperience with new knowledge, relating to the interpretation and understanding of performance information.}

This represents the need for learning and skill development (capability) in the managers in order for them to use efficiency information.

The cluster grouping represents behavioural responses: confusion, lack of knowledge, disbelief, questioning, lack of confidence and of managers continually seeking feedback from their managers. The narratives depict initial questioning of the information, little understanding of interconnections; as well as a lack of perception about the performance signals. The narrative shows that these managers focus on the detail of routine short term matters and worry about the lack of sufficient information, but nonetheless view themselves as having extremely 'busy’ roles to play as service managers. From a management perspective insufficient attention is paid by these senior managers to the more complex and strategic issues around performance improvement of their service. Two initial thematic ideas are identified and numbered to follow on from the initial themes from the first group cluster: 
- IT4 Operational pressures will result in managers giving sole attention to their current ongoing issues; and

- IT5 Day to day issues can distract managers in keeping them occupied and seemingly too busy to pursue strategic change.

\section{$3 \quad$ Reactive performance focus and reporting relating to using information.}

This reflects the basis for management actions which aim at improving service performance. The narratives show that attention is on operational pressures that are the immediate 'in the face' issues, and a reactive approach that is reliant on meeting corporate reporting demands. The narratives are of reference to the needs of senior management, and their need to attend to routine reporting of variances as well as national targets and KPIs. The narratives reflect a reactive and ad hoc focus on managing the maintenance of the status quo. The narratives position routine management practices as preferred management behaviour and represent key barriers to on-going performance improvement. Under these circumstances, the identification of what is important or mission critical is difficult. Two initial thematic ideas are identified:

- IT6 Information can be used to provide performance signals for management attention and focus; and

- $\quad$ IT7 the focus on routine management practices may be prevailed on as a way of not needing to pay attention to service performance goals (a form of 'head in the sand' behaviour).

\section{Low confidence in capacity to overcome barriers, relating to uncertainty about what} or how to use the information.

This denotes the level of uncertainty about managers having the capability to take actions to improve performance.

The cluster group encapsulates managers' response that is representative of: reflection, taking 
no action (on the information); expressions of isolated management and uncertainty about performance levers. The narratives depict managers who are grappling with the notion that based on the information that is presented to them performance improvement will require management actions.

The narrative from this cluster demonstrates a search for instruction from a superior and is suggestive of management behaviour which is seeking avoidance for decision making on performance improvement. There are three initial thematic ideas proposed:

- IT8 Less experienced managers will need guidance and support from senior executives;

- IT9 In service work situations where there are highly skilled, knowledgeable and externally aligned professionals who are uniquely capable to provide the service, the managers may tend to be isolated and be unwilling to interact interfering in service affairs; and

- IT10 Weaker managers may tend to a view that they lack a clear mandate for performance responsibility.

\section{Enhanced collaborative action and influence, relating to increased, positive use of}

\section{the information.}

This reflects the positive impact of using information which can lead to more collaborative management action to improve performance.

This cluster grouping represents behavioural responses that are intent on performance review and demonstrates an improved understanding of performance improvement. The narratives depict managers as being willing to engage collaboratively on the basis of the information, to influence others; and also these managers have a practice of taking accountability for the performance of their service. 
The narratives show managers who accept the information and become focussed on dealing with the consequent performance issues. On the basis of the performance information, the narratives also show managers' intentions to actively engage senior staff; and have a deeper understanding of the multi layered approach needed. Within this cluster, there is strong consideration of the cross-service linkages and system impacts. One thematic idea that can be initially proposed is:

- IT11 Tasks of low organisational complexity can become the focus of a manager when uncertain of the broader performance signals gives attention to routine tasks.

\section{Focussed Performance improvement and accountability, relating to a positive use of}

\section{the information.}

This meaning represents the overview or focus that is required for actions to be taken in order to achieve performance improvement.

Here, the emphasis is on the managers' experience as framed by the group cluster narrative to provide behavioural response perspectives. The narratives show for this group of managers that there is a willingness to develop an increased understanding of the performance information and a growing awareness of the signals in that information. The narratives also depict an interest in performance and an acceptance of their managerial role in performance improvement. In this group the narrative is of managers who have focussed on their clinical staff as important allies in order to increase efficiency; and so have developed channels for dialogue with staff groups. There is one initial thematic idea:

- IT12 Management focus is to pursue objectives under conditions of uncertainty.

In summary the coding process results in groupings of the initial thematic ideas that have been identified and assigned code labels. In each code label, there is a clear interaction of text, 
codes and theme (initial). These initial themes provide a portrait of the narrative and are now ready for the next two TA phases of defining and interpretation to capture the overall phenomenon of the hospital service managers' experiences in using efficiency information.

\subsection{Thematic insights}

This section references phase 5 of the TA process and is focussed on defining the final or secondary themes that best represent the case study of hospital service managers' use of performance information. This presents as a general holistic pattern of the manager (whether a MRE or RRP participant) experience in the management of the performance of their service. In defining the themes, the TA process now moves to finalise the holistic themes that represent the managers' experience of the use of information. The development of the themes was in two parts: first, the 12 initial themes identified above in Section 4.2 were reviewed and further grouped to represent a similar meaning. Then these grouped initial groupings were assigned succinct phrases to best describe the meaning that underpinned the theme of the cluster (Fereday and Muir-Cochrane, 2006). The next second part of defining and finalising the themes involved a broader refinement of the themes to ensure overarching core themes were identified within the research questions.

The finalisation of themes involved a further level of refinement to focus on the validity and accuracy of the individual themes to the research questions, from a thematic perspective. Braun and Clarke (2006, p.91) noted: "To some extent, what counts as 'accurate representation' depends on your theoretical and analytical approach". I recognise that the representation is discussed from a personal researcher perspective, although from a contextual understanding of the work of the participant managers. 
Each of the themes was compared for similarity of meaning to each of the others and then assessed for its relevancy in the context of the research questions. This review and refinement process involved a recursive approach. This recursive approach is supported by qualitative researchers (such as Cutcliffe and McKenna, 2002, and Braun and Clarke 2006) because it involves the close examination and re-examination of the connections between the initial themes and the narratives. Through the re-examination, 12 initial themes were distilled and are labelled IT1 to IT12. Each of these initial themes (IT) is connected to one of four final themes; as follows.

1. Direct leadership - IT1, IT2, IT9: Performance signals are respected and accepted by all within senior teams so that there is credibility in using the information (IT1). Managers will first place emphasis on ensuring that available information is both, correct and validated by the organisation, before taking any action (IT2). The two themes are similar to each other and dissimilar to all the other themes in that their meaning is referenced to appropriate corporate intent which is supported and led by senior managers. If performance information is viewed as important and relevant to senior leadership, it will then be a key management measure for the manager. The underpinning meaning for the two initial themes together is of having and being capable of strong and direct performance leadership.

\section{Operational feedback - IT3, IT4, IT5, and IT9, IT10, IT11, IT13: Managers do need} performance feedback on their actions taken (IT3). This theme has a singular meaning for quick performance feedback to the manager on their management actions, in order to establish a regular and timely reinforcement feedback. Within this meaning, initial themes IT9 to IT11 are included despite having apparent contrary descriptions. The meanings of these descriptions however are all focused on avoidance behaviour that can be mitigated with regular feedback on performance of their operational activity. Operational pressures will 
result in managers giving sole attention to their current issues that require immediate attention (IT4). As managers, key decisions on performance improvement centre on their choice of the mix of inputs and outputs to be employed in the service. Day to day issues can distract managers in keeping them occupied and seemingly busy to pursue strategic change (IT5). These two initial themes have similar meanings; with both reflecting the day to day pressures as a barrier to performance improvement, when viewed from an organisational perspective. The two themes can be further clustered with the theme called 'operational feedback', as it conveys the perceived need to improve performance.

\section{Performance signals -IT6, IT7, and IT8 (excluding IT9, IT 10 and IT11 - which are} already referenced to final theme 2): Information can be used to provide performance signals, for management attention and focus (IT6). The focus on routine management practices may be prevailed on as a form of avoidance management behaviour (IT7). Both of these two initial themes similarly refer to the need for a clear and singular signal that can be presented to operational service managers in order to overcome their everyday work pressures. Less experienced managers will need guidance and support from senior executives (IT8). This theme is not relevant for further analysis because hospital service managers have experience and seniority with in the hospital management organisation to be able to operate confidently in a number of senior roles and settings. Both these initial themes can be labelled performance signals including aspects that relate to the need for operational guidance (especially for the less experienced or confident managers) and are covered in other themes.

In service work situations where there are highly skilled, knowledgeable and externally aligned professionals who are uniquely capable to provide the service, the managers may tend to be isolated and be unwilling to interfere in service affairs (IT9). Weaker managers may tend to a view that they lack a clear mandate for performance responsibility vis. accountability 
(IT10). These two themes are viewed as already covered within theme IT3 above. The feedback on management actions to managers will also ensure that appropriate connections are made within the organisation. Task complexity and high organisational complexity can become the focus of a manager in an attempt to 'keep working' (IT11). The term of being 'harried' was used by a participant who was explaining why she had no time to think about performance improvement. This theme idea is similar to that already covered within the meaning of theme IT3.

4. Management development - IT12: The focus to pursue objectives under conditions of uncertainty require a degree of corporate support (IT12). This theme's meaning refers particularly to managers who within an organisation have an inherent capacity to self-develop, understand system connections and engage on performance improvement activity. These matters centre on the need for corporate level support for the management development of staff to encourage performance improvement'. The hospital's top management as leaders of the organisation can establish an expectation for accountability and self-reflection from managers. This may encourage the management culture to focus on the broader world view (Bhaskar's 1989 world reality) and so is then likely to result in successful and continual performance improvement. In organizations, the effort on performance improvement heavily relies on managers to have a set of interpersonal interactions within their work settings to enable and support work change.

\subsection{Final themes}

The earlier TA process (phases 2 to 4 ) consisted of categorising the narratives in order to identify categories that can define key meanings. The process allowed a transparent pathway from the narratives to the development of the initial 12 themes. The initial themes were the primary view of the experience of using performance information and thus represent a voice 
of the participants. I did not re-process these initial themes through to the later phase of TA to develop final themes as an intellectual exercise to demonstrate researcher prowess, but this was undertaken to strengthen the a worldview of representation of the participants' narratives as reflecting their use of the performance information. These final themes can now be used to discuss aspects of the manager's performance related behaviour and to describe their responses to the use of efficiency performance information.

Table 4.5 summarises the TA progression from the collected narratives to the development of the final themes as the outcome of the TA process.

Table 4.5: Outcome of TA

\begin{tabular}{|l|l|l|}
\hline Narratives & A total of 198 narrative scripts \\
\hline Code labels & & 49 code labels were identified \\
\hline Code clusters & & 26 code clusters \\
\hline Grouping of clusters & & 6 groupings \\
\hline Initial themes & & 12 initial themes \\
\hline Final themes & 4 & 4 final themes \\
\hline
\end{tabular}

The four final themes represent broader and more general ideas in relation to management behaviour response to the use of information. The TA process that was applied to the narrative and subsequent code labels led to the development and identification of four key themes. As themes, they conceptualise the researcher-constructed interpretative analysis of management behavioural responses (in the case study) in relation to the organisational context of performance information and improvement. These themes are directly based on the evidence in the narrative data and are viewed as essential in determining an understanding of the experiences of all of the participants in their use of efficiency information. 
Table 4.6 shows each of the four final themes in context to the research question of most relevance. I judged the relevant placement on the basis of the best fit of each final theme to each research question to provide significant narrative that would then enable a greater understanding of the role of information in managerial behaviour within organisations.

Table 4.6: Final Themes and research questions

\begin{tabular}{|l|l|}
\hline Research questions & Final Theme \\
\hline $\begin{array}{l}\text { \#1.To what extent do managers utilise specific } \\
\text { pieces of information that are made available to } \\
\text { them within the context of their routine reporting } \\
\text { and performance environment? }\end{array}$ & Direct leadership \\
\hline $\begin{array}{l}\text { \#2.From the information that is provided, what } \\
\text { behaviours and actions do managers take that they } \\
\text { perceive as necessary to improve performance? }\end{array}$ & Operational feedback \\
\hline $\begin{array}{l}\text { \#3.What do managers perceive that they need to } \\
\text { learn in order to improve the management of their } \\
\text { service units? }\end{array}$ & Performance signal \\
\hline $\begin{array}{l}\text { \#4.What factors do managers perceive as impeding } \\
\text { their actions as they seek to improve service } \\
\text { performance? }\end{array}$ & Management development \\
\hline
\end{tabular}

The four final themes have been labelled as 'Direct leadership', 'Operational feedback', 'Performance signal' and 'Management development'. Each of these four themes represents a broad spectrum of participant experience and meaning. It is likely, and expected, that there will be a 'cross-over' of aspects of the experience of managers in their use of efficiency information to improve service performance.

Through judgement and placement as outlined above, each of the four research questions are now able to be connected directly to a thematic viewpoint and a corresponding narrative. The connections were discussed earlier in the Chapter offer direct linkages between the narrative to the development of the thematic meaning and insight from an organisation perspective. The insight will be interpretative and supported by participant narrative. 


\section{Direct leadership}

The key theme of direct leadership is symbolic of the broader organisational culture inherent in hospitals. Based on narratives, the influence on the extent to which managers will use information is from overt involvement of senior leaders with their performance expectations. This is then transparently conveyed to managers, who view the interest as an endorsement and mandate to focus on the information and on its use. This theme relates to the form of leadership on performance from the service managers in their own capacity to undertake improvement actions.

The hospital organization is a systemic network that is both complex and dynamic in nature (Ejimabo, 2014). In such an organization, managerial responses are essential on resource use decisions in achieving efficiency goals alongside other quality and delivery objectives. Participants have experience, and the skills to utilise the knowledge to inform their accomplishment of organizational goals of performance. In this regard managers must also have a high degree of self confidence in order to process information. Where there is intent to act, the information is accepted as the opportunity to perform. In this, the ready acceptance of the performance information and its signals is viewed as direct leadership. In practice, the hospital managers' position their actions to align with policy statements from senior executives. Performance actions by managers are based on their understanding of the senior executive's intent. In doing so, the managers seek to have a mandate for future performance related actions. Managers actively participate in the information response process, to utilise the meetings with their general manager to gauge their direction on performance action over the month.

The case study suggests that managers will seek to gain coherence from the signals they obtain from performance information and to link to their perceptions of senior managers' 
desired action or direction. The impact of the efficiency information on their improved understanding of performance is positive and demonstrable. The narratives show that direct leadership is able to be developed in managers through their use of focused performance information. There is narrative to indicate that these managers are also prepared to be accountable as an expression of leadership, on the basis of developing an understanding of and, involvement with, the performance information. Additionally, these managers show an interest in the performance of their service as well as a focus on improvement. An increasing awareness of performance improvement is evident. It is evident from the narrative the capacity exists to apply a performance focus in relevant local contexts, this becomes part of their understanding of their role as service managers.

\section{Operational feedback}

One of the key overarching insight is that the managers who received regular and steady feedback on their actions (if any were taken) became more willing to increase their dialogue with clinical staffing on efficiency performance matters and be prepared to exert more influence and promote collaborative actions with clinicians. Operationally, at first glance, the feedback appears as top down, but the narratives display a common perspective of inclusion and reach out. This can mean that such operational feedback may be self-generating. The feedback may also be a precursor to self-accountability to perform job responsibilities in alignment with growing sense of ownership, regardless of vested authority. This theme is defined by the managers understanding of their roles in performance improvement and in the use of performance information. In an organizational context, operational feedback relates to the information that is sent within. There is a two way process (individual or a group) about behaviour such as the manager's choice of the mix of inputs so that the manager may learn about the resulting performance and accordingly consider future adjustments to their response of input mix choices. Management actions based on information can be encouraged by 
feedback form the organisation's senior managers. This is evident in the narrative from the participants.

The narrative illustrates the potential negative influence of information. In circumstances where there is information overload or a mix of signals, the response may be to operate in a 'status quo, holding pattern', so as to avoid further management responses. The narrative shows that in the absence of direct feedback with efficiency information, managers will not take action. Managers perceive what is necessary to improve performance, and when there is no information focus (on performance) they view their management actions as focused on the need to manage the business on an 'as usual' basis, to maintain the status quo. However, with experience of the new information and a growing awareness of performance knowledge, managers begin to show certainty on how new knowledge can be used.

Managers, who are unaware of performance signals or uncertain of the intent of the signals, that are to manage performance, may perceive that their continuation of their status quo actions as being adequate and necessary in order to continue to manage the service. This aspect of the operational feedback theme relates closely to the theme of management development, where managers use perceptions of barriers as logic to not respond to information or to take management action to improve service performance.

\section{Performance signal}

Performance signal is an important consideration for the hospital establish as a cultural process of showing managers what it is that they need to learn in order to improve performance. Bear in mind Swellar's cognitive load theory (CLT) that implies learning is best through a sequential process. Knowles (1990) had noted that learning activity tends to be approached in a performance-focused frame of mind. Managers are already pre-occupied with work issues and often will first question the relevance of performance information and 
second, see how it is perceived by the organisation. The notion of learning for managers is through interpretation of data and reports and by subsequently framing their meaning for other staff (Atherton, 2013). This theme references the narrative on the experience of managers who receive new information or different knowledge. This is conveyed in meanings of disbelief or confusion about the new information, and may result in further questioning of the data. Performance signals represent powerful symbols of allowing managers the opportunity to consider their situation and options for change.

There is generally however a view that such performance signals may not be aligned to their personal understanding of organisational goals and expectations. In recognising this inexperience, the theme is defined by the capacity of managers to learn from the information. The learning happens over time, with subsequent monthly information and moving the managers from their initial position of confusion, disbelief and low confidence. The lack of knowledge by managers draws attention to misplaced policy assumptions within organisations on self-learning about the appropriate performance signals.

Moreover the knowledge-gap also shows in a lack of confidence, where performance information is not used. The In this situation as the case study highlights, the more experienced of senior managers, who often have multiple years of service, are still unfamiliar with efficiency information and are unaware of the performance signals that are contained therein. This suggests that there may be difficulties in the managers' learning from their routine performance information. The organisation has a challenge to provide information that is more focussed with an inherent mandate towards performance improvement. Organisations can use performance signals within a learning paradigm. 


\section{Management development}

This theme refers to the organisational hierarchy's role in the manager's use of information. Corporate support is viewed as step towards overcoming resistance and detachment from information or performance improvement. Where an organisation does not clearly and explicitly articulate its desired performance focus (with relevant information), the common managerial behavioural response is to not engage in performance improvement activity. This is supported by the theory of planned behaviour (Penz and Stottinger, 2005; Ajzen 1991) that perceived behavioural norm and attitude determines intention and actual behaviour. Moynihan and Landuyt's (2009) view can be extended to view performance information as supporting elements of organisational learning. Managers need to learn or acquire skill in knowing how to use the efficiency information. Managers within organisations perceive there to be several barriers to the management of performance improvement. Resistance to new information is also evident in the narrative. From the early introduction of the new information the narratives display, in the managers a sense of detachment from the information or of indifference to the performance need. Their narrative conveys meanings of challenge to the information. In the routine use of performance reports, there is indifference to the information and on any performance need. The key barriers to the use of information to improve performance cover behavioural responses such as confusion, detachment and resistance. They provide some understanding of the complex nature of service managers' role that is coupled with from information that they are exposed to, and the resistance to its use highlight the key barriers to managers using efficiency to improve performance.

\subsection{Conclusion}

This chapter presented the TA and its results of participants' narratives of their use of efficiency information to improve hospital service performance. The TA process involved a series of research phases and steps that formalised the analysis of qualitative data. Through 
this process, it was possible to explicitly identify the generation of themes from the data and to uncover specific meanings in relation to the use of efficiency information for the participants. The themes and meanings that were uncovered centre on the organisation's management aspects as these relate to the manager's work context. The 12 initial themes (from TA phase 2 to 4 ) have now refined into four final themes (from TA phase 5), which satisfy Thomas's (2006) criteria for an appropriate number of key themes of managerial behaviour. The themes were data driven and inductively extracted from the narratives (after coding, and clustering). This provides the contextual reality of the inductive analytical approach that was taken in a semantic way to reflect the explicit content of the data, to report on an assumed reality evident by narrative.

The four final themes of the managers' experience of using efficiency performance information are generalised from the participant population and are context bound (Patton, 1990). The four themes cover both the roles of the manager and of the organisation. The themes will provide a holistic view on the managers' experience and some understanding of their behaviours and actions. Each of these four themes represents a spectrum of broad participant experience and meaning. In the next chapter the discussion moves to the participants' experience in using information as reflected by their own narratives (Chapter 5). 


\section{Chapter 5}

\section{Narratives of Experience}

\subsection{Introduction}

The interpretative nature of the study means the subjective and exploratory view of the use of efficiency information is a way of understanding the social reality of the managers in a real work context (Schwandt, 2001). Here the focus is the narratives of the two groups of participants over the six month observation. Patton (2002) observed that participants' reflections conveyed in their own words would strengthen the validity and preserve the subjectivity of the interpretation (by the researcher) of the participants under study. The phenomenological rigour of the interpretation is further strengthened with the opportunity given to participants to review what was transcribed. The opportunity to review and amend the transcripts was to ensure the participants' comfort with the transcripts and their publication in this thesis.

Ethical considerations are of paramount importance in the presentation of data from such interpretative research, As outlined in Chapter Three, at the start of the research all participants were informed that the data obtained that would be from them may be used in the thesis and thus possibly available for a wider readership ${ }^{3}$. A further step taken here is to anonymise the data used by not directly identifying the participant or their service in any of the narrative that is referenced in this discussion and in the thesis.

The use of information lead to better outcomes for service efficiency improvement and for stronger perceptions held by managers for having control over the service, which contrasted to those of the R group. The narratives capture the different experiences of both groups of managers who were subject to the same monthly reminder of efficiency information. For both

\footnotetext{
${ }^{3}$ I did advise that it was my intention to seek restricted readership to VUW approved researchers only.
} 
groups, each month's three interviews would have reminded the participant to consider the efficiency performance of their services. The more positive change in the participants' use of the efficiency related information may be explained by their experience with the MRE because both groups were already receiving the routine performance information. While the sample size is too small for any definitive statement on the content of the MRE for the difference in outcome, the narratives show that the specific focus on the efficiency of the service does contribute to the use of the information. It is accepted that all other environmental factors were similar to the two groups. Therefore, it is possible that the experience of receiving specific information may be captured in the participant narratives. In this way, using the social reality as a framework, efficiency information is initially operating at the Empirical level of the individual manager and is in-context to the individual experience. In using the efficiency information, the managers will first connect across from their own empirical reality to the broader Actual realities. Following this and on the basis of this extension, a second connection is made to the use of efficiency information to the Real reality where there are critical considerations of the broader key rules and tendencies of the global organisation in developing performance improvement. Following the principles of pragmatism, there is an ongoing iterative back and for between the three realities.

Section 5.2 outlines the arrangement of the participants' narrative data to show a changing perspective on the use of information. The purpose of the qualitative analysis of the transcripts is to search for differences and similarities between the two participant groups. Each of Sections 5.3 to 5. 6 reference the narrative to one of the four research questions. Then, Section 5.7 presents the conclusions on the Chapter. 


\subsection{Participant Narratives}

During each interview, participants were asked a set of questions that covered each of the four research questions (Table 3.4). This formed the framework for the narrative to be collected on the level and nature of the use of efficiency information. Both participant groups were asked the same questions - and, for the R group the term 'MRE information' was replaced with 'RRP' (routine reports on performance). Questions one to three of the monthly interview questions were asked first as a way of setting the scene and focussing the participant's attention on the information (MRE or RRP as the case may be). The remaining questions were asked in a random manner. The key interest in the use of efficiency information in the hospital service setting the manager's reflected experience in terms of understanding their response.

Preamble and socialising comments were excluded from the transcript unless these related to one of the four research questions. It is important to note here that the transcripts cover only the responses to the formal questions at participant interviews. The transcripts reflect the 'raw data' being each participant's subjective responses and the initial processing of the data. Further supplementary comments and observational data were recorded in observation notes. These help inform understanding the nature of particular aspects of the experience of the use of efficiency information. To illustrate: a participant's attitude change, detected by a different response to their past responses, would mean further interrogatory questions to elicit if the participant were aware of the change and the reasons for the change. Each participant's past responses were taken to each interview - and referred to as necessary for key questions on what management action or response was intended and what actually was undertaken. For the purpose of presenting the narratives for the following Sections 5.3 to 5.7, the following taxonomy is used: In each of the Sections, the Participant Number (P1 to P11) and Group (E or R) are first listed and underlined. A summary comment may be placed here to reflect the overall change in the participant's experience in relation to the particular research 
question. Where appropriate, the month of the case study when the narrative was obtained may be indicated in parenthesis. This is then followed by the particular narrative texts in italics. For the R group participants, their responses were similar with almost all displaying a focus on their monthly variance analysis and short-term reporting of variances. Their responses suggest a strong acceptance of their management of the status quo. Therefore, for the $\mathrm{R}$ group narratives, only a representative sample will be presented in the following Sections below.

\subsection{Using the efficiency information}

As senior managers within a large hospital the participants are familiar with regular monthly management reports on KPIs, where they have to report on the performance of their service to their general managers and to DHB executives. Both participant groups begin with a similar narrative in responding to the use of efficiency information. In the first months, using the routine reports, and for both participant groups, the narrative focussed on short term budget control and pressure to report on KPI variances.

\section{$\underline{\text { P1, E group }}$}

It is going to be difficult to use because I already get performance reports that my GM wants me to review and provide her with reports.

\section{$\underline{\text { P2, E group }}$}

My GM wants me to stay within budget, and to report on clinical delivery targets.

\section{$\underline{\text { P8, R group }}$}

From these reports [routine performance and variance reports] I focus on what my GM wants me to explain and prepare a management report.

Other participants have similar narrative over the initial months. 
Additional narrative from the $\mathrm{R}$ group commented on the lack of any organisational requirement for them to focus on efficiency improvement. The narrative indicated that there is no focus on efficiency because the participants assume that this is already an implicit measure of performance within the routine set of performance information (RRP). This seems to lead the participants into presuming that there is no necessity to have a focus on service efficiency.

\section{$\underline{\text { P11, R group }}$}

I don't have a focus on efficiency for my service, or need to.

For the $\mathrm{R}$ group, the narrative remains constant over the remaining months of the study period and is dominated by a focus on the reporting of routine KPI and analysis reports, as a way of meeting senior leadership demands. The adjunct response of not having to focus on efficiency did not occur amongst the E group, presumably because the MRE presented an immediate highlight on efficiency as a performance outcome. This is illustrated by an E group participant who commented on their intention to use the efficiency improvement signal to directly reduce their budgeted staff costs.

\section{$\underline{\text { P3, E group }}$}

I will look to reducing my staffing costs so will use less FTEs.

\section{$\underline{\text { P5, E group }}$}

The concept [MRE efficiency] sounds reasonable and seems better than the other reports on our performance.

Nonetheless, E group participant also expressed initial reservations about the efficiency information.

$\underline{\text { P7, E group }}$

The one page report is short and summary so I am not sure it has enough detail. 
Ove the remaining case study period, the narrative of the E group begin to show an acceptance of the MRE. The participants' narratives show a growing willingness to reference the efficiency information to staff and a deeper understanding of the drivers of efficiency within the service as an entity.

Participants in the E group become positive in viewing the efficiency information from the second month gaining confidence after viewing two MREs. In showing the result in efficiency improvement caused by the earlier action taken participants appears to be a positive reinforcement. Individual managers have different experiences and perspectives on using the efficiency information, as shown in their respective narratives in relation to the using of the efficiency information is presented below.

$\underline{\text { P1, E group - willingness to embrace the new performance signals }}$

(Month 1) I want to see what else I can do that will improve my efficiency even more.

(Month 3) The report has some merits in providing a composed view of actual performance on efficiency which is a goal for me.

(Month 4) As I mentioned, it is easy to read the efficiency information but I don't know how easy it will be to convince the docs and nurses we can improve efficiency if we change the mix of staff.

(Month 5) The report is very useful in helping me and my team view actual efficiency performance.

(Month 6) The information is useful to talk with my Clinical Director about changes. The participant discussed how she gained confidence in the MRE by its regularity and its transparency of what they called the cause and effect feedback of the management action taken in the previous month.

$\underline{\mathrm{P} 2, \mathrm{E} \text { group -initial reluctance to accept the performance signal }}$

(Month 2) The report is easy to read but what do you expect me to do now? 
(Month 3) The information is useful, I think. But I am not sure how we can change things. I cannot raise this with my CD (Clinical Director) yet.

(Month 4) The report is good in being a yardstick of actual performance on efficiency which I can share with staff.

(Month 5) I need to engage all relevant senior staff and also the allied heads, to talk about this.

(Month 6) The information is useful and interesting in reminding me about being an efficient service.

The participant moved quickly to an acceptance of the efficiency information with initial mixed reactions expressed in the early months.

$\underline{\text { P3, E group - early acceptance of the new performance signal on efficiency }}$

(Month 2) I have read the targets and will continue with the staff discussions on the service review and also keep the mix of the nursing and registrar levels.

(Month 3) This is good information. To improve I need to reduce my doctor and nursing numbers, but this will be a big shock.

(Month 4) The report is good which I can share with staff. I know it shows that because in the past month I deliberately kept up my staffing level, we dropped in the efficiency score.

(Month 5) I have thought about getting all relevant senior staff to agree on further changes to our resource use.

(Month 6) I should just try to maintain the resource levels at current state and ensure that treatment outputs are ok as well.

The narrative shows that this participant has developed a deeper understanding of the notion of efficiency and how its drivers can be managed from within the service.

$\underline{\text { P4, E group - early acceptance and sharing of the efficiency information }}$ 
(Month 2) The information seems useful and interesting in initiating discussions anyway. In the MRE, the targets mean that I should amend the service mix of nursing and medical registrar levels.

(Month 3) To improve I need to continue with the better resource use over the month and also look to reduce clinical numbers a little.

(Month 4) I can share this with staff and this can serve as discussion on improvement opportunities.

(Month 5) I need to continue with the shifts in resource use at the inputs stage.

(Month 6) The information is very useful and I can track the impact of management decisions on staffing and resource use.

The participant shows an early understanding of the new information and the collegial approach that need to be taken to ensure appropriate management changes can occur.

$\underline{\text { P5, E group - positive accepted the efficiency information (in the first month) }}$

(Month1) The information is useful.

(Month 2) The MRE suggests targets in nursing and medical levels.

(Month 3) The MRE is a very useful document to have with me and serves as a reference on performance in staff discussions.

(Month 4) Yes, maybe I should aim for a staffing ratio that shifts the mix of staffing.

(Month 5) Ineed to reduce the resource use of the inputs.

(Month 6) I will continue to make adjustments to the resource mix changes.

$\underline{\text { P6, E group - has an initial cautious view of using the efficiency information }}$

(Month 2) The MRE suggests targets in nursing and medical levels, but I probably won't do anything just yet. I am not convinced yet! 
(Month 3) The MRE is a very useful reference on the performance of my service's efficient use of resources.

(Month 4) The report identifies some targets for my service in order to get improved efficiency.

(Month 5) I need to continue to reduce the resource use burden.

(Month 6) The information is very useful in presenting a clear picture of our service performance.

From an initial cautious view the participant appears to have quickly developed an understanding of the value of the efficiency information.

$\underline{\text { P7, E group - a positive view of using the efficiency information }}$

(Month 2) The MRE suggests targets in nursing levels.

(Month 3) The MRE is very useful in staff discussions.

(Month 4) The report has target staffing levels for my service in order to improve efficiency.

(Month 5) The report is a good measure of the overall actual performance.

(Month 6) I will continue to make adjustments to the resource mix. I would just carry on as usual. I would not do anything specific but just carry on managing as usual.

This participant is confident in the use of the information to monitor their service efficiency, being able to understand its drivers.

\section{$\underline{\text { Rgroup }}$}

The focus is the delivery of my service targets and KPIs.

I don't normally have a specific focus on efficiency.

I don't know what to do about efficiency. 
It is not what we have (that is there is no specific measure of efficiency that is reported and hence it is not a requirement for performance) in our reporting, as long as I achieve my budget and delivery targets.

The new information on efficiency is reflected in the narrative as showing an impact on the participants. The E group participants accepted and used the specific performance information within their organisational context. These participants gained a deeper understanding of the drivers for an efficient service and thus a willingness to initiate dialogue with senior clinicians on efficiency matters (Ackoff, 1998; and Belinger et al, 2004). If we accept that participants can gain deeper understandings of efficiency then this supports the suggestion that managers will use specific pieces of information that are made clear to them within the context of their routine reporting and performance environment. The gain in confidence from initial management action and the transparency of the result provided momentum for on-going and more collaborative interactions with other key stakeholders. In contrast, the narrative from the $\mathrm{R}$ group strongly points to a short term imperative that is focussed on reporting on KPIs and variances, and this dominates the consideration of long term collaborative actions. The routine KPIs and variance reports do not provide clear signals on the efficiency of the service.

\subsection{Actions in response to efficiency information}

The focus here is on managerial processes and behaviour that are informed by MRE (DEA information) or RRP (budget variances, P\&Ls, Balance sheets, KPI factors and ratios). The overall narrative of the E group begins to change to a more positive and more collegial approach being taken to actions in response to the efficiency information. The participants discuss possible service change or resource use in order to improve performance. The E group in contrast to the $\mathrm{R}$ group also show a willingness to facilitate strategic objectives and to 
communicate with clinical colleagues on change. The $\mathrm{R}$ group of participants were focused generally on responding to KPI variances

\section{$\underline{\text { P1, E group - initial caution in communicating with staff }}$}

(Month1) I think I would look at doing a review of the weekly staffing roster and change it around so I can get a cheaper mix of clinical staff.

I do not want to interact with my doctors and staff because the discussions will go all over the place.

(Month 2) I will reallocate the staffing mix around. I will show CD the MRE and talk to him about it.

(Month 3) I will redevelop a service mix plan that changes the staffing roles as well as service times for some of the outputs. At the heads meeting, I will definitely discuss the report and how we can further improve on our efficiency score.

(Month 4) I think we can be more efficient. We should be at 100\% so I will need to take a hard look at how I am using staffing and the mix of capacity.

(Month 5) I am looking at changing the ward structure of one of my wards to have more patient mix and so staff can be reduced with on calls.

(Month 6) I want to cement in the changed resource staffing mix that will lead to higher efficiency. I will be continuing to share the MRE with staff and my GM and maybe with the other service managers.

The participant revealed she had shared the MRE with the service's senior clinicians and discussed the performance signal and their collective need to achieve a higher efficiency rate. The participant advised that they had gained considerable confidence in the information performance signal because the clinicians had accepted the information.

\section{$\underline{\text { P2, E group }}$}


(Month 1) I would look to change the overall performance of the staffing roster and mix of clinical staff. This information will be good to spark discussion with staff and my GM to agree on what we can do.

(Month 2) I don't think I will now. I mean I know that we should change the staffing mix around but this will create a lot of noise and angst.

(Month 3) I will carry on as before. So it means I won't do anything specific to improve efficiency. I will discuss the ER (the term ER - 'efficiency report' is used by this Participant to refer to the MRE) with staff if we get time and the mood is right.

(Month 4) I want to change the nursing mix around to improve on input mix and expenditure.

(Month 5) I I am going to push for a bigger shift in medical to nursing cover over the week wards.

(Month 6) I now discuss the MRE with staff and CD to review any likely improvement possibilities.

The participant showed a positive response to putting into effect resource change initially, which was reversed because of hostile reaction from staff. A more cautious approach was then followed.

\section{$\underline{\text { P3, E group }}$}

(Month 1) I will change the overall staffing roster and mix of clinical staff. I will share this MRE to initiate discussions with staff and my GM and to focus on efficiency as optimising our use of inputs and outputs.

(Month 2) I will carry on improving the efficiency by changing the staff roster mix.

(Month 3) I will allow a slight increase in staffing to cope with the on-ward education programme over the next two weeks. I will discuss the MRE with staff.

(Month 4) I want to reduce the senior nursing mix. 
(Month 5) I will shift lower grade nurses in place of specialised nurse cover as well as limit the registrar call-cover for the wards over the next few weeks.

(Month 6) Similar to last month, nothing too drastic!

The participant was willing to communicating with colleagues on a course of action. In later months more specific actions were discussed and taken on managing efficiency.

\section{$\underline{\text { P4, E group }}$}

(Month 1) I want to understand fully first the MRE means before I decide what it is I need to do although I believe we will need to look at the overall roster mix of clinical staff will change the overall staffing roster and mix of clinical staff.

(Month 2) I will try changing the staff mix.

(Month 3) I will keep changing the staff mix.

(Month 4) I will look at the nursing mix to use lower cost FTEs more.

(Month 5) I will do what I did last month.

(Month 6) Similar to last month, but with more FTEs.

The participant began with a clear focus on using the information and began in later months to consider and discuss various resource use changes that could be managed differently in order to improve efficiency.

\section{$\underline{\text { P5, E group }}$}

(Month 1) I want to look at the overall roster mix of clinical staff and also my administration staff.

(Month 2) I will change slightly the staff mix, by decreasing the hours required.

(Month 3) I will continue to change the staffing mix.

(Month 4) I will look at using lower cost FTEs more.

(Month 5) I will carry on as last month, and also align clinician load. 
(Month 6) Similar to last month.

The participant continued to use the new information and also to undertake management decisions on the mix of available resources for the service in order to improve efficiency.

\section{$\underline{\text { P6, E group }}$}

(Month 1) I have no real idea.

(Month 2) I don't intend to do anything in light of the MRE.

(Month 3) I will continue with my normal pattern.

(Month 4) I will look at using staffing ratios referred to in the report and also realigning consultant use to increase treatment output. I held some meetings with staff and we agreed on using one ward cover to support the other ward.

(Month 5) I will carry on as last month, and also align service delivery.

(Month 6) Similar to last month. I like the MRE. It gives me a context for whole performance and I can discuss this with my clinicians.

By the second month, the participant clearly indicated they would not undertake any specific action. In the fourth month, the participant indicates for the first time, some action towards managing efficiency and in the fifth month a further action to manage efficiency was also indicated showing greater confidence in themselves and the information.

$\underline{\text { P7, E group }}$

(Month 1) Nothing specific at this point in time.

(Month 2) I will amend the nursing roster for the weekly ward coverage.

(Month 3) I will talking to my CD about the way we arrange staff to clinic sessions.

(Month 4) I will look at adjusting towards the target staffing ratios referred to in the report.

(Month 5) I will align resources to service delivery. 
(Month 6) I will consider reduced staffing.

The participant indicates on-going action towards managing efficiency and a willingness to discuss the efficiency of the services with clinical colleagues. In further months, the participant begins to consider resource management options.

\section{$\underline{\text { R group }}$}

All actions are in relation to reporting on the KPIs and analysis. Thus, in terms of actions in response to efficiency information, a single representative narrative continued over the study period and was consistent across the group.

I will look at the reasons for any variance.

During the process of monthly meetings and discussions on the MRE efficiency information, the E group participants appeared to amend their management practice to consider the new data. This change was however, variable amongst the participants (possibly due to individual manager characteristics, which were outside the scope of this study). These participants were able to able to use the new information to reflect on the efficiency goal and actions that had to be taken. Initially, my discussions with participants dealt with the issue of the complexity of implementing any actions. However, over the six months, there were increasing dialogue and confidence in the efficiency information, leading to a greater awareness of the performance situation and the canvassing of management action. In the first month, a common narrative was evident across all participants in both groups: taking a short term view to decipher and respond to major variances within their routine KPI and variance analysis reports. Two of the E group understood and accepted the performance signal in the MRE, and revealed their actions to make resource changes so as to improve their service efficiency. The other five participants of the E group showed a preference to first think through the implications of the 
information and initially indicated benign management action - to conduct reviews of their on-going resource use.

\section{$5.5 \quad$ Learning need}

As senior managers within a large hospital, the participants already have well defined and successful careers. Each of the participants was confident and had a general belief in their own managerial capabilities and skill levels. This confidence was manifest in the early part of the study where the early narratives for both groups reveal that these participants do not consider themselves in need of any further learning for improving the management of their service. This view was held despite the participants not being able to clearly define efficiency or articulate how performance improvement could occur. The narrative however that emerges suggests both groups of participants carry an overwhelming anxiety of being near their senior leadership but without actually being engaged with them. A composite 'text' is as follows: I don't know what the GM is thinking; she seems to her attention always focussed upwards. My GM tends to do whatever SLT decide and then my job is to provide her with reports.

Each of the participants' key narrative in relation to their perceived learning need for improving management is presented below.

\section{$\underline{\text { P1, E group }}$}

(Month 1) I don't think I have any learning need right now. What do you expect me to do with this information?

(Month 2) How do other organisations manage for efficiency? I just manage the service and staff and not had the time to research or study modern techniques.

(Month 3) I need to talk to the business consultants for their help in analysing the information. 
9Month 4) I don't have anything new apart from what I previously told you.

(Month 5) I would like to know how such analysis is done but that is not my role.

(Month 6) I want to be able to a university course to get some expertise in performance analysis and management.

The participant initially noted they had need for no learning in order to improve efficiency. This perception gradually changed to reveal their concern about their lack of knowledge in light of the efficiency information. The participant acknowledged the learning need and attributed this to the busy work routine and the lack of expert help. The participant felt it appropriate to seek the expertise herself through a university course.

\section{$\underline{\text { P2, E group }}$}

(Month 1) I I am quite busy and also I have lots of experience here so I know what needs to be managed.

(Month 2) I I just get on what I need to do.

(Month 3) I don't really need any training as such but would like to have the chance to meet and talk with best practice managers who are from similar environments.

(Month 4) For me, I have realised that I should know where and what the good management practises are and how to apply these here.

(Month 5) I I want to learn more about implementation techniques.

(Month 6) I really feel like I have a lot to learn yet.

From an initial view that there was no learning need, the participant began to realise that in light of the efficiency information, they had a training requirement.

\section{$\underline{\text { P3, E group }}$}


(Month 1) There is nothing! I have been in my role now for six years and previously I was a charge nurse, but I have not been able to get approval to attend any financial or management training outside of the ADHB. Usually I am told that the fees are too high and also that I am needed to be here to manage my service which is critical for the organisation's performance.

(Month 2) I want to improve and move up higher so I need just get on what I need to do.

(Month 3) I need to learn and understand better what efficiency is so that I can communicate with others and lead them on the same path.

(Month 4) Last month I told you and I think it is still the same I have tried to use the data as a black box but because I work with highly educated folk they all want to know the details. (Month 5) There are lots I want to learn, about leadership, management strategy and performance improvement methods.

(Month 6) I can't think of anything else.

The participant initially noted there was nothing for her to learn and that she had been impeded by her general manager to progress her management learning. Over the next months, the participant began to change her stance and indicated a learning need in relation to the efficiency information.

P4, E group:

(Month 1) I Ion't have any university qualifications and so I want to do some graduate level study to gain performance improvement methods.

(Month 2) I get so busy here that there is no time to do any part-time study and I know my GM would not let me anyway.

(Month 3) Maybe if I can spend some time with someone who can teach me on DEA then I will be better placed to discuss these matters with others.

(Month 4) I looked at some university courses but for them I need pre-qualification and it will take too long at my age! 
(Month 5) I have told you what learning I need in the past and it is still the same I feel.

(Month 6) I am looking at enrolling for a diploma. I can't think of anything else.

The participant noted she was inhibited in undertaking any business improvement processes because there were so many techniques and methods available and she would like to learn some key techniques. For a period in the case study the participant used a perceived barrier to legitimise her lack of learning. This stance was amended during the ongoing discussions on the efficiency information to the participant beginning to actively search for training.

\section{$\underline{\text { P5, E group }}$}

(Month 1) Ifeel like I know how to manage but what gets me is the lack of information that accompanies any management direction I get from the top.

(Month 2) I I Im busy and I find that often when I discuss issues with my clinicians they seem to know more about it than I.

(Month 3 to Month 6) - In these subsequent four months, the participant repeated her previously stated need in relation to the efficiency information. The participant expressed considerable frustration at not being supported in her learning and development needs. She felt the GM was deliberately stalling on any approvals, and always counter-commanded training request with service duty obligations. The participant advised that she was aware of the learning she needs to get more knowledgeable on improvement methodologies and change management.

\section{$\underline{\text { P6, E group }}$}

(Month 1) I have good clinical knowledge and experience and what I need is greater understanding on management and planning strategy.

(Month 2) I want to improve as I said to you last month but I don't believe my GM or SLT actually will support me because I may want to move up 
(Month 3) I have told you what I need and I have discussed this with my GM but she says we are too busy.

(Month 4) I think it is still the same I need understanding on management and planning strategy.

(Month 5) There is nothing new, I told you in past months.

(Month 6) I can't think of anything else.

The participant also added a concern about the organisation not being supportive of her need.

\section{$\underline{\text { P7, E group }}$}

(Month 1) I want to develop my management skills further but there is no way I can do it here. My GM already stops me from attending any conference or training I want to go on the grounds that there are no training monies left and also I am critical to the service.

(Month 2) The last time I went to a course, I took annual leave and paid for it myself. I told my GM I had done that and she just sat there.

(Month 3) We don't have management training in this organisation nor is there any real succession planning. Although my GM goes through the performance review and training need assessment with me, we both know nothing will happen as a result.

(Month 4) I think it is just frustrating being here sometimes.

(Month 5) We have discussed this over the past four months.

(Month 6) I still have the same needs.

Over the first months, the participant noted that while they needed to learn more, they believed the organisation was not willing to support them.

\section{$\underline{\text { R group }}$}

These participants were not asked for their perception of their learning needs in relation improved management because this question was aimed at the additional new report to 
consider on top of the routine reporting. However several of these participants voiced some anxiety that was evident in their narrative.

I don't know what my GM knows but she is not helpful at all. She just does SLT's [ADHB's senior leadership team] bidding.

The E group had a similar narrative in the initial months. Over time, the narrative of not having adequate support began to change with E participants becoming more open to admitting 'not knowing' and so identifying their learning need. Based on supplementary observation data, one E group participant revealed that after four months, she had sufficient confidence in being to discuss her personal learning needs with their GM (General Manager to whom the participant reports to). Another participant identified that her on-going development as a manager was being stifled by the organisation and she resolved to seek an external corporate position.

\subsection{Barriers to performance improvement}

The narratives shed light on the participants' perceived barriers to performance improvement actions. The barriers tend to centre on their view of the surrounding world. Both E and R groups have the same tendency towards blaming senior leadership for inhibiting participants from taking performance improving management actions. This is the case during the initial months, with both participant groups expressing a similar perception, that they as managers are prevented from performance-improving actions by senior leadership. For the E group, this view begins to change over time to a more positive approach being taken, that as managers they are able to influence senior leadership and control their work situation. This can be seen in their changing narratives, below.

$\underline{\text { P1, E group }}$ 
(Month 1) My GM is the main problem I have, I think. She is so conscious of keeping corporate sweet and therefore wants me to maintain a relationship that keeps the clinicians happy, at all costs. All she focuses on is meeting targets that she has to report on.

(Month 2) We have a lot of protocols and policies to work through if I want to change anything.

(Month 3) The key constraint is the need to engage with staff and consult with all stakeholders including clinical unions.

(Month 4) I suspect I need to provide the focus for a more efficient service. I think being able to talk through the efficiency issues with my GM first and then develop an action plan helps.

(Month 5) The time factor is quite difficult to get around as there are many other priorities but I think the overall bottleneck is just me getting ideas through.

(Month 6) I am not sure if I would say there are obstacles.

The participant has a strong view that they are prevented from having a more efficient service by their GM's lack of focus and organisation's policies. This perception however changes over time to eventually the participant taking a view that there were no barriers to performance improvement.

$\underline{\text { P2, E group }}$

(Month 1) My GM is entirely focussed on top line reporting and ensuring that we have an explanation available for any variance or bad result.

(Month 2) My GM does not want me to upset my CD so she quickly shuts down any service improvement idea I bring to the table.

(Month 3) We need to consult with all staff and this takes time and a lot of effort and process. 
(Month 4) My GM and CE [here the Participant refers to the Chief Executive who had taken a personal interest in the service] still want to simply have reports that explain my results and variances with action plans that involve lots of meetings.

(Month 5) Doing a business case for any change requires a lot of effort and resources which I don't have.

(Month 6) It gets too much at times to think about performance improvement.

The participant had begun to realise that because of the prevailing organisational culture (which they explained as, 'appeasing the senior clinicians, where possible'), they would need to engage and get the clinicians on-board for any improvement action to succeed. The participant confided that she had to 'play the game' but was intending to also continue to progress ideas on improvement by taking small level actions. She did concede that this meant she was prepared to be opportunistic.

\section{$\underline{\text { P3, E group }}$}

(Month 1) The organisation as a whole is just focussed on maintaining the status quo. I am usually kept busy with information requests and reports to the top.

(Month 2) My GM is worried that this will lead to problems with the clinicians so I had to talk to her with my CD who was supportive.

(Month 3) The time taken to consult with all staff takes a lot of effort and so I rarely pursue an idea unless I get my CD on board first.

(Month 4) We still have no focus, except on our budget expenditure, so I normally will work through my idea for change - as I am going to switch clinical mix to improve efficiency - with the CD first then with the GM and ND and finally with staff.

(Month 5) As I said before my GM is an obstruction and requires effort to shift her away from her normal no change attitude. We get noise from the top to follow process that protects the strong employment collectives.

(Month 6) I am more confident now of being able to manage my service's performance. 
The participant is able to change her perception of the initial view of organisational barriers and strengthened their view of taking responsibility:

\section{$\underline{\text { P4, E group) }}$}

In the first and second months the participant had a similar view of the impediments to performance improvement as she noted:

(Month 1 and 2) The organisation is just madly focussed on reporting as positive as possible to MOH and our Board.

(Month 3) The same senior management pressures and their need for reports and action plans take up considerable time so there is no time to sit, think and plan.

(Month 4 and 5) $\quad$ My GM is a real hurdle and getting her to even consider ideas seriously is a real challenge.

(Month 6) Nothing has changed.

The participant believes that their organisation presents barriers to change/

\section{$\underline{\text { P5, E group }}$}

(Month 1 and 2) There is a hiatus in senior executive level because they are dealing all the time with external demand that they forget us managers actually understand our services very well.

(Month 3 and 4) The employment arrangements make dealing with staff quite a complex process if I want any major change.

(Month 5) Nothing has changed.

(Month 6) Same as before.

\section{$\underline{\text { P6, E group }}$}

(Month 1) Senior leadership is quite weak and politically driven such that their entire focus is on key external stakeholders. 
(Month 3) I don't have enough time. But, I know that I have to make time to "dance" through the hoops to get the changes that I want. I am ok with this. I see massive benefits in improvement.

(Month 5 and 6) It is the same as before. Nothing has changed there.

$\underline{\text { P7, E group }}$

For the first four months, the participant reflected on a similar barrier and noted:

(Month 1 to 4) The employment contracts with clinical staff means to consult on any proposed change takes a lot of time. I have a complex process to go through.

(Month 5 and 6) Nothing really has changed to make it easier but I know I will to need to push through with any change I want to make.

Following discussions in the early months, on her stance, the participant realised that they had to change their defensive approach. They attributed the change to be able to view the MRE each month and knowing what needs to improve finally allowed them to accept the need to act.

$\underline{\text { P8, R group }}$

(Month 1) The existing employment contracts and agreed models of care require considerable effort in looking at service change or improvement. A

(Month 2) The lack of executive support.

(Month 3) We get too busy fighting fires, attending meetings and report writing to do anything else.

(Month 3) The lack of support from senior management makes it difficult for us.

(Month 4) I have mentioned the various barriers before.

(Month 5 and 6) Nothing has changed.

$\underline{\text { P9, R group }}$

(Month 1) The senior executive team controls everything and we don't really get to initiate anything of our own. 
(Month 2) We all get too busy with routine management issues.

(Month 3) You know, we are not given any relevant data or tools or authority to think and act for ourselves.

(Months 4 to 6) We are still with the same leadership expectations of not rocking the boat.

\section{$\underline{\text { P10, R group }}$}

(Month 1) Working within the constraints and rules does dampen my efforts to think about creative ways of delivering the service.

(Months 2 to 6) It is the same situation as in previous months.

The participant referred to her initial perception of the barriers on improving performance in each of the following months.

\section{$\underline{\text { P11, R group }}$}

(Month 1) We are pretty constrained working within this organisation and the rules on how we are to deliver the service.

(Months 2 to 6) It is the same response I gave last month.

The participant continually refers to their initial perception of the barriers on improving performance.

On a cross-case basis, the barriers are the requirement to monitor and report on the routine KPI and variance analysis. These reporting requirements tend to dissociate managers from the efficiency information signals for their service. The new efficiency information requires a shift in the managers' problem-centred frame of mind to a long term broader situation. The narratives suggest that the participant managers hold a strong view that their organisation's leadership does not favour highly performing service managers. Over the six months 
however, the narrative about these barriers tend to dissipate for the E participant group, to taking personal responsibility.

\subsection{Conclusion}

The narratives identified in this chapter provide a context-bound portrayal of the participants' experiences in their use of the available efficiency information. The experience is illustrative of the complex and multifaceted work setting of hospital service managers. There is selfreflection on service performance at a higher rate than for those participants who continue to receive their routine information. The self-reflection enables past practice ('ritualised habits') to change to lead to performance improvement. The narratives suggest it is the accessibility ('easy to read') of the information that appears to facilitate the process of acceptance and use.

The narrative suggests that the managers are slow to admit to a need for learning. The short term imperative of 'running the service' and report writing, and responding to GM queries provide a status quo and task orientated role that is less risky than seeking performance improvement - where it becomes easier to not think of learnings that may be required to improve management. In all participants, there was also 'blame' attributed to senior leadership for a lack of support or for stifling the ambition of participants. This narrative changed for the participants who received the additional and more specific management information on efficiency. All participants had the three monthly meetings on their performance reports and thus had a continual reminder on managing performance. The presentation of the specific information on efficiency performance to some of the participants provided these participants an opportunity to gain feedback on how their management actions in the previous month affected performance improvement. These participants were able to view their actions within a process of reflection. Participants felt more comfortable in exposing their knowledge deficiency in this context. The specific information on efficiency 
appears to enable the participants to be more open about the possibility of new learning so as to aid them in managing the improvement in service efficiency. The signals being provided in the MRE appear to trigger growing realisation in participants that although the performance signals were clear, it would be in managing the process where they are in most need of learning.

It is telling that at the initial stage of the case study, both participant groups had similar perceptions of the barriers to improving performance, where their narratives were to shift responsibility for performance improvement onto the organisation's hierarchy and to dissociate from the performance signals by focussing on day-to-day matters. The participants' narrative shifts to a reflective viewpoint, where they are reviewing the previous month's management action and considering how performance improvement could be further improved. These participants were then prepared to take responsibility and be accountable for service performance results. However the narratives of participants also show different perceptions can be brought about possibly with different information. As an illustration of the possible impact of the efficiency related information (MRE), the participants who don't receive the MRE continued on with their narrative: of blame and dissociation, that their senior managers and hospital policy were perceived to be the major impediments to improving service level performance. In the next chapter (Chapter 6) managerial behaviour as a result of the use of information is discussed in relation to the management themes. 


\section{Chapter 6}

\section{Connecting Perceptions and Behaviour}

\subsection{Introduction}

This chapter presents a discussion of the participants' perceptions of their understanding of the key issues which relate to the management of hospital service efficiency and the connections to service improvement. The connections are made through the change in management actions that are focused on performance improvement (efficiency management). Management as a social science has a large number of variables and interactions and so is often difficult to discuss in cause and effect terms. This research focus is on information as a lens to examine contextual behaviour.

The thematic analysis process that was applied to the participant narratives transcripts elicited key managerial themes relating to the use performance information. Both the thematic analysis process and the subsequent identification of key themes have been discussed in Chapter 4 . The themes are viewed as necessary in determining the understandings of all the participants. The themes are related to each other because of similar shared experiences of using performance information to improve service efficiency. Experience is the product of interpretation and therefore is always constructed but remains real to the experience and the person having the experience (Willig, 2008). In Chapter 5, the participant narratives were used to illustrate the shift in awareness and behaviour that is possible from their use of different performance information.

Here in this Chapter, the reality of performance improvement to the participants and their use of management information are through an exploration of the meanings that participants attach to their experiences, whilst incorporating the broader role that the hospital organisation (and other societal influences) plays in contributing to shape participants meaning and 
understanding of their work environments. Reference is also made to the key management themes identified in the thematic analysis. The key themes are labelled as 'Direct leadership', 'Operational feedback', 'Performance signal', and 'Management development'. These themes are management focussed and thus can be viewed as corporate as well as manager based. In an exploratory sense reference is made to literature-based insights that were discussed in Chapter 2; such as from:

- Bhaskar's (1989) three realities - when critical self-reflection can move the individual manager towards more holistic and strategic actions on a day to day basis.

- $\quad$ Ajzen and Fishbein's (1980) theory of reasoned action provides for attitudes to change as a result of the information signals and so result in behaviour change.

- Sweller's (2011) critical load theory where precise information can provide undistracted signals that will usefully inform the user.

Accordingly, the rest of this chapter is as follows. Section 6.2 presents the responses of the participants on their use of the information and their perceptions of key efficiency management issues. The focus here is on a cross-participants analysis. For the purpose of specific illustration rather than comparison, I refer to the two groups of participants as 'E group' (those participants who received the additional efficiency information) and the ' $\mathrm{R}$ group' (those participants who continued to receive the routine management information). The referencing of the two participant groups is for the purpose of highlighting their use of particular performance information and not for the purpose of comparability. In Section 6.3, I outline and discuss the change in managers towards a more outward and interactive focus in performance improvement. Section 6.4 discusses the impact of the use of information by the participants on two key measures of efficiency improvement and personal confidence. This discussion is followed by Section 6.5 where changes in managerial behaviour due to the use 
of information are presented. These findings are presented as exploratory supported by qualitative analysis and with comment on perceptions on management and on behaviour. Finally in Section 6.6, some key conclusions are presented with an aim at deciphering public policy in relation to the governance of signalling performance to hospital service managers.

\subsection{Perception scorings}

The participants' data covered here were obtained from completed questionnaires for each month of the six month case study. A response rate of $100 \%$ was achieved, with all participants completing each questionnaire each month. It is worth nothing that as the researcher I facilitated regular one-on-one discussion on efficiency performance matters with each participant (three meetings per month) and there would be a strong element of 'action learning'. At these meetings, there was general discussion on the contents of the management information and the participants' self-reflection and consideration of future action. It is the entire cohort of participants and their experiences that are of key interest in understanding managerial behaviour changes.

The commentary is towards understanding and improving the use of information in hospital management and improvement in service performance. Here, I adopt a phenomenological approach because to understand how the participants experienced the use of information, the experience is viewed from that person's perspective. The start point is however the researcher's reflection of the viewed experience and by explicitly stating and acknowledging this, makes it easier for readers to contextualize the discussion that follows. As suggested in Chapter three, an important feature about this qualitative research is that there is no attempt to generalize the findings to a wider population. The qualitative research process is used to gain insight into the experience of the participants as managers and their behaviour in regard to the use of information and managing performance. 


\section{Ongoing reflection Questionnaire}

As explained in Chapter 3, a way of getting into the experiences of the managers was through an ongoing questionnaire that asked them to respond to a set of 20 questions that covered aspects of efficiency information and performance management. The responses are presented in Table 6.1. The responses of the participants presented on a 10 point scale to indicate complete disagreement or a negative view (score of ' 1 '), to a neutral view, neither agree or disagree ('5'), to complete agreement (' 10 '). In the Table, P1 to P7 refers to those participants who received the specific efficiency related performance information and P8 to P11 refers to those participants who received the routine hospital KPI focused performance information.

The rank order scores identified in Table 6.1 are not meant to infer any statistical accuracy or significance but to aid illustration. The instrument was designed to provide a broad picture of participants' views of using management information rather than as a psychometric instrument or a way of conducting statistical significance tests test of hypotheses. The approach is consistent with the qualitative nature of the research.

Table 6.1 presents all of the questions and the respective numerical responses from each of the participants for each month of the six month case study. The table shows changes of perception as movements in scores, which can be seen for each of the 11 participants across the various aspects in relation to their use of information. There are distinct realities for each of the participants which are reflected in the individual scorings. The overall movement in scoring however provides a view of the participants' general perceptions of their understanding of aspects of efficiency management. The proposition reflects the broad range of experience of these managers and their use of information within their work environments. This also allows the researcher to develop an understanding of the contextual reality of the case study participants (Denzin, 2001). 
$1=$ Nothing/No; 5 = something/sometimes; $10=$ A lot/Yes.

1 What do you know overall about service efficiency?

\begin{tabular}{lccccccc|cccc} 
& P1 & P2 & P3 & P4 & P5 & P6 & P7 & P8 & P9 & P10 & P11 \\
Month 1 & 1 & 2 & 3 & 2 & 2 & 2 & 1 & 1 & 2 & 3 & 1 \\
Month 2 & 1 & 2 & 3 & 2 & 3 & 3 & 2 & 1 & 2 & 2 & 1 \\
Month 3 & 2 & 4 & 5 & 5 & 6 & 4 & 5 & 2 & 2 & 2 & 2 \\
Month 4 & 3 & 8 & 7 & 6 & 7 & 8 & 7 & 1 & 2 & 3 & 1 \\
Month 5 & 5 & 8 & 9 & 7 & 8 & 9 & 9 & 2 & 2 & 3 & 2 \\
Month 6 & 7 & 8 & 9 & 7 & 8 & 9 & 10 & 2 & 2 & 3 & 1
\end{tabular}

2 Do you have a particular definition of efficiency you use?

\begin{tabular}{lccccccc|cccc} 
& P1 & P2 & P3 & P4 & P5 & P6 & P7 & P8 & P9 & P10 & P11 \\
Month 1 & 3 & 3 & 2 & 2 & 1 & 2 & 3 & 2 & 2 & 3 & 2 \\
Month 2 & 4 & 4 & 5 & 4 & 3 & 4 & 4 & 3 & 4 & 3 & 2 \\
Month 3 & 5 & 5 & 5 & 6 & 4 & 5 & 5 & 2 & 1 & 3 & 2 \\
Month 4 & 6 & 5 & 5 & 6 & 5 & 5 & 5 & 2 & 3 & 3 & 3 \\
Month 5 & 6 & 6 & 7 & 7 & 5 & 7 & 8 & 2 & 3 & 3 & 3 \\
Month 6 & 8 & 7 & 7 & 8 & 7 & 7 & 8 & 1 & 4 & 3 & 2
\end{tabular}

3 Do the current KPIs indicate to you whether your service is performing efficiently?

\begin{tabular}{lccccccc|cccc} 
& P1 & P2 & P3 & P4 & P5 & P6 & P7 & P8 & P9 & P10 & P11 \\
Month 1 & 4 & 2 & 4 & 5 & 3 & 3 & 3 & 4 & 4 & 4 & 5 \\
Month 2 & 2 & 2 & 2 & 2 & 2 & 1 & 1 & 4 & 2 & 5 & 5 \\
Month 3 & 2 & 2 & 2 & 2 & 3 & 1 & 1 & 4 & 1 & 5 & 5 \\
Month 4 & 2 & 2 & 2 & 2 & 2 & 1 & 1 & 4 & 2 & 5 & 5 \\
Month 5 & 2 & 2 & 2 & 1 & 1 & 1 & 1 & 4 & 3 & 5 & 5 \\
Month 6 & 2 & 2 & 1 & 1 & 1 & 1 & 1 & 6 & 2 & 5 & 5
\end{tabular}

Are you confident that the efficiency information provided to you fits with the

4 organisation's goals?

\begin{tabular}{lccccccc|cccc} 
& P1 & P2 & P3 & P4 & P5 & P6 & P7 & P8 & P9 & P10 & P11 \\
Month 1 & 2 & 1 & 1 & 2 & 4 & 5 & 1 & 1 & 1 & 1 & 1 \\
Month 2 & 7 & 5 & 5 & 4 & 5 & 5 & 1 & 2 & 1 & 2 & 1.5 \\
Month 3 & 7 & 5 & 8 & 5 & 7 & 5 & 1 & 2 & 1 & 1 & 1.25 \\
Month 4 & 7 & 9 & 8 & 5 & 7 & 8 & 2 & 2 & 1 & 2 & 1.75 \\
Month 5 & 10 & 9 & 10 & 5 & 8 & 8 & 2 & 2 & 2 & 1 & 1.75 \\
Month 6 & 10 & 9 & 10 & 6 & 8 & 9 & 2 & 2 & 2 & 1 & 1.75
\end{tabular}

5 How much information are you being provided with on service efficiency?

\begin{tabular}{lccccccc|cccc|} 
& P1 & P2 & P3 & P4 & P5 & P6 & P7 & P8 & P9 & P10 & P11 \\
Month 1 & 3 & 3 & 2 & 2 & 1 & 2 & 3 & 2 & 2 & 3 & 2 \\
Month 2 & 4 & 4 & 5 & 4 & 3 & 4 & 4 & 3 & 4 & 3 & 2 \\
Month 3 & 4 & 4 & 5 & 6 & 4 & 5 & 5 & 2 & 1 & 3 & 2 \\
Month 4 & 6 & 6 & 7 & 5 & 5 & 5 & 8 & 2 & 3 & 3 & 3 \\
Month 5 & 6 & 6 & 7 & 7 & 5 & 5 & 8 & 2 & 3 & 3 & 3 \\
Month 6 & 8 & 7 & 7 & 8 & 7 & 7 & 8 & 1 & 4 & 3 & 2 \\
\hline
\end{tabular}


6 Do you find it useful to compare current efficiency against previous months?

\begin{tabular}{lccccccc|cccc} 
& P1 & P2 & P3 & P4 & P5 & P6 & P7 & P8 & P9 & P10 & P11 \\
Month 1 & 5 & 4 & 4 & 3 & 5 & 3 & 3 & 4 & 4 & 4 & 5 \\
Month 2 & 5 & 4 & 5 & 5 & 8 & 4 & 4 & 4 & 2 & 4 & 5 \\
Month 3 & 5 & 6 & 7 & 8 & 8 & 4 & 7 & 4 & 1 & 4 & 5 \\
Month 4 & 7 & 8 & 7 & 8 & 8 & 5 & 8 & 4 & 2 & 5 & 5 \\
Month 5 & 7 & 9 & 9 & 8 & 10 & 5 & 8 & 4 & 3 & 4 & 5 \\
Month 6 & 10 & 9 & 10 & 10 & 10 & 5 & 8 & 6 & 2 & 4 & 5
\end{tabular}

Do the current hospital report-KPIs allow you to monitor efficiency of your

7 service?

$\begin{array}{lccccccccccc} & \text { P1 } & \text { P2 } & \text { P3 } & \text { P4 } & \text { P5 } & \text { P6 } & \text { P7 } & \text { P8 } & \text { P9 } & \text { P10 } & \text { P11 } \\ \text { Month 1 } & 2 & 3 & 4 & 4 & 6 & 4 & 5 & 4 & 4 & 5 & 1 \\ \text { Month 2 } & 2 & 3 & 2 & 1 & 2 & 2 & 3 & 4 & 4 & 5 & 2 \\ \text { Month 3 } & 2 & 1 & 2 & 1 & 3 & 3 & 2 & 5 & 5 & 5 & 2 \\ \text { Month 4 } & 2 & 1 & 2 & 2 & 2 & 2 & 2 & 5 & 5 & 2 & 2 \\ \text { Month 5 } & 2 & 1 & 1 & 2 & 2 & 3 & 1 & 5 & 5 & 4 & 4 \\ \text { Month 6 } & 2 & 1 & 1 & 1 & 2 & 2 & 1 & 5 & 5 & 4 & 4\end{array}$

At month-end, are you able to discuss the efficiency of the service with your

8 clinical colleagues?

$\begin{array}{lccccccccccc} & \text { P1 } & \text { P2 } & \text { P3 } & \text { P4 } & \text { P5 } & \text { P6 } & \text { P7 } & \text { P8 } & \text { P9 } & \text { P10 } & \text { P11 } \\ \text { Month 1 } & 1 & 1 & 1 & 1 & 1 & 1 & 1 & 1 & 1 & 1 & 1 \\ \text { Month 2 } & 1 & 2 & 2 & 3 & 2 & 2 & 2 & 2 & 1 & 3 & 2 \\ \text { Month 3 } & 2 & 3 & 2 & 2 & 3 & 3 & 2 & 2 & 2 & 3 & 1 \\ \text { Month 4 } & 4 & 6 & 6 & 2 & 6 & 6 & 4 & 2 & 2 & 3 & 2 \\ \text { Month 5 } & 4 & 8 & 8 & 6 & 6 & 5 & 7 & 2 & 2 & 2 & 2 \\ \text { Month 6 } & 4 & 8 & 8 & 8 & 6 & 6 & 8 & 2 & 2 & 3 & 2\end{array}$

9 In terms of efficiency, do you know what you should do to improve?

\begin{tabular}{lccccccc|cccc} 
& P1 & P2 & P3 & P4 & P5 & P6 & P7 & P8 & P9 & P10 & P11 \\
Month 1 & 1 & 1 & 1 & 1 & 1 & 1 & 1 & 1 & 1 & 1 & 1 \\
Month 2 & 2 & 2 & 2 & 2 & 2 & 2 & 2 & 1 & 1 & 1 & 2 \\
Month 3 & 4 & 4 & 6 & 4 & 6 & 6 & 6 & 1 & 2 & 1 & 2 \\
Month 4 & 5 & 6 & 7 & 4 & 7 & 6 & 8 & 1 & 2 & 2 & 2 \\
Month 5 & 6 & 8 & 7 & 6 & 6 & 8 & 8 & 2 & 2 & 1 & 1 \\
Month 6 & 8 & 8 & 9 & 8 & 7 & 9 & 9 & 2 & 1 & 2 & 1
\end{tabular}

10 How would you rate yourself as being able to manage the efficiency of your service?

\begin{tabular}{lccccccc|cccc} 
& P1 & P2 & P3 & P4 & P5 & P6 & P7 & P8 & P9 & P10 & P11 \\
Month 1 & 1 & 1 & 1 & 1 & 1 & 1 & 1 & 1 & 1 & 1 & 1 \\
Month 2 & 2 & 2 & 2 & 2 & 2 & 2 & 1 & 1 & 1 & 1 & 2 \\
Month 3 & 4 & 4 & 4 & 4 & 4 & 6 & 4 & 1 & 2 & 1 & 1 \\
Month 4 & 6 & 4 & 4 & 6 & 6 & 6 & 6 & 1 & 2 & 1 & 2 \\
Month 5 & 6 & 6 & 6 & 6 & 6 & 6 & 6 & 2 & 2 & 1 & 2 \\
Month 6 & 9 & 8 & 8 & 6 & 8 & 9 & 8 & 2 & 1 & 2 & 1 \\
\hline
\end{tabular}


11 How much influence do you have on performance of your responsibility area?

\begin{tabular}{lccccccc|cccc} 
& P1 & P2 & P3 & P4 & P5 & P6 & P7 & P8 & P9 & P10 & P11 \\
Month 1 & 2 & 2 & 3 & 2 & 2 & 2 & 3 & 2 & 2 & 2 & 5 \\
Month 2 & 1 & 2 & 2 & 3 & 3 & 5 & 4 & 1 & 3 & 2 & 6 \\
Month 3 & 2 & 4 & 5 & 5 & 6 & 4 & 5 & 2 & 6 & 2 & 5 \\
Month 4 & 7 & 8 & 7 & 8 & 7 & 8 & 7 & 2 & 5 & 3 & 6 \\
Month 5 & 7 & 8 & 8 & 9 & 9 & 9 & 9 & 2 & 6 & 5 & 6 \\
Month 6 & 8 & 8 & 9 & 10 & 10 & 9 & 10 & 2 & 7 & 4 & 6
\end{tabular}

12 How frequently do you initiate efficiency-related discussions?

\begin{tabular}{lccccccc|cccc} 
& P1 & P2 & P3 & P4 & P5 & P6 & P7 & P8 & P9 & P10 & P11 \\
Month 1 & 1 & 2 & 1 & 2 & 2 & 2 & 1 & 1 & 2 & 2 & 1 \\
Month 2 & 1 & 2 & 2 & 2 & 2 & 5 & 2 & 1 & 2 & 2 & 1 \\
Month 3 & 2 & 4 & 5 & 5 & 6 & 4 & 5 & 2 & 2 & 2 & 2 \\
Month 4 & 7 & 8 & 7 & 8 & 7 & 8 & 7 & 2 & 2 & 3 & 1 \\
Month 5 & 7 & 8 & 8 & 7 & 9 & 9 & 9 & 2 & 2 & 3 & 2 \\
Month 6 & 8 & 8 & 9 & 8 & 9 & 9 & 10 & 2 & 2 & 3 & 1
\end{tabular}

13 How important is your contribution to improving your service' efficiency?

\begin{tabular}{lccccccc|cccc} 
& P1 & P2 & P3 & P4 & P5 & P6 & P7 & P8 & P9 & P10 & P11 \\
Month 1 & 2 & 2 & 3 & 5 & 2 & 1 & 2 & 2 & 2 & 2 & 1 \\
Month 2 & 2 & 5 & 5 & 6 & 8 & 3 & 5 & 4 & 2 & 3 & 1 \\
Month 3 & 4 & 8 & 8 & 8 & 9 & 4 & 9 & 3 & 3 & 3 & 1 \\
Month 4 & 4 & 8 & 8 & 8 & 8 & 7 & 9 & 5 & 5 & 3 & 1 \\
Month 5 & 8 & 9 & 10 & 9 & 10 & 8 & 9 & 6 & 4 & 3 & 1 \\
Month 6 & 10 & 10 & 10 & 10 & 10 & 9 & 9 & 6 & 3 & 4 & 1
\end{tabular}

14 Do other priorities leave little time for improvement because of failure in the organisation?

\begin{tabular}{lccccccc|cccc} 
& P1 & P2 & P3 & P4 & P5 & P6 & P7 & P8 & P9 & P10 & P11 \\
Month 1 & 3 & 3 & 2 & 2 & 1 & 2 & 3 & 2 & 2 & 2 & 1 \\
Month 2 & 5 & 4 & 5 & 4 & 5 & 4 & 4 & 4 & 2 & 3 & 1 \\
Month 3 & 6 & 4 & 5 & 6 & 8 & 5 & 5 & 3 & 3 & 3 & 1 \\
Month 4 & 9 & 6 & 5 & 8 & 8 & 5 & 5 & 5 & 5 & 3 & 1 \\
Month 5 & 9 & 6 & 7 & 10 & 8 & 7 & 8 & 6 & 4 & 3 & 1 \\
Month 6 & 10 & 10 & 9 & 10 & 10 & 9 & 8 & 6 & 3 & 4 & 1
\end{tabular}

Are your Senior managers committed to the idea that you can make things

15 better around here?

\begin{tabular}{lccccccccccc|} 
& P1 & P2 & P3 & P4 & P5 & P6 & P7 & P8 & P9 & P10 & P11 \\
Month 1 & 2 & 2 & 3 & 5 & 2 & 1 & 2 & 2 & 2 & 2 & 4 \\
Month 2 & 2 & 5 & 5 & 6 & 8 & 3 & 5 & 3 & 4 & 2 & 4 \\
Month 3 & 4 & 8 & 8 & 8 & 9 & 4 & 9 & 2 & 1 & 3 & 4 \\
Month 4 & 4 & 8 & 8 & 8 & 8 & 7 & 9 & 2 & 3 & 2 & 4 \\
Month 5 & 8 & 9 & 10 & 9 & 10 & 8 & 9 & 2 & 3 & 3 & 4 \\
Month 6 & 10 & 10 & 10 & 10 & 10 & 9 & 9 & 5 & 4 & 3 & 4 \\
\hline
\end{tabular}


16 How much is the proportion of your responsibility for efficient performance?

\begin{tabular}{lccccccc|cccc} 
& P1 & P2 & P3 & P4 & P5 & P6 & P7 & P8 & P9 & P10 & P11 \\
Month 1 & 2 & 2 & 2 & 2 & 1 & 2 & 3 & 2 & 2 & 2 & 4 \\
Month 2 & 5 & 5 & 5 & 5 & 3 & 4 & 4 & 3 & 4 & 2 & 4 \\
Month 3 & 5 & 5 & 6 & 7 & 6 & 5 & 5 & 2 & 1 & 3 & 4 \\
Month 4 & 6 & 5 & 6 & 6 & 5 & 5 & 5 & 2 & 3 & 2 & 4 \\
Month 5 & 6 & 6 & 9 & 8 & 7 & 8 & 8 & 2 & 3 & 3 & 4 \\
Month 6 & 10 & 10 & 9 & 9 & 8 & 8 & 8 & 5 & 4 & 3 & 4
\end{tabular}

17 Will the information you receive contribute to your work productivity?

\begin{tabular}{lccccccc|cccc} 
& P1 & P2 & P3 & P4 & P5 & P6 & P7 & P8 & P9 & P10 & P11 \\
Month 1 & 3 & 3 & 2 & 2 & 1 & 2 & 3 & 2 & 2 & 2 & 1 \\
Month 2 & 5 & 4 & 5 & 4 & 5 & 4 & 4 & 4 & 2 & 3 & 1 \\
Month 3 & 6 & 4 & 5 & 6 & 8 & 5 & 5 & 3 & 3 & 3 & 1 \\
Month 4 & 9 & 6 & 5 & 8 & 8 & 5 & 5 & 5 & 5 & 3 & 1 \\
Month 5 & 9 & 6 & 7 & 10 & 8 & 7 & 8 & 6 & 4 & 3 & 1 \\
Month 6 & 10 & 10 & 9 & 10 & 10 & 9 & 8 & 6 & 3 & 4 & 1
\end{tabular}

18 Will the information you receive enable you to set a higher performance target?

\begin{tabular}{lccccccc|cccc} 
& P1 & P2 & P3 & P4 & P5 & P6 & P7 & P8 & P9 & P10 & P11 \\
Month 1 & 2 & 2 & 3 & 5 & 2 & 1 & 2 & 2 & 2 & 2 & 4 \\
Month 2 & 2 & 5 & 5 & 6 & 8 & 3 & 5 & 3 & 4 & 2 & 4 \\
Month 3 & 4 & 8 & 8 & 8 & 9 & 4 & 9 & 2 & 1 & 3 & 4 \\
Month 4 & 4 & 8 & 8 & 8 & 8 & 7 & 9 & 2 & 3 & 2 & 4 \\
Month 5 & 8 & 9 & 10 & 9 & 10 & 8 & 9 & 2 & 3 & 3 & 4 \\
Month 6 & 10 & 10 & 10 & 10 & 10 & 9 & 9 & 5 & 4 & 3 & 4
\end{tabular}

19 Is it clear from the information where you have opportunities for improvement?

\begin{tabular}{lccccccc|cccc} 
& P1 & P2 & P3 & P4 & P5 & P6 & P7 & P8 & P9 & P10 & P11 \\
Month 1 & 2 & 2 & 2 & 2 & 1 & 2 & 3 & 2 & 2 & 2 & 4 \\
Month 2 & 5 & 5 & 5 & 5 & 3 & 4 & 4 & 3 & 4 & 2 & 4 \\
Month 3 & 5 & 5 & 6 & 7 & 6 & 5 & 5 & 2 & 1 & 3 & 4 \\
Month 4 & 6 & 5 & 6 & 6 & 5 & 5 & 5 & 2 & 3 & 2 & 4 \\
Month 5 & 6 & 6 & 9 & 8 & 7 & 8 & 8 & 2 & 3 & 3 & 4 \\
Month 6 & 10 & 10 & 9 & 9 & 8 & 8 & 8 & 5 & 4 & 3 & 4
\end{tabular}

20 Do you feel that you are more in control of your service efficiency?

\begin{tabular}{lccccccc|cccc} 
& P1 & P2 & P3 & P4 & P5 & P6 & P7 & P8 & P9 & P10 & P11 \\
Month 1 & 2 & 2 & 2 & 2 & 1 & 3 & 2 & 1 & 2 & 3 & 2 \\
Month 2 & 2 & 3 & 3 & 4 & 2 & 2 & 4 & 2 & 2 & 2 & 2 \\
Month 3 & 2 & 4 & 6 & 6 & 5 & 6 & 7 & 2 & 2 & 2 & 2 \\
Month 4 & 5 & 5 & 6 & 6 & 6 & 6 & 6 & 2 & 2 & 2 & 2 \\
Month 5 & 6 & 6 & 8 & 6 & 6 & 8 & 8 & 2 & 2 & 2 & 2 \\
Month 6 & 7 & 6 & 8 & 8 & 6 & 8 & 8 & 2 & 2 & 2 & 2 \\
\hline
\end{tabular}


In the table, the participants' perceptions in relation to their managerial behaviour are evident as a result of using the specific efficiency information and the hospital organisational routine reports on performance. Despite the seeming difference between the uses of the two information sources, all of the participants have the same management focus and overt objective of seeking service improvement. This means that findings can be generalised for the cohort of managers.

\subsection{Change in focus}

The first observation of the participants on their managerial progress is their change to an outward looking focus in relation to efficiency performance improvement. Participants who received the efficiency related information made progress in increasing their dialogue on performance improvement with clinical stakeholders; and, in emphasising their focus on performance at staff team discussions. The other participants who continued to use the routine performance information focused on status quo activities and reactive responses. A second observation is of change in management behaviour, in that show some participants have increased situational awareness, increased self-confidence and more self- reflection. These participants appear to have gained greater insights about themselves and their capacity to manage and control in situ the local service delivery. The other participants however do not appear to display any such change in behaviour or insight with regard to service efficiency performance.

The pattern that appears to emerge within the E group participants of gaining increased selfawareness over the service performance situation and in taking specific and strategic actions to improve efficiency corresponds to the literature (Swellar 2004, Fishbein, 1998). The improved efficiency scores appear to be a result of the choices being made by service managers on their use of inputs and outputs for the service to be delivered. The responses 
from the participants show that a range of management choices are being exercised in a sequential process: first, continuing with status quo practices; second, initiating dialogue with senior clinicians on possible change to the mix of resources; and third, actively engaging and consulting with clinicians and staff on investigating more efficient models of care. In each of these choices, there are variabilities. The manager in choosing to continue with their status quo practice may acknowledge and discuss the efficiency signal with their clinicians. The manager can initiate dialogue with senior clinicians to improve efficiency by a deeper level of dialogue on understanding the drivers of service efficiency. This begins a planning strategy where the manager can consult with clinicians on how efficiency can be improved by switching choices of resource mix, or changes to care models. In turn this can lead to an engagement strategy where the manager will use the MRE efficiency scoring and then engage in a planning and discussion with clinicians to gain their involve (influence) over considerations for more efficient practices. Even though the participants shared a common environment and had the same researcher, there was a diversity of issues and experiences in using the performance related information.

In interpreting the diversity of experiences from the participant scorings it is suggested that the manager's viewpoint is first for information that is specific and contextual. The manager's perception of value is based on the usefulness of the information for management purposes. Thus if information is to be used effectively, it will be important to consider the nature and structure of the information. Both the existing routine hospital KPIs and the added efficiency measure provided management guidance through performance signals as part of the routine performance information to service managers. However, differences in behaviour and outcome suggest these hospital service managers hold different perceptions on the purpose and value of the two pieces of information, with the routine hospital information viewed as a barrier to be held accountable for performance, and the other more specific efficiency related 
information viewed as providing the opportunity to undertake improvement actions. The overall positive impact of the use of information can be identified by the managers' reported perceived sense of control over the service being managed and by the change in service efficiency performance.

The second viewpoint is the clear and separate focus of information can cause managers to pay more attention to particular signals. The MRE focused only on the local service efficiency as a performance outcome and thus managers were able to decipher the signals and begin to understand the necessary goal-setting processes and relationships needed to improve the outcome. Through regular feedback and discussion giving the participants the opportunity to self-reflect and review their past management choices, the information also provided a signal for the imperative to continue to improve by comparing the performance of the service across earlier periods. The participants in the E group increased their perception of greater personal control over the management of the service, its resources and on the resulting efficiency performance of the service.

\subsection{Impact of information use}

The impact of the use of information can be viewed here in terms of the performance improvement of the service being managed and by the manager's perception of their sense of control over the work performance situation. The two measures of the impact of the use of the efficiency information are: the self-reported sense of control over the service being managed (question 20 in the monthly questionnaire); and the measured service efficiency (monthly DEA measurement of service efficiency).

The participants' scoring reveals an improving perception of their sense of control over the efficiency management of the service. The active learning process of monthly discussions 
stimulated the participants' reflective thinking about the performance signals in the information and the likely response performance context. This is consistent with the theory of action learning and it appears that my role as researcher/manager enhanced the fostering of trust and helped anchor the participants to goal setting actions.

The improvement of the measured service efficiency depicts the perspective of information as a mechanism of performance improvement, where these is a performance focus on efficiency. This view is supported by the performance signal theme, where clarity of performance objective is provided. It is likely that environmental factors may have contributed to the measured service efficiency. Table 6.2 summarises the participants' monthly management response and the achieved efficiency score. The variation of scores between the two groups of participants who receive the different performance information is supportive of the suggestion that environmental factors alone cannot explain the results in both participant groups. Given that improving efficiency is not necessarily the result of an environmental constant or an external artefact, it is more suggestive of the managers making different and localised strategic decisions on their resource use. Managers can respond at different levels, and their actual response can appear to deliver technical efficiency, with higher efficiency levels for the more strategic responses. The different types of management responses action levels have varying impact on service efficiency scores.

The hierarchy of manager response is reflective of their confidence in using the information. These responses or management actions were categorised on a heuristic basis and grouped into a hierarchy of primary, secondary or tertiary management actions, with each of the three levels, that progress from a primary basic level of basic management actions, to the secondary level where a more managerial approach is taken and then onto the tertiary level that exhibits advanced manager behaviour and actions. As shown in Table 6.2, the actual response at the 
higher levels of management action of the manager and the improved service efficiency (depicted by the percentage score of technical efficiency) reflect a possible impact of the use of the efficiency focused performance information for each month. The impact is possibly also the result of the regular self-reflection by the manager because of the monthly interviews and discussion between the managers and me as the researcher. 
Table 6.2: Actual management actions \& service technical efficiency (\%)

\begin{tabular}{|c|c|c|c|c|c|c|c|c|c|c|c|c|}
\hline & Month 1 & & Month 2 & & Month 3 & & Month 4 & & Month 5 & & Month 6 & \\
\hline & $\begin{array}{l}\text { Actual } \\
\text { response }\end{array}$ & $\begin{array}{l}\text { Efficiency } \\
\%\end{array}$ & $\begin{array}{l}\text { Actual } \\
\text { response }\end{array}$ & $\begin{array}{l}\text { Efficiency } \\
\%\end{array}$ & $\begin{array}{l}\text { Actual } \\
\text { response }\end{array}$ & $\begin{array}{l}\text { Efficiency } \\
\%\end{array}$ & $\begin{array}{l}\text { Actual } \\
\text { response }\end{array}$ & $\begin{array}{l}\text { Efficiency } \\
\%\end{array}$ & $\begin{array}{l}\text { Actual } \\
\text { response }\end{array}$ & $\begin{array}{l}\text { Efficiency } \\
\%\end{array}$ & $\begin{array}{l}\text { Actual } \\
\text { response }\end{array}$ & $\begin{array}{l}\text { Efficiency } \\
\%\end{array}$ \\
\hline 1 & $\begin{array}{l}\text { Variance } \\
\text { analysis }\end{array}$ & 92.84 & $\begin{array}{c}\text { Resource } \\
\text { management }\end{array}$ & 95.65 & $\begin{array}{l}\text { Reactive } \\
\text { control }\end{array}$ & 96.75 & $\begin{array}{l}\text { Balance } \\
\text { policy }\end{array}$ & 97.85 & $\begin{array}{l}\text { Strategic } \\
\text { change }\end{array}$ & 98.53 & $\begin{array}{l}\text { Strategic } \\
\text { change }\end{array}$ & 99.75 \\
\hline 2 & $\begin{array}{l}\text { Variance } \\
\text { analysis }\end{array}$ & 90.36 & $\begin{array}{c}\text { Resource } \\
\text { management }\end{array}$ & 94.79 & $\begin{array}{l}\text { Manage } \\
\text { balance }\end{array}$ & 94.21 & $\begin{array}{l}\text { Strategic } \\
\text { change }\end{array}$ & 90.39 & $\begin{array}{l}\text { Resource } \\
\text { management }\end{array}$ & 93.45 & $\begin{array}{l}\text { Strategic } \\
\text { change }\end{array}$ & 95.67 \\
\hline 3 & $\begin{array}{l}\text { Variance } \\
\text { analysis }\end{array}$ & 88.41 & $\begin{array}{l}\text { Policy } \\
\text { change }\end{array}$ & 98.91 & $\begin{array}{l}\text { Manage } \\
\text { balance }\end{array}$ & 95.76 & $\begin{array}{c}\text { Resource } \\
\text { management }\end{array}$ & 98.53 & $\begin{array}{l}\text { Policy } \\
\text { change }\end{array}$ & 99.36 & $\begin{array}{l}\text { Strategic } \\
\text { change }\end{array}$ & 98.3 \\
\hline 4 & $\begin{array}{l}\text { Variance } \\
\text { analysis }\end{array}$ & 90.98 & $\begin{array}{l}\text { Variance } \\
\text { analysis }\end{array}$ & 93.07 & $\begin{array}{l}\text { Variance } \\
\text { analysis }\end{array}$ & 95.09 & $\begin{array}{c}\text { Resource } \\
\text { management }\end{array}$ & 95.68 & $\begin{array}{l}\text { Increase } \\
\text { inputs }\end{array}$ & 95.48 & $\begin{array}{c}\text { Resource } \\
\text { management }\end{array}$ & 96.41 \\
\hline 5 & $\begin{array}{l}\text { Variance } \\
\text { analysis }\end{array}$ & 84.77 & $\begin{array}{l}\text { Variance } \\
\text { analysis }\end{array}$ & 85.6 & $\begin{array}{l}\text { Variance } \\
\text { analysis }\end{array}$ & 88.35 & $\begin{array}{c}\text { Resource } \\
\text { management }\end{array}$ & 88.91 & $\begin{array}{l}\text { Strategic } \\
\text { change }\end{array}$ & 94.59 & $\begin{array}{l}\text { Strategic } \\
\text { change }\end{array}$ & 96.45 \\
\hline 6 & $\begin{array}{l}\text { Variance } \\
\text { analysis }\end{array}$ & 92.77 & $\begin{array}{l}\text { Reactive } \\
\text { control }\end{array}$ & 89.47 & $\begin{array}{l}\text { Reactive } \\
\text { control }\end{array}$ & 88.62 & $\begin{array}{l}\text { Policy } \\
\text { change }\end{array}$ & 100 & $\begin{array}{l}\text { Strategic } \\
\text { change }\end{array}$ & 99.03 & $\begin{array}{l}\text { Strategic } \\
\text { change }\end{array}$ & 99.84 \\
\hline 7 & $\begin{array}{l}\text { Variance } \\
\text { analysis }\end{array}$ & 92.46 & $\begin{array}{l}\text { Variance } \\
\text { analysis }\end{array}$ & 94.91 & $\begin{array}{l}\text { Redesign } \\
\text { policy }\end{array}$ & 97.52 & $\begin{array}{c}\text { Resource } \\
\text { management }\end{array}$ & 95.78 & $\begin{array}{l}\text { Resource } \\
\text { management }\end{array}$ & 90.28 & $\begin{array}{l}\text { Strategic } \\
\text { change }\end{array}$ & 92.96 \\
\hline 8 & $\begin{array}{l}\text { Variance } \\
\text { analysis }\end{array}$ & 91.56 & $\begin{array}{l}\text { Variance } \\
\text { analysis }\end{array}$ & 90.45 & $\begin{array}{l}\text { Variance } \\
\text { analysis }\end{array}$ & 90.87 & $\begin{array}{l}\text { Variance } \\
\text { analysis }\end{array}$ & 89.89 & $\begin{array}{l}\text { Variance } \\
\text { analysis }\end{array}$ & 90.25 & $\begin{array}{l}\text { Variance } \\
\text { analysis }\end{array}$ & 90.07 \\
\hline 9 & $\begin{array}{l}\text { Variance } \\
\text { analysis }\end{array}$ & 89.43 & $\begin{array}{l}\text { Variance } \\
\text { analysis }\end{array}$ & 88.96 & $\begin{array}{l}\text { Variance } \\
\text { analysis }\end{array}$ & 90.38 & $\begin{array}{l}\text { Variance } \\
\text { analysis }\end{array}$ & 89.5 & $\begin{array}{l}\text { Variance } \\
\text { analysis }\end{array}$ & 89.34 & $\begin{array}{l}\text { Variance } \\
\text { analysis }\end{array}$ & 86.9 \\
\hline 10 & $\begin{array}{l}\text { Variance } \\
\text { analysis }\end{array}$ & 87.62 & $\begin{array}{l}\text { Variance } \\
\text { analysis }\end{array}$ & 87.39 & $\begin{array}{l}\text { Variance } \\
\text { analysis }\end{array}$ & 85.25 & $\begin{array}{l}\text { Variance } \\
\text { analysis }\end{array}$ & 83.97 & $\begin{array}{l}\text { Variance } \\
\text { analysis }\end{array}$ & 83.97 & $\begin{array}{l}\text { Variance } \\
\text { analysis }\end{array}$ & 81.85 \\
\hline 11 & $\begin{array}{l}\text { Variance } \\
\text { analysis }\end{array}$ & 90.11 & $\begin{array}{l}\text { Variance } \\
\text { analysis }\end{array}$ & 92.3 & $\begin{array}{l}\text { Variance } \\
\text { analysis }\end{array}$ & 90.37 & $\begin{array}{l}\text { Variance } \\
\text { analysis }\end{array}$ & 91.73 & $\begin{array}{l}\text { Variance } \\
\text { analysis }\end{array}$ & 91.73 & $\begin{array}{l}\text { Variance } \\
\text { analysis }\end{array}$ & 87.24 \\
\hline
\end{tabular}


At the first level, the management actions are centred on providing explanations and analysis of the variance issues. These actions are primarily reactive and are focussed on responding on the current situation. The responses are also directed at their general manager, in providing variance analysis reports. The actions that are undertaken at the primary level of management action includes: variance analysis; reactive control mechanisms over budget or staffing. These actions largely reflect a defensive status quo position of the managers who focus on seeking explanations from staff and who furthermore also avoid direct engagement with senior clinical staff. At this lower level of management, there is no consideration or discussion on opportunities for performance improvement. Within this management level there is a minimal consideration of the choices that are available and possible for mixing and optimising resources, inputs and service production. Instead, at this level of management, the available performance information is viewed as of little relevance in terms of considering service improvement responses. With this stance, the manager views the information as being primarily her general manager's tool to hold her accountable and thus she becomes defensive in her management behaviour.

At the second level the management actions are centred on actions on the control of the available resources within the staffing roster mix and seeking to boost production of outputs. These actions are focused on the management of resources with an aim of at improving efficiency, such as: resource management; manage balance; and increase inputs. The actions require some dialogue with staff and consultation with senior clinical staff. Here, the managers are beginning to reflect an increased but moderate level of self confidence in using the available information to consider and discuss with others opportunities for performance improvement. Here, there are moderated considerations of more optimal choices in resource use, but the managers tend to focus on the feasibility of options within the status quo environment so do not fully extend the opportunity for change. 
At the third level the management actions are focused on developing a strategic approach to enable the manager to use the available resources in an optimum manner so as to maximise the production of service. The actions require extensive engagement with senior clinical staff as well as executive staff (and associated work unions), such as: strategic change; redesign, change or balance policy. Here the managers lead the discussions and are enabling an engagement process with senior staff to influence change in order to improve the efficiency performance of the service. The manager often highlights opportunities for change, facilitates the discussions and bids (attempts to influence) for change. The change in managers' perceptions of their sense of control over the service and the measured service efficiency for each participant's service is now discussed in light of observations of exploratory findings and the management themes.

There are clear indications that it is possible for a positive impact from the use of performance information. It seems however that the positive impact is only possible when the manager perceives that the information can provide performance signals. Based on the perception of the value of the information the manager must then be able to shift the traditional primary paradigm towards the second and third levels of management response to have an effect on service performance.

\subsection{Management and behaviour - some exploratory findings}

From the case study, key observations of changes in managerial behaviour can be identified that frame the common management behaviour of the participants. These key observations are presented and outlined as exploratory findings in the context of the use of information by managers. The exploratory findings are summarised here, as follows. 
1) Participants' knowledge of the prevailing service efficiency improves if their level of understanding also changes;

2) Participants show increasing confidence in using information by increasing their interactions with other key staff;

3) Participants' long standing perceptions of barriers to prevent service efficiency were able to be changed;

4) Participants lessen their variability in their understanding of the performance signals with more focused information; and

5) Participants' response to using information can be improved by feedback on their management actions.

The changes in managerial behaviour outlined above are discussed and further supported by drawing on the results of the TA and the elicited key management themes. For each of the five findings, the participants' scorings of their perceptions are presented to reveal their experience and to identify the change in managerial behaviour.

\section{The management themes and positioning of managerial behaviour}

The management themes help position the changes of managerial behaviour. The TA process that was applied to the transcripts of narratives elicited key themes evidenced from the data (outlined in earlier Chapters 4 and 5). The management themes relate to perceptions held by managers: of management (what managers are to do within their organisation and service) and of behaviour (how managers are to behave with or respond to their service colleagues). The changes in perceptions and of managerial behaviour are discussed as a commentary of the key management themes identified in the thematic analysis (from Chapter 4). The management themes, labelled as 'Direct leadership', 'Operational feedback', 'Performance signal', and 'Management development' provide a very useful frame on the managerial behaviours that have been identified by the use of information on a cross participant basis over the case study 
period. These themes help in determining the understandings of the participants' experiences. The viewpoint of managers within an organisation is that they are individuals who have differences in the nature of changing their behaviour but all undergo a similar process of changing perception (Otara, 2011). The change in managerial behaviour is discretionary to individual managers. The management themes link to the changes in managerial behaviour, and will help in explaining the changes in managerial behaviour.

Organisations must work through managers to achieve organisational objectives. The organisational or corporate policy practice of supplying information for use by managers will need to enable the creation of a positive perception within these managers that they have the managerial capability and organisational support in taking action to improve performance. The qualitative analysis shows that information use appears to encourage knowledge-based behaviours of senior managers. Additionally, the managers' perceived behavioural intentions support their subsequent actions to improve service performance. The theme of direct leadership is defined by the capacity shown by managers to understand the role of senior executive staff in the organisation and their influence on the managers in providing a mandate to utilise information. Collaboration and cooperation are other features that manifest in direct leadership. The themes support the finding in framing the role of management to provide leadership. The themes dominate for all of the five findings.

There may be a positive connection between increased, continuous exposure to the consecutive (monthly) ongoing presentation of efficiency information and an increase in the level of knowledge of service efficiency (Direct leadership). In terms of having a particular definition of service efficiency, in the early months none of the participants report using any definition of service efficiency with which they can guide the management of the service. However, over subsequent months, an increasing use of a definition of efficiency appears to 
have developed (self-identified) to guide the participants' management of their service. The participants' responses appear to show that the exposure to the efficiency information can lead to an improvement in specific knowledge relating to efficiency. The participants who use the specific efficiency related performance information report more positively on having particular definitions of efficiency that they are able to use, and express a high level of confidence in better understanding the monthly performance information. These managers are also more positive about being able to use the definition of efficiency. It is worth noting here that during this time period, all participants in both groups were employed as operational service managers at $\mathrm{ACH}$ who were: (i) subject to similar organisational and environmental factors such as CEO exhortation to maintain expenditure to budget and (ii) also received the routine management information.

In the context of the manager role in performance management, the use of a measure of performance provides a focus on improvement. With the additional efficiency information the participants take the opportunity to look beyond the normal practices and exert influence over discussions with staff and clinicians on performance improvement. In a management context, feedback is the process of information being sent to the manager about prior behaviour (action taken). This process permits the managers to review the past action taken and so consider possible future adjustment. The management themes from the thematic analysis can be treated as a useful framework for the exploratory findings to support performance improvement. The users of performance information seem to be developing a level of self-reflection, which can have changes in their behaviour that lead to taking action to improve the efficiency of the service. In the following discussion the five exploratory findings are presented from the perspective of managers as participants in the case study and as respondents to the questionnaires. This purposefully positions the hospital service work context to the generalised findings. 


\section{- Finding 1}

\section{Participants' knowledge of the prevailing service efficiency improves if their level of understanding also changes.}

Participants' scorings indicate their knowledge of the prevailing service efficiency improves over time with the provision of specific information on efficiency. As participants' understanding of the information changes, they begin to focus on service efficiency improvement. Whereas the existing routine reports on performance do not appear to prepare these participants to identify or be aware of the prevailing efficiency level of their service, and thus, their understanding and knowledge remains constant. Early in the case study period all of the participants show similar low levels of awareness of the efficiency of their service. All participants were previously receiving the routine reports on performance information. With the exposure to the specific efficiency information the participants begin to incrementally increase their scoring to report an increased awareness of service efficiency. This increase in knowledge is in sharp contrast to the reported level of understanding by recipients of the routine reports on performance, who continue to report low levels knowledge of the prevailing service efficiency.

The two participant groups' respective knowledge about service efficiency continues at different levels over the case study period. At the midpoint of the case study period, month 3 , a more dramatic increase in levels of confidence being reported about their knowledge of service efficiency by the participants who receive the management report on efficiency. This increase in confidence about understanding service efficiency continues in the following months for all these participants. The increase is significant from a policy and management viewpoint because during the same period, those participants who receive only the routine hospital management reports show no increase in confidence about having greater understanding of service efficiency. Over the case study in the last three months, the 
participants who receive efficiency information continue to indicate that they have increasing understanding of the efficiency of their service.

The participants report different levels in their understanding of service efficiency. Increases in the participants' confidence in understanding service efficiency occur with repeated exposures to the specific information on efficiency, gaining greater familiarity with and experience of the information presented. Participant confidence and knowledge are individual experiences. Participant experiences follow a similar pattern but are specific to their work context, leading to different knowledge levels. Those participants who continued to receive only routine information all have a similar pattern of experience in reporting minimal knowledge about service efficiency. From the point of view of the measurement of performance, participants deviate rapidly within three months in their self-rating of the value of the measurement of service efficiency. For example, participants who believe they have an efficiency measure that they can use, are more likely to take actions that enable the service efficiency performance to improve (this is discussed later in this Chapter).

At the beginning of the case study, all participants held a similar view of their existing performance information, that it contains useful KPIs as indicators of service efficiency performance. By the end of the case study, however, participants who were provided with the efficiency related performance information changed their previous positive view to having a more negative view of the current KPIs. These participants' had lower ratings of the value of the routine performance reporting reports. The low ratings began early, in month 2 , therefore suggesting an almost immediate increase in the awareness of the limitations being provided by the routine reports. In month 3 , at the monthly meetings with these participants, I probed their awareness in reducing value of the routine performance reports and these participants noted the MRE provided more of a clear signal on their service efficiency performance. 
The information that is provided on specific performance matters such as efficiency appear to have an influence on participants self-reflection where they can begin to recognise the value of different information and make critical judgements on the usefulness or otherwise of the existing performance information within the organisation. This appears to suggest that continued consistent information improves confidence in the specific context of knowledge. At my monthly meetings with the participants, they began to show confidence in the specific efficiency information and indicated a greater willingness to undertake specific actions which involve an increase in dialogue with clinicians. Over the six month period, the participants using the MRE reports increasingly rated themselves as gaining higher levels of confidence that the efficiency information contained in the MRE aligned with the organisation's goals.

At the same time, the participants using the routine hospital reports continued to rate the RRP as sufficient information to indicate the efficiency performance of their service. Yet, earlier, these same participants reported low levels of knowledge about service efficiency. These participants were consistent in their positive response about the RRP, but they were unconcerned that they were not being able to specifically identify any precise measure of service efficiency. This was a matter I raised with these participants at the monthly meetings; to which they reported that a measure of efficiency was not necessarily needed to improve the efficiency of their service because they were largely driven by the information contained in the routine information on performance.

Of the R group, only one individual (out of four participants) rated the RRP as providing indications of service efficiency performance at a score of $60 \%$ (by participant 8 at month 6 ). One participant revealed that they had a discussion with her general manager on the overall goals for the service and was therefore more comfortable with the RRP providing the signals on performance (Participant 8). This stance was also taken by the other $\mathrm{R}$ group participants 
who continued to view the RRP as providing useful indicators of efficiency performance. This is in sharp contrast to the E group, where all individuals continued to reduce their perception of the value of the routine performance information (RRP). In contrast the participants using the routine hospital reports continued to rate their information as a poor fit to the organisation's goals. This is an interesting finding because it appears to contradict this group's earlier view that they already have useful KPIs as indicators of service efficiency. This suggests some support for Sweller's (2011) CLT, where developing specific information signals may enable managers to better align their focus and actions with organisational goals.

Participants reported high values of the efficiency related performance information (MRE). For theses participants the perceived value of the specific efficiency related performance information (MRE) continues to grow over subsequent months. These participants began to be more positive about the usefulness of comparing efficiency for performance monitoring and took an increasingly more critical view of their routine hospital reports. The critical stance is reflected in the low scores for performance monitoring with the current routine reports. Despite the historical use of routine reports for information on management performance, the participants had different responses to the need for benchmarking or comparison of efficiency against previous months. The participants who began to use the efficiency related performance information (MRE) rated the value of benchmarking higher than those participants who continued to utilise only the routine performance reports.

\section{Finding 2}

\section{Participants show increasing confidence in using information by increasing their interactions with other key staff.}

Managers show confidence in using the specific efficiency information in their willingness to engage with senior clinicians and executives on efficiency improvement matters. At the 
phenomenological level, the social interaction between the manager and other senior staff suggest that the manager's individual actions are now becoming projections of progressive shifts in Actual and Real realities from the initial Empirical perspective (Bhaskar, 1998). The managers and staff interact within a social system and create representations for each other's actions which eventually become habituated into roles in relation to each other, and a different and new social (work) reality that may be considered as the accepted social tenets of a collaborative community between managers and clinicians with relatively stable social representations.

Over the case study the additional efficiency information appears to enable the participants to increase their dialogue on performance improvement matters with clinicians. The regularity of focussed information on service efficiency appears to encourage participants to use the efficiency information in discussions with clinical stakeholders. Managers may or not, know what should be done to improve the efficiency of the service. Thus, reports with weak indicators of performance (such as the hospital's routine reports on performance) do not appear to provide useful data signals about service efficiency improvement opportunities. Participant confidence in their ability to use the information appears to improve with more precise performance information. The case study shows that the increase in confidence is facilitated by familiarity with the performance signal. In turn, this familiarity appears to generate greater confidence in the manager in being able to understand and discuss service efficiency performance requirements with other stakeholders. The level of personal influence that managers perceive that they as service managers can have on service performance appears to grow. Managers can hold differing views of how they manage performance by their practice and knowledge. The managers who begin to initiate discussions with clinical staff and colleagues on the possible improvement of efficiency and service performance tend to have timely feedback on past endeavours to improve performance. This serves to create 
ongoing growth in manager confidence for greater collegial discussion on performance related issues and for increased staff interactions.

The managers' continued initiation of efficiency related discussions with other stakeholders including senior staff appears to be affected by feedback on performance improvement performance improvement.

\section{Finding 3}

Participants' long standing perceptions of barriers to prevent service efficiency were able to be changed.

Perceived barriers play an important role in stopping managers from pursuing performance improvement actions. Participants' long standing perceptions of the barriers that they believe are in place to prevent service efficiency were able to be changed. The two participant groups' perspective of personal responsibility is reflected in their response to whether they believe that their senior managers (CEO and General Managers) are committed to performance improvement activity. Both participant groups initially report a low level of support from senior managers for improving service performance. The participants show different ratings of being able to contribute to improving their service efficiency. The difference in rating is based on the information that each participant has used as a reference point. The participants' responses show their perception of the importance of their contribution to improving efficiency of their service. This is indicative of the managers' perception of their capability. In month 1, all of the participants across the two groups have a similar low rating of their contribution to improving service efficiency. Initially both participant groups accept that conflicting priorities prevent them from pursuing performance improvement actions. 
Over the following months, the two participant groups develop different perceptions of their respective contribution as managers to improving service efficiency. The participants with the efficiency related performance information rate themselves highly as contributors to improving service performance. This reveals that possibly these participants have now gained a high level of understanding of the signals provided in the MRE information.

Participants' belief in their managerial role appears to be strengthened by the use of the efficiency related information. The focus of the participants on the barriers to taking managerial action on performance improvement seems to dissipate over time with the efficiency information. In the R group the participants report only a marginal growth in their contribution to improving efficiency. In terms of performance improvement, managers have choices on the action that they take at a given time. The choice of action will be based on whether there are conflicting priorities that may inhibit their capacity (and energy) to focus on service efficiency. There is a clear and different view held by the two participant groups on their capacity to manage performance improvement.

Over the course of receiving the MRE, the participants begin to rate themselves as being able to undertake performance improvement actions. The E group shows strong disagreement that there is any failure in the organisation which prevents performance improvement for the service. The $\mathrm{R}$ group on the other hand continue to apportion blame onto the organisation for a lack of performance improvement focus. Discussions with participants reveal the reported scores is a reflection of the nature of their interactions with senior managers where service managers are confined generally to providing explanations on previous months' results. The participants all have a similar initial view of senior leadership as providing 'poor support' to service managers. But, over the case study period in later months the E group begins to hold a different perception of the support that is provided by senior leadership. The initial prevailing 
view changes over the study period for both participant groups. This is possibly a result of the monthly discussions and review of the information and its signals on performance which occurred at the monthly meetings with all participants based on their respective information sets.

A further barrier to performance improvement action is the participant's disinterest in taking action. The apparent lack of personal responsibility is reflected in the self-reported ratings to being personally responsible for the efficient performance of their service. In the first months, participants' responsibility for taking action remains low. However, over the following months, participants begin to develop a greater sense of personal responsibility which is reflected in higher rating responses to the proportion of personal responsibility with the efficiency related performance information. The focus on efficiency in the performance information may improve awareness of their managerial role in achieving service efficiency.

\section{Finding 4}

\section{Participants lessen their variability in their understanding of the performance signals with more focussed information.}

The E group lessen their variability in the understanding of the performance signals contained in information. The response by the participants to the value of the information they use to manage service performance (MRE or RRP) is based on its perceived contribution to work productivity. The responses are markedly different between the two participant groups.

In the initial months both the $\mathrm{E}$ and $\mathrm{R}$ groups appear to share a similar view of the performance information in not contributing to their work productivity. Over the following months, this rating improves for all participants. The general improvement in the understanding of performance matters is reflective of the ongoing action learning aspects of 
the monthly meetings and discussions on performance. The difference between the groups suggests that the participants may have made a reasoned action (Ajzen and Fishbein, 1980) as a result of the change in information. Discussions with participants indicate that their initial focus was on budget control in order to monitor variances. By month 6, participants were using the efficiency related performance information to shift their management focus onto the broader management considerations of resources and staff relationship. The shift in management focus is stronger in the participants who receive the efficiency related performance information. Participants who receive the routine hospital reports continue with their customary management practice of using the performance information to react only to budget control and variance matters. The relative depiction on the usefulness of the available information to set performance targets is shown in Table 6.2.

All participants initially indicated a minimal use for their performance information. Over the case study period, these participants improved on their self-ratings on being able to use the performance information to set higher performance targets. The increase in ratings of the value of the information by both participant groups is attributed to the monthly meetings and the regular discussions on efficiency performance matters. This may have raised the topic of the value of information onto the participant's agenda and thereby resulted in the more positive ratings over the latter months. The large positive increase amongst the participants who receive the efficiency related performance information can suggest that significant effort to improve or effect performance levels are able to be being made by those managers who are given appropriate performance signals.

In the initial period of the case study, both participant groups had relative low ratings on the information being clear where opportunities for improvement are within the service. The low rating level in the first few months would appear to indicate that all of the participants are still tending to be conservative in their approach to using the information. Over months 3 and 4, 
those participants with the efficiency related information begin to value the information signals and begin to use the data to consider performance improvement actions. The participants who continue to receive the routine performance information that contain the collection of KPIs continue to place no value on the data to provide improvement signals. The month 6 ratings continue the difference between the two groups with the efficiency information as providing opportunities for improvement compared to the lower value placed by the RRP participant group.

\section{Finding 5}

Participants' response to using information can be improved by feedback on their management actions.

The participants' response to using information can be improved by feedback on their management actions. The focus is on the actual managerial action by the manager and the result in terms of service efficiency performance. For the discussion on this finding I use survey and observational data as well as quantitative measurements using DEA for service efficiency. The data on management actions was obtained during meetings with participants. The observational data represents the management actions referred to the statement on the finding above. At the third meeting of each month, the participants were asked what management action they took to improve efficiency performance of their service (stated actual response).

In the initial first month, all of the participants take a similar reactive approach to the use of performance information and preferring to a status quo management stance. Some of the participants continue to take this approach over the months and do not vary in their managerial practice, which focus on solely explaining performance variances to their senior managers. 
Initially changes to this behaviour began by low-level reactive actions centred on budget control and variance analysis. At the monthly discussions, these participants expressed their view that as hospital service managers they needed to consider the performance information although they still needed to comply with a competing and more urgent priority in preparing and presenting a variance analysis report to their general manager. The variance analysis report was viewed by the managers as their usual response that was expected by general managers. One participant who having reviewed the efficiency performance information indicated to me that they intended to take a resource management approach to improving efficiency, such as deciding on making a change to the coming months' staffing roster mix. This intention reflects confidence in the information and a moderate level of management maturity. However, by the end of the month, the manager had not implemented the resource management approach to the change the service's staffing roster mix. Instead the manager chose to adopt the more customary reactive action (variance analysis). The participant's reason for ultimately adopting completing a variance analysis report' was because of, as they termed it, 'a negative and hostile reaction' from their general manager to their suggestion of taking a resource management approach to improving efficiency. The participant reported that she had been told by her general manager to avoid potential staff dissatisfaction in pursuing the staffing roster mix change.

Over the following months, the defensive behaviour described above begins to change for the participants. The use of the performance information tends to consideration and action at the higher management levels. Noticeably participants who receive the routine hospital reporting continue to respond with low level management actions that are primarily a reactive focus on responding on the current situation to their general manager. In terms of actual management response, the first month's pattern continued into the second month, with all participants typically continuing with historical management actions that reflect low levels of confidence 
in the information. In later months participants begin to use the performance information more forcefully. In month 2, several participants use the performance information to choose to move from the primary and reactive level of management to put into effect higher levels of actions. The management option of seeking to take a policy change action to begin to redesign the model of care policy within the speciality service. Given that, this would require considerable discussions with senior clinical staff as well as executive managers, this intended action is a strategic approach reflecting higher levels of maturity and confidence with the information. At month end, one participant completed the action as intended while the other participant did not because of strong negative clinician reaction and her unwillingness to engage in any acrimonious dispute.

The participant that did complete the intended action also faced initial criticisms from their clinicians but was willing to engage staff on the efficiency information that had been provided. In the third month, the separation of management action levels between the two participant groups becomes clearer. Now, participants are beginning to take a more mature approach to looking at the performance information with a viewpoint of improving the efficiency of the service. These participants begin to consider careful action to achieve the desired outcome of improved service efficiency. These participants use the information on efficiency (MRE) to reflect on their choices of resource inputs and production outputs, and also to engage more with senior staff including clinicians to discuss options in managing service efficiency. This behaviour is a manifestation of having more confidence in their use of the performance information and represent higher levels of management maturity. In month 6 , all of these participants carry out tertiary level of management actions involving work strategy or staffing policy to enable an optimum use of resources. 
The participants appear to change their perceptions about the specific performance information (MRE) as providing the information tool to consider opportunities for further improvement. The different and changed perceptions appear to be reflected in the management action that is subsequently taken, as show in Table 6.2. The more positive perceptions can lead to management actions at the third level, which appear to then lead to improved monthly service efficiency. There is an impact of the differently held perceptions or views by the participants on the purpose of the performance information (MRE or RRP). Specific information signals can be used to stimulate particular approaches to management actions. Within two months, participants move quickly from viewing the performance information as an accountability mechanism to an improvement opportunity if they receive the specific performance information. The participants who use the routine performance information continue to view the provision of this information only as an accountability tool by senior management.

\section{Behaviour change and social reality}

Changing behaviour requires trust according to the American psychological Association (Swin et al, 2009). For these participants as managers the shifting from the routine and reactive behaviours to taking a more collaborative and collegial approach to establishing relationships that enable discussions on performance improvement, must be viewed as providing more benefit than cost. In this context, the social reality represents the workplace reality of managers within an organisation. Bhaskar, $(1998,2011)$ has outlined behaviours as being at three interlinked and overlapping but hierarchical levels of action. Thus, in order to improve performance which requires interactions with clinicians, it would be necessary to place interventions that seek interdependent 'realities' to move from having localised assumptions to making pragmatic connections to deeper understanding of operational context with a higher level of strategic intent. 
Bhaskar provides a philosophical framework for dealing with the realities in which the research is undertaken. Although Bhaskar's theory is a transcendental philosophical view of social relations, it resonates in its simplicity of mapping the possible progression of a manager's behaviour in terms of understanding their realities. In this way the routine performance information is initially operating at the localised Empirical level of the individual manager and is in-context to the individual experience. In using the efficiency information, the managers begin to first connect across from their own empirical reality to the broader Actual reality. Following this extension, a second connection is made to the use of efficiency information to the Real reality where there are critical considerations of the broader key rules and tendencies of the global organisation in developing performance improvement. Following the principles of pragmatism, there is an ongoing iteration between the three realities.

These behavioral factors are involved in management and the process to have meaning and clarity with staff and other stakeholders. There can be uncertainty for managers in understanding performance because the organisational setting multi-layered and with groupings of staff and services with different objectives. Having clarity on the performance that is required can be viewed as necessary to optimize the performance of the service.

\subsection{Conclusion}

There is a beneficial outcome of providing hospital service managers with performance related information. At the commencement of the case study, all participants, who were service managers, reported similar barriers which they perceived to impede any performance improvement actions. However, over time, the perception of barriers on managing the efficiency of their services began to diminish in participants receiving efficiency information 
compared to the participants who continued behaving as they always did with the routine reports of hospital performance information. These findings tend to show individuals do act on few pieces of actionable advice and are able to transcend from their day to day routine to a strategic outlook. Managers wishing to improve performance will use information. As shown by these results, information can motivate the necessary and appropriate behaviours within large complex organisations such as public hospitals. More importantly, by having specific information, signals can be sent to those managers who need it the most. In other words, the research lends some weight to the proposition that it is possible to lead public hospital (and sector) managers who are in complex multi-stakeholder organisations to focus on specific intelligence from information, and thus to direct their managerial responses on performance improvement action. This experience of hospital service managers and their use of information intersect management and behaviour, taking an integrative perspective of the doing and the knowing within the work context.

The pathway of linking of the new information to new knowledge and broader contextual awareness and then onto the behaviour and actions of those managers who receive information can be now seen. In the next and final Chapter Seven, the participants' experiences within the reality of their work contexts are discussed in light of the study's research questions and identified themes. 


\section{Chapter 7}

\section{Conclusions}

\subsection{Summary of thesis}

This thesis is on the use of performance information in the delivery of public hospital services. The focus is on hospital service managers' use of the information to improve service efficiency. There has been little empirical research on how hospital service managers, who are the key level three operational managers within hospital organisations, respond to or use efficiency information. Public hospitals are complex systems having multiple services and multiple decision-makers with varying patient flows and complicated treatment requirements, and have largely unknown management processes (Wennberg, 2010). New Zealand public hospitals were referenced as having a policy and management problem from not knowing how performance information is used by those managers who are tasked with improving performance.

This thesis presents, possibly for the first time, a qualitative analysis of the use of efficiency information by hospital service managers. The research provides some insight into the issue of managers' use of information. The issue poses an epistemological problem, and will require further work to know with more certainty. In this regard there is a real possibility that resources are being wasted in preparing information for New Zealand hospital managers; and that these managers are being distracted from the focus on performance improvement. The study also suggests that information that is structured to identify and provide performance information could eventually produce the desired effect on performance improvement. The research methodology and methods outlined a research design which was framed as exploratory research in order to begin to understand the topic of study. The research explored in a site specific case study, the use of routine and efficiency information in order to improve service performance. The case study setting was New Zealand's largest hospital; the 
participants in the study were service managers in level 3 management roles with budget responsibility and performance accountability. In addition to the role of the researcher, I had a planning and funding management role at the hospital.

I developed, for the study, a monthly review process based on existing work patterns. This process involved: assessment of performance signals in the information, consideration of any mitigation actions, and a confirmation or follow up of actions. This process provided clarity to, and on, the managers' use of performance information. The process also provided the platform for the observation of participants' response to efficiency information.

The focus on performance was on the technical efficiency of hospital services. The technical efficiency was measured using DEA and the available hospital routine data. This showed a level of performance improvement in those services whose managers received the specific efficiency information. In this study a monthly structured questionnaire was used for each of the six months, in which participants scored themselves on aspects of their experience in their use of the performance and efficiency information Hospital service managers tended to focus on performance improvement actions if directed by specific information. The participant narratives show different responses based on to the individual's contextual reality of using performance information in their local work settings in order to improve performance. The narratives of the participants showed differences in their experience. The use of the performance information and management responses moved across the spectrum from reactive actions to more strategic actions in relation to decisions on more optimum uses of the key input resources. There was also a similar and corresponding move to a more collaborative and sharing of the efficiency information with staff and clinicians. Levine (2000) in a discussion on the future of management noted that: "when information is shared, it becomes part of an organisation's knowledge base, and it can be used to create better products, 
services and organisations." (cited in Choudhry, 2000 p.88), This view appears to be supported by the findings in this study, where over the course of six months positive change occurred in the participants who were exposed to the MRE efficiency information. The positive change manifested in: an increased perception of the managers ability to manage the performance of their service; and, in their improved attitude towards continued performance improvement.

A formal thematic analysis process was applied to the collected narratives to distil themes on management behaviour. The four final themes provide further argument for the localisation of performance signals and the consequent information. The themes and their meanings centre on the organisation's management as it influences the individual manager's work context and learning experiences. This provides the opportunity to develop deeper insight to understanding the contextual use of efficiency information by hospital service managers.

These themes are necessarily researcher-constructed. The essence of thematic analysis is that it can contextualise the case study and so remains an interpretative analysis from the researcher's viewpoint. The themes are exploratory in nature and are of contextual meaning for hospital service management. The management framework within the hospital organisation can be better structured to support managerial use of performance information. The policy framework around hospital performance could be improved by being more centred on the development of cultural support for managers. In this context, the thesis supports a behavioural perspective be taken on management models of service operations. The research suggests that managers' experience with specific information may enable management actions that are more collaborative and strategic, and serve to improve efficiency performance. From these experiences, the managers appear to gain an enhanced perception of having control over their services. In addition, the findings may be used as policy and management frameworks in 
further research on the use of information in performance improvement. The current prevailing central government public sector policy is that more data and more performance reports need to be made available so that hospital managers can be enabled to manage services more efficiently.

\subsection{Research questions and themes}

Four research questions were identified in Chapter One. Each of these research questions is discussed in connection to the participants' experience and the resulting theme.

Research question 1: To what extent do managers use specific pieces of information that are made available to them within the context of their routine reporting and performance environment?

This study's first research question seeks to understand the extent to which managers will utilise specific pieces of information that are made available to them within the context of their routine reporting and performance environment. From the perspective of the manager, there are drivers for change that focus on the processes of change. The manager needs to accept the information as providing a signal on performance. The manager will have to be comfortable with their mandate to be responsible for the performance improvement of the service. In this way, the manager may begin to then use the information and gain an overall awareness of the performance situation and increase their understanding of the performance signal contained in the information.

From the perspective of the organisation, it will be necessary to develop mechanisms that will enhance collaboration between managers and stakeholders in order to support managers and so influence their managerial behaviours. The organisation needs to implement a review process of service performance and develop leadership, conviction and commitment to 
improvement activity. This will encourage managerial attempts to make service efficiency more systematic within the service, and to challenge variations in practice. There will be need to positive support to managers to develop the required level of engagement with clinicians. Within this context, the manager can be held accountable for the performance results as well as the level of collaborative influence within the work setting.

Research question 2: From the information that is provided, what behaviours and actions do managers take that they perceive as necessary to improve performance?

The behaviours and actions managers perceive as necessary to improve performance centre on two key areas. The first key area references the low confidence that the managers have in believing they have the capacity to overcome the status quo situation. There is a general belief that the available performance information provides for uncertainty about performance and its levers. The second area is the existing pattern of reactive management and focus on performance reporting. These are connected to the provision of information from a status quo position. Therefore, in general, managers will take little action while continuing to reflect and report on the information. There is a sense of isolation by the manager which then reinforces the justification for not perceiving any actions as necessary. The isolation also creates uncertainty about performance improvement levers.

One of the key overarching insights is that the managers who receive regular and steady (regular) feedback on their use for the information in terms of actions became more willing to increase their dialogue with clinical staff on efficiency performance matters. These managers were also becoming more willing to exert more influence or pressure on clinicians and promote collaborative actions. The operational feedback appears as top down but the narratives display a common perspective of inclusion by the managers to reach out to other key actors involved in and pivotal to, the use and mix of resources. This can mean that such 
operational feedback may be self-generating. rom the organisation's perspective, the overall performance reporting system and the performance information that are provided to the manager can be re-focussed to provide direction on the likely areas for performance improvement actions. The managers' focus is then on reporting on these aspects of performance.

Research question 3: What do managers perceive that they need to learn in order to improve the management of their service units?

The managers' perception of that they need to learn in order to improve the management of their service centre on the notion of the development of new knowledge. The lack of familiarity and inexperience with the information, results in a reluctance to consider the performance signal, not first without seeking senior leadership direction. Over time, however, as shown in this case study, familiarity with the information leads to a more active interest in how performance can be improved. Performance signals can be an important consideration for the hospital to establish as a cultural process of showing the managers what it is that they need to learn in order to improve performance. The proposition that managers need in order for them to learn is a sequential process which is supported by Swellar's $(1994,2001)$ cognitive load theory that implies learning is best through a sequential process.

Knowles (1990) had earlier noted that the manager's activity of learning tends to be approached in a performance focussed frame of mind and within the contextual reality of the work situation. Managers are already preoccupied with work issues and competing pressures and therefore they will often question the relevance of performance information and then ascertain more senior staff's reaction and level of support for the information. The notion of learning for managers is through interpretation of data and reports and by subsequently framing their meaning (of the performance signal) for other staff (Atherton, 2013). 
Research question 4: What factors do managers perceive as impeding their actions as they seek to improve service performance?

The perceptions held by managers as impeding their actions to improve service performance centre on their detachment from, and in other circumstances their challenge to, the information. The managers can view the organisation and its leadership as creators of the barriers for any potential improvement actions. There is then a general indifference to the information as well as resistance or challenge to the performance signals. The managers however are able to amend their perception of the organisational barriers over time with repeated and consistent performance information. In support of this are Moynihan and Landuyt's (2009) view that can be extended to performance information as a support element of organisational learning.

From a behavioural perspective, corporate support is viewed as a step forward to overcoming the resistance and the detachment from information or performance improvement. Where an organisation does not clearly and explicitly articulate its desired performance goal and has reinforcing information, then the common managerial behavioural response is to not engage in performance improvement activity. This stance is supported by the theory of planned behaviour (Penz and Stottinger, 2005; Ajzen, 1991) that the perceived behavioural norm and attitude determines the intention and actual behaviour.

\subsection{Implications and lessons}

Public hospitals are under very substantial pressure compelling them to improve their efficiency. Hospitals are under pressure to reduce costs, particularly through the introduction of reimbursement systems that are based on case mix, and to cut costs by eliminating duplicated services and reducing fixed costs. As a contribution, this thesis sets out a holistic 
understanding of the experience of using information so that in developing the policy and management frameworks that are necessary to address the use of efficiency information by hospital service managers. The thesis suggests that all of the four themes need to factor in developing the use of information in order to have performance improvement. Policy-makers may need to reflect on the role of performance measurement and rethink the reporting of information that is made available to hospital managers.

A number of key policy issues need to be considered in overseeing hospitals and understanding the role of information in improving performance. Perhaps the most important message to convey to hospital planners is that the performance of a hospital is associated with its workload and is, to a considerable extent, under its own control and the control of the health care system. By using appropriate incentives and information signals, significant performance improvement can be encouraged. In this, the major human resources policy challenge for hospital planners is how to break down the traditional barriers between the managers and the different clinical professions; where barriers owe more to history than to logic, and they result in frequently inappropriate use of staff members and fragmentation of patient care, causing errors as patients are passed from professional to professional (Carayon and Wood, 2010). A further policy challenge is that hospital services have often been structured according to traditional divisions between medicine, surgical specialties and other functional departments rather than patient needs. This structure is being challenged by increasing awareness of improving the patient experience, by grouping services by specialists with different skills and training but similar interests to work together. On another scale, services can be grouped according to patient severity and care need rather than by specialty, so that services are grouped into critical, acute and step-down. Finally, policy-makers need to create incentives and management structures for appropriate collaboration amongst hospital 
staff to develop a greater understanding of, and use, efficiency information within hospital institutions.

The prevailing presumption that hospital service managers already have existing information which guides them to achieve the organisation's performance goals was tested by the participant managers, who on the basis of receiving efficiency information contained in the MRE, rated the routine performance reports as providing poor guidance on performance. There are a number of lessons for policy and management. The first lesson is that perhaps by the nature of their work, hospital managers tend to adopt a reactive and crisis mode as their modis operandi. Perhaps, hospital managers need directed information. The focus should be on gaining greater understanding of the situation that a consistent, stable and regular signal (perhaps like the monthly MRE) can provide managers with a mandate to respond with management actions which are strategic and improve performance. Another key lesson is the importance of putting in place a mechanism to promote interaction and knowledge development among managers and with the organisation. The response of managers as users of information will typically be first internal (thoughts and awareness change) and then move onto externally focussed management action and with increased cross-collegial dialogue. Managers need to be made aware of their current pattern of thinking and behaviour (Chowdhry, 2000). While hospital service managers are close to their work and best understand how to foster improvement (Moynihan, 2009) they lack the motivation to make informed judgements and act appropriately if there is no explicit information signal to act (Senge, 1990).

\section{A Recommendation on Policy}

Based on the research findings, it is recommended that hospital policymakers consider the coordinated development of governance to overview performance related reporting and its 
translation to hospital service level. This would encourage performance discussions at individual service manager level and a focus on appropriate information.

There is need to have co-ordination of the message for public hospitals to be technically efficient. The message needs to be oriented by consensus. Governance of the consensus orientation requires active participation and responsiveness of the senior managers, funders and policy makers. The work of the National Benchmarking Programme can serve as a putative model of a joint and collaborative exercise involving all the major actors, in allowing for the development of consensus. By assuring hospital manager participation in the planning, management and monitoring of technical efficiency, the governance becomes responsive and provides a co-ordinated overview.

\subsection{Future research}

Different uses of information coexist within the organization, and so the role of information might require a nuanced consideration. Within the hospital setting, ambiguity and differences in use reduce their capacity to link performance measurement to performance management.

Further studies are needed to evaluate the effectiveness of information in different settings and among different levels of healthcare and hospital managers. In addition, research is needed to explore the optimal preparation of training of managers most closely associated with performance. Finally, more work is needed to better understand the type of information that is best associated with optimal performance outcomes, and whether the type of information changes in different settings. The research findings that were reported in this thesis are of an exploratory nature and there is a need for a much larger database of research findings, to gain a more definitive understanding of the use of information and subsequent management responses. 
There is a case for further research into the association of information and performance improvement and the managers' sense of enhanced control of the service; as follows:

1 A survey of a larger sample of public hospitals in New Zealand is conducted to examine the use of information by managers to assess the extent to which the same of similar findings would be uncovered as in this study.

2 A closer examination of the use of DEA as an embedded tool within hospitals. The change in efficiency ratings over a period of several months can present a real cost saving to both the hospital and the funder of hospitals.

3 To develop evidenced-based theoretic practice guidelines for the use of thematic analysis in ongoing service management research.

In terms of contributing to the literature, a little more is now known on 'how' performance information is used by service managers. This study adopted Stake's (1995) purpose of the inquiry, to provide insight into an issue. The research questions in this study were an attempt to explore and understand, from a philosophical and practical paradigm that are foundational to qualitative research methodology, the general behaviour and response of managers to their use of information. I took a common pedagogical approach to blend learning and doing for myself and for my participants; where we were both engaged in discussing management information on performance and in self-reflection.

The challenge is to provide information that fits the context of the manager. A way of doing this is to link information to the situational context of the manager in a culturally relevant and pragmatic manner. As more and more research data is collected and more performance-related information reports are produced, consideration of their use will need to take hold and perhaps this will lead to a focus on the role of specific and careful use of information. 


\subsection{A final reflection}

This thesis explores the intersecting link between information, managerial response, and performance improvement of service efficiency and in so doing presents a qualitative analysis of hospital service managers' use of management performance information. The research goes some way towards uncovering the experience of managers in their use of information. The modelling of the use of information by hospital service managers as a three stage information response process has potential to further develop the role of information in performance improvement. The qualitative analysis identifies that a more collaborative and strategic policy on management information might better encourage improved service efficiency, in the local New Zealand hospital context. The management of public hospitals require paradigms that shift focus onto information that is directed at improvement.

As a final comment, this study was immensely enhanced by the feedback from the participant hospital service managers who willingly gave their time and shared their individual experiences and insights with me. 


\section{References}

Ackoff, R. L. (1989). From Data to Wisdom, Journal of Applies Systems Analysis, Volume 16 p 3-9.

Ajzen, I. (1991). The theory of planned behaviour. Organizational Behavior and Human Decision Processes, 50, 179-211.

Ajzen, I., \& Fishbein, M. (1980). Understanding attitudes and predicting social behavior. Englewood Cliffs, NJ: Prentice-Hall.

Ali, N., Rose, S., \& Ahmed, L. (2014). Psychology students' perception of and engagement with feedback as a function of year of study. Assessment \& Evaluation in Higher Education, (ahead-of-print), 1-13.

Anderson, C. (2010). Presenting and Evaluating Qualitative Research. American Journal Pharmacy Education: 74(8): 141-149.

Anema, H., Kievit, J., Fischer, C., Steyerberg, E., \& Klazinga, N. (2013). Influences of hospital information systems, indicator data collection and computation on reported Dutch hospital performance indicator scores. BioMed Central Health services research vol 13: 212222.

Askim, J. (2006). How do politicians use performance information? An analysis of the Norwegian local government experience. Inter. Rev. Admin. Ser. vol 73(3): 453-472.

Atherton, J. (2013). Learning and Teaching; Knowles' andragogy: an angle on adult learning. [On-line: UK]; ttp://www.learningandteaching.info/learning/knowlesa.htm.

Attride-Stirling, J. (2001). Thematic networks: an analytic tool for qualitative research. Qualitative Research (December) vol. 1(3): 385-405; doi: 10.1177/146879410100100307.

Avis, M. (2003). Do we need methodological theory to do qualitative research? Qualitative Health Research, 13(7), 998-1004.

Bandura, A. (1986). The explanatory and predictive scope of self-efficacy theory. Journal of Clinical and Social Psychology, 4, 359-373.

Banker, R., Charnes, A., \& Cooper, W. (1984). Some models for estimating technical and scale inefficiencies in data envelopment analysis. Management Science 30: 1078-1092.

Barnum, D., \& Gleason, C. (2008). DEA Efficiency Analysis Involving Multiple Production Processes with an Application to Urban Mass Transit. Great Cities Institute Publication Number: GCP-08-02 U Illinois of Chicago.

Barrados, M., \& Mayne, J. (2003). Can Public sector organisations learn? OECD Journal on Budgeting Vol 3(3): 87-104.

Behn, R. (2003). Why measure performance? Different purposes require different measures. Public Administrative Review vol 63(5): 586-606.

Bhaskar, R. (2011). Reclaiming Reality: A critical introduction to contemporary philosophy. NY, Routledge. 
Bhaskar, R. (1998). The Possibility of Naturalism: A Philosophical Critique of the Contemporary Human Sciences. (3 Ed) NY Routledge.

Bird, C. (2005), How I Stopped Dreading and Learned to Love Transcription. Qualitative Inquiry (April):11(2): 226-248; doi: 10.1177/1077800404273413.

Bloomberg, L., \& Volpe, M. (2012). Completing your qualitative dissertation: a road map from beginning to end. Thousand Oaks, CA: Sage.

Bolton, M., \& Stolcis, G. (2003). Ties that do not bind: Musings on the specious relevance of academic research. Public Administration Review vol 63(5): 626-650.

Boyatzis, R. (1998). Transforming qualitative information: Thematic analysis and code development. Thousand Oaks, CA: Sage.

Braun, V., \& Clarke, V. (2006). Using thematic analysis in psychology. Qualitative Research in Psychology, 3(2), 77-101.

Braun, V., \& Clarke, V. (2013). Successful qualitative research: A practical guide for beginners. London: Sage.

Bryman, A. (2003). Triangulation. Encyclopaedia of Social Science Research Methods. London: Sage.

Burgess, J., \& Wilson, P. (1993). Technical efficiency in Veterans Administration Hospitals. : 335-351 in Fried \& Schmidt (Eds), The measurement of productive efficiency: techniques and applications. Oxford UK.

Burrell, G. \& Morgan, G. (1979). Sociological Paradigms and Organisational Analysis: Elements of the Sociology of Corporate Life, Pearson Education.

Buttell, P., Hendler, R., \& Daley, J. (2008). Quality in healthcare: concepts and practice: the business of healthcare. Westport, CT: Praeger.

Cameron, R. (2011). Mixed Methods Research: The Five Ps Framework. The Electronic Journal of Business Research Methods Volume 9 Issue 22011 (pp 96-108), available online at www.ejbrm.com.

Carayon, P., \& Wood, K. (2010)., Patient Safety: The Role of Human Factors and Systems Engineering. Stud. Health Technol. Inform. Vol 153: 23-46.

Chamberlain, K. (2000). Methodolatry and qualitative health research. Journal of Health Psychology, 5(3), 285-296.

Charmaz, K. (2006). Constructing Grounded Theory. Sage.

Charnes, A., Cooper, W., \& Rhodes, E. (1978). Measuring the efficiency of decision-making units. Eur. J. Oper. Res. 159: 513-527.

Carifio J, \& Perla R., (2007). Ten common misunderstandings, misconceptions, persistent myths and urban legends about Likert scales and Likert response formats and their antidotes. Journal of Social Sciences 3(3): 106-116. 
Chiesa, M., \& Hobbs, S. (2008). Making sense of social research: how useful is the Hawthorne Effect?

Chilingerian, J. (1995). Evaluating physician efficiency in hospitals: a multivariate analysis of best practices. European Journal of Operational Research 80: 548-574.

Choo, C. (2002). Information management for the intelligent organisation: the art of scanning the environment. Information Today incorporated. NY.

Chowdhry, S. (2000). Management 21C. Financial Times Prentice Hall, UK.

Clandinin, D. \& Connelly, F. (2004). Narrative Inquiry: Experience and Story in Qualitative Research. San Francisco: Jossey-Bass Publishers.

Collins, J. (2001). Good to Great. Barnes \& Noble, NJ.

Coombs, S., \& Smith, I. (2003). The Hawthorne effect: Is it a help or hindrance in social science research? Change: Transformations in Education, 6(1), 97-111.

Crabtree, B., \& Miller, W. (1999). Doing Qualitative Research (2nd ed.) (Eds). Forum Qualitative Sozialforschung / Forum: Qualitative Social Research, 3(4), Art. 3, http://nbnresolving.de/urn:nbn:de:0114-fqs020432.

Crema, M., \& Verbana, C. (2013). Future developments in health care performance management. J Multidiscip. Healthcare 6: 415-421.

Creswell, J., \& Plano, C. (2011). Designing and conducting mixed methods research (2nd ed.). Thousand Oaks, CA: Sage Publications, Inc.3.

Creswell J., (2008). Educational research: Planning, conducting, and evaluating quantitative and qualitative research. Upper Saddle River, NJ: Pearson/Merrill Education.

Crotty, M. (1998). The foundations of social research: Meaning and perspective in the research process. London; Thousand Oaks, Calif.

Cruise, P., \& Nyhan, R. (2000). First among (UN) equals: assessing hospital performance using data envelopment analysis. J. Health Hum. Serv. Adm. (Winter) 22(3): 354-373.

Cutcliffe, J., \& McKenna, H. (2002). When do we know that we know?: Considering the truth of research findings and the craft of qualitative research. International Journal of Nursing Studies, 39(6), 611-618.

Czarniawska, B. (2014), Social Science Research: From Field to Desk. London: Sage.

Davenport, T. (2000)., Mission critical: realising the promise of enterprise systems. Harvard Business School Press, Boston MA.

Davenport, T. \& Beck, J. (2000). Getting the attention you need. Harvard Business Review, 78(5): 118-126.

Davenport, T., \& Beck, J. (2002). The attention economy: understanding the new currency of business. Harvard Business Review Press. 
Davenport, T., and Harris, J., (2007), Competing on Analytics: The New Science of Winning. HBR Press.

Davidson, C. (2009). Transcription: Imperatives for Qualitative Research. International Journal of Qualitative Methods 8(2): 36-52

Davis, F. (1989). Perceived Usefulness, Perceived Ease of Use, and User Acceptance of Information Technology. MIS Quarterly, 13(3), 319-340.

Davis, F., Bagozzi, P., \& Warshaw, P. (1989). User acceptance of computer technology: A comparison of two theoretical models. Management Science V35: 982-1003.

Denzin, N., (2001), Interpretive Interactionism (2nd Ed). Sage.

Denzin, N., \& Lincoln, Y. (2008), Strategies of Qualitative Inquiry, Third Edition, The SAGE Handbook of Qualitative Research, 3rd.

Dervin, B., Foreman-Wernet, L., \& Lauterbach, E. (2003). Sense making methodology reader: selected writings of Brenda Dervin. Hampton Press, NY.

Dexter, F., \& O’Neill, L. (2004). Data envelopment analysis to determine by how much hospitals can increase elective inpatient surgical workload for each specialty. Anesthesia \& Analgesia 99: 1492-1500,

Dexter, F., O’Neill, L., Lei, X., \& Ledolter, J. (2008). Sensitivity of super-efficient data envelopment analysis results to individual decision-making units: an example of surgical workload by specialty. Health Care Management Science 11: 307-318.

Dresser, R., (1998), Setting Priorities for Science Support. Hastings Center Report, 28: 21-23. doi: $10.2307 / 3528647$.

Dwyer, S., \& Buckle, J., (2009). The Space Between: On Being an Insider-Outsider in Qualitative Research. Int.J. Qual. Methods Vol 8(1): 54-63.

Eakin, B. (1991), Allocative inefficiency in the production of hospital services. Southern Economic Journal (July) 58(1):240-248.

Ellingson, L., (2011). Analysis and representation across a continuum. In Norman K. Denzin \& Yvonna. S. Lincoln (Eds.), The Sage handbook of qualitative research (4th ed., pp.595610). Thousand Oaks, CA: Sage.

Emrouznejad, A., Parker, B., \& Tavares, G. (2008), Evaluation of research in efficiency and productivity: a survey and analysis of the first 30 years of scholarly literature in DEA. Journal of Socio-economic Planning Science 42(3): 151-157.

Färe, R. \& Grosskopf, S. (2000), Network DEA, Socio-Economic Planning Sciences, 34 (1), $35-49$.

Farrell, M. (1957). The measurement of productive efficiency. Journal of the Royal Statistical Society Series A: 120: 253-290.

Feldman, M., \& March, J. (1981), Information in organisations as signal and symbol. Administrative Science Quarterly Vol 26(2): 171- 186. 
Farsi, M., \& Filipini, M. (2004). An Empirical analysis of cost in non-profit and public nursing homes. Annals of Public and Coperative ecommy 75(3): 339-365.

Fereday, J., and Muir-Cochrane, E., (2006), Demonstrating Rigor Using Thematic Analysis: A Hybrid Approach of Inductive and Deductive Coding and Theme Development. International Journal of Qualitative Methods (March) 5(1): 2-11.

Ferrance, E. (2000). Action Research. Brown University: LAB.

Fetterman, D., (2010), Ethnography. (3rd Ed), Sage.

Fielden, A., Sillence, E., and Little, L. (2011). Children's understandings' of obesity, a thematic analysis. International Journal of Qualitative Studies on Health and Well-Being, 6(3), 10.3402/qhw.v6i3.7170. http://doi.org/10.3402/qhw.v6i3.7170

Fishbein, M., \& Ajzen, I. (1975). Belief, attitude, intention, and behavior: An introduction to theory and research. Reading, MA: Addison-Wesley.

Franklin, D., O'Neill, L., Xin, L. (2008), Sensitivity of super-efficient data envelopment analysis results to individual decision-making units: an example of surgical workload by speciality. Health Care Management Science 11: 307-318.

Fried, H.; Lovell, C. and Schmidt, S. (eds.) (1993). The Measurement of productive efficiency: techniques and Applications. OUP: NY.

Fried, M., \& Jarden, M. (2008), Field arithmetic: a series of modern surevys in mathematics. Springer Mishawaka.

Galliers, R. (1991). Choosing appropriate informationsystems research approaches: a revised taxonomy. In: Information Systems Research: Contemporary Approaches and Emergent Traditions, Nissen, H.-E.,Klein, H.K. \& Hirschheim, R. (eds), pp. 327-345.

Gay, L., Mills. G., \& Airasian, P. (2006). Educational research: Competencies for analysis and application (8th ed.). New York: Prentice Hall.

Gerhard, T. (2008). Bias: considerations for research practice.Am J Health Syst Pharm. 2008 Nov 15;65(22):2159-68. doi: 10.2146/ajhp070369.

Glaser, B., \& Strauss, A. (1967). The Discovery of Grounded Theory: Strategies for Qualitative Research. Chicago, IL: Aldine Publishing.

Golany B \& Roll, Y. (1989). “An Application Procedure for DEA.” Omega 1(3): 237-250.

Gonzalez, E., \& Gascon, F. (2004). Sources of productivity growth in the Spanish pharmaceutical industry (1994-2000). Research Policy 33(5): 735-745.

Grbich, C. (2007). Qualitative data analysis. Thousand Oaks, CA: Sage.

Greenwood, D. J., \& Levin, M. (1998). Introduction to Action Research: Social research for social change. Thousand Oaks: Sage.

Hayes, J. (2002). Interpersonal skills at work. (2nd ed), New York: Routledge 
Ho, C. (2005). Corporate governance and corporate competitiveness: an international analysis. Corporate Governance vol 13(2): 211-253.

Hollingsworth, B. (2008). The measurement of efficiency and productivity of healthcare delivery. Health Econ. 17(10): 1107-1128.

Hollingsworth, B., \& Parkin, D. (2003). Efficiency and productivity change in the English national health service: can data envelopment analysis provide a robust and useful measure? J. Health Serv Res Pol 8: 230-236.

Hollingsworth, B., \& Peacock, S. (2008). Efficiency management in health and health care. Routledge international studies in health economics. Taylor \& Francis, UK.

Hollingsworth, B., \& Street, A. (2006). The market for efficiency analysis of health care organisations. Health Econ. 15: 1055-1059.

Holloway, E. (2005). Qualitative Research in Health Care. OUP, UK McGraw-Hill.

Holloway, I., \& Todres, L. (2003). The status of method: flexibility, consistency and coherence, Qualitative Research, V3 (3): 345-358.

Hussey, P., de Vries, H., Romley, J., Wang, M., Chen, S., Shekelle, P., \& McGlynn, E. (2009). A systematic review of health care efficiency measures. Health Services Research 44(3): 784-805.

Jacobs, R., and Dawson, D. (2003). Hospital efficiency targets. Health Economics 12(8): 66984.

Janesick, V., (2000). The choreography of qualitative research design: minutes, improvisations, and crystallization. In M. K. Denzin \& Y. S. Lincoln (Eds.), Handbook of qualitative research. (pp. 379-399). Thousand Oaks: Sage Publications.

Jarvalin, K., \& Ingwersen, P. (2004). Information seeking research needs extension towards tasks and technology. Information research vol 10(1): paper 212 at http://informationR.net/ir/10-1/paper212.html.

Johnson, R., Onwuegbuzie, A., \& Turner, L. (2007). Toward a Definition of Mixed Methods Research. Journal of Mixed Methods Research 2007; 1; 112-133.

Johnson, R., \& Onwueghuzie, A. (2004). Mixed Methods Research: A Research Paradigm Whose Time Has Come. Educational Researcher (October) vol 33(7): 14-26.

Kaiser, K. (2009). Protecting Respondent Confidentiality in Qualitative Research. Qualitative health research. Vol 19(11):1632-1641. doi:10.1177/1049732309350879.

Kaplan, R., \& Norton, D. (1993). Putting the balanced scorecard to work. Harvard Business Review (September-October) vol 71(5): 134-147.

Karr-Wisniewski, P., \& Lu, Y. (2010). When more is too much: operationalizing technology overload and exploring its impact on knowledge worker productivity. Computers in Human Behaviour vol 26(5): 1061-1072. 
Klein, H. \& Michael D. (1999). A Set of Principles for Conducting and Evaluating Interpretive Field Studies in Information Systems," MIS Quarterly, Special Issue on Intensive Research (23:1), pp. 67-93.

Knowles, M. (1990). The Adult Learner: a neglected species (4th ed). Houston: Gulf Publishing.

Kontodimopoulos, N., \& Niakas, D. (2005). Efficiency measurement of hemodialysis units in Greece with data envelopment analysis. Health Policy 71(2): 195-204.

Koopmans, T. (1951). An analysis of production as an efficient combination of activities in Koopmans, T., (Ed.): Activity Analysis of Production and Allocation, Proceeding of a Conference, p.33-97, John Wiley and Sons Inc., London.

Kravchuk, R., \& Schack, R. (1996). Designing effective performance measurement systems under the Government Performance and Results Act 1993. Public Administration Review: 56(4): $348-58$.

Kumbhakar, S., \& Lovell, C. (2000). Stochastic Frontier Analysis. Cambridge Press.

Kuper, A., Lingard, L., \& Levinson, W. (2008). Critically appraising qualitative research. BMJ;337: 686-692.

Kvale, S. (2002). DIALOGUE AS OPPRESSION AND INTERVIEW RESEARCH. Presentation at the Nordic Educational Research Association Conference Tallinn, Estonia, March 7-9.

Latham, G. P. (2003). Goal setting: A five-step approach to behavior change. Organisational Dynamics Vol 32(3): 309-318.

Leedy, P., \& Ormrod, J. (2001). Practical Research: Planning and Design (7 Ed) Merrill Prentice Hall,NY.

Lingard, L., \& Kennedy, T. (2007). Qualitative research in medical education. Edinburgh: Association for the Study of Medical Education.

Ludwig, M., Van Merode, F., \& Groot, W. (2010). Principal agent relationships and the efficiency of hospitals. Eur J Health Econ. 11(3): 291-304.

Magnussen, J., \& Nyland, K. (2008). Measuring efficiency in clinical departments. Health Policy (July) 87(1): 1-7.

Mannion, R., \& Goddard, M. (2000). The impact of performance measurement in the NHS. Report 3: Performance measurement systems - a cross-sectoral study, report prepared for the Department of Health. Centre for Health Economics, University of York.

Marshall, C., \& Rossman, G. (2011). Designing qualitative research (5th ed). Thousand Oaks: Sage.

Mauthier, M., Birch, M., Jessop, J., \& Miller, T. (2002). (EDs) Ethics in qualitative research. Thousand Oaks, CA: Sage.

Maxwell, J. (1992). Understanding and Validity in Qualitative Research. Harvard Educational Review: September Vol 62(3): 279-301. 
Mays, N., \& Pope, C. (2000). Qualitative research in health care: assessing quality in qualitative research. BMJ; 320: 50-52.

Merode, G., Groothuis, S., \& Hasman, A. (2004). Enterprise resource planning for hospitals. Int J Med Inform 73: 493-501

Merriam, S. (2009). Qualitative research: a guide to design and implementation. SF: JosseyBass.

Mertens, D. (1998). Research methods in education and psychology: Integrating diversity with quantitative and qualitative approaches. London: Sage.

Messick, S. (1993). Validity. In R.L. Linn (Ed.), Educational measurement (3rd ed.).

Mintzberg, H. (2009), Managing. Berrett Koehler, USA

Moorman, C., Zaltman, G., \& Deshpande, R., (1992). Relationships between providers and users of market research: the dynamics of trust within and between organisations. J. Marketing Research vol 29(Aug): 314-329.

Morgan, D. (2006). Connected contributions as a motivation combining qualitative and quantitative methods. In L. Curry, R. Shield, \& T. Wetle (Eds.), Applying qualitative and mixed methods in aging and public health research. Washington, DC: American Public Health Association.

Morrow, S. (2005). Quality and Trustworthiness in Qualitative Research in Counselling Psychology. J. Counselling Psychology Vol52(2): 250-260.

Morse, J., Swanson, J., \& Kuzel, A. (2001). The Nature of Qualitative Evidence. SAGE

Moynihan, D. (2005). Goal-based learning and the future of performance management. Public Administrative Review Vol 65(2): 203-216.

Moynihan, D., \& Landuyt, N. (2009). How Do Public Organizations Learn? Public Admin. Review Vol 69(6): 1097-1105.

Mukherjee, C., White, H., \& Wuyts, M. (1998). Econometrics and Data Analysis for Developing Countries. Psychology Press.

Namey, E., Guest, G., \& Thairu, L. (2008). Data reduction techniques for large qualitative data sets in Handbook for team-based qualitative research, G \& MacQueen, M

Nathanson, B., Higgins, T., Giglio, R., Munshi, I., \& Steingrub, J. (2003). An exploratory study using data envelopment analysis to assess neurotrauma patients in the intensive care unit. Health Care Management Science 6: 43-55.

Neuman, W. (2000). Social research methods qualitative and quantitative approaches. 4th Edition, Allyn \& Bacon, Needham Heights.

Ngwenyama, O., \& Lee, A. (1997), Contextuality of Research on Managerial and Organizational. MIS Quarterly, vol. 21 no. 2, pp. 145-167

Nunamaker, T. (1983). Measuring routine nursing service efficiency: a comparison of cost per patient day and data envelopment analysis models. Health Services Research 18(2): 183-208. 
Otara, A. (2011). Perception: A guide for managers and leaders. J Management \& Strategy: 2(3): 21-24.

Oiler, C. (1982). The Phenomenological approach in nursing research. Nursing Review V31(3): 178-81.

O'Neill, L., Rauner, M., Heidenberger, K., \& Kraus, M. (2008). A cross-national comparison and taxonomy of DEA-based hospital efficiency studies. Socio. Econ. Plan. Sci. 42(3): 158189.

Orlikowski, W., \& Baroudi, J. (1991). "Studying information technology in organizations: research approaches and assumptions", Information Systems Research, Vol. 2 No. 1, pp. 1-28. [Google Scholar]

Ozcan, Y. (2008). Health care benchmarking and performance evaluation: an assessment using DEA. Springer

Ozgen, H. (2006). Does chain affiliation make a difference in efficiency in multiple output dialysis markets. Health Care Management Science \&: 253-261.

Paas, F., Renkl, A., \& Sweller, J. (2003). Cognitive load theory and instructional design: recent developments. Educational Pyschologist vol 38(1): 1-4.

Palinkas, L.,,Horwitz, S., Green, C., Wisdom, J., Duan, N., \& Hoagwood, K. (2015). Purposeful sampling for qualitative data collection and analysis in mixed method implementation research. Administration and Policy in Mental Health, 42(5), 533-544. http://doi.org/10.1007/s10488-013-0528-y.

Pannucci, C., \& Wilkins, E. (2010). Identifying and Avoiding Bias in Research. Plastic and reconstructive surgery. Vol 126(2):619-625. doi:10.1097/PRS.0b013e3181de24bc.

Parand A, Dopson, S, Renz A, et al. (2014), The role of hospital managers in quality and patient safety: a systematic review. BMJ Open 2014;4:e005055. doi: 10.1136/bmjopen-2014005055

Parkin, D., \& Hollingsworth, B. (1997). Measuring production efficiency of acute hospitals in Scotland 1991-1994: validity issues in data envelopment analysis. Applied Economics 29: $1425-1433$.

Patton, M. (2002). Qualitative research and evaluation methods (3rd ed). Thousand Oaks, CA: Sage.

Peltokorpi, A. (2011). How do strategic decisions and operative practices affect operating room productivity? Health Care Management Science: 14(4): 370-382.

Peters, T., \& Waterman, R. (1982). In Search of Excellence. Harper Collins NY.

Pfeffer, J., \& Sutton, R. (1999). The Knowing-Doing Gap: How Smart Companies Turn Knowledge into Action. HBS Press.

Podsakoff, P., MacKenzie, S., Lee, J., \& Podsakoff, N. (2003). Common method biases in behavioral research: A critical review of the literature and recommended remedies. J. Applied Psychology vol 88(5): 879-903. 
Pope, C., Mays, N., (2006). Qualitative Research in Healthcare. 3rd ed. Oxford: Wiley Blackwell.

Prasad, A.,\& Prasad, P. (2002), The coming age of interpretative organisational research, Organisational Research Methods, V5 (1): 4-11.

Propper, C., \& Wilson, D. (2003). The use and usefulness of performance measures in the public sector. Oxford Review of Economic Policy: 19(2): 250-67.

Pyett, P. M. (2003). Validation of Qualitative Research in the "Real World. Qualitative Health Research, 13(8), 1170-1179.

Ramanathan, R. (2005). Operations assessment of hospitals in the Sultanate of Oman. Int. J. Prod. Oper. Manag. 25(1): 39-54.

Reason, P., \& Bradbury, H. (Eds.), (2001). Handbook of Action Research: Participative Inquiry and Practice, London: Sage.

Rice, P.,\& Ezzy, D. (1999). Qualitative research methods: A health focus. Melbourne: OUP

Riessman, C. (1993). Narrative Analysis. Qualitative Research Methods Series, No. 30. Newbury Park, CA: Sage.

Rouse, P., \& Ryan, D. (1994). Measuring the effects of local government reform: a New Zealand highway maintenance application.

Rouse, P., \& Putterill, M. (2003). An integral framework for performance measurement. Management Decision vol 41(8):791-805.

Rouse, P., \& Swales, R. (2006). Pricing public health care services using DEA: methodology versus politics. Ann. Oper. Res. 145: 265-280.

Rouse, P., Putterill, M., \& Ryan, D. (2002). Integrated performance measurement design: insights from an application in aircraft maintenance. Management Accounting Research 13(2): 229-248.

Rusu, T. (2016). From Information to Wisdom. New Economics Papers on Knowledge Management \& Knowledge Economy

Rutledge, R., Parsons, S., \& Knaebel, R. (1995). Assessing hospital efficiency over time: an empirical application of data envelopment analysis. Journal of Information Technology Management 6(1): 13-23.

Saldana, J. (2009). The coding manual for qualitative researchers. Los Angeles, CA: SAGE.

Saracevic, T., \& Kantor, P. (1997). Studying the value of library and information services.

Part 1: establishing a theoretical framework. J. American Society for information science, vol 48(6): 527-542.

Schram, T. (2003). Conceptualizing and Proposing Qualitative Research (2nd Edition). Pearson.

Schwandt, T. (2001). Dictionary of Qualitative Inquiry, 2nd Ed, Sage, Thousand Oaks, California. 
Seale, C. (1999). The Quality of Qualitative Research. Sage.

Senge, P. (1990). The Fifth Discipline. The art and practice of the learning organization. London: Random House.

Sherman, H. (1984). Hospital efficiency measurement and evaluation. Empirical test of a new technique. Medical care 22(10): 922-38.

Shortell, S., \& Kaluzny, A. (1994). Health care management: Organisation, design and behaviour. New York, NY: Delmar.

Sieber, J. (1992). Planning Ethically Responsible Research. Sage.

Sikka, V., Luke, R., \& Ozcan, Y. (2009), The efficiency of hospital-based clusters: Evaluating sustem performance using data envelopment analysis. Health Care Manage Rev 34 (3): 251 261.

Slack, N., Chambers, S., \& Johnston, R., (2004), Operations Management, Harlow: FT Prentice Hall.

Solomon, P. (2002). Discovering information in context. Annual Review of information science Chap 5: 229-264 .

Stake, R. (2005). Qualitative case studies. In Denzin \& Lincoln (Eds.), Handbook of qualitative research (3rd ed., pp. 443-466). Thousand Oaks, CA: Sage.

Swales, R., \& Rouse, P. (2006). Pricing public health care services using DEA: Methodology versus politics. Ann. Oper. Res: 145: 265-80.

Sweller, J. (1994). Cognitive load theory, learning difficulty and instructional design. Learning and Instruction vol 4(4): 295-312.

Sweller, J. (2011). Cognitive Load Theory in pp 37-76, http://dx.doi.org/10.1016/B978-0-12387691-1.00002-8

Taylor, R. (1991). Information use environments. In B. Dervin \& M. Voight (Eds), Progress in Communication Sciences 10:217-255, Norwood NJ

Thomas, D. (2006). A General Inductive Approach for Analysing Qualitative Evaluation Data. Amer. J. Eval. Vol 27(2): 237-246.

Tolich, M. (2004). Internal confidentiality: When confidentiality assurances fail relational informants. Qualitative Sociology Vol 27(1): 101-106.

Tuckett, A. (2005). Applying thematic analysis theory to practice: a researcher's experience. Contemp Nurse. (Jul-Aug); 19(1-2): 75-87.

Tutulmaz, O. (2014). The Relationship of Technical Efficiency with Economical or Allocative Efficiency: An Evaluation, Journal of Research in Business and Management Volume 2 (9) pp: 01-12 ISSN(Online) : 2347-3002

Van de Walle, S., \& Bovaird, T. (2007). Making better use of information to drive improvement in local public services: A report for the Audit Commission. Birmingham Institute of local government studies. 
van Thiel, S., \& Leeuw, F. (2002). The performance paradox in the public sector. Public Performance and Management Review 25(3): 267-281

Vinkova, K. (2005). Using DEA Models to Measure Efficiency. BIATEC, Volume XIII, 8/2005, National Bank of Slovenia.

Waal, A. de (2010)., The characteristics of a high performance organisation, Social Science Research Network vol 32: 568-575.

http://papers.ssrn.com/sol3/papers.cfm?abstract_id=931873.

Webb, G. (1992). On pretexts for higher education development activities. Higher Education 24(3): 351-361. Google Scholar.

Webb, G. (1996). Understanding Staff Development. Buckingham: Open University Press.Google Scholar.

Wennberg, J. (2010). Tracking Medicine: A Researcher's Quest to Understand Health Care. OUP, NY.

Wiles, R., Crow, G., Heath, S., \& Charles, V. (2008). The Management of Confidnetiality amd Anonymity in Social Research. Int. J. Soc. Res. Method. Vol 11(5): 417-428.

Willig, C. (2008). Introducing qualitative research in psychology. $2^{\text {nd }}$ ed. England: OUP

Willis, J., \& Ricketts, M. (2004). The continuous learning cycle. Executive Edge.

Wilson, T. (1999). Models in information behaviour research. Journal of Documentation vol 55(3): 249-270.

Worthington, A. (2004). Frontier efficiency measurement in health care: A review of empirical techniques and selected applications. Medical Care Research and Review 61: 135170.

Yin, R. (1984). Case Study Research: Design and Methods. Beverly Hills, Calif: Sage Publications.

Yin, R. (2014). Case Study Research: Design and Methods (5th edn.). Thousand Oaks, CA: SAGE

Yin, R. (2015). Qualitative research from start to finish. (2nd ed). Thousand Oaks, CA: Sage. 


\section{Appendix 1: Narrative text and coding labels.}

\section{Narrative text}

The narrative text is from the interviews with participants. The focus is on managerial behaviour that is informed by management information. The management information referred to includes the MRE (DEA efficiency information) or RRP (traditional normative budgets, P\&Ls, Balance sheets, KPI factors and ratios).

\section{Coding}

- Each separate narrative text was categorised by a code label to identify in that text the important feature that might be relevant to answering the research questions. The code labels are terms or phrases to describe the narrative text; and allow sorting of text into categories of common description

- All of the narrative texts (data set) were coded.

- Code labels were based on the presumed meaning of underlying the narrative and framed from the perspective of the manager's response to the efficiency information.

- For example, with text: "Tell me that the result is real and not gobble de gook!" is coded as 'disbelief' in the information presented. I have not ventured into the participant's prevailing motive or attitude for the text as this is not relevant to the coding and theme development process.

- As each piece of text was read and the key feature identified and compared to all previous code labels to ascertain if there was a fit with an already developed code label. If no existing code labels would fit the new text, then a new code label would be identified.

- The coding approach was a semantic way where the focus is on reporting on the reality evident in the data (narrative text). This compares with the constructionist approach where the focus is on reporting on a particular, certain reality created by the data. The semantic way is preferred because it will more closely align the code labels to the data. 


\section{Participant 1}

\begin{tabular}{|c|c|}
\hline Text & \begin{tabular}{|c|} 
Code label \\
\end{tabular} \\
\hline $\begin{array}{l}\text {-Ok, so what does this tell me actually? I am surprised } \\
\text { about the efficiency score and do not really understand the } \\
\text { result. Can you check the data sources and calculation and } \\
\text { get back to me on how it can be useful to me? } \\
\text {-Tell me that the result is real and not gobble de gook! } \\
\text { - I like the report format and it is easy to read but I am not } \\
\text { sure of what it means. } \\
\text { - What do you expect [me to do] with this information? } \\
\text { - It is going to be difficult to use because I already get } \\
\text { performance reports that my GM wants me to review and } \\
\text { provide her with reports. }\end{array}$ & $\begin{array}{l}\text { Challenge to information } \\
\text { Disbelief in results } \\
\text { Resistance to signal } \\
\text { Questioning of action } \\
\text { Reference to senior management } \\
\text { need }\end{array}$ \\
\hline $\begin{array}{l}\text { - I have many reports that I use in writing my performance } \\
\text { reports. } \\
\text { - I am more interested in meeting my targets and what my } \\
\text { GM wants me to achieve. This is mainly to stay within } \\
\text { budget and keep clinical work going. }\end{array}$ & $\begin{array}{l}\text { Refer to variance reporting } \\
\text { Reference to senior management } \\
\text { need }\end{array}$ \\
\hline $\begin{array}{l}\text { - I am Ok based on your explanation of the DEA and the } \\
\text { MRE } \\
\text { - I think I would look at doing a review of the weekly } \\
\text { staffing roster and change it around so I can get a cheaper } \\
\text { mix of clinical staff. }\end{array}$ & Performance review intent \\
\hline $\begin{array}{l}\text {-It is interesting to look at the MRE just to remind myself } \\
\text { of what the score is for my service - because I know you } \\
\text { are coming! } \\
\text {-I am beginning to compare this with all the other reports I } \\
\text { get and I can see what the result means but I do not know } \\
\text { how to progress with the information. } \\
\text { - I am not sure if I am ready to talk to others about the } \\
\text { EMR. } \\
\text { - I mentioned it - your research I mean - to my GM and } \\
\text { she said to not let it hamper my normal duties or my } \\
\text { reporting of the performance reports. My CD was } \\
\text { interested though in learning about the research. }\end{array}$ & $\begin{array}{l}\text { Performance interest } \\
\text { Uncertain about performance } \\
\text { levers } \\
\text { Lack of confidence } \\
\text { Reference to senior management } \\
\text { need }\end{array}$ \\
\hline $\begin{array}{l}\text {-Yes, I do know what efficiency is and so do the other } \\
\text { service managers because we all have this as an objective } \\
\text { and we meet monthly. } \\
\text { - My definition of efficiency that I have in my mind is } \\
\text { when my service meets all its targets and stays within } \\
\text { budget. }\end{array}$ & $\begin{array}{l}\text { Resistance to new performance } \\
\text { signal } \\
\text { Refer to targets \& KPIs }\end{array}$ \\
\hline $\begin{array}{l}\text { - I do not know what is acceptable for efficiency } \\
\text { - I do not want to interact with my doctors and staff } \\
\text { because it - the discussions - will go all over the place. } \\
\text { - I also do not understand DEA well. Maybe you can come } \\
\text { and present it to them? }\end{array}$ & Refer to targets \& KPIs \\
\hline $\begin{array}{l}\text { - I reported on my variance analysis as normal because this } \\
\text { is what my GM wants of me. } \\
\text { - I did not believe there is enough information to talk about } \\
\text { roster changes from an efficiency point but I did reduce the } \\
\text { number of nurses over the weekend - made sense because } \\
\text { the CD/1 clinician number were away at a conference } \& \\
\text { patient-work was down. } \\
\text { - The real prompt for me was the MRE so I want to see if }\end{array}$ & $\begin{array}{l}\text { Refer to variance reporting } \\
\text { Improved Understanding of PI }\end{array}$ \\
\hline
\end{tabular}




\begin{tabular}{|c|c|}
\hline there has been an effect already! & \\
\hline $\begin{array}{l}\text {-No, I did not discuss the MRE in a formal setting with } \\
\text { clinicians but mentioned to the CD that we were doing this } \\
\text { research and that there was some interesting information } \\
\text { that I will share with him in the future. } \\
\text { - I am not sure I am able or even ready to discuss this } \\
\text { efficiency. I know my 'docs' will just fight me on it means. }\end{array}$ & $\begin{array}{l}\text { Collaboration influence } \\
\text { Lack of confidence }\end{array}$ \\
\hline $\begin{array}{l}\text { - The organisation and my GM! All she focuses on is } \\
\text { meeting targets that she has to report on; you know the } \\
\text { national targets and to make sure we remain in budget. } \\
\text { - we have a lot of protocols and policies to work my way } \\
\text { through if I want to change anything - then we get the } \\
\text { corporate experts and six sigma guys weighing in too, and } \\
\text { so as a service manager I am struggling to do my core job. }\end{array}$ & $\begin{array}{l}\text { Refer to variance reporting } \\
\text { Resistance to change - isolation }\end{array}$ \\
\hline $\begin{array}{l}\text { - I see my score has slightly increased - Is this because of } \\
\text { the change I made to the nurse roster? } \\
\text { - My other [routine] monthly reports show varied results, so } \\
\text { I will first need to write my variance reports for my GM. } \\
\text { - I want to see what else I can do that will improve my } \\
\text { efficiency even more. }\end{array}$ & $\begin{array}{l}\text { Improved Understanding of PI } \\
\text { Refer to variance reporting } \\
\text { Improved understanding of PI }\end{array}$ \\
\hline $\begin{array}{l}\text { - I think to improve the score I would really need to look at } \\
\text { the nursing and medical model of care and as first step } \\
\text { perhaps engage with them on looking at or service design. }\end{array}$ & Collaboration influence \\
\hline $\begin{array}{l}\text { - I will reallocate the staffing mix around, perhaps keep the } \\
\text { same number of consultant cover but reduce registrar } \\
\text { placements and specialist nursing over the weekends. } \\
\text {-This will be Ok with my CD, I hope and I will have to } \\
\text { show him the MRE and talk to him about it. }\end{array}$ & $\begin{array}{l}\text { Improved Understanding of PI } \\
\text { Collaboration influence }\end{array}$ \\
\hline $\begin{array}{l}\text { - I have thought about it and about using the information but } \\
\text { it is quite hard to talk to staff about an efficiency score as a } \\
\text { \% because they will say 'rubbish, we are already working } \\
\text { hard'. } \\
\text {-the report has some merits in providing a composed view } \\
\text { of actual performance on efficiency, which is a goal for me. }\end{array}$ & $\begin{array}{l}\text { Lack of confidence } \\
\text { Improved Understanding of PI }\end{array}$ \\
\hline $\begin{array}{l}\text { - As I said before I do think though the MRE can become } \\
\text { good in that it is a single reference point I can use. }\end{array}$ & Performance focus \\
\hline $\begin{array}{l}\text { - Yes, I will have to this time if I want to do what I said } \\
\text { about re-looking at or care service levels. }\end{array}$ & Collaboration influence \\
\hline $\begin{array}{l}\text { - I did what I said I was going to, there was some heat with } \\
\text { staff wanting to keep the normal staffing mix but it all } \\
\text { worked out. } \\
\text { - I was able to defend the change in staffing mix by still } \\
\text { staying within the care model and stating that this was more } \\
\text { efficient! }\end{array}$ & $\begin{array}{l}\text { Collaboration influence } \\
\text { Accountability practice }\end{array}$ \\
\hline $\begin{array}{l}\text {-Yes, I did! And I mentioned the increase score and the docs } \\
\text { were interested in knowing more and asked to be kept } \\
\text { informed. } \\
\text { - My nurse leader was a bit miffed though and said to be } \\
\text { careful about making sure of the quality of care provided. }\end{array}$ & $\begin{array}{l}\text { Accountability practice } \\
\text { Collaboration influence }\end{array}$ \\
\hline $\begin{array}{l}\text { - The same factors as I mentioned last time. } \\
\text { - My GM is the main problem I have I think! She is so } \\
\text { conscious of keeping corporate 'sweet' and therefore wants } \\
\text { me to maintain good clinical relationships. }\end{array}$ & Refer to variance reporting \\
\hline $\begin{array}{l}\text { - This is good information but I have to urgently concentrate } \\
\text { on why I did not meet my compliance target for treatment }\end{array}$ & Refer to targets \& KPIs \\
\hline
\end{tabular}


access

- I want to know if this method (MRE) is actually correct.

- I have thought about this and I think I would define

Improved Understanding of PI

efficiency as being able to do as much as possible within the budget.

- I will continue with the discussions on the service review and also keep reducing the nursing component over the weekends especially and maybe tweak the registrar level a bit too.

- I will redevelop a service mix plan that changes the staffing roles as well as service times for some of the outputs.

- I need to engage more with staff on this issue as well.

-the report has some merits in providing a composed view of actual performance on efficiency which is a goal for me

- I have started to speak of the MRE and the efficiency score as my benchmark.

- We are having a full staff meeting and I have placed this MRE report on the agenda as an information item only - so staff will not get too worried but we will discuss the results and targets in the MRE and what these mean at the meeting. - At the heads meeting I will definitely discuss the report and how we can further improve on or efficiency score.

- Yes, I managed to get agreement to adjust slightly the roster mix based on or preliminary view that we could amend or service pathway.

- I was surprised by the debate and the heat though - it would have been easier to not do anything but I sold it on the change in efficiency by your MRE.

- They were interested in the result, and thought it was great $\quad$ Collaboration influence we could improve or efficiency by slight staffing adjustments.

- They did say to me that they would be worried if I forgot quality and service levels in looking at efficiency only. - I agreed with them and said the challenge is to keep on maintaining the quality and level whilst gradually improving efficiency.

- The key constraint really is the need to engage with staff and consult with all stakeholders including clinical unions.

- We have to make sure we do not stuff anyone's employment agreement or imply there are staff performance issues.

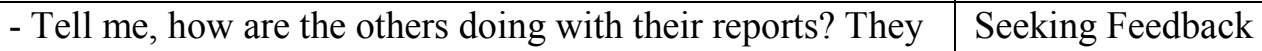
tell me that they like the information but often are not too sure as to what to do next.

- It is getting easier to read the MRE and know what to do to improve.

- I want to look at how my mix of staffing should change, so to achieve a higher efficiency score.

- As I mentioned, it is easy to read the efficiency

information but I don't know how easy it will be to convince the docs and nurses we can improve or efficiency if we change the mix of staff.

-I want to change the nursing mix around to improve on

input mix and expenditure.

Collaboration influence

Improved Understanding of PI

Collaboration influence

Improved Understanding of PI

Improved Understanding of PI

Collaboration influence

Collaboration influence

Improved Understanding of PI

Improved Understanding of PI 


\begin{tabular}{|c|c|}
\hline $\begin{array}{l}\text { - I think of how we can be more efficient. We should be at } \\
100 \% \text { so I will need to take a hard look at how I am using } \\
\text { staffing and the mix of capacity }\end{array}$ & \\
\hline $\begin{array}{l}\text {-the report is good in being a yardstick of actual } \\
\text { performance on efficiency, which I can share with staff. } \\
\text { - I realise also that the efficiency scoring DEA is quite } \\
\text { neutral isn't it? It takes the actual staffing mix and what we } \\
\text { have achieved in output terms and gives a score of } \\
\text { efficiency. }\end{array}$ & Improved Understanding of PI \\
\hline $\begin{array}{l}\text { - as I said before there are several reports I use in both } \\
\text { weekly during the month and monthly at month-end usually } \\
\text { early in the following months, that contain a range of } \\
\text { information on how well my service is performing and } \\
\text { progressing. But overall I think the MRE is good in that it is } \\
\text { a single reference point I can use. }\end{array}$ & Improved Understanding of PI \\
\hline $\begin{array}{l}\text { - You know I am now more comfortable with the EMR than } \\
\text { I was at the beginning. } \\
\text { - I used to be so nervous before in letting others see the } \\
\text { MRE but I see it in the monthly meeting as a discussion } \\
\text { item. }\end{array}$ & Collaboration influence \\
\hline $\begin{array}{l}\text { - I managed to switch the nursing mix around to have } \\
\text { assistants and so less registered nurses for the weekly wards. } \\
\text { - I talked to my CD and team about the MRE result and how } \\
\text { we could change to improve on the efficiency. }\end{array}$ & $\begin{array}{l}\text { Improved Understanding } \\
\text { Collaboration influence }\end{array}$ \\
\hline $\begin{array}{l}\text { - This last meeting I did not place it on the agenda, as we } \\
\text { had to focus on compliance rates with the timelines for } \\
\text { treatment. They asked me though to provide some feedback } \\
\text { at the end of the meeting. }\end{array}$ & Reference to variance reporting \\
\hline $\begin{array}{l}\text { - I suspect I need to provide the focus for a more efficient } \\
\text { service. } \\
\text { - We still need the support of lots of people and the OK of } \\
\text { my GM. I think being able to talk through the efficiency } \\
\text { issues with my GM first and then develop an action plan } \\
\text { helps }\end{array}$ & Collaboration influence \\
\hline $\begin{array}{l}\text { - Just to let you I will be talking to my director about the } \\
\text { way we arrange services. }\end{array}$ & Collaboration influence \\
\hline $\begin{array}{l}\text { - I have thought about this and I think I would define } \\
\text { efficiency as being able to do as much as possible within the } \\
\text { budget. } \\
\text { - I need to engage all relevant senior staff and also the allied } \\
\text { heads, to talk about this. }\end{array}$ & Collaboration influence \\
\hline $\begin{array}{l}\text { - I am looking at changing the ward structure of one of one } \\
\text { of my wards to have more patient mix and so staff can be } \\
\text { reduced with on calls. }\end{array}$ & Collaboration influence \\
\hline $\begin{array}{l}\text {-the report is very useful in helping me and my team view } \\
\text { actual efficiency performance. }\end{array}$ & acceptance \\
\hline $\begin{array}{l}\text { - As I said, the MRE is a single reference. } \\
\text { - The MRE and the monthly efficiency score is my measure } \\
\text { of efficiency. }\end{array}$ & Improved Understanding \\
\hline $\begin{array}{l}\text { - Yes, as I said last month, this is now part of our monthly } \\
\text { agenda. } \\
\text { - I suspect that folk look to this item to bring to the table } \\
\text { ideas and issues around efficiency. }\end{array}$ & Collaboration influence \\
\hline $\begin{array}{l}\text { I had several discussions and a formal meeting with staff } \\
\text { and my GM on making a ward change to merge with }\end{array}$ & Collaboration influence \\
\hline
\end{tabular}




\begin{tabular}{|c|c|}
\hline $\begin{array}{l}\text { another service ward. This way, we can both have shared } \\
\text { staff across both services. }\end{array}$ & \\
\hline $\begin{array}{l}\text { - Yes we did, I pointed out that we were steadily improving } \\
\text { but do better if we increased or treatment levels - will need } \\
\text { their support; or continue to look for other mixes of staffing. } \\
\text { - I talked about DEA and efficiency as if I had invented it! }\end{array}$ & $\begin{array}{l}\text { Collaboration influence } \\
\text { Improved confidence }\end{array}$ \\
\hline $\begin{array}{l}\text {-I have to be sure of the facts and get good data, which is } \\
\text { quite hard to do here. } \\
\text { - The time factor is quite difficult to get around as there are } \\
\text { many other priorities but I think the overall bottleneck is } \\
\text { just me getting ideas through. }\end{array}$ & Lack of confidence \\
\hline $\begin{array}{l}\text { - I have nothing really. I understand the MRE I hope. } \\
\text { - The efficiency signal and the targets are clear enough and } \\
\text { give me discussion points with staff and my GM. }\end{array}$ & Collaboration influence \\
\hline $\begin{array}{l}\text { - The results in the MRE are encouraging as it is improving } \\
\text { steadily. } \\
\text { - It means that I need to continue with what I am doing and } \\
\text { just push it more. }\end{array}$ & Improved Understanding \\
\hline $\begin{array}{l}\text { - Similar to last month, I want to cement in the changed } \\
\text { resource staffing mix that will lead to higher efficiency. }\end{array}$ & Improved Understanding \\
\hline $\begin{array}{l}\text {-the report has merit in providing us with a composed view } \\
\text { of actual performance on efficiency which is a goal for me. }\end{array}$ & Improved understanding \\
\hline $\begin{array}{l}\text { - as I said before there are several reports I use to use in } \\
\text { both weekly during the month and monthly at month-end } \\
\text { early in the following months, that contain a range of } \\
\text { information on how well my service is performing and } \\
\text { progressing. } \\
\text { - But overall I think the MRE is good in that it is a single } \\
\text { and a common reference point for me and staff. }\end{array}$ & $\begin{array}{l}\text { Collaboration influence } \\
\text { Improved Understanding }\end{array}$ \\
\hline $\begin{array}{l}\text { - I continued on with what I was going to do. I got positive } \\
\text { support from the } \mathrm{CD} \text { and also my GM and so I was able to } \\
\text { maintain the merged service ward and new staffing mix. }\end{array}$ & Collaboration influence \\
\hline $\begin{array}{l}\text { - I can and I now do - although there are some heated } \\
\text { discussions between staff about the way forward and ways } \\
\text { of changing the efficiency score. } \\
\text { - I am thinking of distributing the MRE when it comes } \\
\text { available to me so that my staff/CD can get a chance to } \\
\text { review the information before we have a discussion on it. } \\
\text { - this the EMR is also on my list of agenda items for my } \\
\text { one-on-one meeting with my GM. }\end{array}$ & $\begin{array}{l}\text { Improved Understanding } \\
\text { Growing confidence } \\
\text { Collaboration influence }\end{array}$ \\
\hline
\end{tabular}

\section{Participant 2}

\begin{tabular}{|c|c|}
\hline Text & Code label \\
\hline $\begin{array}{l}\text { - I don't know what the efficiency score really means. } \\
\text { - The report is easy to read but what do you expect me to do } \\
\text { now? } \\
\text { - I get other reports which the GM wants me to present my } \\
\text { performance. }\end{array}$ & $\begin{array}{l}\text { Challenge } \\
\text { Resistance } \\
\text { Refer to variance reporting }\end{array}$ \\
\hline $\begin{array}{l}\text { - My GM wants me to stay within budget. And to report on } \\
\text { clinical delivery targets. } \\
\text { - I think though that we can look at how we are using staff fo }\end{array}$ & $\begin{array}{l}\text { Refer to variance reporting } \\
\text { Improved understanding }\end{array}$ \\
\hline
\end{tabular}




\begin{tabular}{|c|c|}
\hline the treatment outputs. & \\
\hline $\begin{array}{l}\text { - I don't know if this is relevant on its own. - But, I think I } \\
\text { would look to change the overall performance of the staffing } \\
\text { roster and mix of clinical staff. }\end{array}$ & Improved understanding \\
\hline $\begin{array}{l}\text { - The MRE for my service compares with the other reports I get } \\
\text { and gives a sense of where my overall performance level is. } \\
\text { - I have talked to some staff about the EMR and they agree it } \\
\text { appears useful in showing a result on performance. But, it will } \\
\text { be difficult to get everyone to agree. }\end{array}$ & $\begin{array}{l}\text { Improved understanding } \\
\text { Collaboration influence }\end{array}$ \\
\hline $\begin{array}{l}\text {-My measure of efficiency is we do things at lower cost as } \\
\text { possible and we keep within budget. } \\
\text { - Your MRE suggests another way and it makes some sense, I } \\
\text { think, to look at my inputs and the outputs together. }\end{array}$ & $\begin{array}{l}\text { Improved understanding } \\
\text { Improved understanding }\end{array}$ \\
\hline $\begin{array}{l}\text { - I want to understand it more myself first. } \\
\text { - This information will be good to spark discussion with staff } \\
\text { and my GM to agree on what we can do. }\end{array}$ & $\begin{array}{l}\text { Lack of confidence } \\
\text { Improved understanding }\end{array}$ \\
\hline $\begin{array}{l}\text { - I reduced the usual doctor complement for the weekend and } \\
\text { based it on the likely workload with fewer patients expected. } \\
\text { - I discussed the report with senior staff at our team meeting } \\
\text { although the response was not that positive as we did not know } \\
\text { how this would be accepted by the executive leadership team. }\end{array}$ & $\begin{array}{l}\text { Improved understanding } \\
\text { Collaboration influence }\end{array}$ \\
\hline $\begin{array}{l}\text {-Yes, I did discuss the MRE in a formal setting with clinicians } \\
\text { as mentioned earlier. }\end{array}$ & Collaboration influence \\
\hline $\begin{array}{l}\text { - My GM is entirely focussed on top line reporting and ensuring } \\
\text { that we have an explanation available for any variance or bad } \\
\text { result. } \\
\text { - We are busy with the national \& ESPI targets making sure that } \\
\text { we report as many volumes as possible. So all my information is } \\
\text { geared towards results of target achievement. } \\
\text { - We are not tasked with being specifically efficient and we } \\
\text { don't get any data on this anyway. }\end{array}$ & Refer to variance reporting \\
\hline $\begin{array}{l}\text { - I assume the increase in the efficiency score is because of the } \\
\text { change I made to the doctor numbers. } \\
\text { - I still have to write my GM's monthly report based on my } \\
\text { variance reports and I would like to mention this information. } \\
\text { - I like the report's display of my resource inputs and outputs } \\
\text { and then the indicative targets to improve. Is this valid? }\end{array}$ & $\begin{array}{l}\text { Improved understanding } \\
\text { Refer to variance reporting } \\
\text { Improved understanding }\end{array}$ \\
\hline $\begin{array}{l}\text { - To improve I need to reduce doctor and nursing numbers, but I } \\
\text { won't as there will be hard fight-back. }\end{array}$ & Lack of confidence \\
\hline $\begin{array}{l}\text { - I don't think that I will now. I mean I know that we should } \\
\text { change the staffing mix around, but this will create a lot of noise } \\
\text { and angst. } \\
\text {-My GM is Ok with my results overall so why should I do } \\
\text { anything with this. }\end{array}$ & $\begin{array}{l}\text { Lack of confidence } \\
\text { Refer to variance reporting }\end{array}$ \\
\hline $\begin{array}{l}\text { - I have thought about it and about using the information but it } \\
\text { is quite hard to talk to staff about an efficiency score as a \% } \\
\text { because they will say 'rubbish, we are already working hard'. }\end{array}$ & Barrier/no action intent \\
\hline $\begin{array}{l}\text { - I will use the EMR as my measure but also need to cover the } \\
\text { other reports. }\end{array}$ & Accountability practice \\
\hline - No, I will wait and see if anyone asks for this. & Refer to variance reporting \\
\hline $\begin{array}{l}\text { - I sort of did in that I kept roughly the same staffing mix. } \\
\text { - I had several engaged discussions with staff and GM on the } \\
\text { care model to be more efficient! }\end{array}$ & $\begin{array}{l}\text { No action intent } \\
\text { Collaboration influence }\end{array}$ \\
\hline -Yes, I did mention the increase of the score and that this was & Improved understanding \\
\hline
\end{tabular}




\begin{tabular}{|c|c|}
\hline $\begin{array}{l}\text { due to reducing slightly the number of doctor but also conceded } \\
\text { that this was a one off. }\end{array}$ & \\
\hline $\begin{array}{l}\text { - The same factors as I mentioned last time. } \\
\text { - My GM is the main problem I have She wants me to maintain } \\
\text { clinical relationships and not to upset my CD. }\end{array}$ & Refer to variance reporting \\
\hline $\begin{array}{l}\text { - This is good information but I won't be using it. } \\
\text { - I have to urgently report on why my service did not meet our } \\
\text { compliance target for treatment access. }\end{array}$ & $\begin{array}{l}\text { Lack of confidence } \\
\text { Refer to variance reporting }\end{array}$ \\
\hline $\begin{array}{l}\text { - I have thought about this and I think I would define efficiency } \\
\text { as being able to do as much as possible within the budget. } \\
\text { - I will continue with the discussions on the service review and } \\
\text { also keep reducing the nursing component over the weekends } \\
\text { especially and maybe tweak the registrar level a bit too. }\end{array}$ & $\begin{array}{l}\text { Improved understanding } \\
\text { Collaboration influence }\end{array}$ \\
\hline $\begin{array}{l}\text {-this does provide a balanced view of actual performance on } \\
\text { efficiency which is a long term goal for me }\end{array}$ & $\begin{array}{l}\text { Acceptance of new } \\
\text { knowledge }\end{array}$ \\
\hline $\begin{array}{l}\text { - I understand the measure as provided by MRE but this is } \\
\text { difficult to align with the other KPIs and budget results we get. } \\
\text { - The MRE is useful as a benchmark of efficiency and so I will } \\
\text { keep it in my mind. }\end{array}$ & $\begin{array}{l}\text { Uncertainty of } \\
\text { performance levers } \\
\text { Growing confidence }\end{array}$ \\
\hline $\begin{array}{l}\text { - I will discuss the EMR with staff if we get time and the mood } \\
\text { is right. }\end{array}$ & Uncertainty \\
\hline $\begin{array}{l}\text { - Yes, I managed to get agreement to adjust slightly the roster } \\
\text { mix based on or preliminary view that we could amend or } \\
\text { service pathway. } \\
\text { - I was surprised by the debate and the heat though - it would } \\
\text { have been easier to not do anything but I sold it on the change in } \\
\text { efficiency by your MRE. }\end{array}$ & $\begin{array}{l}\text { Improved understanding } \\
\text { Collaboration influence }\end{array}$ \\
\hline $\begin{array}{l}\text { - They were interested in the result, and thought it was great we } \\
\text { could improve or efficiency by slight staffing adjustments. } \\
\text { - They did say to me that they would be worried if I forgot } \\
\text { quality and service levels in looking at efficiency only. } \\
\text { - I agreed with them and said the challenge is to keep on } \\
\text { maintaining the quality and level whilst gradually improving } \\
\text { efficiency. }\end{array}$ & Collaboration influence \\
\hline $\begin{array}{l}\text { - The key constraint really is the need to consult with all staff } \\
\text { and this takes time and a lot of effort and process. }\end{array}$ & Barrier \\
\hline $\begin{array}{l}\text { - I know that because I haven't done anything on efficiency in } \\
\text { the past two months, I am back to when we started from. - } \\
\text { From reading the EMR, it is fairly clear where we can improve } \\
\text { but the how is hard and will involve talking to others/GM. }\end{array}$ & Lack of confidence \\
\hline $\begin{array}{l}\text { - Yes, my mix of staffing must change to achieve a higher } \\
\text { efficiency score. } \\
\text { - I think of how we can be more efficient. We should be at } \\
100 \% \text { so I will need to take a hard look at how I am using } \\
\text { staffing and the mix of capacity } \\
\text { - I will bring this up with my GM and CD on how we can } \\
\text { improve efficiency by switching the mix of staff a little. }\end{array}$ & $\begin{array}{l}\text { Improved understanding } \\
\text { Confidence } \\
\text { Collaboration influence }\end{array}$ \\
\hline $\begin{array}{l}\text {-I want to change the nursing mix around to improve on input } \\
\text { mix and expenditure. }\end{array}$ & Improved understanding \\
\hline $\begin{array}{l}\text {-the report is good in being a yardstick of actual performance on } \\
\text { efficiency, which I can share with staff. } \\
\text { - I realise also that the efficiency scoring DEA is quite neutral } \\
\text { isn't it? It takes the actual staffing mix and what we have } \\
\text { achieved in output terms and gives a score of efficiency. }\end{array}$ & $\begin{array}{l}\text { Practice of accountability } \\
\text { Performance focus }\end{array}$ \\
\hline - as I said before there are several reports I use both weekly & Uncertainty/status quo \\
\hline
\end{tabular}




\begin{tabular}{|c|c|}
\hline $\begin{array}{l}\text { during the month and monthly at month-end usually early in the } \\
\text { following months, that contain a range of information on how } \\
\text { well my service is performing and progressing. But overall I } \\
\text { think the MRE is good in that it is a single reference point I can } \\
\text { use. }\end{array}$ & \\
\hline $\begin{array}{l}\text { - Yes, I am comfortable with the MRE than I was earlier and } \\
\text { will table it discussion item when we meet. }\end{array}$ & Collaboration influence \\
\hline $\begin{array}{l}\text { - I talked to my CD and team about the MRE result and how we } \\
\text { could change to improve on the efficiency. }\end{array}$ & Practice of accountability \\
\hline $\begin{array}{l}\text { - This last meeting I did not place it on the agenda, as we had to } \\
\text { focus on compliance rates with the timelines for treatment. } \\
\text { They asked me though to provide some feedback at the end of } \\
\text { the meeting. }\end{array}$ & Refer to variance reporting \\
\hline $\begin{array}{l}\text { - We don't have an agreed focus on what it means for a more } \\
\text { efficient service, although when we talk about this we always } \\
\text { mean less expenditure. } \\
\text { - My GM and CE still prefer to simply have reports that explain } \\
\text { my results and variances with action plans that involve lots of } \\
\text { meetings. }\end{array}$ & Refer to variance reporting \\
\hline $\begin{array}{l}\text { - It is good that we can see the improved result from the staffing } \\
\text { switch last month. This is good feedback and I know my staff } \\
\text { and CD will be keen. }\end{array}$ & Improved understanding \\
\hline $\begin{array}{l}\text { - I think I would define efficiency as being able to keep within } \\
\text { the budget whilst doing much as possible. } \\
\text { - I need to engage all relevant senior staff and also the allied } \\
\text { heads, to talk about this. }\end{array}$ & $\begin{array}{l}\text { Refer to variance reporting } \\
\text { Collaboration intent }\end{array}$ \\
\hline $\begin{array}{l}\text { - I am going to push for a bigger shift in medical to nursing } \\
\text { cover over the week wards. }\end{array}$ & Performance focus \\
\hline $\begin{array}{l}\text { - As mentioned, I am finding the report easy to read and } \\
\text { understand and I think it is a good way of measuring our overall } \\
\text { view of actual efficiency. }\end{array}$ & Improved understanding \\
\hline $\begin{array}{l}\text { - As I said, the MRE is a single reference. } \\
\text { - The MRE and the monthly efficiency score is my measure of } \\
\text { efficiency. }\end{array}$ & $\begin{array}{l}\text { Confidence in new } \\
\text { information } \\
\text { Confidence in new } \\
\text { information }\end{array}$ \\
\hline - Yes, I will table this item to discuss ideas around efficiency. & Collaboration influence \\
\hline $\begin{array}{l}\text { I had several formal discussions with staff and my GM on } \\
\text { making a change to shift staff across the service to get more } \\
\text { nurses and less cover at the ward side by medical staff and to } \\
\text { use on-call staff instead. }\end{array}$ & Collaboration influence \\
\hline - Yes we did, we had improved over the past month. & $\begin{array}{l}\text { Confidence in new } \\
\text { information }\end{array}$ \\
\hline $\begin{array}{l}\text { - My GM is always nervous about any possible ructions with } \\
\text { clinical staff and their unions so is keen to keep them happy and } \\
\text { for me to just focus on administration matters. } \\
\text { - doing a business cases for any change requires a lot of effort } \\
\text { and resources which I don't have and so I am reliant on others } \\
\text { and this gets difficult at times. }\end{array}$ & $\begin{array}{l}\text { Refer to variance reporting } \\
\text { Resistance to change - } \\
\text { isolation }\end{array}$ \\
\hline - The MRE is clear. & Improved understanding \\
\hline $\begin{array}{l}\text { The results in the MRE show that I should continue with what I } \\
\text { am doing and just push it more. }\end{array}$ & Improved understanding \\
\hline - Similar to last month. & \\
\hline $\begin{array}{l}\text { - The information is useful and interesting in reminding me } \\
\text { about being an efficient service. }\end{array}$ & Improved understanding \\
\hline
\end{tabular}




\begin{tabular}{|l|l|}
\hline $\begin{array}{l}\text { - Yes, the DEA measure as shown in the MRE is good, I think, } \\
\text { and will serve as a good benchmark. }\end{array}$ & Improved understanding \\
\hline $\begin{array}{l}\text { - Yes, I will be continuing to share the MRE with staff and my } \\
\text { GM and maybe with the other service managers. } \\
\text { - Maybe there is some learning from across the other service } \\
\text { managers as well - what do you think? }\end{array}$ & $\begin{array}{l}\text { Collaboration influence } \\
\text { Collaboration influence }\end{array}$ \\
\hline $\begin{array}{l}\text { I just carried on talking with the CD and my GM to maintain the } \\
\text { new staffing mix. }\end{array}$ & Collaboration influence \\
\hline $\begin{array}{l}\text { - I now discuss the MRE with staff/CD to review any likely } \\
\text { improvement possibilities. }\end{array}$ & Collaboration influence \\
\hline $\begin{array}{l}\text { - Same as before, I am under pressure like the other service } \\
\text { managers to meet targets, keep to budget and keep staff happy, } \\
\text { so it gets too much at times to think about performance } \\
\text { improvement. } \\
\text { - We don't get good data the way this MRE. }\end{array}$ & Refer to variance reporting \\
\hline
\end{tabular}




\begin{tabular}{|c|c|}
\hline Text & Code label \\
\hline $\begin{array}{l}\text { - This is good. I like the one page report and the score with } \\
\text { the targets to improve on. }\end{array}$ & Acceptance \\
\hline $\begin{array}{l}\text { - I will look to reducing my staffing costs so will use less } \\
\text { FTEs. }\end{array}$ & Performance focus \\
\hline $\begin{array}{l}\text { - I will change the overall staffing roster and mix of clinical } \\
\text { staff. }\end{array}$ & Improved understanding \\
\hline $\begin{array}{l}\text { - It provides me with a sense of how well my service } \\
\text { efficiency is at this point in time compared to past months, } \\
\text { so it is very useful because we should be improving. } \\
\text { Shouldn't we? } \\
\text { - I want to have this as a team discussion but it will be } \\
\text { difficult to get everyone to agree to do this. }\end{array}$ & $\begin{array}{l}\text { Improved understanding } \\
\text { Lack of confidence }\end{array}$ \\
\hline $\begin{array}{l}\text {-I used to think it was minimal cost but now I will use the } \\
\text { DEA example, of optimum mix of inputs and outputs. }\end{array}$ & Improved understanding \\
\hline $\begin{array}{l}\text { - I will share this EMR to initiate discussions with staff and } \\
\text { my GM and to focus on efficiency as optimising our use of } \\
\text { inputs and outputs. }\end{array}$ & Collaboration influence \\
\hline $\begin{array}{l}\text { - I did manage to reduce the staffing complement for one of } \\
\text { the wards, with cover from the other in case of overload. } \\
\text { - My senior staff took a while to talk through the EMR and } \\
\text { my action, but I was able to show them as you had outlined } \\
\text { the possible cause effect on efficiency. }\end{array}$ & $\begin{array}{l}\text { Performance focus/confidence } \\
\text { Collaboration influence }\end{array}$ \\
\hline $\begin{array}{l}\text {-Yes, the MRE was tabled and discussed. } \\
\text { - The GM was not happy and asked me for an explanation } \\
\text { and so this took time but I think I did convince her that it } \\
\text { would be ok. }\end{array}$ & $\begin{array}{l}\text { Collaboration influence } \\
\text { Refer to variance reporting }\end{array}$ \\
\hline $\begin{array}{l}\text { - I think the organisation as a whole is just focussed on } \\
\text { maintaining the status quo and we have a lot of people } \\
\text { employed to write reports and produce data but it is top } \\
\text { driven, and although I get send some of it, it is no use. } \\
\text { - I am usually kept busy with information requests and } \\
\text { reports to the top. }\end{array}$ & $\begin{array}{l}\text { No specific knowledge } \\
\text { Refer to variance reporting }\end{array}$ \\
\hline $\begin{array}{l}\text { - I like it that it shows the big change almost immediately } \\
\text { because of the change I made to the roster. } \\
\text { - It is a shame I still write my monthly report based on } \\
\text { variance information. }\end{array}$ & $\begin{array}{l}\text { Improved understanding } \\
\text { Refer to variance reporting }\end{array}$ \\
\hline $\begin{array}{l}\text { - I have read the targets and will continue with the staff } \\
\text { discussions on the service review and also keep the mix of } \\
\text { the nursing and the registrar levels. }\end{array}$ & Collaboration influence \\
\hline $\begin{array}{l}\text { - I will carry on improving the efficiency by changing the } \\
\text { staff roster mix. }\end{array}$ & Improved understanding \\
\hline $\begin{array}{l}\text { - I am finding it exciting to see the positive change in score, } \\
\text { and useful in having this information to be able to show } \\
\text { staff and talk about it. }\end{array}$ & Collaboration influence \\
\hline $\begin{array}{l}\text { - Yes, as I said last month the optimum use of inputs to } \\
\text { outputs is an interesting measure which I found that the } \\
\text { doctors also like as a concept on an intellectual level. }\end{array}$ & Collaboration influence \\
\hline $\begin{array}{l}\text { - Yes, it is actually not all threatening because I sell it as a } \\
\text { concept of getting an optimal mix of resource use to output } \\
\text { delivered. }\end{array}$ & Improved understanding \\
\hline $\begin{array}{l}\text {-Yes, I did mention the increase of the score and that this } \\
\text { was due to reducing slightly the number of doctor but also }\end{array}$ & Collaboration influence \\
\hline
\end{tabular}




\begin{tabular}{|c|c|}
\hline conceded that this was a one off. & \\
\hline $\begin{array}{l}\text { - The same as I mentioned last time. } \\
\text { - My GM is worried that this will lead to problems with the } \\
\text { clinicians, so I had to talk to her with my CD who is } \\
\text { supportive. }\end{array}$ & barrier \\
\hline - This is good information. & Improved understanding \\
\hline $\begin{array}{l}\text { - To improve I need to reduce my doctor and nursing } \\
\text { numbers, but this will be a big shock and in this month we } \\
\text { have a 'registrar learning lab' so we will have an increased } \\
\text { FTE on the wards. }\end{array}$ & Improved understanding \\
\hline $\begin{array}{l}\text { - I will allow a slight increase in staffing to cope with the } \\
\text { on-ward education programme over the next two weeks. } \\
\text { - But, overall I know we will keep changing the staffing mix } \\
\text { around. }\end{array}$ & $\begin{array}{l}\text { Improved understanding } \\
\text { Collaboration influence }\end{array}$ \\
\hline -this does provide actual performance on efficiency. & Improved understanding \\
\hline $\begin{array}{l}\text { - Yes, as last month. I now am beginning to share this with } \\
\text { staff as well. }\end{array}$ & Collaboration influence \\
\hline - I will discuss the MRE with staff. & Collaboration influence \\
\hline - Yes, I adjusted upwards the roster mix. & Collaboration influence \\
\hline $\begin{array}{l}\text { - Staff seems interested in the result. I think it is because I } \\
\text { was flexible in our staffing and did not simply use the EMR } \\
\text { as a big stick to force more efficiency behaviours but } \\
\text { adjusted it to suit the context. }\end{array}$ & Collaboration influence \\
\hline $\begin{array}{l}\text { - The time taken to consult with staff takes effort and a lot of } \\
\text { process. }\end{array}$ & Improved understanding \\
\hline $\begin{array}{l}\text { - I know it shows that because in the previous month I } \\
\text { deliberately kept up my staffing level, we dropped in the } \\
\text { efficiency score. }\end{array}$ & Refer to variance reporting \\
\hline $\begin{array}{l}\text { - Yes, my mix of staffing must change to achieve a higher } \\
\text { efficiency score. }\end{array}$ & Performance focus \\
\hline $\begin{array}{l}\text {-I want to change the nursing mix around to improve on } \\
\text { input mix and expenditure. }\end{array}$ & Improved understanding \\
\hline - The report is good, which I can share with staff. & Collaboration influence \\
\hline $\begin{array}{l}\text { - Yes, thinking about the optimum mix is very useful in } \\
\text { generating ideas about performance but I am limited in my } \\
\text { ability to act. }\end{array}$ & barrier \\
\hline - Yes, I will keep tabling it as a meeting discussion item. & Collaboration influence \\
\hline $\begin{array}{l}\text { - I managed to switch the nursing mix around to have } \\
\text { assistants and so had fewer registered nurses for the weekly } \\
\text { wards. }\end{array}$ & Improved understanding \\
\hline $\begin{array}{l}\text { - Yes, the team showed interest and provided positive } \\
\text { feedback at the end of the meeting. }\end{array}$ & Collaboration influence \\
\hline $\begin{array}{l}\text { - As an organisation, we are still to agree on efficiency of a } \\
\text { service; rather the focus is on budget centres and on the } \\
\text { hospital as a whole and we forget the hospital is a collection } \\
\text { of services. }\end{array}$ & Collaboration influence \\
\hline - I am ok with the information as it is outlined in the EMR & Improved understanding \\
\hline $\begin{array}{l}\text { - I have thought about this and believe all relevant senior } \\
\text { staff need to agree on further changes to our resource uses. }\end{array}$ & \\
\hline $\begin{array}{l}\text { - I will shift more lower-grade nurses in place of specialist } \\
\text { nurse cover as well as limit the registrar call-cover for the } \\
\text { wards over the next few weeks. }\end{array}$ & Improved understanding \\
\hline $\begin{array}{l}\text { - As mentioned, I am finding the report easy to read and } \\
\text { understand and I think it is a good way of measuring our }\end{array}$ & Improved understanding \\
\hline
\end{tabular}




\begin{tabular}{|l|l|}
\hline overall view of actual efficiency. & \\
\hline $\begin{array}{l}\text { - As I said, the EMR is a single reference. } \\
\text { - The MRE and the monthly efficiency score is my measure } \\
\text { of efficiency. }\end{array}$ & $\begin{array}{l}\text { Improved understanding } \\
\text { Improved } \\
\text { understanding/acceptance }\end{array}$ \\
\hline $\begin{array}{l}\text { - Yes, I will table this report to generate discussion and } \\
\text { hopefully this will show people why my staff changes are } \\
\text { needed. }\end{array}$ & \\
\hline I did shift nursing staff grades across the wards. & Improved understanding \\
\hline $\begin{array}{l}\text { - The usual noise that comes from the top and all the } \\
\text { processes in place that protect the strong employment } \\
\text { collectives. } \\
\text { - as I said before my GM is also an obstruction and requires } \\
\text { considerable effort in getting her to shift her away from her } \\
\text { normal no change attitude. }\end{array}$ & Refer to variance reporting \\
\hline $\begin{array}{l}\text { - The MRE is clear. I am happy with the last months result. } \\
\text { I don't think we can do any better, can we? Without major } \\
\text { restructure! I am just joking about restructuring because I } \\
\text { don't want to do this as it will be pointless, we will just have } \\
\text { a lot of stress and for what. }\end{array}$ & Collaboration influence \\
\hline $\begin{array}{l}\text { - I should just try to maintain the resource levels at current } \\
\text { state and ensure that treatment outputs are ok as well. }\end{array}$ & Improved understanding \\
\hline - Similar to last month, nothing too drastic! & Improved understanding \\
\hline $\begin{array}{l}\text { - As I said, the information is useful. } \\
\text { - I will keep using the DEA measure in the MRE. }\end{array}$ & Improved understanding \\
\hline - Yes, I do share the MRE with staff and my GM. & Collaboration influence \\
\hline $\begin{array}{l}\text { - I don't think I did anything specific but we still carried on } \\
\text { with the previous months roster mix }\end{array}$ & Performance focus \\
\hline $\begin{array}{l}\text { - The EMR and the efficiency score is discussed and } \\
\text { reviewed with my CD. }\end{array}$ & Collaboration influence \\
\hline $\begin{array}{l}\text { - Same as before. Nothing has change there. } \\
\text { - I am more confident now of being able to manage my } \\
\text { service's performance, which I never was before this. }\end{array}$ & Improved understanding \\
\hline
\end{tabular}




\begin{tabular}{|c|c|}
\hline Text & Code label \\
\hline $\begin{array}{l}\text { - I really like the one page report and the targets to improve } \\
\text { on. } \\
\text { - I don't really understand the concept but it is ok and sounds } \\
\text { reasonable. However, we already have a lot of other reports } \\
\text { on our performance. } \\
\text { - I like the specific efficiency focus on this report. }\end{array}$ & $\begin{array}{l}\text { Acceptance } \\
\text { Refer to variance reporting } \\
\text { acceptance }\end{array}$ \\
\hline $\begin{array}{l}\text { - I am not sure because up to now I have focussed on } \\
\text { managing my budget well and keeping service productivity as } \\
\text { high as possible. } \\
\text { - In fact I have just realised that despite all the performance } \\
\text { reports we get, there is actually nothing on productivity. } \\
\text { - Maybe I may look at seeing how I can improve my service } \\
\text { efficiency score using your method. }\end{array}$ & $\begin{array}{l}\text { Refer to variance reporting } \\
\text { Awareness increase } \\
\text { Growing awareness }\end{array}$ \\
\hline $\begin{array}{l}\text { - I want to understand fully first the MRE means before I } \\
\text { decide what it is I need to do although I believe we will need } \\
\text { to look at the overall roster mix of clinical staff. }\end{array}$ & $\begin{array}{l}\text { Information challenges/ } \\
\text { uncertainty }\end{array}$ \\
\hline $\begin{array}{l}\text { - As I said to you when we met at the first meeting, I wanted } \\
\text { to understand better the DEA and the MRE. } \\
\text { - I think I do, I like the month on month scoring just for my } \\
\text { service alone so I am not compared to other different services. } \\
\text { - I will wait a while to decide if I take this to a team } \\
\text { discussion. }\end{array}$ & $\begin{array}{l}\text { Information challenge } \\
\text { Uncertainty } \\
\text { Barrier }\end{array}$ \\
\hline $\begin{array}{l}\text { - For me, it is getting things done at lowest cost or effort. But, } \\
\text { I see that you have defined it differently in your EMR. } \\
\text { - I may think about the DEA, of optimum mix of inputs and } \\
\text { outputs. }\end{array}$ & $\begin{array}{l}\text { Awareness increase } \\
\text { uncertainty }\end{array}$ \\
\hline $\begin{array}{l}\text { - I am not sure if I am ready to share this MRE or that staff } \\
\text { are in a space where they will be positive in any discussions. }\end{array}$ & $\begin{array}{l}\text { Lack of confidence (in } \\
\text { reactions) }\end{array}$ \\
\hline $\begin{array}{l}\text { - I did not do anything in particular. As I said I wanted to wait } \\
\text { a while. }\end{array}$ & Refer to variance reporting \\
\hline $\begin{array}{l}\text { - I mentioned the MRE but I did not discuss it nor did I table } \\
\text { it. }\end{array}$ & Lack of confidence \\
\hline $\begin{array}{l}\text { - The organisation is just madly focussed on reporting as } \\
\text { positive as possible to MOH and our Board. So I as a service } \\
\text { manager am kept very busy most of the times by corporate } \\
\text { demand. }\end{array}$ & Barrier status quo \\
\hline $\begin{array}{l}\text { - I like that it shows a slight change because of the resource } \\
\text { change that occurred early in the last month. }\end{array}$ & Increased understanding \\
\hline $\begin{array}{l}\text { - In the EMR, the targets mean that I should amend the } \\
\text { service mix of nursing and medical registrar levels. }\end{array}$ & Increased understanding \\
\hline - I will try changing the staff mix. & Acceptance/confidence \\
\hline $\begin{array}{l}\text { - The information seems useful and interesting in initiating } \\
\text { discussions anyway. }\end{array}$ & Collaboration influence \\
\hline $\begin{array}{l}\text { - Yes, as I said last month the DEA measure of efficiency is a } \\
\text { good measure. }\end{array}$ & Acceptance \\
\hline $\begin{array}{l}\text { - I will share the information out by discussing it with staff } \\
\text { and also my CD. I think they will be interested and I will be } \\
\text { keen to get their views on the information. }\end{array}$ & Collaboration influence \\
\hline $\begin{array}{l}\text { - The staffing mixes were amended to have increase in nurse } \\
\text { assistants with reduced nurse specialists. }\end{array}$ & Performance focus \\
\hline -Yes, the efficiency score and its cause by our resource use & Collaboration influence \\
\hline
\end{tabular}




\begin{tabular}{|c|c|}
\hline were discussed with the senior clinical team. & \\
\hline - No, I understand the data and this is good information. & Acceptance \\
\hline $\begin{array}{l}\text { - To improve I need to continue with the better resource use } \\
\text { over the month and also look to reduce clinical numbers a } \\
\text { little. }\end{array}$ & Improved understanding \\
\hline - I will keep changing the staffing mix. & Performance focus \\
\hline -this does provide actual performance on efficiency. & uncertainty \\
\hline $\begin{array}{l}\text { - Yes, as last month. I now am beginning to share this with } \\
\text { staff as well. }\end{array}$ & Collaboration influence \\
\hline - I will discuss the MRE with staff. & Collaboration influence \\
\hline $\begin{array}{l}\text { - Yes, I changed the staffing mix a little, to incorporate more } \\
\text { nursing to make up for less registrar/consultant daily cover. }\end{array}$ & \\
\hline $\begin{array}{l}\text { - The clinical staff is interested in the MRE information } \\
\text { result. They are not convinced and think the information can } \\
\text { also be wrongly used or misinform managers. }\end{array}$ & Collaboration influence \\
\hline $\begin{array}{l}\text { - The same senior management pressures and their need for } \\
\text { reports and for action plans take up considerable time so there } \\
\text { is no time to sit, think and plan. }\end{array}$ & Refer to variance reporting \\
\hline $\begin{array}{l}\text { - I have no issue with the report. I see that we improved on } \\
\text { our score slightly because our staffing cost went down. }\end{array}$ & Improved understanding \\
\hline $\begin{array}{l}\text { - Yes, maybe I should aim for a tighter staffing ratio and shift } \\
\text { the mix of staffing. } \\
\text { - But, I need to be careful to not upset the staff/unions. }\end{array}$ & Improved understanding \\
\hline -I will look at the nursing mix to use lower cost FTEs more. & Performance focus \\
\hline - The report is good, which I can share with staff. & Collaboration influence \\
\hline $\begin{array}{l}\text { - Yes, thinking about the optimum mix is very useful in } \\
\text { generating ideas about performance but I am limited in my } \\
\text { ability to act. }\end{array}$ & $\begin{array}{l}\text { Resistance to change - } \\
\text { isolated }\end{array}$ \\
\hline $\begin{array}{l}\text { - I managed to switch the nursing mix only slightly in one } \\
\text { ward only. }\end{array}$ & Improved understanding \\
\hline $\begin{array}{l}\text { - Yes, the senior team was interested in looking at the data in } \\
\text { the report. } \\
\text { - The general feedback I got from the discussion was not } \\
\text { hugely supportive but also not negative, being more of luke- } \\
\text { warm cautious interest. }\end{array}$ & $\begin{array}{l}\text { Collaboration influence } \\
\text { Indifference to performance } \\
\text { need }\end{array}$ \\
\hline - I have mentioned this already, nothing much has changed. & Collaboration influence \\
\hline - I am ok with the information in the EMR & acceptance \\
\hline $\begin{array}{l}\text { - I need to continue with the shifts in resource use at the } \\
\text { inputs stage. }\end{array}$ & Improved understanding \\
\hline - I will do what I did last month. & Performance focus \\
\hline $\begin{array}{l}\text { - As mentioned, I am finding the report easy to read and } \\
\text { understand and I think it is a good way of measuring our } \\
\text { overall view of actual efficiency. }\end{array}$ & Improved understanding \\
\hline - As I said, the MRE DEA measure is what I will use. & Improved understanding \\
\hline I did get more nursing grade staff to the wards. & Performance focus \\
\hline $\begin{array}{l}\text { - The same old stuff as before. } \\
\text { - My GM is also a real hurdle and getting her to even consider } \\
\text { ideas seriously is a challenge. }\end{array}$ & barrier \\
\hline $\begin{array}{l}\text { - The EMR is clear. I am not happy with the result at the end } \\
\text { of last month. I thought I had done enough but obviously the } \\
\text { small shift was not significant. }\end{array}$ & Improved understanding \\
\hline $\begin{array}{l}\text { - I will adjust the change I made last month to a slightly } \\
\text { higher level to affect more FTEs. }\end{array}$ & Improved understanding \\
\hline - Similar to last month, but with more FTEs. & Improved understanding \\
\hline
\end{tabular}




\begin{tabular}{|l|l|}
\hline $\begin{array}{l}\text { - The information is very useful and I can track the impact of } \\
\text { management decisions on staffing and resource use. }\end{array}$ & acceptance \\
\hline - I will use the DEA measure in the MRE. & acceptance \\
\hline $\begin{array}{l}\text { - Yes, I do share the MRE with staff and GM. } \\
\text { - I am more confident now of being able to manage my } \\
\text { service's performance, which I never was before this. }\end{array}$ & Collaboration influence \\
\hline - I specific targeted more change in the roster mix. & Improved understanding \\
\hline $\begin{array}{l}\text { - The MRE and the efficiency score is discussed and reviewed } \\
\text { with my CD. }\end{array}$ & Collaboration influence \\
\hline - Same as before. Nothing has changed there. & acceptance \\
\hline
\end{tabular}

\section{Participant 5}

\begin{tabular}{|c|c|}
\hline Text & Code label \\
\hline $\begin{array}{l}\text { - I like the one page report. } \\
\text { - The concept sounds reasonable and seems better than the } \\
\text { other reports on our performance. }\end{array}$ & $\begin{array}{l}\text { Acceptance } \\
\text { Acceptance }\end{array}$ \\
\hline $\begin{array}{l}\text { - I have to keeping service treatment outputs high while } \\
\text { reducing resource costs. }\end{array}$ & Increase awareness \\
\hline $\begin{array}{l}\text { - I want to look at the overall roster mix of clinical staff and } \\
\text { also my administration staff. }\end{array}$ & Increased understanding \\
\hline - I understand the DEA and the EMR. & Information acceptance \\
\hline $\begin{array}{l}\text { - Yes, I always focussed on lowest cost or least resource } \\
\text { effort. }\end{array}$ & Refer to variance reporting \\
\hline - I am ok about sharing the MRE with staff. & Accountability practice \\
\hline $\begin{array}{l}\text { - I did not do anything in particular. As I said I wanted to wait } \\
\text { a while. }\end{array}$ & Reflection \\
\hline $\begin{array}{l}\text { - I mentioned the MRE but I did not discuss it nor did I table } \\
\text { it. }\end{array}$ & Lack of confidence \\
\hline $\begin{array}{l}\text { - There is a hiatus in senior leadership/executive level because } \\
\text { they are dealing all the time with external demand that they } \\
\text { forget we service managers can actually understand our } \\
\text { services very well. }\end{array}$ & Refer to variance reporting \\
\hline - No, I am happy with the report. & Acceptance/confidence \\
\hline - The MRE suggests targets in nursing and medical levels. & Increased understanding \\
\hline $\begin{array}{l}\text { - I will change slightly the staff mix, by decreasing the hours } \\
\text { required. }\end{array}$ & Increased understanding \\
\hline - The information is useful. & acceptance \\
\hline - Yes, the DEA measure of efficiency is a good measure. & Acceptance \\
\hline - I will share the information with staff and also my CD. & Collaboration influence \\
\hline $\begin{array}{l}\text { - I had an increase in nursing to cover the reduction in } \\
\text { registrar hours. }\end{array}$ & Performance focus \\
\hline -Yes. & Collaboration influence \\
\hline - The same as I mentioned last time. & Acceptance \\
\hline - No, this is good information. & Acceptance \\
\hline $\begin{array}{l}\text { - To improve I need to continue with the better resource use } \\
\text { over the month and also look to reduce clinical numbers a } \\
\text { little. }\end{array}$ & Improved understanding \\
\hline - I will continue to change the staffing mix. & Performance focus \\
\hline $\begin{array}{l}\text { - The EMR is a very useful document to have with me and } \\
\text { serves as a reference on performance in staff discussions. }\end{array}$ & Collaboration influence \\
\hline $\begin{array}{l}\text { - Yes, as last month. I now am beginning to share the DEA } \\
\text { measure with staff as well. }\end{array}$ & Collaboration influence \\
\hline
\end{tabular}




\begin{tabular}{|c|c|}
\hline - I will discuss the MRE with staff. & Collaboration influence \\
\hline $\begin{array}{l}\text { - Yes, I changed the staffing mix a bit more, but not enough to } \\
\text { cause lengthy negotiations with staff groups. }\end{array}$ & Performance focus \\
\hline - There is clinical staff interest in the MRE information result. & Collaboration influence \\
\hline $\begin{array}{l}\text { - I still have the same senior management pressures and the } \\
\text { considerable time this takes up, as well as the employment } \\
\text { arrangements which make dealing with staff quite a complex } \\
\text { process if I want any major change. }\end{array}$ & Refer to variance reporting \\
\hline $\begin{array}{l}\text { - I like the report. It shows our score improving slightly which } \\
\text { is good as it is gradual change in our use of resources. }\end{array}$ & Improved understanding \\
\hline $\begin{array}{l}\text { - Yes, maybe I should aim for a staffing ratio that shifts the } \\
\text { mix of staffing. }\end{array}$ & Improved understanding \\
\hline -I will look at using lower cost FTEs more. & Improved understanding \\
\hline $\begin{array}{l}\text { - The report and information it contains is good and useful to } \\
\text { discuss with staff. }\end{array}$ & Collaboration influence \\
\hline - Yes. I will. & Collaboration influence \\
\hline - I managed to slightly switch the nursing level and mix. & Improved understanding \\
\hline - Yes. & Collaboration influence \\
\hline - I am ok with the information in the MRE & acceptance \\
\hline - I need to reduce the resource use of the inputs. & Improved understanding \\
\hline - I will carry on as last month, and also align clinician load. & Improved understanding \\
\hline $\begin{array}{l}\text { - As mentioned, the report is a good measure of the overall } \\
\text { actual efficiency. }\end{array}$ & Improved understanding \\
\hline - I use the MRE DEA measure. & Improved understanding \\
\hline - Yes. & Collaboration influence \\
\hline I did get more nursing grade staff to the wards. & Performance focus \\
\hline - Yes. & Collaboration influence \\
\hline - The same old stuff as before. & Refer to variance reporting \\
\hline $\begin{array}{l}\text { - The EMR is clear. I am happy with the result at the end of } \\
\text { last month. I had done enough to get a quite significant result } \\
\text { change. }\end{array}$ & Improved understanding \\
\hline $\begin{array}{l}\text { - I will continue to make adjustments to the resource mix } \\
\text { changes. }\end{array}$ & Improved understanding \\
\hline $\begin{array}{l}\text { - The information is very useful and I can track the impact of } \\
\text { management decisions on staffing and resource use. }\end{array}$ & Improved understanding \\
\hline - The DEA measure in the EMR. & Confidence/acceptance \\
\hline - Yes, I share the MRE with staff and my GM. & Collaboration influence \\
\hline - I specific targeted more change in the roster mix. & Improved understanding \\
\hline $\begin{array}{l}\text { - Yes, the MRE and the efficiency score is discussed and } \\
\text { reviewed with my CD. } \\
\text { - It is also worthwhile to discuss the improvement action } \\
\text { taken and how or whether it worked out well. }\end{array}$ & Collaboration influence \\
\hline
\end{tabular}

\section{Participant 6}

\begin{tabular}{|l|l|}
\hline \multicolumn{1}{|c|}{ Text } & \multicolumn{1}{c|}{ Code label } \\
\hline $\begin{array}{l}\text { - I like the one page report. } \\
\text { - The report is better than the other reports we get on our } \\
\text { performance. }\end{array}$ & $\begin{array}{l}\text { Acceptance } \\
\text { Acceptance }\end{array}$ \\
\hline - I am not sure as yet. & Lack of confidence \\
\hline - I have no real idea. & na \\
\hline $\begin{array}{l}\text { - I understand the MRE but don't understand the DEA } \\
\text { technique. }\end{array}$ & confusion \\
\hline
\end{tabular}




\begin{tabular}{|c|c|}
\hline - I focus on lowest resource effort. & Refer to variance reporting \\
\hline $\begin{array}{l}\text { - I am not that ok about sharing the EMR with staff just yet. I } \\
\text { need to fully understand the report and what it contains first. }\end{array}$ & Information challenge \\
\hline $\begin{array}{l}\text { - I did not do anything in particular. As I said I wanted to wait } \\
\text { a while. }\end{array}$ & $\begin{array}{l}\text { Reflection on information - } \\
\text { no action }\end{array}$ \\
\hline - I mentioned the MRE but I did not table it. & Lack of confidence \\
\hline $\begin{array}{l}\text { - Senior leadership is quite weak and politically driven such } \\
\text { that their entire focus is on key external stakeholders. }\end{array}$ & Barrier status quo \\
\hline $\begin{array}{l}\text { - No, but I see that the efficiency has dropped. Can you } \\
\text { explain this please? }\end{array}$ & Uncertainty \\
\hline $\begin{array}{l}\text { - The EMR suggests targets in nursing and medical levels, but } \\
\text { I probably won't do anything just yet. I am not convinced yet! }\end{array}$ & Resistance to signal \\
\hline - I don't intend to do anything in light of the MRE. & No action \\
\hline $\begin{array}{l}\text { - The information is interesting. Your explanation at the last } \\
\text { meeting was very useful for me to understand the real cause } \\
\text { effect of resource use on performance. }\end{array}$ & acceptance \\
\hline - Yes, the DEA measure of efficiency is a good measure. & Acceptance \\
\hline - I will share the information with staff and also my CD. & Collaboration influence \\
\hline - Nothing. & No action \\
\hline -Yes, I will this month. & Collaboration influence \\
\hline - The same as I mentioned last time. & $\mathrm{Na}$ \\
\hline - No, this is good information. & Acceptance \\
\hline - I know what the report is suggesting I do to improve. & Improved understanding \\
\hline - I will continue with my normal pattern. & status quo \\
\hline $\begin{array}{l}\text { - The MRE is a very useful reference on performance in staff } \\
\text { discussions. }\end{array}$ & Collaboration influence \\
\hline $\begin{array}{l}\text { - Yes, as last month. I am beginning to share the DEA } \\
\text { measure with staff as well. I think it is important to get staff } \\
\text { on-board before making any resource use decisions. }\end{array}$ & Collaboration influence \\
\hline - I will discuss the EMR with staff. & Collaboration influence \\
\hline - Nothing in respect of the EMR. & Status quo \\
\hline $\begin{array}{l}\text { - There is some clinical staff interest in the monthly EMR } \\
\text { information. }\end{array}$ & Collaboration influence \\
\hline $\begin{array}{l}\text { - The same senior management pressures, and employment } \\
\text { arrangements make dealing with staff a lengthy and complex } \\
\text { process and I don't have enough time! }\end{array}$ & $\begin{array}{l}\text { Reference to senior } \\
\text { management need }\end{array}$ \\
\hline - I like the report. It shows our score is getting worse. & Improved understanding \\
\hline $\begin{array}{l}\text { - Yes, the report identifies some targets for my service in } \\
\text { order to get improved efficiency. }\end{array}$ & awareness \\
\hline $\begin{array}{l}\text {-I will look at using the staffing ratios referred to in the report } \\
\text { and also realigning consultant use to increase treatment } \\
\text { output. }\end{array}$ & Improved understanding \\
\hline - The report information is good and useful. & Collaboration influence \\
\hline - Yes. & confidence \\
\hline $\begin{array}{l}\text { - Yes. I held some meetings with staff initially and we agreed } \\
\text { on using one ward cover to support the other ward. }\end{array}$ & Collaboration influence \\
\hline $\begin{array}{l}\text { - I re-aligned treatment delivery arrangements and mixed } \\
\text { coverage for wards. }\end{array}$ & Performance focus \\
\hline - Yes. & Collaboration influence \\
\hline - I have mentioned this already. & $\mathrm{Na} /$ status quo \\
\hline $\begin{array}{l}\text { - I am ok with the information in the EMR. This shows that } \\
\text { we at } 100 \% \text { efficient but I realise this is a rating of our past } 24 \\
\text { months. }\end{array}$ & acceptance \\
\hline - I need to continue to reduce the resource use burden. & Improved understanding \\
\hline
\end{tabular}




\begin{tabular}{|l|l|}
\hline - I will carry on as last month, and also align service delivery. & $\begin{array}{l}\text { Focus/Improved } \\
\text { understanding }\end{array}$ \\
\hline - The report is a measure of the overall actual efficiency. & Improved understanding \\
\hline - EMR DEA measure. & Confidence \\
\hline $\begin{array}{l}\text { - Yes. I think staff will be interested in the result we got and } \\
\text { how we achieved it. }\end{array}$ & Collaboration influence \\
\hline $\begin{array}{l}\text { I held the same staffing pattern but allowed extra nursing staff } \\
\text { to the wards, due to full occupancy. }\end{array}$ & Performance focus \\
\hline - Yes. & Collaboration influence \\
\hline - The same as before. & Status quo barrier \\
\hline $\begin{array}{l}\text { - No. The report is straight-forward and shows we had a good } \\
\text { result. }\end{array}$ & Improved understanding \\
\hline $\begin{array}{l}\text { - I will continue to make adjustments to the resource mix } \\
\text { changes. }\end{array}$ & Improved understanding \\
\hline - Similar to last month. & na \\
\hline $\begin{array}{l}\text { - The information is very useful in presenting a clear picture } \\
\text { of our service performance. }\end{array}$ & Improved understanding \\
\hline - I continue to use the DEA measure in the MRE. & Confidence/acceptance \\
\hline - Yes. & Collaboration influence \\
\hline - I continued with the staffing pattern of the past two months. & Improved understanding \\
\hline - Yes, with the team and my CD. & Collaboration influence \\
\hline $\begin{array}{l}\text { - Same as before. Nothing has changed there. } \\
\text { need }\end{array}$ \\
\hline
\end{tabular}

\section{Participant 7}

\begin{tabular}{|l|l|}
\hline \multicolumn{1}{|c|}{ Text } & \multicolumn{1}{|c|}{ Code label } \\
\hline $\begin{array}{l}\text { - The one page report is short and summary so I am not sure it } \\
\text { has enough detail. }\end{array}$ & Challenge \\
\hline $\begin{array}{l}\text { - I have no real idea at this stage. I know there are some } \\
\text { targets in the report but these relate to clinical staffing and I } \\
\text { would rather not go there. }\end{array}$ & Focus on targets delivery \\
\hline - Nothing specific at this point in time. & Reflection \\
\hline $\begin{array}{l}\text { - It is OK and the report is easy to follow but maybe it is too } \\
\text { high level. }\end{array}$ & Lack of confidence \\
\hline - My measure is best economy. I mean the cheapest cost. & Resistance to signal \\
\hline - I am not sure yet. & No acceptance \\
\hline - I did not do anything in particular. & No action \\
\hline $\begin{array}{l}\text { - I mentioned the MRE and I went through the report and its } \\
\text { findings, targets but mentioned that it was only for guidance. }\end{array}$ & Seeking feedback \\
\hline $\begin{array}{l}\text { - Because of the employment contracts with clinical staff, a } \\
\text { lot time can be taken to consult on any proposed change and } \\
\text { this takes a lot of effort. }\end{array}$ & $\begin{array}{l}\text { Resistance to change - } \\
\text { isolated }\end{array}$ \\
\hline - No & na \\
\hline - The EMR suggests targets in nursing levels. & Growing awareness \\
\hline $\begin{array}{l}\text { - I will amend the nursing roster for the weekly ward } \\
\text { coverage. }\end{array}$ & Performance focus \\
\hline - The information is interesting. & acceptance \\
\hline $\begin{array}{l}\text { - Yes, the DEA measure of efficiency is another good } \\
\text { measure. }\end{array}$ & Acceptance \\
\hline - I will share the information with staff and also my CD. & Collaboration influence \\
\hline $\begin{array}{l}\text { - I adjusted the nursing numbers down a little to save some } \\
\text { FTEs over the week. }\end{array}$ & Performance focus \\
\hline
\end{tabular}




\begin{tabular}{|c|c|}
\hline -Yes, I will this month. & Collaboration influence \\
\hline - The same as I mentioned last time. & $\begin{array}{l}\text { Reference to senior } \\
\text { management need }\end{array}$ \\
\hline - This is good information. & Acceptance \\
\hline $\begin{array}{l}\text { - The report is suggesting I further adjust the staffing levels to } \\
\text { improve efficiency. }\end{array}$ & Improved understanding \\
\hline $\begin{array}{l}\text { - I will examine the staffing patterns and initiate discussion } \\
\text { with the nursing leadership. }\end{array}$ & Collaboration influence \\
\hline - The EMR is a very useful in staff discussions. & Collaboration influence \\
\hline $\begin{array}{l}\text { - Yes, as last month. } \\
\text { - I share the DEA measure with staff as well. }\end{array}$ & $\begin{array}{l}\text { Acceptance } \\
\text { Collaboration influence }\end{array}$ \\
\hline - I will discuss the MRE with staff. & Collaboration influence \\
\hline - I reduced the nursing roster FTE. & Performance focus \\
\hline $\begin{array}{l}\text { - Yes, staff are interested in the monthly MRE result and any } \\
\text { information around it. }\end{array}$ & Collaboration influence \\
\hline $\begin{array}{l}\text { - There are difficulties placed in the way like senior } \\
\text { management and employment arrangement, which mean that } \\
\text { if I want to make significant or permanent change then I have } \\
\text { a complex process to go through. }\end{array}$ & $\begin{array}{l}\text { Reference to senior } \\
\text { management need }\end{array}$ \\
\hline - I like the report. It shows our score is getting better. & Improved understanding \\
\hline $\begin{array}{l}\text { - Yes, the report has target staffing levels for my service in } \\
\text { order to improve efficiency. }\end{array}$ & Improved understanding \\
\hline $\begin{array}{l}\text {-I will look at adjusting towards the target staffing ratios } \\
\text { referred to in the report. }\end{array}$ & Improved understanding \\
\hline - The report information is good and useful. & Collaboration influence \\
\hline - Yes. & confidence \\
\hline $\begin{array}{l}\text { - Yes. I held some meetings with staff initially and this } \\
\text { identified a national screening program had been initiated and } \\
\text { referrals were being made to the service and so we would } \\
\text { need extra nursing coverage for a period. }\end{array}$ & Collaboration influence \\
\hline $\begin{array}{l}\text { - The intended reduction did not proceed as screening based } \\
\text { referrals required extra nursing support. }\end{array}$ & Performance focus \\
\hline - Yes. & Collaboration influence \\
\hline - I have mentioned the various barriers and hurdles already. & $\begin{array}{l}\text { Reference to senior } \\
\text { management need }\end{array}$ \\
\hline $\begin{array}{l}\text { - The MRE information is straightforward and easily } \\
\text { understood }\end{array}$ & acceptance \\
\hline $\begin{array}{l}\text { - The continued screening programme means the increase in } \\
\text { referrals needs to be adequately supported. }\end{array}$ & Improved understanding \\
\hline - I will align resources to service delivery. & Improved understanding \\
\hline - The report is a good measure of the overall actual efficiency. & Improved understanding \\
\hline - MRE DEA measure. & Increased Confidence \\
\hline - Yes. Staff are interested in the result achieved. & Collaboration influence \\
\hline $\begin{array}{l}\text { I held the same staffing pattern but allowed extra nursing } \\
\text { staff. }\end{array}$ & Performance focus \\
\hline - Yes. & Collaboration influence \\
\hline - The same as before. & $\begin{array}{l}\text { Reference to senior } \\
\text { management need }\end{array}$ \\
\hline $\begin{array}{l}\text { - No. The report is straight-forward and the efficiency result is } \\
\text { understood. }\end{array}$ & Improved understanding \\
\hline - I will make adjustments to the resource mix. & Improved understanding \\
\hline - I will consider reduced staffing. & Improved understanding \\
\hline - The information is useful. & Improved understanding \\
\hline - I continue to use the DEA measure in the EMR. & Confidence/acceptance \\
\hline
\end{tabular}




\begin{tabular}{|l|l|}
\hline - Yes. & Collaboration influence \\
\hline - I adjusted downwards the staffing roster pattern. & Improved understanding \\
\hline - Yes, with the team. & Collaboration influence \\
\hline - Same as before. Nothing has changed there. & $\begin{array}{l}\text { Reference to senior } \\
\text { management need }\end{array}$ \\
\hline
\end{tabular}

\section{Participant 8}

\begin{tabular}{|c|c|}
\hline Text & Code label \\
\hline $\begin{array}{l}\text { - I am used to these reports although there is a lot of material for } \\
\text { me to go through and often I am not sure of what it is I am being } \\
\text { measured against. } \\
\text { - From these reports, I focus on what my GM wants me to explain } \\
\text { and prepare a management report. }\end{array}$ & $\begin{array}{l}\text { Isolated management } \\
\text { Reference to senior } \\
\text { management need }\end{array}$ \\
\hline $\begin{array}{l}\text { - I have no real idea about efficiency itself, at this stage. } \\
\text { - There are targets in my reports which are efficiency related such } \\
\text { as length of stay but these relate to clinical-decision and I would } \\
\text { rather not go there. }\end{array}$ & $\begin{array}{l}\text { Lack of knowledge } \\
\text { Reference to senior } \\
\text { management need }\end{array}$ \\
\hline $\begin{array}{l}\text { - Nothing specific. } \\
\text { - I will look at the reasons for any variances. }\end{array}$ & $\begin{array}{l}\text { Reference to senior } \\
\text { management need }\end{array}$ \\
\hline $\begin{array}{l}\text { - It is OK and I am used to the reports. } \\
\text { - It is a chore to go through the reports. }\end{array}$ & $\begin{array}{l}\text { Routine variance } \\
\text { reporting }\end{array}$ \\
\hline $\begin{array}{l}\text { - As a service or even at the hospital level, we don't have specific } \\
\text { measures for efficiency. } \\
\text { - For me, it is about budget compliance. }\end{array}$ & $\begin{array}{l}\text { No specific knowledge } \\
\text { Reference to variance } \\
\text { reporting }\end{array}$ \\
\hline $\begin{array}{l}\text { - I do not normally share any of the reports with staff unless there } \\
\text { is a specific variance or issue I need to get to the bottom of. }\end{array}$ & Isolated management \\
\hline $\begin{array}{l}\text { - I just managed normally, there was nothing in particular on } \\
\text { efficiency. }\end{array}$ & $\begin{array}{l}\text { Reference to senior } \\
\text { management need }\end{array}$ \\
\hline $\begin{array}{l}\text { - I did not mention the efficiency as this was not an issue raised } \\
\text { with me by them or my GM. }\end{array}$ & Reactive ad hoc \\
\hline $\begin{array}{l}\text { - The existing employment contracts and agreed models of care } \\
\text { require considerable effort in looking at service change or } \\
\text { improvement. } \\
\text { - The lack of senior executive support. }\end{array}$ & $\begin{array}{l}\text { Reference to senior } \\
\text { management need }\end{array}$ \\
\hline - No & indifference \\
\hline - I would just carry on as usual. & Reactive ad hoc \\
\hline - Nothing specifically. & Routine reactive \\
\hline $\begin{array}{l}\text { - It takes time to go through it all. } \\
\text { - I am used to it and look just for the negative variances as I know } \\
\text { that is what the GM will want answers for. }\end{array}$ & $\begin{array}{l}\text { No acceptance } \\
\text { Reactive ad hoc }\end{array}$ \\
\hline - As I mentioned last month, No. & $\begin{array}{l}\text { Reference to senior } \\
\text { management need }\end{array}$ \\
\hline - No, the information won't be shared generally with staff. & $\begin{array}{l}\text { Reference to senior } \\
\text { management need }\end{array}$ \\
\hline $\begin{array}{l}\text { - Nothing } \\
\text { - I did prepare a management report on target non-compliance } \\
\text { and our planned mitigation. }\end{array}$ & $\begin{array}{l}\text { Reference to senior } \\
\text { management need }\end{array}$ \\
\hline $\begin{array}{l}\text {-No. I think I explained last month that unless it is a subject raised } \\
\text { I won't necessarily discuss it. }\end{array}$ & Reactive ad hoc \\
\hline $\begin{array}{l}\text { - The same as I mentioned last month. } \\
\text { - Also, I think we all get too busy fighting fires and report writing } \\
\text { to do anything else. }\end{array}$ & $\begin{array}{l}\text { na } \\
\text { Reactive ad hoc }\end{array}$ \\
\hline - No, but tell me about your efficiency information report. & Awareness \\
\hline
\end{tabular}




\begin{tabular}{|c|c|}
\hline $\begin{array}{l}\text { - Nothing specifically to improve efficiency. } \\
\text { - I will carry out my normal duties and tasks over the month. }\end{array}$ & Reactive ad hoc \\
\hline - I don't intend to do anything. & No action \\
\hline $\begin{array}{l}\text { - The information forms part of my first week's task to read } \\
\text { through and get ready an agenda for my GM meeting. }\end{array}$ & Status quo \\
\hline $\begin{array}{l}\text { - No. this is because I have no focus on this aspect specifically. } \\
\text { My reports are all about results and where I have not achieved } \\
\text { target. }\end{array}$ & Status quo \\
\hline - Not really. & Status quo \\
\hline - I did nothing in relation to efficiency. & Status quo \\
\hline - No, we talked about issues that the GM wants explanations for. & Status quo \\
\hline $\begin{array}{l}\text { - As I said last month, the lack of support from senior } \\
\text { management makes it difficult for us. }\end{array}$ & barrier \\
\hline $\begin{array}{l}\text { - I am so used to these reports that I just glance at them to note } \\
\text { any variances. }\end{array}$ & Status quo \\
\hline $\begin{array}{l}\text { - No. } \\
\text { - My GM has talked about getting a review of my service so I } \\
\text { guess this will throw up some efficiency issues. }\end{array}$ & $\begin{array}{l}\text { Status quo } \\
\text { reactive }\end{array}$ \\
\hline - There is nothing specific in mind. & Status quo \\
\hline $\begin{array}{l}\text { - It is all ok information, but talking to my colleague (intervention } \\
\text { subject) it seems we don't have any focussed information like you } \\
\text { are giving them. }\end{array}$ & Increase awareness \\
\hline - No. I don't need one. & barrier \\
\hline $\begin{array}{l}\text { - No, at our meetings, we just quickly go through the variances } \\
\text { and decide how we would respond to any query. }\end{array}$ & Status quo \\
\hline $\begin{array}{l}\text { - The intended reduction did not proceed as screening based } \\
\text { referrals required extra nursing support. }\end{array}$ & reactive \\
\hline $\begin{array}{l}\text { - No, we only discuss issues that there are serious negative } \\
\text { variances for and when I need to report, explain this upwards. }\end{array}$ & reactive \\
\hline - I have mentioned the various barriers already. & status quo barrier \\
\hline - No. & Status quo \\
\hline - I don't normally have a specific focus on efficiency. & barrier \\
\hline - Nothing specific. & Status quo \\
\hline -Ok. & Status quo \\
\hline - Not yet! & na \\
\hline - Only the variances with the staff. & reactive \\
\hline - I did nothing special. & Status quo \\
\hline - No. & Status quo \\
\hline - The same as before. & Status quo barrier \\
\hline - No. The reports tell me where my variances are. & Status quo \\
\hline - No & Improved understanding \\
\hline - Nothing. & Status quo \\
\hline - I am used to it! & Improved understanding \\
\hline - No, I don't think I will need this here, anyway. & Status quo \\
\hline $\begin{array}{l}\text { - No. } \\
\text { - I discuss any variances with the CD or finance guy. }\end{array}$ & $\begin{array}{l}\text { Status quo } \\
\text { reactive }\end{array}$ \\
\hline - Nothing. & Status quo \\
\hline - No, there will be no interest. & barrier \\
\hline - Same as before. Nothing has changed there. & Status quo barrier \\
\hline
\end{tabular}




\section{Participant 9}

\begin{tabular}{|c|c|}
\hline Text & Code label \\
\hline $\begin{array}{l}\text { - No, I am used to these reports and I only worry about any large } \\
\text { variances which I have to explain and report to my GM. }\end{array}$ & Status quo \\
\hline $\begin{array}{l}\text { - I don't know what to do about efficiency itself; it is not } \\
\text { something we have in our reporting, as long as I achieve my } \\
\text { budget and delivery targets. }\end{array}$ & $\begin{array}{l}\text { Indifference to } \\
\text { performance need }\end{array}$ \\
\hline - Nothing. & barrier \\
\hline - I am used to the reports. & Routine/status quo \\
\hline - For me, it is about keeping within budget. & Status quo \\
\hline $\begin{array}{l}\text { - I don't share the reports with staff generally. } \\
\text { - If I have a query then I will pass on the relevant information to } \\
\text { the appropriate staff member for a response. }\end{array}$ & $\begin{array}{l}\text { Lack of confidence } \\
\text { reactive }\end{array}$ \\
\hline $\begin{array}{l}\text { - I continued my usual tasks and duties, attended meetings and } \\
\text { dealt with firefighting issues mainly. }\end{array}$ & Status quo \\
\hline - I don't refer to efficiency. & Barrier \\
\hline $\begin{array}{l}\text { - The senior executive team controls everything and we don't } \\
\text { really get to initiate anything of our own } \\
\text { - The process of getting approval from the GM requires me to } \\
\text { write up a business case, which she then just refers upwards. }\end{array}$ & $\begin{array}{l}\text { Barrier } \\
\text { Barrier/reactive }\end{array}$ \\
\hline - No. & barrier \\
\hline $\begin{array}{l}\text { - I would not do anything specific but just carry on managing as } \\
\text { usual to make sure all is smooth over the month. }\end{array}$ & Status quo \\
\hline - Nothing specifically. & Routine reactive \\
\hline $\begin{array}{l}\text { - it is OK, as I said I am used to it } \\
\text { - I look for the negative variances as I know the GM will want } \\
\text { explanations. }\end{array}$ & $\begin{array}{l}\text { Barrier } \\
\text { Status quo reactive }\end{array}$ \\
\hline - As I mentioned last month, no. & barrier \\
\hline $\begin{array}{l}\text { - No, I won't share the information with staff. If I do, it will just } \\
\text { raise a lot of questions and I don't know all the answers. }\end{array}$ & Status quo \\
\hline $\begin{array}{l}\text { - Nothing, apart from the usual running around and a report on } \\
\text { how we will improve on a key target poor result. }\end{array}$ & reactive \\
\hline $\begin{array}{l}\text {-No. I explained last month that I don't refer to efficiency unless } \\
\text { I have to. }\end{array}$ & Status quo \\
\hline $\begin{array}{l}\text { - What I referred to last month, we all get too busy with routine } \\
\text { management issues. }\end{array}$ & barrier \\
\hline - No. & Status quo \\
\hline $\begin{array}{l}\text { - Nothing specific. I really don't know what the information I get } \\
\text { tells me aside from whether or not I have met my various targets. }\end{array}$ & Status quo \\
\hline - There is nothing I can do. & Status quo \\
\hline - The information is standard. & Status quo \\
\hline - No. & barrier \\
\hline - No. & barrier \\
\hline $\begin{array}{l}\text { - As I told you at the start of the month, I do nothing about } \\
\text { efficiency. }\end{array}$ & barrier \\
\hline - No. & Status quo \\
\hline $\begin{array}{l}\text { - I think it is the same as I said last month. You know, we are not } \\
\text { given any relevant data or tools or authority to think and act for } \\
\text { ourselves. }\end{array}$ & barrier \\
\hline - No. & Status quo \\
\hline - No. & Status quo \\
\hline $\begin{array}{l}\text { - I don't think I will actually do anything as I would not know } \\
\text { what to do. }\end{array}$ & barrier \\
\hline
\end{tabular}




\begin{tabular}{|l|l|}
\hline - The information is ok, it has become quite routine for me now & $\begin{array}{l}\text { Status quo } \\
\text { reactive }\end{array}$ \\
\hline - Nook for the areas where there is a variance. & barrier \\
\hline $\begin{array}{l}\text { - No, only if there is something I need some help with and this is } \\
\text { usually to do with writing a variance explanation. }\end{array}$ & Status quo \\
\hline - Again, nothing specific in relation to efficiency. & barrier \\
\hline - No. & reactive \\
\hline - It is still the same! & barrier \\
\hline - No. & Status quo \\
\hline $\begin{array}{l}\text { - I think there is nothing to do. } \\
\text { - The information does not address this efficiency but indicates } \\
\text { to me where my shortfalls are in terms of the targets and KPIs. }\end{array}$ & $\begin{array}{l}\text { Barrier } \\
\text { reactive }\end{array}$ \\
\hline - Nothing specific. & Status quo \\
\hline $\begin{array}{l}\text { - Ok. } \\
\text { - I told you at the first meeting; it just points to where my service } \\
\text { is not delivering to target. }\end{array}$ & $\begin{array}{l}\text { Status quo } \\
\text { Status quo }\end{array}$ \\
\hline - No. & Status quo \\
\hline - No, I won't share all of the information, it will get messy. & reactive \\
\hline - I did nothing in regard to efficiency. & Status quo \\
\hline - No, I did not. & barrier \\
\hline $\begin{array}{l}\text { - We are still in the same environment as before, with the same } \\
\text { leadership expectations of not rocking the boat. }\end{array}$ & barrier \\
\hline - No, as you will know these reports is just variance reporting. & Status quo \\
\hline $\begin{array}{l}\text { - I don't get any sense of what I need to do from the reports so it } \\
\text { must not be important! } \\
\text { - I will not do anything. }\end{array}$ & $\begin{array}{l}\text { Status quo } \\
\text { barrier }\end{array}$ \\
\hline - Nothing. & Status quo \\
\hline - OK! & Status quo \\
\hline - No, I do not need a definition, anyway. & barrier \\
\hline - No. & Status quo \\
\hline - Nothing. & Status quo \\
\hline $\begin{array}{l}\text { - I can if I want to but I did not as it would not be useful for me } \\
\text { just to get all their views and opinions. }\end{array}$ & barrier \\
\hline $\begin{array}{l}\text { - Same as I said in previous months. The situation is still the } \\
\text { same. }\end{array}$ & Status quo barrier \\
\hline
\end{tabular}




\begin{tabular}{|c|c|}
\hline Text & Code label \\
\hline $\begin{array}{l}\text { - No, I don't need to discuss my reports. I am well used to them } \\
\text { and they are great. }\end{array}$ & Status quo \\
\hline $\begin{array}{l}\text { - I don't know what the question is. I don't believe I really have to } \\
\text { worry about efficiency at the service level. We do deliver on our } \\
\text { targets and we keep within our budget, so we are OK. }\end{array}$ & Barrier/status quo \\
\hline - Nothing. & barrier \\
\hline $\begin{array}{l}\text { - The reports are good and allow me to monitor my achievement } \\
\text { on targets and KPIs. }\end{array}$ & status quo \\
\hline $\begin{array}{l}\text { - For me, it is about keeping within budget and being able to } \\
\text { achieve the KPIs. }\end{array}$ & Status quo \\
\hline $\begin{array}{l}\text { - I sometimes do send out the reports to senior staff. } \\
\text { - I will ask staff for explanations as appropriate. }\end{array}$ & $\begin{array}{l}\text { Status quo } \\
\text { reactive }\end{array}$ \\
\hline - I had my usual tasks and duties to do and this kept me busy. & Status quo \\
\hline - I don't discuss efficiency as a topic itself as I don't need to. & Barrier \\
\hline $\begin{array}{l}\text { - My service is pretty good already. } \\
\text { - I will say that working within the organisation's constraints and } \\
\text { rules does dampen my efforts to think about creative ways of } \\
\text { delivering the service. }\end{array}$ & $\begin{array}{l}\text { Barrier } \\
\text { Resistance to change - } \\
\text { isolation }\end{array}$ \\
\hline - No. it is all OK. & barrier \\
\hline $\begin{array}{l}\text { - I would not do anything specific. As I told you last month, this is } \\
\text { not an issue for me. }\end{array}$ & Status quo \\
\hline - Nothing specifically. & reactive \\
\hline - The information suits my needs and is what the GM also looks at. & reactive \\
\hline - No. & barrier \\
\hline - Only sometimes. & Status quo \\
\hline $\begin{array}{l}\text { - Nothing in regard to efficiency, but plenty of routine } \\
\text { management. }\end{array}$ & reactive \\
\hline -No. I don’t refer to efficiency unless I have to. & Status quo \\
\hline - I referred to this last month. & barrier \\
\hline - No. the information is all good and I understand it well. & Status quo \\
\hline - Nothing specific. & Status quo \\
\hline - Nothing to do! & barrier \\
\hline $\begin{array}{l}\text { - As I said in the previous months, the information is good and lets } \\
\text { me monitor how we are doing in terms of KPIs. }\end{array}$ & barrier \\
\hline - No, I still don’t need a definition. & barrier \\
\hline - Only as necessary and then with the appropriate staff. & barrier \\
\hline $\begin{array}{l}\text { - I continued as normal, dealing with firefighting of issues, routine } \\
\text { reports and meetings. } \\
\text { - I did not focus on efficiency at all. }\end{array}$ & $\begin{array}{l}\text { Status quo } \\
\text { barrier }\end{array}$ \\
\hline - No, I don't need to. & barrier \\
\hline - It is the same as last month. & barrier \\
\hline - No. & barrier \\
\hline - No. & Status quo \\
\hline $\begin{array}{l}\text { - I don't need to do anything. } \\
\text { - Anyway, I would not know what to do. }\end{array}$ & $\begin{array}{l}\text { barrier } \\
\text { uncertainty }\end{array}$ \\
\hline $\begin{array}{l}\text { - The information is routine and identifies where there is a } \\
\text { variance for me to look at. }\end{array}$ & Status quo \\
\hline - No. & barrier \\
\hline - No, only if I need help with writing a variance explanation. & Status quo \\
\hline - Again, nothing specific in relation to efficiency. & barrier \\
\hline - No. & barrier \\
\hline
\end{tabular}




\begin{tabular}{|l|l|}
\hline - It is still the same! & barrier \\
\hline - No. & Status quo \\
\hline - There is nothing to worry about in regard to efficiency. \\
- The focus is the delivery of my service targets and KPIs. & $\begin{array}{l}\text { Barrier } \\
\text { reactive }\end{array}$ \\
\hline - Nothing specific. & Status quo \\
\hline -Ok. & barrier \\
\hline - No. & barrier \\
\hline - No, not all, only as required. & reactive \\
\hline - I did nothing and had no direct focus on efficiency. & Status quo \\
\hline - No, I did not need to. & barrier \\
\hline - The same as before! & barrier \\
\hline - No. & Status quo \\
\hline - The reports are OK for my service so I don't need to do anything & Status quo \\
specific. & Status quo \\
- I will not do anything. & \\
\hline - Nothing. & barrier \\
\hline - OK! & Status quo \\
\hline - No. & barrier \\
\hline $\begin{array}{l}\text { - No. but I will talk generally about our results at our senior } \\
\text { meeting. }\end{array}$ & Status quo \\
\hline - Nothing. & Status quo \\
\hline - I did not as it would be irrelevant. & barrier \\
\hline - Same situation as in previous months. & barrier \\
\hline
\end{tabular}

\section{Participant 11}

\begin{tabular}{|l|l|}
\hline \multicolumn{1}{|c|}{ Text } & \multicolumn{1}{|c|}{ Code label } \\
\hline $\begin{array}{l}\text { - No, there is nothing I have to ask about. } \\
\text { - I don't mean that I like the reports, they just have all the KPIs } \\
\text { and target results and I have to go through them each time. }\end{array}$ & $\begin{array}{l}\text { Indifference to } \\
\text { performance need }\end{array}$ \\
\hline $\begin{array}{l}\text { - I don't have to focus on efficiency for my service. } \\
\text { - Because our targets and budget results are fine, there is not much } \\
\text { for me to do. }\end{array}$ & $\begin{array}{l}\text { Barrier } \\
\text { status quo }\end{array}$ \\
\hline - Nothing. & barrier \\
\hline - The reports are OK. & status quo \\
\hline $\begin{array}{l}\text { - No, as service manager, I don't need a measure for efficiency } \\
\text { - In my role, I need to monitor the budget and if we able to } \\
\text { achieve the KPIs. }\end{array}$ & $\begin{array}{l}\text { Barrier } \\
\text { Status quo }\end{array}$ \\
\hline $\begin{array}{l}\text { - I will share the information with staff as matters relate to each of } \\
\text { them. }\end{array}$ & $\begin{array}{l}\text { reactive } \\
\text { reactive } \\
\text { - I also talk one on one with the relevant staff to sort out any poor } \\
\text { variance result. } \\
\text { - This allows me to better understand the problem and so I can } \\
\text { prepare the report. }\end{array}$ \\
\hline $\begin{array}{l}\text { - I did not undertake any action in relation to efficiency. } \\
\text { - I was busy anyway with the routine tasks and duties. }\end{array}$ & $\begin{array}{l}\text { Status quo } \\
\text { status quo }\end{array}$ \\
\hline $\begin{array}{l}\text { - I am able to if I want. I am not sure if it will be useful though } \\
\text { because we are not measured on it for our performance. }\end{array}$ & Barrier \\
\hline $\begin{array}{l}\text { - I don't know if we can be more efficient! } \\
\text { - We are pretty constrained working within this organisation and } \\
\text { the rules on how we are to deliver the service. }\end{array}$ & $\begin{array}{l}\text { Barrier } \\
\text { Barrier }\end{array}$ \\
\hline
\end{tabular}




\begin{tabular}{|c|c|}
\hline - No. & barrier \\
\hline $\begin{array}{l}\text { - I would not do anything specific. } \\
\text { - This is not an issue for me. }\end{array}$ & $\begin{array}{l}\text { Status quo } \\
\text { barrier }\end{array}$ \\
\hline - Nothing I need to need. & barrier \\
\hline $\begin{array}{l}\text { - The information suits what I want to look at. } \\
\text { - These reports present the results of my performance targets. } \\
\text { - I need these reports for discussion with the GM. }\end{array}$ & $\begin{array}{l}\text { Reactive } \\
\text { Status quo } \\
\text { reactive }\end{array}$ \\
\hline $\begin{array}{l}\text { - No. } \\
\text { - I can repeat what I said last month to you; I don't need any } \\
\text { definition or measure. } \\
\text { - Unless of course, the GM wants to measure our efficiency! }\end{array}$ & $\begin{array}{l}\text { Barrier } \\
\text { Status quo } \\
\text { reactive }\end{array}$ \\
\hline $\begin{array}{l}\text { - I will not always share the reports with staff because they will be } \\
\text { distracted and can take things the wrong way. } \\
\text { - When I need specific feedback form staff then I will share the } \\
\text { relevant information. }\end{array}$ & $\begin{array}{l}\text { Status quo } \\
\text { reactive }\end{array}$ \\
\hline - There was nothing I did in regard to efficiency. & barrier \\
\hline $\begin{array}{l}\text {-No. } \\
\text { - But I can if I wanted to but there is no value in doing so. }\end{array}$ & $\begin{array}{l}\text { Barrier } \\
\text { Status quo }\end{array}$ \\
\hline - It is the same as what I said to you last month. & barrier \\
\hline - No. I understand it well. & Status quo \\
\hline - Nothing specific. & Status quo \\
\hline - Nothing. & barrier \\
\hline $\begin{array}{l}\text { - The information lets me monitor how we are doing in terms of } \\
\text { KPIs. }\end{array}$ & Status quo \\
\hline - No, I don't need any measure or definition. & barrier \\
\hline - Only as I need to and with the appropriate staff. & reactive \\
\hline $\begin{array}{l}\text { - I continued normal meetings and my routine reports. } \\
\text { - I did not have any focus on efficiency. }\end{array}$ & $\begin{array}{l}\text { Status quo } \\
\text { barrier }\end{array}$ \\
\hline - No, this was not necessary. & barrier \\
\hline - The same response I gave last month! & na \\
\hline - No. & barrier \\
\hline - No, there is little for me to worry about on that score. & Indifferent \\
\hline - I don't need to do anything. & barrier \\
\hline - The information is routine and what I use. & Status quo \\
\hline - No. & barrier \\
\hline - No. & Status quo \\
\hline - Again, nothing specific. & barrier \\
\hline - No. & barrier \\
\hline - It is still the same! & barrier \\
\hline - No. & Status quo \\
\hline - There is nothing to improve in relation to efficiency. & $\begin{array}{l}\text { Indifferent to } \\
\text { performance signal }\end{array}$ \\
\hline - Nothing. & Status quo \\
\hline - It is all Ok. & barrier \\
\hline - No. & Status quo \\
\hline $\begin{array}{l}\text { - Only sometimes when I need some feedback or analysis from } \\
\text { staff. }\end{array}$ & reactive \\
\hline - I did nothing. & Status quo \\
\hline - There was no need to. & barrier \\
\hline - The same. & No action \\
\hline - No. & No action \\
\hline $\begin{array}{l}\text { - The reports are good for me. } \\
\text { - I will not do anything. }\end{array}$ & $\begin{array}{l}\text { Status quo } \\
\text { No action }\end{array}$ \\
\hline
\end{tabular}




\begin{tabular}{|l|l|}
\hline - Nothing. & barrier \\
\hline - OK! & barrier \\
\hline - No. & Status quo \\
\hline $\begin{array}{l}\text { - No. } \\
\text { - The results will be tabled at my meeting with my CD and also } \\
\text { with my GM. }\end{array}$ & $\begin{array}{l}\text { Status quo } \\
\text { reactive }\end{array}$ \\
\hline - No, I did not do anything special. & Status quo \\
\hline - There was no need to again. & barrier \\
\hline - It is the same as in previous months. & Status quo \\
\hline
\end{tabular}

